University of Nebraska - Lincoln

DigitalCommons@University of Nebraska - Lincoln

Evolution of Large Carnivores During the Mid-Cenozoic of North America: The Temnocyonine Radiation (Mammalia, Amphicyonidae)

Robert Hunt Jr.

University of Nebraska-Lincoln, rhunt2@unl.edu

Follow this and additional works at: https://digitalcommons.unl.edu/museummammalogy

Hunt, Robert Jr., "Evolution of Large Carnivores During the Mid-Cenozoic of North America: The Temnocyonine Radiation (Mammalia, Amphicyonidae)" (2011). Mammalogy Papers: University of Nebraska State Museum. 285.

https://digitalcommons.unl.edu/museummammalogy/285

This Article is brought to you for free and open access by the Museum, University of Nebraska State at DigitalCommons@University of Nebraska - Lincoln. It has been accepted for inclusion in Mammalogy Papers: University of Nebraska State Museum by an authorized administrator of DigitalCommons@University of Nebraska Lincoln. 


\section{EVOLUTION OF LARGE CARNIVORES DURING THE MID-CENOZOIC OF NORTH AMERICA \\ THE TEMNOCYONINE RADIATION (MAMMALIA, AMPHICYONIDAE)}

ROBERT M. HUNT, JR.

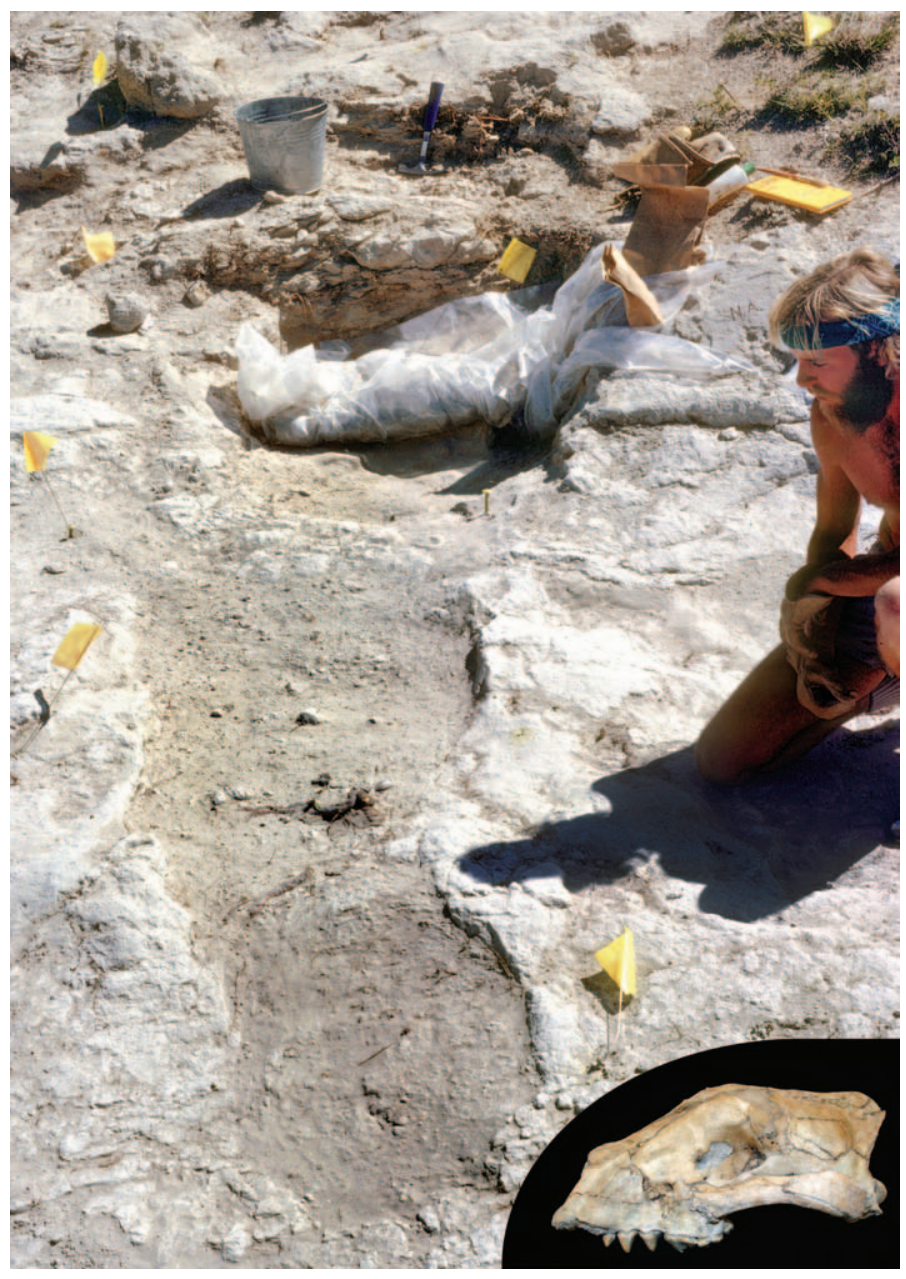

BULLETIN OF THE AMERICAN MUSEUM OF NATURAL HISTORY 


\title{
EVOLUTION OF LARGE CARNIVORES DURING THE MID-CENOZOIC OF NORTH AMERICA: \\ THE TEMNOCYONINE RADIATION \\ (MAMMALIA, AMPHICYONIDAE)
}

\author{
ROBERT M. HUNT, JR. \\ Department of Earth and Atmospheric Sciences \\ University of Nebraska \\ Lincoln, NE 68588-0514
}

BULLETIN OF THE AMERICAN MUSEUM OF NATURAL HISTORY Number 358, 153 pp., 72 figures, 17 tables

Issued November 23, 2011 


\section{DEDICATION}

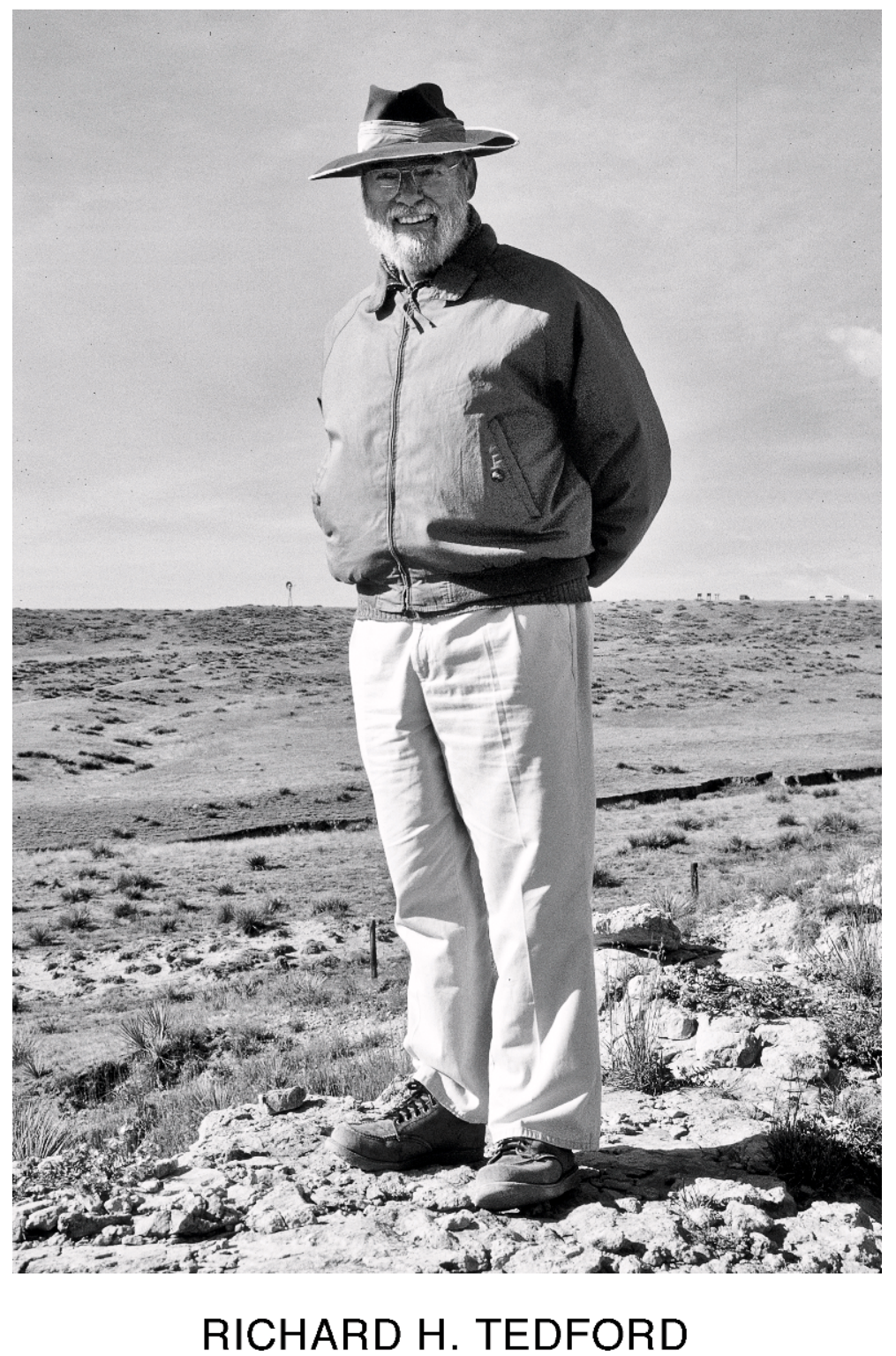

Pawnee Buttes, Colorado, 1999 


\section{CONTENTS}

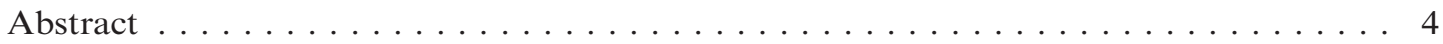

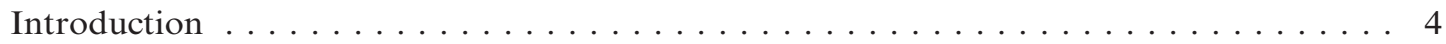

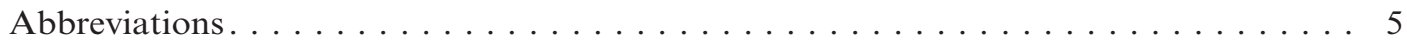

Discovery and Geographic Distribution of Temnocyonines $\ldots \ldots \ldots \ldots \ldots \ldots$

John Day Basin, Oregon . . . . . . . . . . . . . . . . . . . . 7

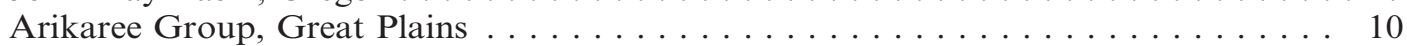

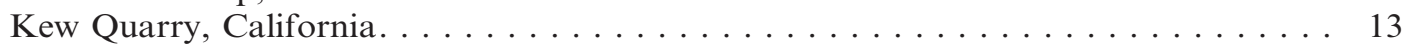

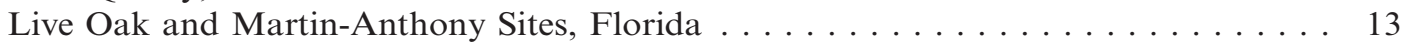

Identification of Temnocyonine Lineages . . . . . . . . . . . . . . . . . . . 14

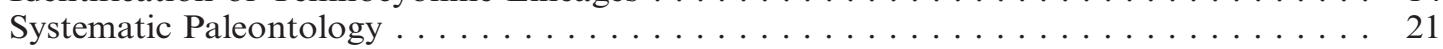

Subfamily Temnocyoninae Hunt, $1998 \ldots \ldots \ldots \ldots \ldots \ldots \ldots \ldots$

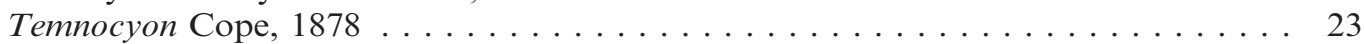

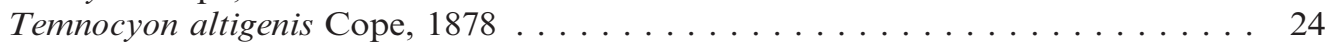

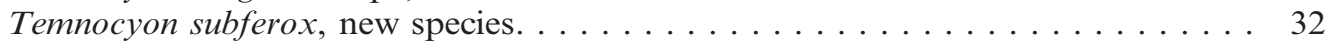

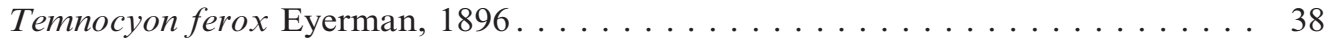

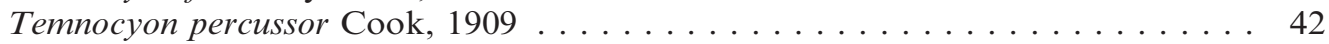

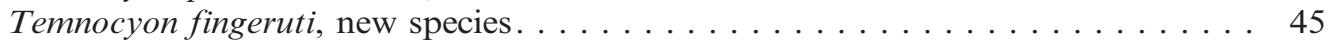

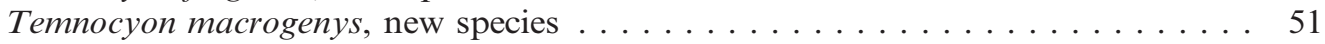

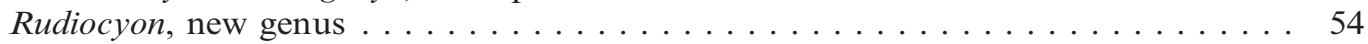

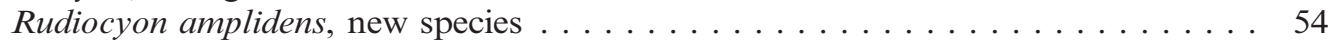

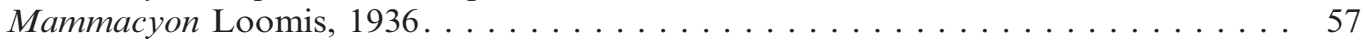

Mammacyon obtusidens Loomis, $1936 \ldots \ldots \ldots \ldots \ldots \ldots \ldots \ldots$

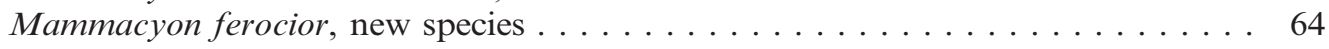

Delotrochanter, new genus . . . . . . . . . . . . . . . . . 74

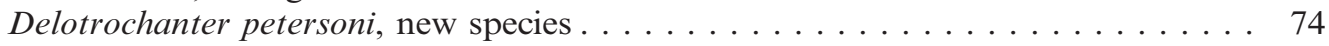

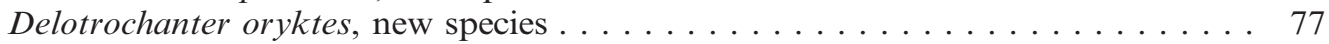

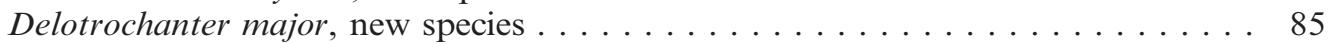

Dentition and Feeding: Appearance of Durophagous Amphicyonids. . . . . . . . . . . 88

Postcranial Osteology: The First Large Carnivoran Cursors . . . . . . . . . . . . . . . 103

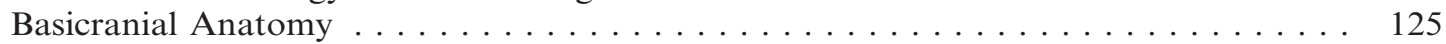

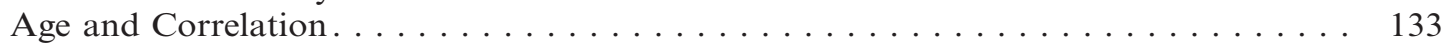

Radioisotopic and Biochronologic Calibration of Temnocyonine Sites . . . . . . . 133

John Day Basin . . . . . . . . . . . . . . . . . . . . . . . . . . . . 134

Arikaree Group, Great Plains . . . . . . . . . . . . . . . . . . . 135

Kew Quarry, California. . . . . . . . . . . . . . . . . . . . . . . 138

Discussion and Conclusions . . . . . . . . . . . . . . . . . . . . . . 139

Origin and Geographic Distribution of an Archaic Predator Guild . . . . . . . . . . 139

Global Climate and the Temnocyonine Radiation . . . . . . . . . . . . . . . . . . . . 141

Regional Climate and Temnocyonine Diversity . . . . . . . . . . . . . . . . . . 143

Epilogue: Cursorial Predators and Durophagy. . . . . . . . . . . . . . . . . 144

Acknowledgments . . . . . . . . . . . . . . . . . . . . . . 145

References . . . . . . . . . . . . . . . . . . . . . . . . . . 146

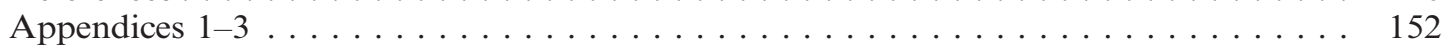




\begin{abstract}
This study describes and summarizes the Temnocyoninae (Mammalia, Carnivora), a subfamily of amphicyonid carnivores of considerable diversity and singular ecomorphology within Cenozoic faunas of North America. In temnocyonines, we see the first carnivorans to occupy an ecological niche as large cursorial predators. The subfamily is confined to the Arikareean NALMA, ranging in age from the latest early Oligocene to the early Miocene. Distributed from the Pacific Northwest to the Great Plains and Florida, there are four genera (Temnocyon, Mammacyon, Delotrochanter n. gen., Rudiocyon n. gen.) and 12 species, of which eight are newly described (Temnocyon subferox, T. fingeruti, T. macrogenys; Rudiocyon amplidens; Mammacyon ferocior; Delotrochanter petersoni, D. oryktes, D. major). Among the specimens examined are eight skulls, three with intact basicranial morphology that establish the presence of a plesiomorphic arctoid auditory region in the subfamily. Temnocyonine dentitions and postcranial skeletons reveal a blend of morphological characteristics not previously nor subsequently seen among the Carnivora. From a stem species, Temnocyon altigenis, there evolve both large hypercarnivorous (Temnocyon) and durophagous forms (Mammacyon, Delotrochanter); these genera share a derived dentition that defines the Temnocyoninae. Delotrochanter oryktes $\mathrm{n}$. sp., an early Miocene species, was found in a den, suggesting a possible burrowing capability and sheltering of offspring.
\end{abstract}

The John Day basin of Oregon and the central Great Plains (western Nebraska, southeast Wyoming) are the source of most temnocyonine fossils; a few have been found in southern California and Florida, indicative of a continent-wide distribution. Temnocyonines have often been confused with canids, however their basicranial anatomy places them securely within the Amphicyonidae. First discovered in the 1870s, only $\sim 30$ individuals comprise the entire record of the subfamily. Many were found in proximity to radioisotopically calibrated tuffs and ignimbrites and/or were closely associated with mammals of established biochronologic age. Thus, most species can be placed in a temporal context. With rare exception, the fossils represent isolated occurrences, hence estimates of variation within a population are lacking.

Cursorial postcranial features characterize several lineages (Mammacyon, Delotrochanter) and probably were present in other temnocyonines known only from dental remains. Late Oligocene Mammacyon ferocior and early Miocene Delotrochanter oryktes evolved uniquely configured crushing cheek teeth and cursorial limbs, combining distinctive dental and skeletal traits in a manner not seen in any living carnivore. These species are interpreted as large durophagous predators with craniodental characteristics that parallel living hyaenids (Crocuta crocuta) and postcranial adaptations approaching those of cursorial canids such as the wolf (Canis lupus). Expansion of semiarid grasslands and savanna during the late Oligocene and early Miocene in the central Great Plains seems to have favored the evolution of these wide-ranging durophagous amphicyonid carnivores.

Analysis of the jaws of temnocyonines employing Therrien's method of beam analysis demonstrates pronounced bending strength focused beneath the crushing dental battery in the molar region. Similarly, the canines and mandibular symphysis manifest an ability to resist strong parasagittal, transverse, and torsional forces occurring during prey capture and feeding.

Temnocyonines share a pronounced similarity in dentition with European haplocyonine beardogs, which doubtless are their sister group among the Amphicyonidae. Some haplocyonines also show cursorial tendencies. Examination of European material, however, reveals subtle dental distinctions indicating that the evolution of the two subfamilies proceeded separately yet in parallel in Europe and North America.

\section{INTRODUCTION}

In North America the guild of large mammalian carnivores was transformed at specific intervals during the Cenozoic. At these times, long-standing associations of large predators were disrupted by extinctions, resulting in loss of species diversity, and were replaced by species representing newly emergent endemic or immigrant taxonomic groups.

The transition from the Oligocene to the Miocene epoch is marked by such an event: 
an archaic creodont-carnivoran association of hyaenodonts, nimravid cats, and endemic daphoenine amphicyonids is replaced by a new carnivoran association characterized by Eurasian migrant amphicyonines, hemicyonine ursids, and the first New World felids (Hunt, 2002a, 2004). The decline of the archaic association takes place over $\sim 4-5$ million years in the late Oligocene, from $\sim 29 \mathrm{Ma}$ to $24-25 \mathrm{Ma}$, and the new arrivals are not evident until $\sim 23 \mathrm{Ma}$ in the early Miocene. During this transitional interval there appears a unique and specialized group of amphicyonids, the Temnocyoninae, that diversified into 3-4 lineages over $\sim 7$ million years $(\sim 29-22 \mathrm{Ma})$. Temnocyonines are the only group of large North American carnivorans to successfully diversify at this time, filling an ecological vacuum that developed during the North American faunal turnover event at the Paleogene-Neogene boundary (fig. 1, NALCTE).

Temnocyonines are the first New World carnivorans to combine large body size, a digitigrade stance, and elongated limbs, with a uniquely configured crushing dentition. The subfamily represents a radiation yielding a number of cursorial durophagous species, the earliest experiment uniting these locomotor and feeding strategies within the Carnivora in North America. Their origin from a plesiomorphic amphicyonid stem is evidenced by basicranial morphology and a rudimentary auditory bulla structure.

Temnocyonine genera mark out three and possibly four lineages: Temnocyon, including the stem temnocyonine species, $T$. altigenis; Mammacyon, the first line to attain large size and to develop a massive crushing dentition; Delotrochanter, new genus, a second durophagous group reaching large size later in the Arikareean than Mammacyon; and Rudiocyon, new genus, exclusive to the John Day Formation of Oregon and a possible relative of Mammacyon, distinguished by the proportions of its molar teeth.

A striding or "cursorial" gait evolved several times within the large carnivores of the Oligocene and Miocene of North America. In the Oligocene, large hyaenodonts (Hyaenodon) developed digitigrady and cursorial tendencies despite mesaxonic fore- and hind feet and rather short fore-and hind limbs (Mellett, 1977; Gunnell, 1998). In the late Oligocene and early Miocene a different cursorial strategy was adopted by the temnocyonines, and in the early Hemingfordian a lineage of endemic daphoenine amphicyonids (Borocyon) evolved long-limbed predators with a fully digitigrade stance (Hunt, 2009). Also, digitigrade hemicyonine ursids migrated to the New World from Eurasia in the early Miocene and sustained their derived limb morphology until their extinction in the late Miocene $(\sim 9 \mathrm{Ma})$. However, the advanced form of digitigrady typical of canine canids developed only in the latest Miocene and Pliocene, long after the demise of earlier experiments in cursorial digitigrade carnivory by hyaenodonts, temnocyonine and daphoenine amphicyonids, and hemicyonine ursids.

This report attempts to clarify temnocyonine systematics, despite the sparse fossil record, recording dental and cranial features identifying the constitutent genera and species. Representative postcrania associated with several species indicate that the subfamily exhibited a common specialized limb and foot anatomy that apparently persisted until the termination of these lineages. The known geographic distribution of the Temnocyoninae is almost entirely limited to regions where Arikareean sediments are common and prominently exposed-the John Day Formation of north-central Oregon, and the Arikaree Group of the central Great Plains. Even in these geographic areas where rich Arikareean mammal assemblages have been found, these carnivores are extremely rare: in the 130 years since the first temnocyonines were discovered, the remains of only $\sim 30$ individuals have been conserved in museum collections (appendix 1). Temnocyonines share a similar dentition with haplocyonine amphicyonids of Europe, yet the genera in each subfamily appear to have evolved in parallel in isolation.

\section{AbBreviations}

\section{Anatomical}

$\begin{array}{ll}\text { AL } & \text { alisphenoid } \\ \text { BO } & \text { basioccipital } \\ \text { BS } & \text { basisphenoid }\end{array}$




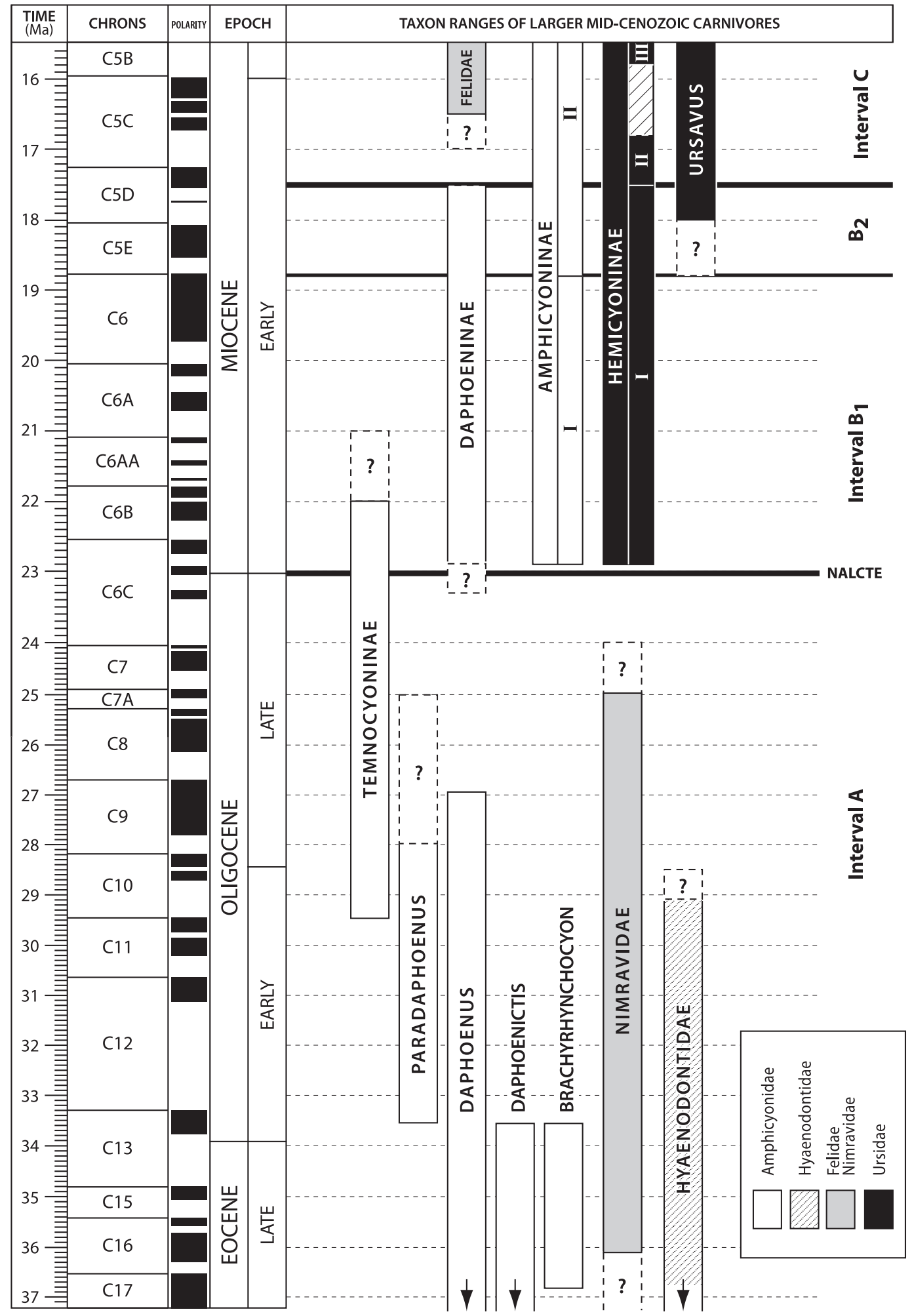


C (IPS) sediment cast of inferior petrosal sinus in basioccipital

$\mathrm{E}_{1}, \mathrm{E}_{2} \quad$ caudal entotympanics 1 and 2

EO exoccipital

ETR epitympanic recess

FO-AC foramen ovale-alisphenoid canal

FR

GF

$\mathrm{H}$

M, MP

M-EO

MLF

$\mathrm{P}$

PC

PE (IPS)

\section{PGF}

PGP

PLF

PP

SMF

SQ

$\mathrm{T}$

\section{Institutional}

ACM Amherst College Museum of Natural History, Amherst, Massachusetts

AMNH Division of Paleontology, American Museum of Natural History, New York

CM Division of Vertebrate Fossils, Carnegie Museum of Natural History, Pittsburgh

F:AM Frick Collection, American Museum of Natural History, New York

FMNH Field Museum of Natural History, Chicago

LACM, Natural History Museum of Los CIT
MNHN Muséum national d'Histoire naturelle, Paris

NM Northwest Museum, Portland State University, Portland, Oregon

UCMP Museum of Paleontology, University of California, Berkeley

UF Vertebrate Paleontology, Florida Museum of Natural History, Gainesville

UNSM Vertebrate Paleontology, University of Nebraska State Museum, Lincoln

USNM Department of Paleobiology, Smithsonian Institution, Washington, D.C.

TRO Timberlane Research Organization, Lake Wales, Florida

YPM Peabody Museum, Yale University, New Haven

YPM-PU Princeton Collection, Peabody Museum, Yale University, New Haven

ZM Division of Zoology, University of Nebraska State Museum, Lincoln

\section{DISCOVERY AND GEOGRAPHIC DISTRIBUTION OF TEMNOCYONINES JOHN DAY BASIN, OREGON}

Temnocyonines were first discovered in the John Day basin of Oregon. C.H. Sternberg and J.L. Wortman, collectors for E.D. Cope, recovered three specimens between 1877 and 1879 . Included were two isolated rami (AMNH 6855, 6856) and a rostrum with associated mandible (AMNH 6857), all assigned to Temnocyon altigenis. A fourth example of this taxon was collected in 1883 by William Day for O.C. Marsh; in this case, a partial juvenile rostrum and associated ramus (USNM 7940). All had been discovered in badland outcrops of the

Fig. 1. Temporal range of temnocyonine amphicyonids in North America during the PaleogeneNeogene transition relative to ranges of other large carnivores (modified from Hunt, 2004, 2009, where Intervals A-C are defined: see Age and Correlation). Temnocyonine and daphoenine amphicyonids survived the North American Large Carnivore Turnover Event, placed here at the present OligoceneMiocene boundary (Lourens et al., 2004). 


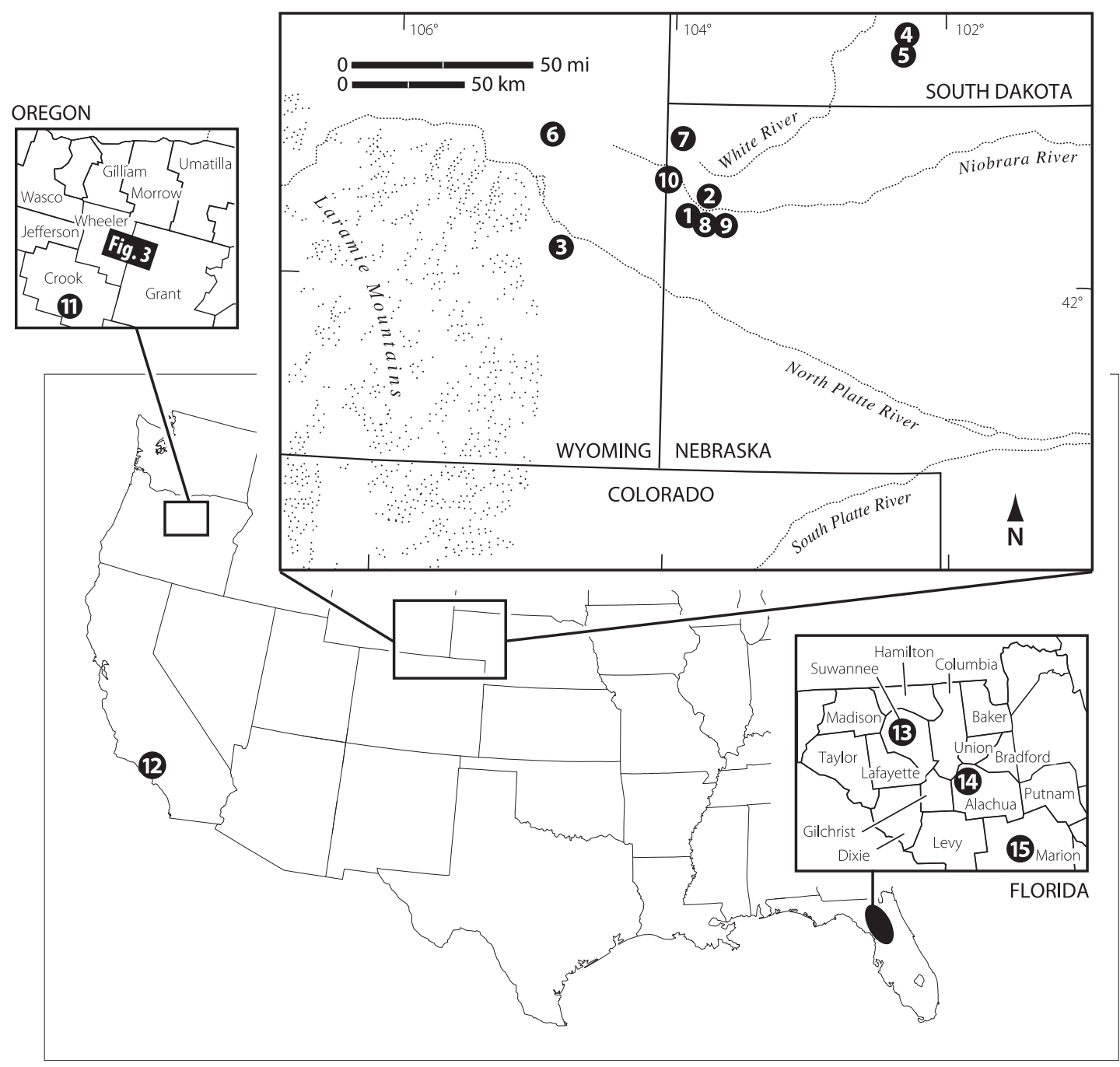

Fig. 2. Geographic distribution of temnocyonines in North America: Great Plains-1, Temnocyon percussor (Syndyoceras Quarry: AMNH 81005); 2, T. percussor (AMNH-Cook Quarry: AMNH 81054, 81047); 3, Temnocyon macrogenys (2 Mile District, near Guernsey, Wyoming: F:AM 54139); 4, cf. Mammacyon (LACM loc. 1872: LACM 15908); 5, Mammacyon obtusidens (Porcupine Creek, South Dakota: ACM 34-41, LACM 9194); 6, M. ferocior (north of Keeline, Wyoming: F:AM 27562, F:AM 54134); 7, Delotrochanter petersoni (Warbonnet Creek, Nebraska: CM 1603); 8, D. oryktes (Carnegie Qu. 3, Agate Natl. Monument, Nebraska: UNSM 48700); 9, D. oryktes (Stenomylus Qu., Agate Natl. Monument, Nebraska: ACM 4804); 10, D. major (near Van Tassell, Wyoming: F:AM 27561). Pacific Northwest-11, Logan Butte (Temnocyon altigenis (UCMP 9999), see fig. 3 for other John Day localities. California-12, Kew Quarry. Florida-13, Live Oak (SB-1A); 14, Buda; 15, Martin-Anthony.

John Day Formation exposed along the main fork of the John Day River in the collecting district known as Turtle Cove (figs. 2, 3), with the possible exception of Cope's genoholotype ramus (AMNH 6855). These, and most later discoveries of temnocyonines, were found before the establish- ment of the currently accepted stratigraphic paradigm for the John Day Formation (Hay, 1963; Fisher, 1967; Fisher and Rensberger, 1972; Woodburne and Robinson, 1977; Robinson et al., 1984); consequently, a specific stratigraphic assignment for many fossils is difficult. 


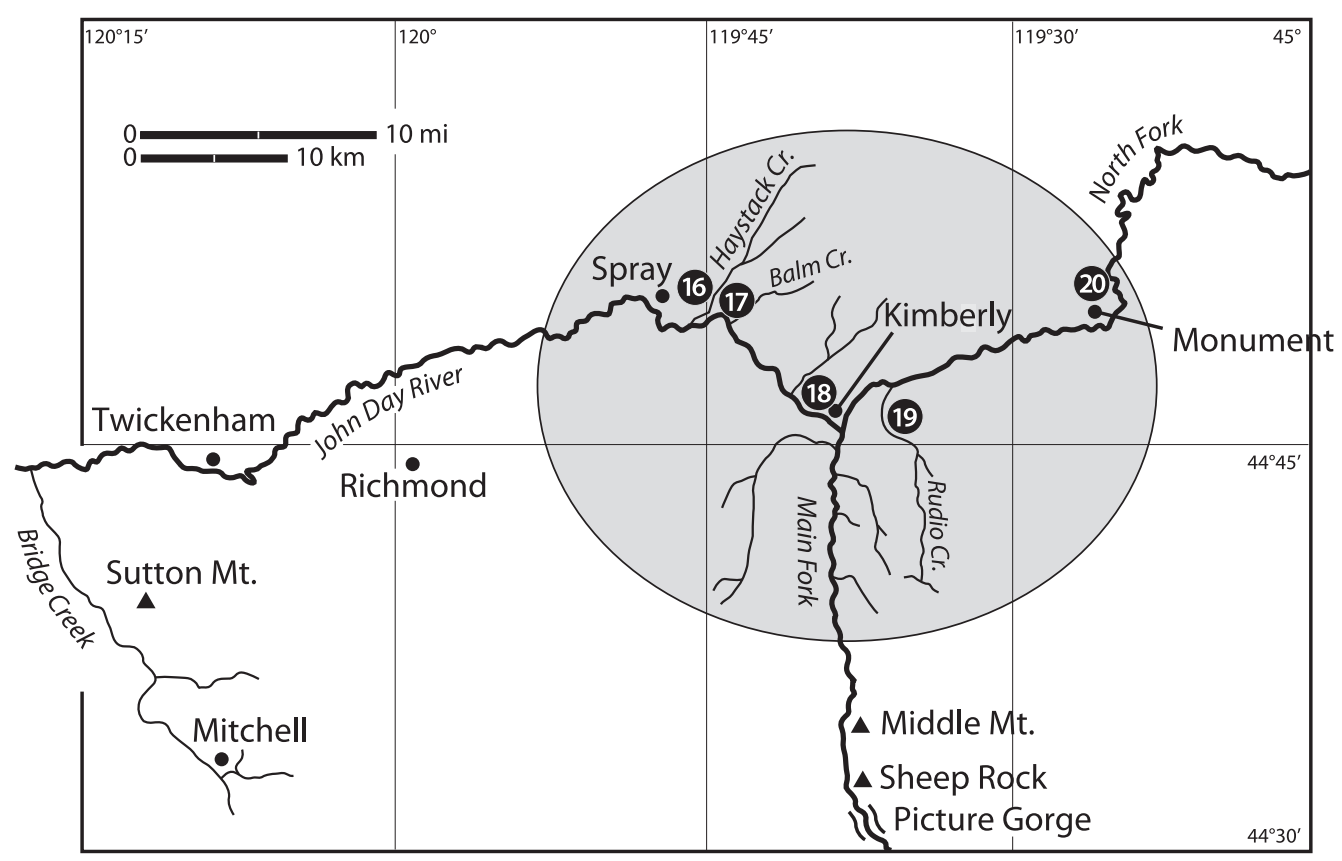

Fig. 3. Geographic distribution of temnocyonines from the John Day region of north-central Oregon. 16, Mammacyon obtusidens (LACM 5386); 17, Temnocyon fingeruti (NM 280/61); 18, Temnocyon ferox (YPM-PU 10787); 19, Rudiocyon amplidens (LACM 480); 20, Temnocyon altigenis (UCMP 1549). T. altigenis (AMNH 6855, 6856, 6857) and T. subferox (YPM 10065) are from unspecified John Day Formation localities.

No complete skulls were included in these initial collections. However, the hypodigm of Temnocyon altigenis was soon augmented by the discovery of two crania $(\sim 17-18 \mathrm{~cm}$, basilar length) during the 1899 and 1900 field expeditions of the University of California (Merriam, 1901, 1906). One was accompanied by an associated skeleton (UCMP 9999) found at Logan Butte in 1900 and was briefly discussed by Merriam (1906). Field methods employed at the time and subsequent handling resulted in some damage to the remains. Although the cranium is distorted by crushing, its particular value lies in its intact basicranium, which lacks only the auditory bullae. The other cranium (UCMP 1549) was found in 1899 southeast of the town of Monument, Oregon. It lacks the occiput and much of the basicranium but is uncrushed. One of the mandibles (AMNH 6856) in the hypodigm occludes perfectly with this cranium.

All of these John Day fossils, discovered from 1877 to 1900, were small doglike carnivorans, and comprise the most plesio- morphic species of the subfamily, Temnocyon altigenis Cope. The species displays what are considered primitive temnocyonine traits: (1) a carnivorous dentition with shearing carnassials, well-developed premolars, and the loss of M3; (2) deep basicranial embayments in the basioccipital for venous sinuses in which the internal carotid artery is presumed to be nested; (3) small body size $(\sim 10-15 \mathrm{~kg})$; (4) absence of elongation of the lower limbs and feet (UCMP 9999), a condition that preceded limb elongation evident in several derivative temnocyonine lineages. The skull and skeleton (UCMP 9999) from Logan Butte collected by Merriam's party in 1900 is regarded as the most plesiomorphic temnocyonine, differing only slightly in its dental morphology from the amphicyonid Daphoenus, a plausible sister taxon. UCMP 9999 is also one of the earliest reliably dated records of the subfamily at $\sim 29$ to $29.3 \mathrm{Ma}$.

Other temnocyonines found in the John Day basin represent larger species that are plausible descendants of $T$. altigenis. Thorpe 
(1922) described a skull (YPM 10065, basilar length, 21-22 cm) from the John Day Formation in the O.C. Marsh collection at Yale University. The skull was probably collected prior to 1900 , conceivably between 1871 and 1877, when L.S. Davis and Wm. Day explored the John Day beds in Marsh's employ (Merriam, 1906). Cranial dimensions and dentition indicate a more advanced species than $T$. altigenis. This isolated skull (T. subferox n. sp., YPM 10065) retained an intact basicranium and partial auditory bulla, which Thorpe did not recognize. The bulla remnant demonstrates that only a rudimentary demibulla was present in this species, comparable to the plesiomorphic ectotympanic demibullae of the stem amphicyonids Daphoenus and Cynodictis. This would have also been the probable bulla type for $T$. altigenis, as indicated by the auditory region of UCMP 9999.

The only other large temnocyonine found in the John Day basin prior to 1900 was collected by L.S. Davis during the 1889 Princeton University expedition to the John Day beds under the direction of $\mathrm{Wm}$. B. Scott. Davis discovered a nearly complete skeleton, skull (basilar length, $26 \mathrm{~cm}$ ), and lower jaws of the largest temnocyonine found up to that time, associated with a partial oreodont skeleton in the "Upper John Day beds," Turtle Cove, later described by Eyerman (1896) as Temnocyon ferox. The articulated skeleton occurred in an indurated gray tuffaceous sandstone, which made preparation difficult, particularly as the crushed and fragmented bones exhibit significant diagenetic alteration. The skeleton remains today in its partially articulated state.

Since 1900 only three additional temnocyonines have been found in the John Day beds of Oregon, indicating the rarity of these carnivorans. Two were found by California Institute of Technology field parties led by Chester Stock: (a) a partial maxilla with P4 M1 (LACM 5386), from green tuffaceous claystone, John Day Formation, in Haystack Valley, Wheeler County, representing the only occurrence of Mammacyon in the John Day region; (b) a partial mandible of a large temnocyonine, Rudiocyon n. gen., associated with a crushed braincase (LACM 480), from gray tuffaceous sandstone, Kimberly Mem- ber, John Day Formation, in the valley of Rudio Creek, Grant County. Rudiocyon is the largest temnocyonine known from the John Day beds. These two specimens were collected shortly before 1933. No additional temnocyonines were recorded from the John Day Formation until 1986 when M. Fingerut and G. Pierson discovered an articulated skull and jaws along Balm Creek east of Haystack Valley (Hunt and Stepleton, 2004). Proximity to a radioisotopically dated bed ( $\sim 23.8 \mathrm{Ma})$ demonstrated that this temnocyonine, here described as Temnocyon fingeruti n. sp., is the youngest occurrence of the subfamily in the Pacific Northwest.

\section{Arikaree Group, Great Plains}

Temnocyonines occur in Arikaree Group (Oligocene-early Miocene) volcaniclastic sandstones of the central Great Plains as rare isolated individuals, primarily partial mandibles with teeth. Only three relatively complete crania are known, the first found in 1934, the second in 1944, and the third in 1981. Temnocyonine fossils from the Great Plains represent a total of only 14 individuals, of which three are known from single teeth.

Three geographic areas with well-exposed Arikaree rocks have produced temnocyonines (fig. 2): (a) the Pine Ridge of Nebraska, Wyoming, and South Dakota, a prominent regional Arikaree escarpment-seven individuals extending through the stratigraphic sequence; (b) upper Arikaree rocks of Agate Fossil Beds National Monument and vicinity, Nebraska-six individuals; (c) upper Arikaree rocks of the North Platte valley near Guernsey, Wyoming - a single large temnocyonine discovered in 1939.

In May 1904, O.A. Peterson of the Carnegie Museum (Pittsburgh) discovered a pair of damaged lower jaws (CM 1603) and associated fragments of a temnocyonine, somewhat smaller than a wolf, at the Pine Ridge escarpment near the head of Warbonnet Creek, Sioux County, Nebraska. Peterson's field labels attribute CM 1603 to the "middle Monroe Creek beds," whereas his published description of the specimen (Peterson, 1907) reads "from the upper Monroe Creek horizon." Although the exact stratigraphic level is uncertain, sediment with CM 
1603 shows it was collected within the upper $400 \mathrm{ft}$ of the Arikaree Group in northwestern Sioux County. This was the first temnocyonine discovered in the Great Plains or, for that matter, anywhere in North America outside the John Day basin. Peterson's lack of familiarity with these carnivorans led him to simply identify it as "Family Canidae, Gen. et sp. indet." It is described here as the earliest known representative of a new genus and species, Delotrochanter petersoni.

In August 1904, Peterson traveled south to the 04 Ranch in central Sioux County where he, with the young rancher Harold Cook, initiated excavations that would become the incredibly rich "Agate Spring Quarries," later set aside as Agate Fossil Beds National Monument in 1965. News of the discovery led to an influx of paleontologists into Sioux County from 1905 to 1909 (Peterson, 1909). Although attention was focused on the principal bonebed exposed on University and Carnegie hills (Matthew, 1923; Peterson, 1923; Hunt, 1990), explorations along the Niobrara River near Agate eventually led to the discovery of temnocyonines in upper Arikaree rocks.

The first temnocyonine was found by Harold Cook (1909). Spurred by scientists' interest in the Agate bonebed, Cook began to search for fossils in Arikaree outcrops along the Niobrara River valley near his ranch. In 1905, he discovered mammal bones about 0.5 mile west of the Agate 04 ranch headquarters in a bluff overlooking the river. Here oreodont, horse, and rhinoceros fossils were found in the same horizon as a partial skeleton of the rare protoceratid antelope Syndyoceras (Barbour, 1905). These remains, attributed by Cook to the Syndyoceras level or "quarry," occur in the Harrison Formation $\sim 45 \mathrm{ft}(14 \mathrm{~m})$ below its upper boundary. The site is rather nondescript, and the bones do not seem to have accumulated in a stream channel or waterhole as in the principal Agate quarries. The fossilferous level yields only scattered isolated specimens from finegrained, gray volcaniclastic sandstone that extends for over $75 \mathrm{ft}(23 \mathrm{~m})$ along the face of the bluff. Cook continued to visit this prolific horizon and recorded his discoveries in a small notebook (titled, "Entry Catalog of Fossils, Harold J. Cook"). His entry H.C.
116 is given as "Canid gen. \& sp. indet., Syndyoceras layer, July 1906. H.C. coll." H.C. 116 today is AMNH 81005, the partial right and left mandibles and isolated canine of a robust wolf-sized temnocyonine, later described by Cook (1909) as the holotype of Temnocyon percussor. Although there remains some question about the attribution of AMNH 81005 to the Syndyoceras level, the weight of evidence indicates it came from that site.

Two years later, in July 1908, Harold Cook found an isolated M1 in the American Museum-Cook Quarry (H.C. 1197, AMNH 81047), which he identified as "carnivore." This is the only known upper molar of Temnocyon percussor, a determination based on the occlusal form of lower molars of AMNH 81005. In August 1909, a lower carnassial (H.C. 229, AMNH 81054) of T. percussor was collected by Cook from the same quarry. These fossils (AMNH 81005, 81047, 81054) indicate a species similar to yet somewhat larger than T. ferox of the John Day beds. The American Museum-Cook Quarry occurs in the basal Anderson Ranch Formation (Hunt, 2002b), $2 \mathrm{mi}$ north of the Agate waterhole bonebed on Carnegie Hill, and at the same stratigraphic level. The quarry is $45-$ $50 \mathrm{ft}(14-15 \mathrm{~m})$ stratigraphically above the Syndyoceras level (Hunt, 1990: fig. 4). The Syndyoceras locality and the American Museum-Cook Quarry today remain outside the boundaries of the Agate Fossil Beds National Monument on private land and are the only localities where $T$. percussor has been found.

In 1939 Charles Falkenbach of the Frick Laboratory excavated a mandible and postcranial fragments of a huge temnocyonine (F:AM 54139) from Arikaree rocks near Guernsey, Platte County, Wyoming. Although Falkenbach did not record the exact location, Frick Laboratory records show that this individual probably came from upper Arikaree beds a few miles south of the North Platte River referrable to the Anderson Ranch Formation. The teeth indicate affinity with $T$. percussor from Agate. This taxon, Temnocyon macrogenys $\mathrm{n}$. sp., represents the terminal species of a dentally plesiomorphic lineage of carnivorous temnocyonines in which the cusp pattern of the teeth can be derived from the teeth of $T$. altigenis. 
In addition to the small sample of Temnocyon percussor from the vicinity of Agate Fossil Beds National Monument, more complete material of four individuals belonging to a different temnocyonine lineage, Delotrochanter n. gen., was found within the present boundaries of the monument, first by Amherst College in 1909 at Stenomylus Quarry, then by Princeton University in 1914 in the Carnegie Hill bonebed, and finally in 1981 by the University of Nebraska working in the carnivore dens at Beardog Hill.

In 1909, while collecting at Stenomylus Quarry, F.B. Loomis (Amherst College) and his party found a large amphicyonid skeleton (ACM 4804) that he believed to be Daphoenodon superbus, the large beardog found in the carnivore dens at Beardog Hill (Loomis, 1910; Peterson, 1910; Hunt et al., 1983). However, Loomis was mistaken: the skeleton represents a previously unrecognized cursorial temnocyonine, Delotrochanter oryktes n. gen., n. sp. The skeleton was never described by Loomis and was damaged when it was pressed into a wall of wet plaster at the Amherst College Museum shortly after it was collected. It was later carefully removed by Dr. Margery Coombs for study by a graduate student, Mildred Schlain (Schlain, 1980), and is one of the most complete temnocyonine skeletons yet discovered. Some bones of a juvenile (ACM 4804A) were associated with the skeleton of the adult.

In 1914 Princeton University removed a section of the waterhole bonebed on Carnegie Hill for exhibition in their museum. This slab eventually was transferred to Yale University where it was cataloged as YPM 12213. Although carnivores are uncommon in the bonebed, a calcaneum referrable to $D$. oryktes (YPM 24872) was found in this slab, the only record of a temnocyonine from the waterhole itself.

In September 1981, UNSM investigators at Agate Fossil Beds National Monument relocated O.A. Peterson's Quarry 3 on Beardog Hill, which in 1904-1905 yielded abundant carnivore material (amphicyonids, canids, and mustelids). One of the first items recovered was a fragment of a temnocyonine upper molar, which ultimately led to the crushed skull and postcranial remains of a large temnocyonine (UNSM 47800) lying within a burrow, one of several making up a den complex (front cover and fig. 37B; also Hunt et al., 1983: fig. 1, burrow C). This individual proved similar to the temnocyonine from Stenomylus Quarry found by Loomis in 1909, and both are referred here to D. oryktes. The presence of Delotrochanter oryktes in these dens together with multiple skeletons of Daphoenodon superbus demonstrated their coexistence in the region during the early Miocene.

Upper Arikaree rocks exposed in the Niobrara River valley at Agate Fossil Beds National Monument can be traced northwest through Sioux County into Niobrara County in southeastern Wyoming. Here, near the town of Van Tassell, Paul Miller in 1927 found fragmented lower jaws and a few upper teeth of a large temnocyonine (F:AM 27561), Delotrochanter major n. sp., a dentally more advanced descendant of $D$. oryktes. Its stratigraphic occurrence was not well documented by Miller, but pale reddishbrown, fine-grained sediment associated with the remains indicates its derivation from Peterson's "Upper Harrison" beds near Van Tassell (now Anderson Ranch Formation, Hunt, 2002b), possibly from the stratotype section itself. Thus, the biochron of Delotrochanter in the Great Plains involves three species: (a) D. petersoni n. sp., the jaws (CM 1603) found by O.A. Peterson in 1904 near the head of Warbonnet Creek in Sioux County, and the earliest representative of the genus in the Great Plains; (b) D. oryktes n. sp., occurring at Agate Fossil Beds National Monument - the genotypic species including the most complete material; and (c) Van Tassell Delotrochanter major n. sp., the terminal occurrence of the lineage in North America.

Arikaree rocks of the Pine Ridge escarpment have produced remains of a third temnocyonine lineage, Mammacyon, which became extinct before the early Miocene when Delotrochanter and Temnocyon still survived in the Great Plains. In 1934 F.B. Loomis collected from the Wounded Knee area of South Dakota a crushed skull and partial skeleton (ACM 34-41) of a temnocyonine somewhat larger than a wolf but with heavy blunt-cusped cheek teeth, suggestive of a durophagous habit. This dental 
morphology caused Loomis to name the taxon Mammacyon obtusidens in reference to the pestlelike cusps. No jaw was found with the skull, but in 1964 Harley Garbani collected a mandible (LACM 9194) in the Monroe Creek Formation of the Wounded Knee area that can be assigned to the same species. The skull of ACM 34-41 included the basicranium and was only the second temnocyonine to retain the auditory bulla.

A similar but much larger skull and partial mandible of Mammocyon were found by Charles Falkenbach of the Frick Laboratory in younger Arikaree rocks of the Pine Ridge escarpment north of Keeline, in Niobrara County, Wyoming. The mandible and skull were not associated but occlude satisfactorily, share a complementary cusp morphology, and are assigned here to the same species, $M$. ferocior $\mathrm{n}$. $\mathrm{sp}$. The mandible (F:AM 27562) was found in 1931, and the magnificent skull (F:AM 54134) 13 years later in 1944; a partial postcranial skeleton is associated with the mandible and indicates cursorial tendencies. This large species marks the termination of the Mammocyon lineage in the Great Plains.

The Oligocene Sharps Formation in the Wounded Knee area, South Dakota, has produced a mandibular fragment with two molars (LACM 15908) that probably represents the earliest occurrence of Mammocyon. Found in 1963 by J. Harksen, this specimen represents both the smallest individual and the lowest stratigraphic record of a temnocyonine in the Great Plains. It was first mentioned by Macdonald (1970: 60) who referred it to the canid genus Sunkahetanka. Despite its early appearance, its teeth are larger and m1-2 more derived than specimens of Temnocyon altigenis from the John Day basin, suggesting that the John Day sample from the Turtle Cove area is chronologically older than the level in the Sharps Formation that produced LACM 15908.

\section{Kew Quarry, California}

The only temnocyonine from western North America found outside the John Day region is represented by a badly crushed and fragmented lower jaw (LACM 470), collected in Kew Quarry, Las Posas Hills, California by Thurston in 1930 (fig. 2). Associated mammals have indicated either a late Whitneyan or early Arikareean age for the Kew Quarry assemblage (Prothero et al., 1996). The temnocyonine mandible and dentition are difficult to reconcile with a late Whitneyan age: the cheek teeth are somewhat larger and more derived than in any individual from the early Arikareean John Day T. altigenis sample, including Cope's holotype. The teeth of LACM 470 occlude appropriately with the upper dentition of Temnocyon subferox and could represent that species. Here the Kew Quarry temnocyonine is assigned to Temnocyon cf. T. subferox. Prothero et al. (1996: 183) suggested that an age in the interval 28.7-29.3 Ma seemed reasonable, which relies heavily on the carnivores from the quarry and correlation to Global Polarity Chron 10r (see Age and Correlation).

\section{Live OAK AND Martin-ANTHONY SITES, FLORIDA}

Arikareean localities in Florida have produced a few rare temnocyonine fossils discovered in 1966 and 1974-75 (fig. 2). Other reports of Temnocyon in Florida in the scientific literature (e.g., Olsen, 1958: 595-fossils now referred to Daphoenodon notionastes) are inaccurate and have been found to be canids or other genera of amphicyonids. The few teeth that are known are adequate to demonstrate the existence of Temnocyoninae in southeastern North America in the Arikareean, but these fossils can only be tentatively assigned to genera recognized in the Great Plains and John Day basin of Oregon.

Frailey (1978) described a temnocyonine M1 (TRO 390) from the Live Oak locality (SB-1A), north-central Florida. The site is a limestone mine: in the mining pits, sediments overlying the Suwanee Limestone have yielded fossil mammals from the fine interstitial matrix of an unstratified, poorly sorted limestone conglomerate (Frailey, 1978). The form of this M1 is more derived than any M1 attributed to Temnocyon and is most similar to the M1 of Delotrochanter oryktes from Stenomylus Quarry. If so, the tooth would come from a slightly smaller, less advanced species. Referral to Mammacyon is less likely but cannot be ruled out. Also found at Live 
Oak is a temnocyonine unciform (TRO 661), lower canine (TRO 388), and two phalanges (TRO 386, 387) that correspond in size to the M1 and likely represent the same species. The temnocyonine unciform is most similar to the unciform of the wolf (Canis lupus) among living carnivores in contrast to the taller, narrow unciforms of living ursids and felids. The unciform compares closely with that bone in Temnocyon ferox, and also D. oryktes described by Schlain (1980), and shows that the Live Oak carnivore was much larger than $T$. ferox and only slightly smaller than $D$. oryktes. This temnocyonine and D. notionastes occur together at Live Oak.

MacFadden (1980) mentioned a temnocyonine M2 (UF 24203) found at the MartinAnthony locality in northern Florida in 1966. Clastic sediments assigned to the Hawthorne Group at this site have yielded not only the M2 but also turtles, dugongs, a rhinoceros, and a small camelid. These sediments have been allocated to the Penney Farms Formation, the basal unit of the Hawthorn Group at this locality (Scott, 1988). A strontium isotope age of $\sim 24.6 \mathrm{Ma}$ derived from molluscs in the underlying limestone bed at Martin-Anthony could approximate the age of the temnocyonine molar. A late Oligocene age is not improbable because the M2, a large tooth, compares most closely with M2s of Mammacyon ferocior and $M$. obtusidens. However, M2 is not yet known for the larger species of Temnocyon ( $T$. percussor, $T$. macrogenys) and Delotrochanter (D. major).

Frailey (1979: 143) described a calcaneum (UF 16908) from the Buda local fauna, Alachua County, north Florida, as an Arikareean felid; at that time the similarity between the calcanea of felids and temnocyonines was not recognized. This calcaneum is the only record of a temnocyonine in the Buda fauna where this species also occurs with $D$. notionastes. It shows the tall, narrow axial form, elongate distal region, and high sustentaculum typical of the subfamily, details already evident in the calcaneum of the plesiomorphic $T$. altigenis from Logan Butte. Although a generic or specific assignment is not possible because of the near anatomical identity of temnocyonine calcanea, its form indicates a carnivore of the size of Temnocyon ferox. UF 16908 is $22 \%$ larger than the calcaneum of $T$. altigenis (UCMP 9999), $11 \%$ smaller than that of D. oryktes (UNSM 48700), and $22 \%$ smaller than that of Mammacyon ferocior (F:AM 27562).

More complete material of Florida temnocyonines is required to place them confidently within lineages recognized elsewhere in North America. However, the M1 and calcaneum suggest an age prior to the latest Arikareean (Ar 4) for the Live Oak and Buda sites.

\section{IDENTIFICATION OF TEMNOCYONINE LINEAGES}

North American temnocyonines range from the latest early Oligocene to early Miocene, species in each lineage attaining their largest size as they approach extinction. Dentitions provide the strongest evidence for the existence of discrete temnocyonine lineages (fig. 70). Three genera are recognized in the John Day Formation of Oregon (Temnocyon, Rudicyon n. gen., Mammacyon), and three in the Arikaree Group of the Great Plains (Temnocyon, Mammacyon, Delotrochanter n. gen.). Only Temnocyon and Delotrochanter extend into the early Miocene in the Great Plains. Temnocyonines are unknown in the Miocene except for the Great Plains occurrences. Previously, lineages within the subfamily have been difficult to identify, due to scarcity of material, and the distribution of fossils among a number of different collections. Although the known sample of temnocyonines still remains small, recent radioisotopic dating and stratigraphic studies in the Great Plains and in the John Day basin have provided the necessary foundation for evaluating and comparing specimens.

This study is based on simultaneous examination of all North American temnocyonine fossils: comparison was greatly facilitated by viewing the entire sample in one location. This resulted in recognition of three dentally specialized and geochronologically young end-member species (Temnocyon macrogenys n. sp., Delotrochanter major n. gen. et sp., Mammacyon ferocior n. sp.), which then were traced backward in time into older rocks. The terminal species of Temnocyon and Delotrachanter occur in the latest Arikareean (Ar4); the terminal species of Mammacyon, M. ferocior, is found in the upper Arikaree 
Group of Wyoming and is believed to be earliest late Arikareean in age (Ar3).

Future students of the group may find that these lineages require modification in the light of new fossil discoveries. Because of the small number of fossils, intraspecific variation in temnocyonines cannot be adequately addressed by this study, particularly dental variation. If species eventually prove highly variable in dental features, then the fossils discussed here may have been split into an excessive number of morphospecies. However, based upon dental variation among living carnivorans, and that observed in the stem temnocyonine, Temnocyon altigenis, the variation permitted in species described in this report is not exceptional.

Table 1 presents the diagnostic differences used to recognize these genera. These involve the teeth: (1) size and form of the premolars; (2) proportions of the upper and lower carnassials; (3) cusp pattern of the lower carnassial, including presence or absence of the metaconid; (4) form of the first upper molar; (5) length and configuration of $\mathrm{m} 2$. These features, singly or in combination, define the genera. The genera Mammacyon and Delotrochanter are phyletic lineages or clades; Temnocyon is a paraphyletic genus that includes the ancestry of the subfamily and its descendants retaining plesiomorphic craniodental features - species in the genus differ in size and autapomorphic dental traits. Within each genus there is an evident increase in body size over time best reflected in skull size and dimensions of the mandibular (table 2) and maxillary (table 3 ) dentitions.

PREMOLARS: Tall, laterally compressed premolars first observed in John Day temnocyonines by E.D. Cope are one of the most evident diagnostic traits of the subfamily. Cope's genoholotype mandible of Temnocyon, as well as those of all other plesiomorphic temnocyonines, features tall welldeveloped p2-4 and P2-3. P1/p1 are small, often low and peglike teeth that lack the height of the more posterior premolars and are not replaced by a second-generation tooth (they belong to the milk dentition as in many other mammals). In Temnocyon and Mammacyon the upper and lower premolars (except of course P4) are typically triangular (in lateral view), narrow, elongate teeth, and are not shortened or widened. This is also true for the only surviving premolar of Rudiocyon. Delotrochanter on the other hand has short, posteriorly wide premolars, distinguishing it from Mammacyon and Temnocyon. Temnocyon and Mammacyon also lack a well-defined posterior accessory cusp on the posterior slope of p3, whereas Delotrochanter has such a cusp. Premolars increase in size as body size increases within all lineages; however in Delotrochanter there is a trend toward short, wide premolars, whereas in Temnocyon and Mammacyon the longer, relatively narrow teeth are maintained (except for a broad p4 in Mammacyon ferocior). Premolars (p1-4) increase in size posteriorly in the toothrow, and p4 is often of striking size relative to $\mathrm{m} 1$. These robust premolars accompany crushing carnassials and molars, particularly in the large terminal species of Mammacyon and Delotrochanter, suggesting a durophagous adaptation. The prominent premolars of temnocyonines distinguish them from amphicyonines, which have greatly reduced $\mathrm{p} 2-3 / \mathrm{P} 2-3$.

CARNASSIALS: One of the most diagnostic temnocyonine teeth is the upper carnassial. Initially in early John Day temnocyonines this tooth is little different in form from the shearing upper carnassial of a typical plesiomorphic beardog like Daphoenus. However, in Delotrochanter and Mammacyon the upper carnassial evolves into an enlarged, bluntcusped crushing tooth in which shear is no longer the principal function. This is accomplished by shortening of the metastylar blade (thus metastylar shear is diminished), while the protocone region becomes lingually extended and much enlarged, and the protocone itself transforms into a blunt pestlelike cusp (table 4). The occlusal outline of the upper carnassial thus takes the form of an equilateral triangle, not the more common isosceles triangle found in most arctoid and cynoid carnivorans with a shearing P4. Whether this same trend occurred in Temnocyon remains to be demonstrated because the large end-member species of that genus from the Great Plains (T. macrogenys) is not known from specimens that preserve the upper carnassial. The terminal species of John Day Temnocyon (T. fingeruti, T. ferox) suggest that such modification occurred but 
TABLE 1

Comparison of Dental Traits of North American Temnocyoninae

\begin{tabular}{ccc}
\hline \hline Temnocyon & Delotrochanter & Mammacyon \\
\hline
\end{tabular}

c, C Upper and lower canines show no evident differences among the 3 genera. Upper canines are less recurved than lower canines. Strong enamel ridges run along the posterior face and the anterointernal face in these genera. These two ridges are also present on the lower canine, however, the more posterior ridge is placed on the posterointernal border and the canine itself is rotated clockwise in dorsal view.

p1 No evident differences in this tooth allow discrimination among the genera. It is small, low, single-cusped, and single-rooted, with a longer posterior slope. The milk dentition in a juvenile of T. altigenis demonstrates that p1/ P1 erupt as part of the deciduous dentition and are not replaced in the adult.

p2 In the John Day holotype of T. altigenis Cope and other specimens of the species hypodigm, this tooth is tall, laterally compressed, without a posterior accessory cusp (PAC). The Temnocyon $\mathrm{p} 2$ retains this simple form yet becomes taller in T. ferox and T. macrogenys. The $\mathrm{p} 2$ of Temnocyon is difficult to distinguish from $\mathrm{p} 2$ of Mammacyon without the remainder of the dentition. In Delotrochanter the p2 is short, posteriorly wide, without PAC, and with a steep anterior face; the anterior root is much smaller than the posterior root, which differs in this regard from the equi-sized roots of the other genera.

p3 Simple triangular tooth without PAC, not significantly widened posteriorly

p4 Tall, triangular, laterally compressed tooth, robust, with strong PAC placed toward labial side about halfway up posterior face; shelflike posterior cingulum with small cusp

m1 With metaconid; basal labial cingulum sinuous; para- protohypoconid not aligned; no notch at posterointernal corner of talonid (talonid border convex)

$\mathrm{m} 2$ Short relative to $\mathrm{m} 1$ with protoconid taller and larger than hypoconid

Robust anteroposteriorly short triangular tooth, with PAC, posteriorly widened

Shorter posteriorly wide tooth with enlarged PAC that is centrally located on posterior face; posterior cingulum shelf absent or very abbreviated, and cusp on remnant of shelf applied closely against PAC Without metaconid; basal labial cingulum nearly straight; paraproto- hypoconid aligned; hypoconid enlarged; weak notch at posterointernal corner of talonid Short relative to $\mathrm{m} 1$ with protoconid and hypoconid about equal in size and height
Simple triangular tooth without PAC, elongate, widened posteriorly only in $M$. ferocior, the terminal species

Similar to Temnocyon tooth but not as tall; PAC placed toward labial side on posterior face; shelflike posterior cingulum with small cusp

Without metaconid (vestigial in LACM 15908); basal labial cingulum sinuous; para- proto- hypoconid not aligned; strong internal notch at posterointernal corner of talonid Elongate relative to $\mathrm{m} 1$ with protoconid and hypoconid about equal in size and height

m3 Known in only three individuals in which no significant differences can be identified.

P1 No evident differences in this tooth allow discrimination among the genera. It is small, low, single-cusped, and single-rooted. In T. ferox (YPM-PU 10787), P1 is a triangular, more bladelike tooth; in M. ferocior (F:AM 54134) it is a simple large peg.

P2 Laterally compressed triangular tooth with slightly elongated posterior part; no PAC

P3 Laterally compressed triangular tooth with somewhat widened posterior part; small PAC present

P4 T. altigenis retains plesiomorphic form of amphicyonid P4 in which protocone is anteriorly placed and metastylar blade is not abbreviated; T. ferox damaged but like $T$. altigenis; $\mathrm{P} 4$ unknown in $T$. macrogenys but probably as in $T$. altigenis
Triangular tooth, shorter and Laterally compressed triangular posteriorly wider than in Temnocyon tooth with somewhat widened and Mammacyon; no PAC

Triangular tooth, shorter and posteriorly wider than in Temnocyon tooth with somewhat widened and Mammacyon; small PAC on labial side of expanded posterior part of tooth

Protocone region enlarged but not extended lingually beyond internal border of M1; metastylar blade short; tooth robust and blunt-cusped, and smaller than Mammacyon P4; parastylar region less anteriorly extended than in Mammacyon
Laterally compressed triangular

posterior part; no PAC (P2 known only in M. obtusidens) posterior part; PAC absent or very small (P3 known only in $M$. obtusidens)

Protocone region greatly enlarged and extended lingually beyond internal border of M1; metastylar blade short; tooth robust and bluntcusped, and relatively larger than Delotrochanter P4; parastylar region strongly anteriorly extended 
TABLE 1

(Continued)

\begin{tabular}{|c|c|c|c|}
\hline & Temnocyon & Delotrochanter & Mammacyon \\
\hline & $\begin{array}{l}\text { T. altigenis retains plesiomorphic } \\
\text { M1 form (UCMP 9999) with little } \\
\text { or no anteroposterior widening } \\
\text { of protocone region; although } \\
\text { some protocone expansion occurs } \\
\text { in later Temnocyon species } \\
\text { (T. percussor, T. ferox), it is much } \\
\text { less than in Mammacyon and } \\
\text { Delotrochanter }\end{array}$ & $\begin{array}{l}\text { M1 with pronounced thickening of } \\
\text { lingual cingulum resulting in } \\
\text { anteroposterior widening of } \\
\text { protocone region relative to the } \\
\text { length of the labial margin of M1 }\end{array}$ & $\begin{array}{l}\text { M1 with pronounced thickening of } \\
\text { lingual cingulum resulting in } \\
\text { anteroposterior widening of } \\
\text { protocone region relative to the } \\
\text { length of the labial margin of M1; } \\
\text { labial M1 margin also extended }\end{array}$ \\
\hline & \multicolumn{3}{|c|}{$\begin{array}{l}\text { In all genera M2 is significantly smaller than M1 and occlusal form is variable; metacone greatly reduced relative } \\
\text { to paracone as body size increases; lingual border of M2 at about same level as that of M1 in Temnocyon whereas } \\
\text { in Mammacyon and Delotrochanter the M2 lingual margin appears labially retracted due to transverse expansion } \\
\text { of the M1 lingual cingulum; M2 occlusal form more rectangular with parallel straight anterior and posterior } \\
\text { margins in Delotrochanter oryktes and Mammacyon; M2 with labial and lingual halves "folded" nearly at right } \\
\text { angle in Mammacyon obtusidens yet less so in M. ferocior and Delotrochanter oryktes. }\end{array}$} \\
\hline 135 & Absent & Absent & \\
\hline
\end{tabular}

was not as pronounced as in the other two genera.

The lower carnassial alters its cusp pattern and proportions in both Delotrochanter and Mammacyon (and in Rudiocyon) but only minor changes occur in Temnocyon. Early John Day temnocyonines (T. altigenis) have lower carnassials that closely approach a plesiomorphic shearing amphicyonid $\mathrm{ml}$ (e.g., Daphoenus vetus). This plesiomorphic pattern in Daphoenus incorporates a prominent tricuspid trigonid with well-developed paraconid-protoconid shear and a distinct metaconid; the talonid lies at a lower level than the trigonid and forms a shallow basin bordered labially by a prominent hypoconid and lingually by a thin enamel rim often with a tiny entoconid cusp. In early John Day temnocyonines the only significant modification of this plesiomorphic pattern is the loss of the entoconid and development of an enlarged hypoconid that occupies nearly the entire talonid. Consequently in the earliest temnocyonines the $\mathrm{ml}$ talonid is already a blunt crushing instrument.

As the three lineages evolve, only two (Delotrochanter, Mammacyon) show significant changes in $\mathrm{m} 1$ cusp pattern and form. Temnocyon does not and $\mathrm{m} 1$ simply becomes larger: even its terminal latest Arikareean species ( $T$. macrogenys) still retains the plesiomorphic $\mathrm{m} 1$ cusp pattern (tall trigonid with metaconid, and low talonid with enlarged blunt hypoconid). The most pronounced modification of $\mathrm{m} 1$ occurs in Delotrochanter in which the metaconid is lost even in the oldest species (D. petersoni); the paraconid and hypoconid approach each other in height; and the hypoconid becomes an enlarged bulbous cusp occupying the entire talonid. The talonid becomes enlarged to such a degree that in the terminal species, D. major, the hypoconid exceeds the paraconid in size.

The terminal species of Temnocyon and Delotrochanter (T. macrogenys, D. major), which coexisted in the latest Arikareean (Ar4) of the central Great Plains, demonstrate the divergent extremes attained by the lower carnassial. The former retains an enlarged, massive plesiomorphic $\mathrm{m} 1$; the latter a completely transformed crushing tooth. However, the lower carnassials of Mammacyon and Delotrochanter are less readily distinguished since in both genera the metaconid is lost early, and the paraconid and hypoconid tend to approach each other in height. Isolated lower carnassials of the two genera may be identified by the larger, more expanded talonid and hypoconid in Delotrochanter and the form of the labial cingulum, which is straight in Delotrochanter and sinuous in Mammacyon. In addition to loss of the metaconid, the $\mathrm{m} 1$ paraconidprotoconid cusps in Mammacyon and Delotrochanter become more rounded and less sectorial. Delotrochanter major represents the 
TABLE 2

Measurements (length $\times$ width, $\mathrm{mm}$ ) of the Mandibular Dentition of Temnocyoninae

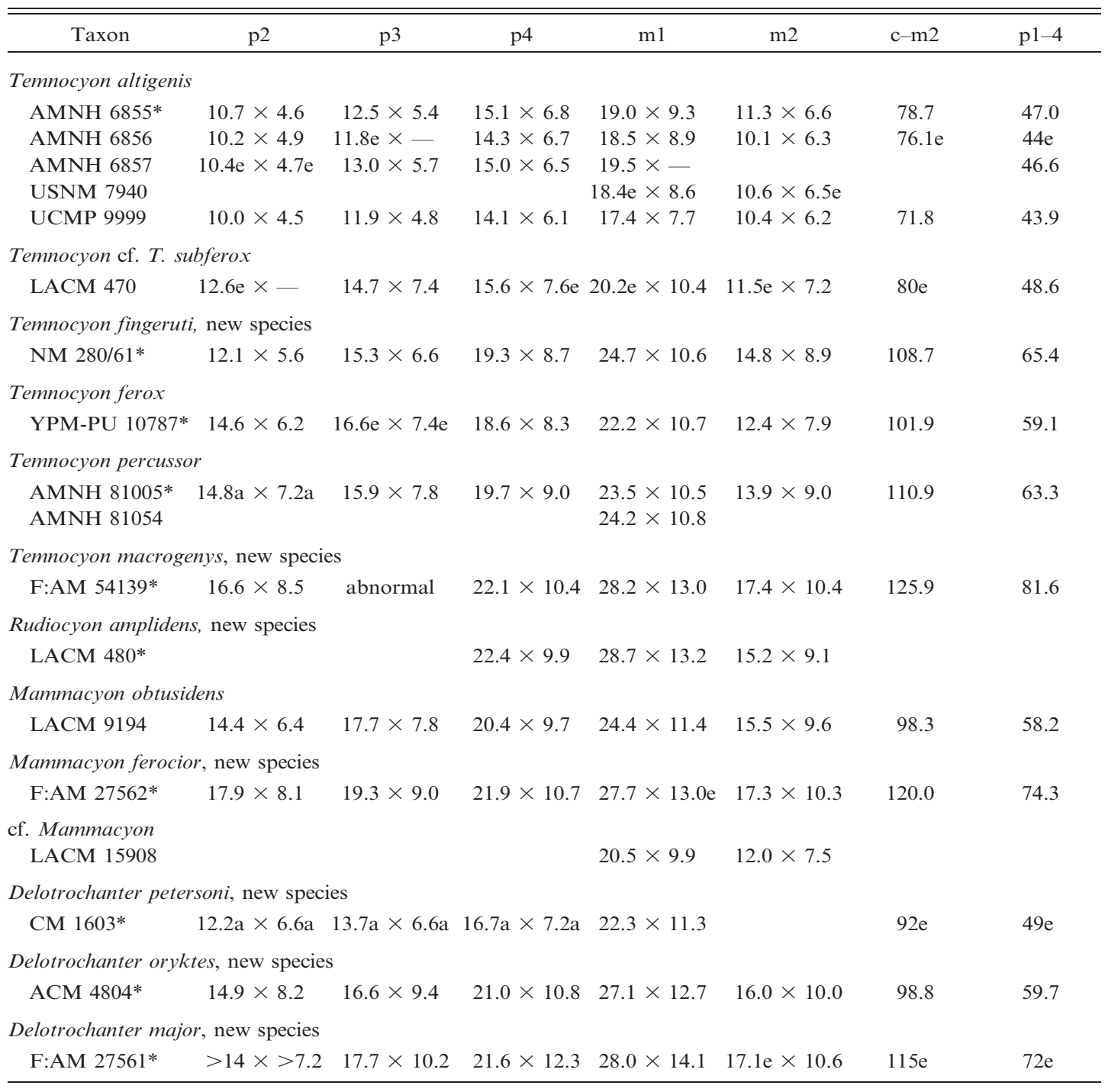

$*=$ holotype, $\mathrm{e}=$ estimated measurement, $\mathrm{a}=$ alveolar measurement.

extreme expression of this trend: the lower carnassial is little more than three linearly arranged, rounded cusps (with paraconid slightly offset lingually from the protoconid; paraconid-hypoconid nearly equal in height), creating a formidable crushing instrument when coupled with the robust premolars. In Mammacyon ferocior the $\mathrm{m} 1$ is modified in similar fashion but fails to attain the size and degree of simplification seen in D. major.

FIRST UPPER MOLAR: This tooth, together with P4, is particularly diagnostic for Tem- nocyoninae. Even the most plesiomorphic species from the John Day basin can be identified as members of the subfamily by the form of the M1 protocone isolated on an enamel flat surrounded by a thickened lingual cingulum. In the larger, dentally derived species of Mammacyon and Delotrochanter the protocone evolves to a prominent isolated knoblike cusp; the enamel flat is conspicuously enlarged; and the lingual cingulum is thicker and more prominent. A ratio of the anteroposterior length of the 
TABLE 3

Measurements (length $\times$ width, $\mathbf{m m}$ ) of the Maxillary Dentition of Temnocyoninae

\begin{tabular}{|c|c|c|c|c|c|}
\hline Taxon & $\mathrm{P} 2$ & $\mathrm{P} 3$ & $\mathrm{P} 4$ & M1 & M2 \\
\hline \multicolumn{6}{|l|}{ Temnocyon altigenis } \\
\hline UCMP 9999 & $10.5 \times 4.6$ & $12.2 \times 5.8$ & $16.5 \times 12.1$ & $13.8 \times 19.5$ & $7.1 \times 12.0$ \\
\hline AMNH 6857 & & & $19.1 \times 12.6 \mathrm{e}$ & $14.0 \times 21.5 \mathrm{e}$ & $8.0 \times 13.8$ \\
\hline USNM 7940 & & & $16.9 \times 12.7$ & $13.8 \times 20.5$ & $8.7 \mathrm{e} \times 13.0 \mathrm{e}$ \\
\hline UCMP 1549 & $10.9 \mathrm{e} \times 4.6$ & $12.8 \mathrm{e} \times 5.9$ & $17.8 \mathrm{e} \times 13.2 \mathrm{e}$ & $13.5 \mathrm{e} \times 18.7 \mathrm{e}$ & $8.4 \mathrm{e} \times 12.0$ \\
\hline \multicolumn{6}{|c|}{ Temnocyon subferox, new species } \\
\hline YPM $10065^{*}$ & & $12.9 \times 6.6$ & $19.3 \times 14.4$ & $14.7 \times 20.6$ & $8.3 \times 13.0$ \\
\hline \multicolumn{6}{|c|}{ Temnocyon fingeruti, new species } \\
\hline NM 280/61* & $13.4 \times 5.7$ & $16.1 \times 7.0$ & $22.0 \times 15.4$ & $17.1 \times 22.4$ & $9.6 \times 17.4$ \\
\hline \multicolumn{6}{|l|}{ Temnocyon ferox } \\
\hline YPM-PU 10787* & $13.9 \times 6.3$ & $16.6 \times 7.8$ & $22.2 \mathrm{e} \times 16.5$ & $18.2 \times 23.9$ & $8.4 \times 13.6$ \\
\hline \multicolumn{6}{|l|}{ Temnocyon percussor } \\
\hline AMNH 81047 & & & & $20.9 \times 27.9$ & \\
\hline \multicolumn{6}{|c|}{ Mammacyon obtusidens } \\
\hline ACM $34-41^{*}$ & $18.5 \times 7.7$ & $20.3 \times 10.6$ & $25.2 \times 21.5$ & $20.4 \times 28.2$ & $10.5 \times 17.9$ \\
\hline LACM 5386 & & & $21.8 \times 18.2$ & $17.8 \times 24.8 \mathrm{e}$ & \\
\hline \multicolumn{6}{|c|}{ Mammacyon ferocior, new species } \\
\hline F:AM 54134 & $18.6 \mathrm{a} \times 9.4 \mathrm{a}$ & $21.1 \mathrm{a} \times 13.4 \mathrm{a}$ & $26.0 \times 23.1$ & $21.4 \times 29.8$ & $10.8 \times 17.4$ \\
\hline \multicolumn{6}{|c|}{ Delotrochanter oryktes, new species } \\
\hline ACM 4804* & $15.8 \times 8.7$ & $18 \mathrm{e} \times-$ & $21.4 \times 18.8$ & $17.7 \times 25.4$ & $9.3 \times 17.4$ \\
\hline UNSM 47800 & $15.9 \times 8.0$ & $18.2 \times 9.8$ & $22.8 \times 17.9$ & $17.5 \times 23.9$ & $8.9 \times 15.3$ \\
\hline \multicolumn{6}{|l|}{ cf. Delotrochanter } \\
\hline TRO 390 & & & & $17.6 \times 23.5$ & \\
\hline \multicolumn{6}{|c|}{ Delotrochanter major, new species } \\
\hline F:AM 27561* & $17.0 \times 9.0$ & $18.7 \times 11.9$ & $23.5 \times 19.8$ & & \\
\hline
\end{tabular}

labial margin compared to the length of the lingual half of the tooth measures this change in $\mathrm{M} 1$ form in temnocyonines (table 5).

The M1 of Temnocyon is unknown in the terminal species, T. macrogenys; it probably did not differ from the plesiomorphic form still retained in $T$. percussor, one of the youngest species of Temnocyon in which M1 is preserved and the probable predecessor to $T$. macrogenys. The plesiomorphic M1 of $T$. altigenis (Logan Butte) is only slightly modified in $T$. percussor and $T$. ferox, less so in $T$. fingeruti. These species lack the blunt knoblike cusp seen in Mammacyon and Delotrochanter, maintaining a preprotocrista diverging from the more normally configured protocone (a postprotocrista may also occur).

SECOND LOWER MOLAR: Species of Temnocyon preserve the plesiomorphic cusp pattern of this tooth in which the protoconid and hypoconid are situated at the labial margin. In contrast, the $\mathrm{m} 2$ of Mammacyon and Delotrochanter share a derived condition in which a rather blunt protoconid and hypoconid, placed one behind the other, are situated in the center of the tooth so that the former cusp fills the trigonid and the latter occupies the talonid.

In other respects this tooth is one of the more variable elements of the temnocyonine dentition. It is unwise to attribute too much significance to slight differences in $\mathrm{m} 2$ form. However, Mammacyon includes large carnivorans with a definitely elongate, rectangular $\mathrm{m} 2$ (table 6 , ratio E/F), and this trait, coupled with the $\mathrm{m} 1$ form and the elongate, narrow premolars, identifies the lineage dentally. Furthermore, a small notch or indentation 
TABLE 4

Temnocyonine P4 Proportions (in mm)

\begin{tabular}{|c|c|c|c|}
\hline & Measurement $C^{a}$ & Measurement $\mathrm{D}^{\mathrm{b}}$ & Ratio C/D \\
\hline \multicolumn{4}{|l|}{ Temnocyon altigenis } \\
\hline UCMP 9999 & 16.5 & 12.1 & 1.36 \\
\hline AMNH 6857 & 19.1 & $\sim 12.6$ & - \\
\hline USNM 7940 & 16.9 & 12.7 & 1.33 \\
\hline UCMP 1549 & $\sim 17.8$ & $\sim 13.2$ & $\sim 1.35$ \\
\hline \multicolumn{4}{|c|}{ Temnocyon subferox, new species } \\
\hline YPM 10065 & 19.3 & 14.4 & 1.34 \\
\hline \multicolumn{4}{|c|}{ Temnocyon fingeruti, new species } \\
\hline NM 280/61 & 22.0 & 15.4 & 1.43 \\
\hline \multicolumn{4}{|l|}{ Temnocyon ferox } \\
\hline YPM-PU 10787 & $\sim 22.2$ & 16.5 & $\sim 1.35$ \\
\hline \multicolumn{4}{|c|}{ Mammacyon obtusidens } \\
\hline ACM $34-41$ & 25.2 & 21.5 & 1.17 \\
\hline LACM 5386 & 21.8 & 18.2 & 1.20 \\
\hline \multicolumn{4}{|c|}{ Mammacyon ferocior, new species } \\
\hline F:AM 54134 & 26.0 & 23.1 & 1.13 \\
\hline \multicolumn{4}{|c|}{ Delotrochanter oryktes, new species } \\
\hline ACM 4804 & 21.8 & 18.8 & 1.16 \\
\hline UNSM 47800 & 22.8 & 17.9 & 1.27 \\
\hline \multicolumn{4}{|c|}{ Delotrochanter major, new species } \\
\hline F:AM 27561 & 23.5 & 19.8 & 1.19 \\
\hline
\end{tabular}

${ }^{\mathrm{a}}$ Length of the labial margin of $\mathrm{P} 4$.

${ }^{\mathrm{b}}$ Greatest width of P4 measured transversely at the level of the protocone (fig. 47).

in the posterolingual cingulum of the Mammacyon $\mathrm{m} 1$ is also present at the same location on $\mathrm{m} 2$.

The $\mathrm{m} 2$ of Delotrochanter is known only in D. oryktes (only the anterior half of $\mathrm{m} 2$ survives in $D$. major) where it is elongated relative to $\mathrm{m} 1$ but not to the extent seen in Mammacyon. The $\mathrm{m} 2$ in species of Temnocyon is not elongate (table 6 , ratio $\mathrm{E} / \mathrm{F}$ ), with values $>1.67$ for all but $T$. macrogenys; however, the range of values for $T$. altigenis itself suggests this is a variable trait. In Rudiocyon, $\mathrm{m} 2$ length is quite short relative to $\mathrm{m} 1$ length, demonstrating a marked difference from Mammacyon.

In summary, the temnocyonine genera are identified as follows: (1) Temnocyon (a paraphyletic taxon) retains the plesiomorphic dentition in which premolars are robust, tall, narrow, not reduced; $\mathrm{m} 1$ retains a tall trigonid with metaconid, a low talonid with enlarged hypoconid; $\mathrm{m} 2$ is short, not elongate relative to $\mathrm{m} 1$; $\mathrm{P} 4-\mathrm{M} 1$ are similar to the shearing carnassial pair in the dentally unspecialized amphicyonid Daphoenus (except that all teeth are proportionately larger in Temnocyon); (2) Delotrochanter has a derived durophagous dentition in which premolars (p2-4, P2-3) are short, robust, and posteriorly widened; the posterior accessory cusp (PAC) of p4 is centrally placed; $\mathrm{m} 1$ has lost the metaconid; the labial cingulum of $\mathrm{m} 1$ is straight, not sinuous; there is less height differential between $\mathrm{ml}$ paraconid and hypoconid than in Temnocyon; $\mathrm{ml}$ evolves a large centrally placed hypoconid in the terminal species, $D$. oryktes and D. major; $\mathrm{m} 2$ is slightly elongate in $D$. oryktes, the only species that preserves $\mathrm{m} 2$; in both Delotrochanter and Mammacyon, P4 has lost the typical form of a shearing carnassial and developed a short, rather blunt metastylar blade and an enlarged protocone for crushing occlusion, accompanying the lingual expansion of M1; P4 in Delotrochan- 
TABLE 5

Measurements (in mm) Demonstrating Expansion of the M1 Protocone Region in Temnocyoninae

\begin{tabular}{|c|c|c|c|}
\hline & Measurement $\mathrm{A}^{\mathrm{a}}$ & Measurement $\mathrm{B}^{\mathrm{b}}$ & Ratio A/B \\
\hline \multicolumn{4}{|l|}{ Temnocyon altigenis } \\
\hline UCMP 9999 & 13.8 & 8.3 & 1.66 \\
\hline AMNH 6857 & 14.0 & $\sim 9.3$ & 1.51 \\
\hline USNM 7940 & 13.8 & 9.0 & 1.53 \\
\hline UCMP 1549 & $\sim 13.5$ & 8.8 & 1.53 \\
\hline \multicolumn{4}{|c|}{ Temnocyon subferox, new species } \\
\hline YPM 10065 & 14.7 & 10.2 & 1.44 \\
\hline \multicolumn{4}{|c|}{ Temnocyon fingeruti, new species } \\
\hline NM 280/61 & 17.1 & 10.5 & 1.62 \\
\hline \multicolumn{4}{|l|}{ Temnocyon ferox } \\
\hline YPM-PU 10787 & 18.2 & 12.1 & 1.50 \\
\hline \multicolumn{4}{|c|}{ Temnocyon percussor } \\
\hline AMNH 81047 & 20.9 & 12.9 & 1.62 \\
\hline \multicolumn{4}{|c|}{ Mammacyon obtusidens } \\
\hline ACM 34-41 & 20.4 & 15.5 & 1.32 \\
\hline LACM 5386 & 17.8 & 13.1 & 1.36 \\
\hline \multicolumn{4}{|c|}{ Mammacyon ferocior, new species } \\
\hline F:AM 54134 & 21.4 & 17.4 & 1.23 \\
\hline \multicolumn{4}{|c|}{ Delotrochanter oryktes, new species } \\
\hline ACM 4804 & 17.7 & 14.7 & 1.20 \\
\hline UNSM 47800 & 17.5 & 14.1 & 1.24 \\
\hline \multicolumn{4}{|l|}{ cf. Delotrochanter } \\
\hline TRO 390 & 17.6 & 15.7 & 1.12 \\
\hline
\end{tabular}

${ }^{\mathrm{a}}$ Length of the labial margin of M1.

${ }^{\mathrm{b}}$ Anteroposterior width of the M1 protocone region (fig. 46).

ter never attains the large size seen in Mammacyon despite the much younger geologic age of $D$. oryktes and $D$. major; (3) Mammacyon has a derived durophagous dentition in which premolars (p2-4) are elongate, narrow, with only $\mathrm{p} 4$ broadened posteriorly in $M$. ferocior; the p4 PAC is labially placed; $\mathrm{m} 1$ has lost the metaconid and the labial cingulum is sinuous; $\mathrm{m} 1$ shows less height differential between paraconid and hypoconid than in Temnocyon, and is similar in this respect to Delotrochanter. Mammacyon develops the longest $\mathrm{m} 2$ (relative to $\mathrm{m} 1$ length) of any temnocyonine. P4-M1 and $\mathrm{m} 1-2$ are massive crushing teeth with an enlarged, bulbous P4 protocone more developed than in Delotrochanter; (4) Rudiocyon amplidens is a large carnivore, possibly a sister taxon to Mammacyon; its $\mathrm{m} 1$ is the size of that in D. oryktes or M. ferocior; it has lost the $\mathrm{m} 1$ metaconid but differs from these species in retaining a narrow, laterally compressed p4 and short $\mathrm{m} 2$ lacking elongation.

\section{SYSTEMATIC PALEONTOLOGY}

CLASS MAMMALIA LINNAEUS, 1758 SUBCLASS THERIA PARKER AND HASWELL, 1897

INFRACLASS EUTHERIA GILL, 1872 ORDER CARNIVORA BOWDICH, 1821 INFRAORDER ARCTOIDEA FLOWER, 1869

FAMILY AMPHICYONIDAE HAECKEL, 1866

SUBFAMILY TEMNOCYONINAE HUNT, 1998: 207

Amphicyonid carnivorans in which the premolars (P2-3, p2-4) are particularly tall 
TABLE 6

Temnocyonine Dental Ratios ${ }^{\mathrm{a}}$

\begin{tabular}{|c|c|c|c|c|}
\hline & Ratio A/B & Ratio C/D & $\mathrm{m} 1$ metaconid & Ratio E/F \\
\hline \multicolumn{5}{|l|}{ TEMNOCYON } \\
\hline altigenis & $1.51-1.66$ & $1.33-1.36$ & yes & $1.67,1.68,1.73,1.83$ \\
\hline subferox & 1.44 & 1.34 & ? & - \\
\hline fingeruti & 1.62 & 1.43 & yes & 1.67 \\
\hline ferox & 1.50 & $\sim 1.35$ & yes & 1.79 \\
\hline percussor & 1.62 & - & yes & 1.69 \\
\hline macrogenys & - & - & yes & 1.62 \\
\hline \multicolumn{5}{|l|}{ RUDIOCYON } \\
\hline amplidens & - & - & no & 1.89 \\
\hline \multicolumn{5}{|l|}{ DELOTROCHANTER } \\
\hline petersoni & - & - & no & - \\
\hline oryktes & $1.20-1.24$ & $1.16-1.27$ & no & 1.69 \\
\hline major & - & 1.19 & no & $\sim 1.64$ \\
\hline \multicolumn{5}{|l|}{$M A M M A C Y O N$} \\
\hline cf. (LACM 15908) & - & - & vestigial & 1.71 \\
\hline obtusidens & $1.32-1.36$ & $1.17-1.20$ & no & 1.57 \\
\hline ferocior & 1.23 & 1.13 & no & 1.60 \\
\hline
\end{tabular}

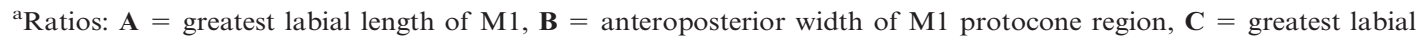
length of P4, $\mathbf{D}=$ greatest width of $\mathbf{P} 4$ measured transversely at the level of the protocone, $\mathbf{E}=\mathrm{m} 1$ length, $\mathbf{F}=\mathrm{m} 2$ length.

and well developed, and the carnassials and molars of several genera adopt a specialized crushing-shearing morphology unique among the Carnivora. In older individuals these premolars show strong apical wear similar to living bone-crushing hyaenids in which the principal cusps are worn to flat platforms by contact with hard materials. Such apical wear also can be observed on carnassials and molars. The carnassial pair remains functionally prominent throughout the history of the subfamily, and is always flanked by a large first and smaller second molar in the maxilla, and by a prominent $\mathrm{m} 2$ and small $\mathrm{m} 3$ in the mandible. Plesiomorphic species retain an $\mathrm{m} 1$ metaconid that is lost in derived forms. The talonid of the lower carnassial is occupied by an enlarged hypoconid cusp (there is no entoconid), followed in series by the $\mathrm{m} 2$ protoconid and hypoconid, forming a line of three strong, blunt, crushing cusps (there is a vestigial $\mathrm{m} 2$ metaconid in some species but never an entoconid). In the maxilla the M3 is always absent, a loss occurring in only a few other amphicyonid groups. M1 is diagnostic of the subfamily: its protocone becomes isolated on an enamel platform forming the lingual half of the tooth, and an enlarged lingual cingulum develops surrounding the protocone region. M2 is similar in form to M1 but is much reduced in size and also has an isolated protocone and developed lingual cingulum. The upper carnassial is as morphologically diagnostic as M1, especially in younger species: the $\mathrm{P} 4$ protocone is enlarged and lingually directed, becoming a bulbous crushing cusp, and in the more derived species a shortening of the metastylar blade accompanies the size increase of the $\mathrm{P} 4$ protocone.

Skull form differs among temnocyonines. The larger species of Temnocyon are characterized by dolichocephalic skulls, similar to the wolf skull, although with broader, shorter snouts. The only complete skull of Mammacyon displays proportions similar to living ursids, whereas the only skull of Delotrochanter reveals a short, deep hyenalike skull. In several species the frontal region of the skull is strongly inflated. As body size increases, the volume of the braincase fails to keep pace with skull size; consequently brain volume in the large terminal species does not equal that 
TABLE 7

Cranial Dimensions (in mm) of Temnocyoninae

\begin{tabular}{llccc}
\hline \hline \multicolumn{1}{c}{ Taxon } & Museum No. & Basilar length & Width, braincase & Width, frontal sinuses \\
\hline Temnocyon altigenis & UCMP 9999 & 167 & 53 & 41 \\
Temnocyon altigenis & UCMP 1549 & 180 & 55 & 46 \\
Temnocyon subferox & YPM 10065 & 210 & 62 & 47 \\
Temnocyon ferox & YPM-PU 10787 & 260 & 72 & 58 \\
Temnocyon fingeruti & NM 280/61 & 250 & 64 & 64 \\
Temnocyon macrogenys & F:AM 54139 & $300^{\mathrm{a}}$ & - & $50^{\mathrm{b}}$ \\
Mammacyon obtusidens & ACM 34-41 & 255 & 64 & 71 \\
Mammacyon ferocior & F:AM 54134 & 280 & 67 & - \\
Delotrochanter oryktes & ACM 4804 & $250^{\mathrm{a}}$ & - & $69^{\mathrm{d}}$ \\
Rudiocyon amplidens & UNSM 47800 & 245 & 65 & - \\
\hline
\end{tabular}

${ }^{\mathrm{a}}$ Estimated from mandibular length.

${ }^{b}$ Estimated width of damaged frontal region.

${ }^{\mathrm{c}}$ Estimated by measuring from the midline of the skull to the braincase on one side and doubling the measurement.

${ }^{\mathrm{d}}$ Estimated by measuring from the midline to the postorbital process on one side and doubling the measurement.

All measurements are approximate due to minor distortion and crushing of skulls.

seen in large living carnivorans of the same size (table 7). The skulls that preserve the basicranium display an embayed basioccipital and small plesiomorphic auditory bullae. An ossified entotympanic contribution to an ectotympanic bulla is confirmed in a single species, Temnocyon fingeruti, from the John Day Formation. However, no entotympanic inflation or enlargement occurs in these temnocyonines. Dental formula for the subfamily: 3-1-4-2/ 3-1-4-3.

Postcranial bones associated with a few crania and mandibles (table 8) indicate that the forelimbs and feet were often elongated, with the exception of the stem species Temnocyon altigenis. The forelimb was not everted at the elbow, as is common in the large amphicyonines (Amphicyon, Ysengrinia), but was held in a more erect vertical alignment. Species of Mammacyon, Delotrochanter, and Temnocyon were experimenting with a cursorial gait: longer limbs were becoming adapted for fore-aft parasagittal motion, and an erect stance accompanied paraxonic, digitigrade fore- and hind feet.

Temnocyon Cope, 1878

TyPE SPECIES: Temnocyon altigenis Cope, 1878.

INCLUDED SPECIES: Temnocyon altigenis Cope, 1878; T. subferox, new species; T. ferox
Eyerman, 1896; T. percussor Cook, 1909; T. fingeruti, new species; $T$. macrogenys, new species.

DistRIBUTION: Early Arikareean, Oregon and California; late Arikareean, Oregon and western Nebraska; latest Arikareean, southeastern Wyoming.

DiAGNOSIS: A paraphyletic genus distinguished from other temnocyonines by presence of a metaconid on $\mathrm{m} 1$; by plesiomorphic form and proportions of M1-2, m2 (with labially situated proto-and hypoconids), upper and lower carnassials, and premolars (P4-M1 ratios A/B, C/D, table 6). See tables 1-5.

Discussion: The genus includes stem temnocyonines that preserve the plesiomorphic form of the cheek teeth, only slightly modified in the younger and larger derivative species of the genus. T. subferox apparently evolved from $T$. altigenis, the earliest and smallest temnocyonine species. Larger and more dentally derived $T$. ferox, $T$. percussor, and $T$. fingeruti retain a number of primitive dental features and represent larger species evolved from within the $T$. altigenis $-T$. subferox group. The enormous T. macrogenys, the last representative of the genus, is most likely derived from $T$. percussor. The genus ranges in time from the earliest to latest Arikareean. 
TABLE 8

Dimensions of the Temnocyonine Postcranial Skeleton

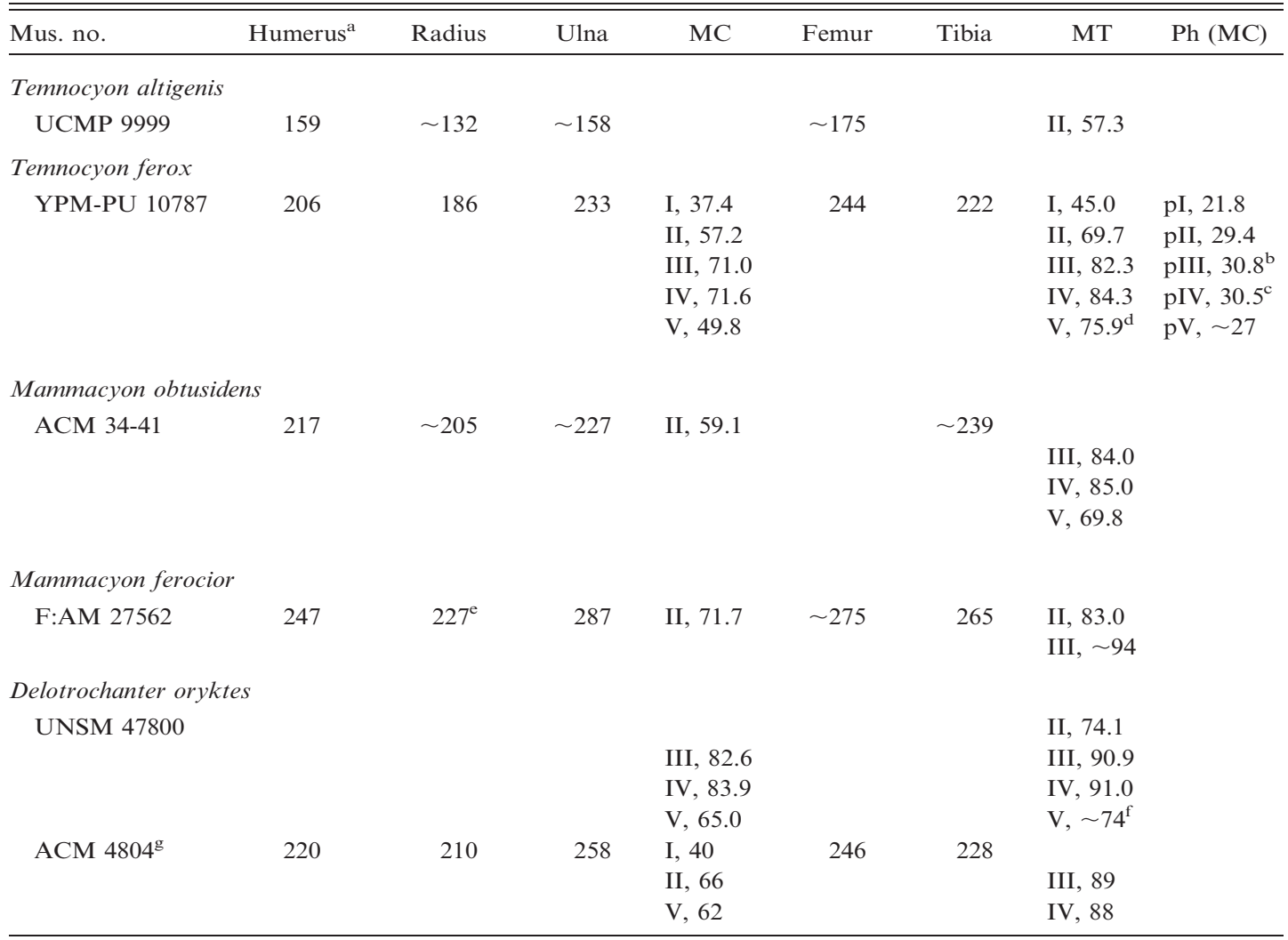

${ }^{\mathrm{a}} \mathrm{All}$ measurements are lengths in mm (MC, metacarpal; MT, metatarsal; Ph, proximal phalanges of MC I-V).

${ }^{\mathrm{b}}$ Intermediate phalanx, digit III, 18.9.

${ }^{\mathrm{c} I n t e r m e d i a t e ~ p h a l a n x, ~ d i g i t ~ I V, ~ 19.2 ; ~ u n g u a l ~ p h a l a n x, ~ d i g i t ~ I V, ~} \sim 13$.

${ }^{\mathrm{d}}$ Intermediate phalanx, digit $\mathrm{V}, 15.2$; ungual phalanx, digit $\mathrm{V}, 13.2$.

${ }^{\mathrm{e}}$ Calculated from complete ulna; radius absent.

${ }^{\mathrm{f}}$ This metatarsal V was found in 1904-1905 by the Carnegie Museum and numbered CM 1589b but it is likely the same individual as UNSM 47800 from the Beardog Hill den.

${ }^{\mathrm{g}}$ Measurements from Schlain (1980).

\section{Temnocyon altigenis Cope, 1878}

Figures 4-8, 65

Temnocyon altigenis Cope, 1878 (December 3): 68; 1879a: 68-70; 1879b: 55-69; 1881: 179; 1883: 238, figs. 2-3; 1884: 903-905, pl. 68, fig. 9, pl. 70 , fig. 11.

Temnocyon altigenis: Merriam, 1906: 21-28, text figs. 7-11, pl. 3 (fig. 2).

non Temnocyon altigenis: Thorpe, 1922: 167-168; Hough, 1948: 100-101 (YPM 10065 is removed from $T$. altigenis).

TYPE: AMNH 6855, right mandible with $\mathrm{p} 2-\mathrm{m} 2$ and alveoli of the canine and p1, from the John Day beds, Oregon.
DisTRIBUTION: Early Arikareean, John Day Formation, Oregon.

Diagnosis: Smallest and most plesiomorphic North American temnocyonine species distinguished from all other species of Temnocyon by small size and range of $\mathrm{m} 1$ lengths, $17.4-19.5 \mathrm{~mm}$ (table 2), and from $T$. subferox, $T$. fingeruti, and $T$. percussor by either M1 or $\mathrm{P} 4$ proportions (dental ratios $\mathrm{A} / \mathrm{B}, \mathrm{C} / \mathrm{D}$, table 6); from $T$. ferox and the huge $T$. macrogenys by much smaller size. Ratio of $\mathrm{m} 1 / \mathrm{m} 2$ lengths, $1.67-1.83$, indicating a short $\mathrm{m} 2$ relative to $\mathrm{m} 1$, thus distinct from species of Mammacyon $(1.57,1.61)$ but not 

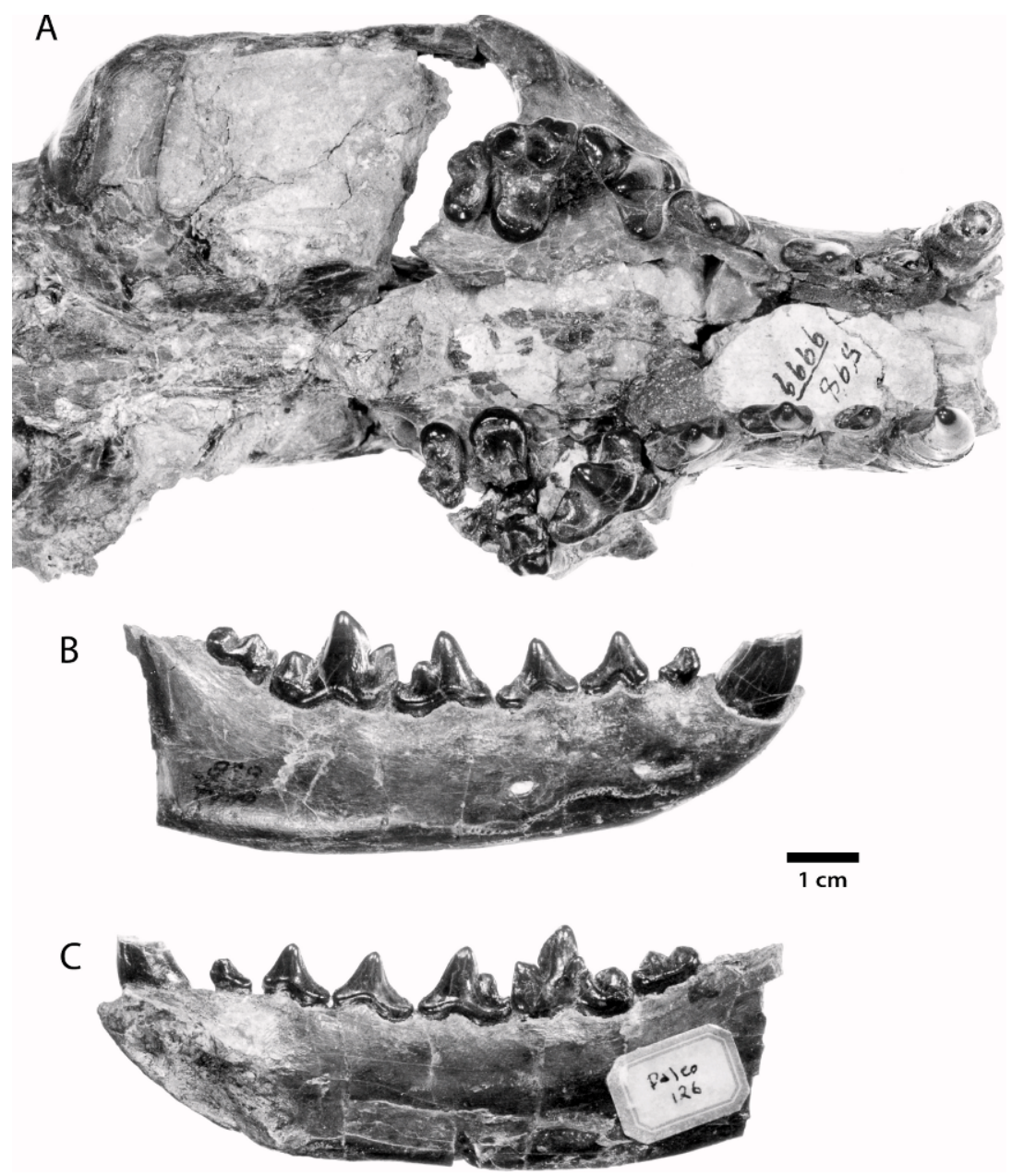

Fig. 4. Temnocyon altigenis (UCMP 9999) from Logan Butte, Crook Co., Oregon: A, palate with right C, P1-M2; B, C, right mandible with c, p1-m2 in labial and lingual views. Its skull, dentition, and small size establish UCMP 9999 as the most plesiomorphic temnocyonine.

from other Temnocyon species (ratios of 1.62-1.79) or Delotrochanter (1.64-1.69). Basilar length of skull, $\sim 16-18 \mathrm{~cm}$ relative to $21-30 \mathrm{~cm}$ for other Temnocyon species (table 7); frontal sinuses moderately inflated.

REFERRED SPECIMENS: (1) AMNH 6856, left lower jaw with c, p2, p4-m2, alveoli of p1, p3, and m3, from the John Day beds, Turtle Cove, Grant County, Oregon; (2) AMNH 6857, right lower jaw with p2-m1, roots or alveoli of $\mathrm{c}, \mathrm{p} 1, \mathrm{~m} 2-3$, partial rostrum anterior to the orbits, with attached left lower jaw fragment, right C, P2-M2, alveolus of P1, left I3-C, P1-3, left c, p1-4, the entire left dentition highly fragmented, and a partial postcranial skeleton, from the John Day beds, Turtle Cove, Grant County, Oregon; (3) USNM 7940, left lower jaw with $\mathrm{m} 1, \mathrm{~m} 2$ erupting, and damaged deciduous teeth; right maxilla with $\mathrm{C}, \mathrm{P} 1, \mathrm{P} 2-3$ erupting, M1 fully erupted, P4 and M2 erupting, DP2-3, DC, from the John Day beds, Turtle Cove, Grant County, Oregon; (4) UCMP 1549 , nearly complete uncrushed skull without basicranium, with right I1-2, alveolus for I3, C, P1-M2 (P4-M2 with parts missing); left I1-P1, P2 roots, P3-M2 (P4-M1 damaged), partial endocast of temporal lobes 


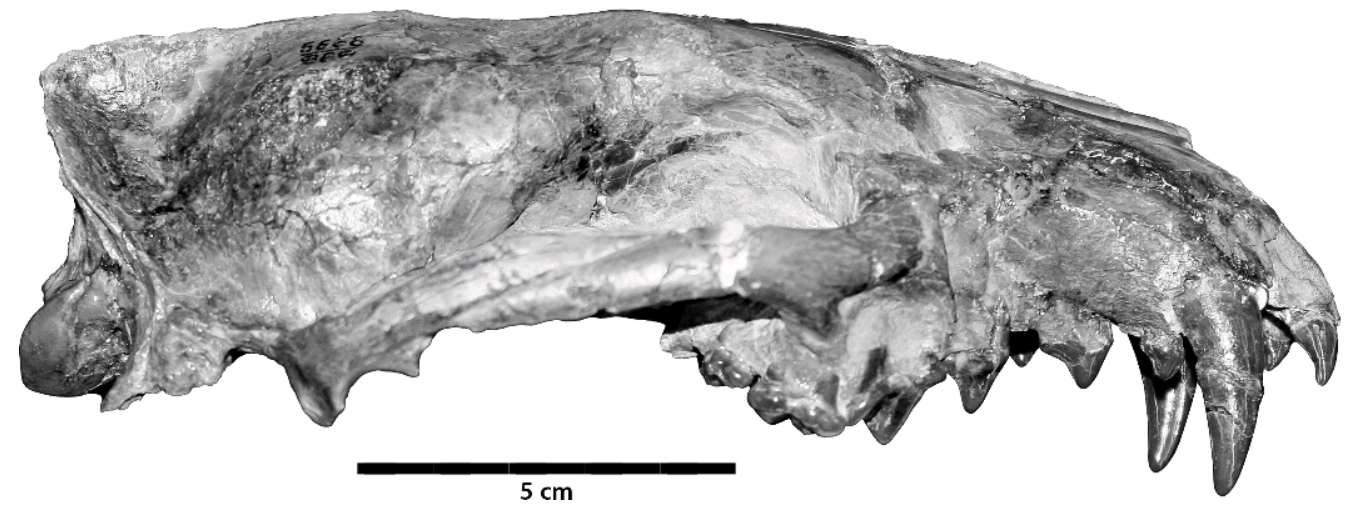

Fig. 5. Temnocyon altigenis (UCMP 9999), John Day Formation, Logan Butte, Crook Co., Oregon.

exposed and undistorted, from John Day beds, Morgan's Place, UCMP loc. 874, Grant County, Oregon, collected by UCMP party, 1899; (5) UCMP 9999, skull with wellpreserved basicranium, associated lower jaws, and much of the postcranial skeleton; teeth present include right $\mathrm{C}-\mathrm{M} 2$, left $\mathrm{C}-\mathrm{P} 4$, M2 (damaged M1); right C-M2 (broken M3); left C-M3; from the John Day beds, Logan Butte, Crook County, Oregon, collected by Davis and Osmont, 1900.
DESCRIPTION: The lower jaws of the hypodigm are very similar in dental morphology and size and can be described as a group (AMNH 6855, 6856, 6857, USNM 7940, UCMP 9999). In 1884 Cope described and figured AMNH 6855 and the rostrum of AMNH 6857; he briefly mentioned AMNH 6856 and the jaws of AMNH 6857. Although Merriam (1906) mentioned UCMP 1549, it has never been described or figured, but in this same paper considerable attention was given

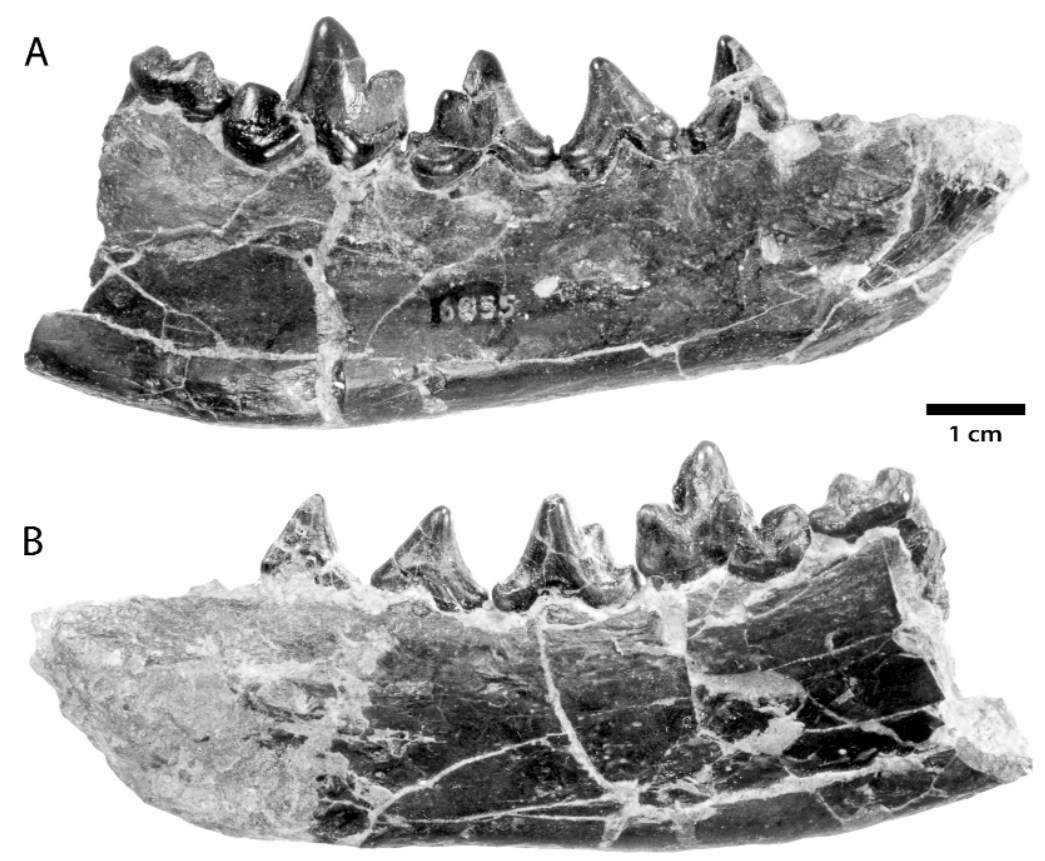

Fig. 6. Holotype of Temnocyon altigenis Cope (AMNH 6855), John Day Formation, Oregon. Right mandible with p2-4, m1-2 in (A) labial and (B) lingual views. 

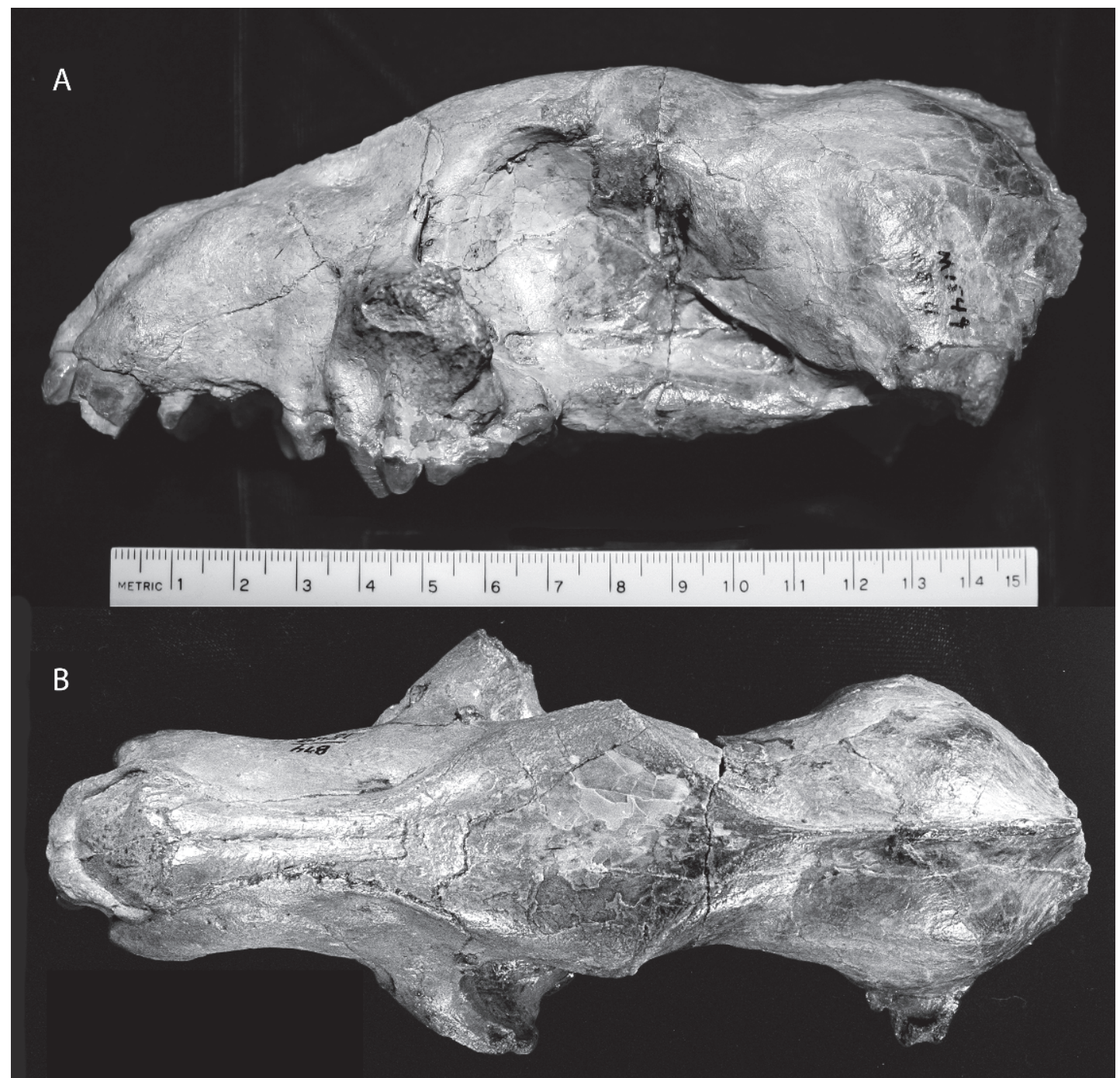

Fig. 7. Temnocyon altigenis (UCMP 1549), John Day Formation, Morgan's Place, UCMP loc. 874, near the town of Monument, Grant Co., Oregon. (A) lateral and (B) dorsal views of uncrushed cranium.

to the associated skull, jaws, and skeleton from Logan Butte (UCMP 9999), which is arguably the most plesiomorphic North American temnocyonine, based upon its dental traits.

The premolars of these lower jaws from the John Day beds are exceedingly similar in form and size: there is a progressive increase in size from $\mathrm{p} 1-4$, with $\mathrm{p} 1$ a rather small single-rooted tooth relative to $\mathrm{p} 2-4$. There are no accessory cusps with the exception of a prominent laterally placed posterior accessory cusp on $\mathrm{p} 4$, the plesiomorphic state for the subfamily. The premolars are not crowded except in young animals with newly erupting premolars. In adults the premolars are ranked in a linear series and are narrow with anterior and posterior slopes each traversed by a fine enamel ridge, running down each slope from the tip of the principal cusp to the base of the tooth. Only p4 shows any posterior expansion in width at the base of the tooth, and this is very slight $(6.8 \mathrm{~mm}$ vs. $5.4 \mathrm{~mm}$ anterior width, AMNH 6855).

The molars are also similar in form and size within the hypodigm, with the exception of AMNH 6856, which has a short $\mathrm{m} 2$ 


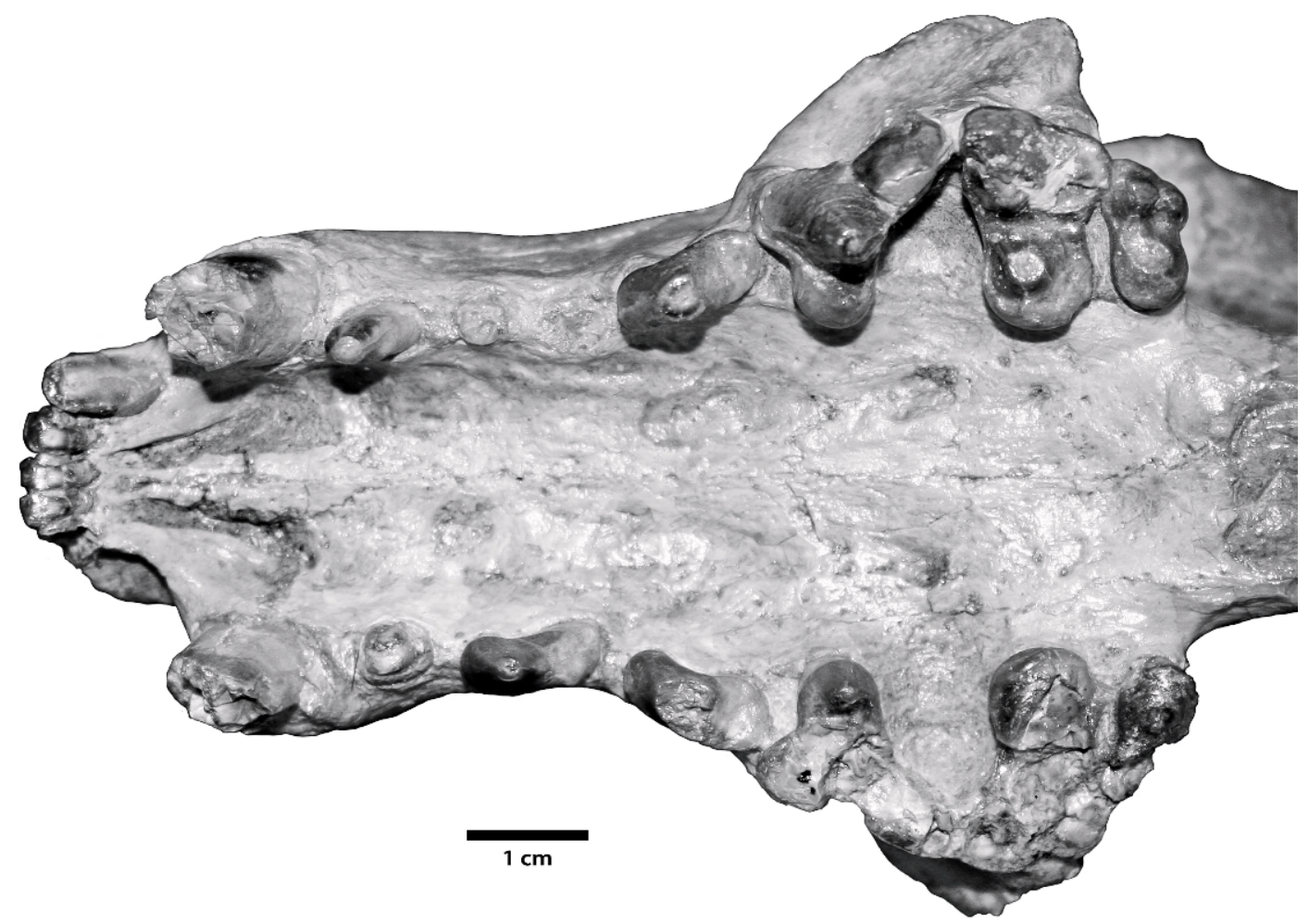

Fig. 8. Palate with I1-3, C, P1-4, M1-2 of Temnocyon altigenis (UCMP 1549), John Day Formation, Morgan's Place, UCMP loc. 874, near the town of Monument, Grant Co., Oregon.

relative to $\mathrm{m} 1$ length (table 6 , ratio $\mathrm{E} / \mathrm{F}$, 1.83). All lower carnassials conform to a common pattern: the trigonid is high, the three principal cusps present but unequally developed - the tall protoconid is the main cusp, the paraconid and metaconid lower and at about the same height. The metaconid is somewhat reduced and is located both internal to and posterior to the protoconid. The paraconid forms a robust bladelike cusp anterointernally directed. The $\mathrm{m} 1$ talonid is short relative to the trigonid: it is much lower relative to the trigonid than in younger, larger species of temnocyonines in which the height inequity is resolved. The $\mathrm{m} 1$ talonid is dominated by a large, prominent, centrally placed hypoconid; there is no entoconid. The $\mathrm{m} 2$ is characterized by a trigonid somewhat longer than the talonid; there are two main cusps, the protoconid and hypoconid, situated one behind the other toward the labial edge of the tooth. The paraconid is small, occupying the anterointernal corner of $\mathrm{m} 2$. The $\mathrm{m} 2$ metaconid is absent or in USNM 7940, a juvenile with unworn teeth, a small vestigial metaconid is discernible; a low ridge extends from protoconid to the lingual edge of $\mathrm{m} 2$, and in all other specimens except USNM 7940 the ridge is uninterrupted by a metaconid cusp. The anterolabial corner of $\mathrm{m} 2$ is slightly protruded in some individuals (AMNH 6856).

The $\mathrm{m} 3$ is preserved only in UCMP 9999, where it is a very reduced version of $\mathrm{m} 2$. It is rectangular in occlusal outline, not circular. The protoconid and hypoconid are labially placed; there is a small paraconid.

Depth of the lower jaw below the $\mathrm{ml}$ hypoconid (in $\mathrm{mm}$ ) is: AMNH 6855, 30.7; AMNH 6856, 26.8; AMNH 6857, 25.4; USNM 7940, 20.6 (juvenile); UCMP 9999, 23.3.

The rostrum described by Cope (1884: 904-905, pl. 70, fig. 11) is much less well preserved than his description implies. The 
left upper and lower jaws are still in matrix and the teeth badly shattered so that preparation is unwarranted. The right upper dentition, which Cope figured, is so badly damaged that it would be useless for diagnosis were it not for the associated lower jaws. The only undamaged tooth is M2.

However, the intact upper teeth of UCMP 9999, described by Merriam (1906), can be used to supplement the description of Cope's rostrum. UCMP 9999 from Logan Butte has a gracile dentition relative to the Turtle Cove material, which forms the greater part of the T. altigenis hypodigm. UCMP 9999 may prove eventually to represent a somewhat older and more primitive species but is here considered a gracile female morph of $T$. altigenis.

The upper premolars of UCMP 9999 are without accessory cusps and were not as crowded nor as tall as the lower premolars. They are triangular, narrow teeth with a slight widening at the posterior base of P3. P4 is a shearing carnassial, although the protocone is enlarged, anticipating the marked change in $\mathrm{P} 4$ form that occurs in the younger, more derived temnocyonines. There is little to distinguish the $T$. altigenis $\mathrm{P} 4$ from that of Daphoenus, other than the more prominent protocone in the former. P4 is surrounded by a distinct basal cingulum, more defined lingually.

M1 is intact only in UCMP 9999 and USNM 7940 where it demonstrates the plesiomorphic temnocyonine pattern. Portions of M1 occur in UCMP 1549 and AMNH 6857 where they indicate a tooth of the same type. The protocone is low and anteriorly placed as in Daphoenus, not yet completely isolated on a broad enamel flat as in younger, more derived temnocyonines. The cingulum anterior to the protocone was not swollen as it is in more derived species, an indication that this carnivore retained a highly sectorial carnassial. However, temnocyonine hallmarks have already appeared: the lingual cingulum is slightly swollen, and the paracone and metacone are prominent with a developed parastylar region. Consequently, both the labial and lingual parts of M1 are enlarged, creating the impression that the tooth is somewhat constricted in its middle part in occlusal view. The protocone of M1 is connected by a preprotocrista to the anterior cingulum, a feature retained in most larger, derived species of the genus. A small paraconule is present on the preprotocrista. The postprotocrista is absent and there is no metaconule. The configuration of M1 in UCMP 9999 is the most plesiomorphic of any North American temnocyonine. From this pattern evolved the enormous crushing M1s of the more dentally derived Arikareean species of the subfamily.

M2 is much smaller than M1. Its metacone is more reduced, and its protocone is isolated on an enamel shelf surrounded by a thickened lingual cingulum. Length of the upper toothrow of AMNH 6857 from the anterior alveolar border of $\mathrm{P} 1$ to the posterior edge of M2 is $67.2 \mathrm{~mm}$ : crushing has to some extent altered the actual distance, but in UCMP 9999 where distortion is less, the same measurement is $67.3 \mathrm{~mm}$. The only significant difference warranting mention between the rostrum of AMNH 6857 and UCMP 9999 is that the upper canine is larger and more robust in AMNH 6857, suggesting it is a male, and more slender and gracile in UCMP 9999, presumably a female.

The Logan Butte skull (UCMP 9999) preserves the basicranium in which the auditory region shows a deeply embayed basioccipital bone containing an enlarged inferior petrosal venous sinus that conforms to the amphicyonid pattern (see Basicranial Anatomy).

I refer to $T$. altigenis a well-preserved, undistorted skull (figs. 7, 8, UCMP 1549), lacking the basicranium, mentioned by Merriam (1906: 22-24, 29) but not figured. The skull was collected near the town of Monument during the 1899 University of CaliforniaBerkeley expedition to the John Day beds. Merriam considered this skull merely an uncrushed version of UCMP 9999 from Logan Butte; its large canines, broad rostrum, and inflated frontal region suggest that it represents an intact male cranium of the species.

In dorsal view UCMP 1549 is a robust skull, similar in overall form to the much larger skull of Mammacyon ferocior (F:AM 54134). The inflated frontals and expanded rostrum swollen around the large canines are believed to be male traits. The braincase of 
UCMP 1549, measuring $55 \mathrm{~mm}$ in greatest width, is surmounted by a low sagittal crest whose height is undetermined (the occiput is missing). Skull width decreases to $35 \mathrm{~mm}$ at the postorbital constriction, its narrowest point, and the width of the expanded frontal sinuses at the level of the postorbital processes is $46 \mathrm{~mm}$. Anterior to the frontal region and the orbits, the maxillae are shallowly depressed, but in front of these depressions the snout expands due to the swelling of the maxillary region around the large canine roots: width of rostrum at the base of the canine roots is $40.7 \mathrm{~mm}$. Both zygomatic arches are lost as is the occipital region and basicranium posterior to the basisphenoid. The distance between the infraorbital foramen and the posterior opening of the alisphenoid canal measures $83.4 \mathrm{~mm}$.

I1-3 are preserved on the left side. I 2 is somewhat larger than $\mathrm{I} 1$, but $\mathrm{I} 3$ is considerably larger than I2. I1 and I2 are worn flat at their tips but I 3 is grooved obliquely on the posteroexternal face by the lower canine. There is a diastema of $4-5 \mathrm{~mm}$ between I3 and the upper canine. Width at the base of I3 $(6.1 \mathrm{~mm})$ relative to the more gracile I3 (4.6 mm) of UCMP 9999 reflects the malefemale dichotomy.

The canine is robust, its root causing inflation of the maxilla and consequently a widening of the rostrum. Only the canine root and a small segment of the base of each tooth is preserved, so wear grooves cannot be identified. The left canine measures $14.6 \mathrm{~mm}$ in anteroposterior length by $9.7 \mathrm{~mm}$ in width at the alveolar margin.

About $2 \mathrm{~mm}$ posterior to the canine is a small peglike unicuspid $\mathrm{P} 1$, measuring 5.8 in length, $4.0 \mathrm{~mm}$ in width at the base of the crown.

P2 measures $10.9 \mathrm{~mm}$ in length, $4.6 \mathrm{~mm}$ in greatest width. It is heavily worn on its posterior surface, is wider behind the main cusp than in front, and has no accessory cusps. The posterior slope is slightly more inclined than the anterior, and a fine enamel ridge runs down each slope.

P3 measures $12.8 \mathrm{~mm}$ in length, $5.9 \mathrm{~mm}$ in greatest width. It is expanded at its posterior base, has a posterior slope somewhat longer than the anterior, but because of wear it is not possible to decide if accessory cusps were present.

P4 measures $17.8 \mathrm{~mm}$ in length of the labial margin, $13.2 \mathrm{~mm}$ in greatest width. Although both upper carnassials are damaged, the form of the tooth is discernible, much like P4 of UCMP 9999, although the protocone is somewhat more enlarged than in UCMP 9999. Also, the P4 protocone of UCMP 1549 was somewhat more posteriorly situated relative to the protocone of UCMP 9999, although the difference is quite small. P4 remains a shearing tooth but its height and enlarged protocone foreshadow the change in $\mathrm{P} 4$ form that occurs in the more derived temnocyonines from younger rocks.

M1 is $13.5 \mathrm{~mm}$ in length, $18.7 \mathrm{~mm}$ in width, and is best preserved on the left side. Although the left M1 has a broken metacone, the tooth is nearly intact, whereas most of the right M1 is missing. M1 is worn, the tips of paracone and protocone beveled to flat surfaces. The paracone was larger than the metacone, and the labial portion of M1 bearing the paracone-metacone was elevated, with a developed parastylar region. As in UCMP 9999, the lingual faces of paracone and metacone form a shear surface that descends to an enamel platform forming the lingual half of the tooth. On this enamel flat is situated an apically worn protocone. A distinct ridge (preprotocrista) leads from the protocone to the anterior cingulum; there is no postprotocrista. The protocone region is widened but no more than in UCMP 9999; this expansion is the result of the swollen or thickened posterior and medial parts of the lingual cingulum surrounding the protocone region: there is no expansion of the tooth anterior to the protocone and an anterior cingulum of normal width is developed. Thus a tricuspid $\mathrm{m} 1$ trigonid with developed metaconid would be expected in the lower jaw and such a tooth occurs in UCMP 9999. Cope's holotype lower jaw (AMNH 6855) and AMNH 6856, both with an $\mathrm{m} 1$ metaconid, occlude well with this skull. A small cuspule on the posterior border of M1 may represent a vestigial metaconule.

M2 measures $8.4 \mathrm{~mm}$ in length, $12.0 \mathrm{~mm}$ in greatest width. M2 is a small replica of M1 except that the protocone is more centrally located within the enamel flat forming the 
lingual half of the tooth. The paracone is slightly larger than the metacone. No conules seem to be present but the tooth is well worn. The protocone was apparently a prominent knoblike cusp, which has been worn to a flat surface; it was surrounded by a slightly swollen lingual cingulum. As in UCMP 9999, the M2 is situated on a plane slightly above M1 in order to occlude with the $\mathrm{m} 2$, which was elevated and tilted forward on the ascending ramus of the mandible.

No M3 was present. M2 is the most posterior tooth in the maxilla and there is no space available for an M3.

The orbital region of the skull is intact and is characterized by a deeply excavated trough, which in its posterior part contains the sphenorbital fissure and the anterior foramen for the alisphenoid canal (the foramen rotundum in the beardog opens internally into the alisphenoid canal as in Ursus and Canis, hence cannot be seen). They are placed almost side-by-side where they perforate the sidewall of the skull, similar to their location in Ursus. Dorsal and anterior to this is a smaller optic foramen that also lies within the elliptical depression that includes the sphenorbital fissure and foramen for the alisphenoid canal. Leading directly forward beneath the optic foramen is a low horizontal ridge which extends craniad $\sim 35 \mathrm{~mm}$ to end directly above the sphenopalatine foramina. This ridge probably marks the dorsal extent of the pterygoid musculature and corresponds closely to the palatine-orbitosphenoid suture. A second ridge runs upward at a $45^{\circ}$ angle to the first, beginning above the sphenorbital fissure and coursing anterodorsad above the optic foramen. It forms the dorsal border of the elliptical depression housing these orbital foramina and terminates $\sim 18 \mathrm{~mm}$ below the postorbital process. This same arrangement of ridges and foramina occurs throughout the Temnocyoninae and is evident in F:AM 54134 (Mammacyon ferocior) and YPM 10065 (Temnocyon subferox), and is suggested in YPM-PU 10787 (T. ferox) in which the orbital region is badly crushed.

Structure in the vicinity of the foramen ovale is similar in other members of the subfamily. The foramen ovale and posterior opening of the alisphenoid canal are contained in a deep common fossa. Anterior to this fossa is a shallow depression for pterygoid musculature, which is even more pronounced in T. subferox (YPM 10065) and Mammacyon (ACM 34-41, F:AM 54134). Medial to the common fossa for the foramen ovale and alisphenoid canal is an oval percussion fracture in the sphenoid bone, evidence that the missing basicranium may have been lost to a scavenger. Lateral to the foramen ovale is a remnant of the glenoid fossa. Little can be inferred about the middle ear cavity and surrounding basicranial structures other than that the anterointernal corner of the auditory region was deep, suggesting the presence of an auditory bulla similar to that known in Temnocyon (YPM 10065) and Mammacyon (ACM 34 41).

The skull of UCMP 1549 measures $146.5 \mathrm{~mm}$ in length from a point between the first incisors to the posterior border of the foramen ovale. The approximate distance between the same points on UCMP 9999 is $\sim 130 \mathrm{~mm}$. Basilar skull length of UCMP 9999 is $\sim 167 \mathrm{~mm}$. Assuming similar proportions for UCMP 1549, basilar length would be $\sim 180 \mathrm{~mm}$.

The rostrum of a juvenile animal (USNM 7940) from the John Day beds collected by William Day in 1883 includes part of the deciduous (DP2-3, DC) and permanent (P1, P4-M2 erupted) dentition. This animal agrees most closely with UCMP 1549 in the form of its P4-M1. P4-M1 are somewhat less sectorial than these teeth in UCMP 9999. This is evident in the more expanded protocone region of $\mathrm{M} 1$ and in the larger P4 protocone of USNM 7940. The unworn condition of these newly erupted teeth shows that initially the upper carnassial of $T$. altigenis had a modest cingulum entirely surrounding the tooth that was only weakly developed on the lingual face of the protocone. M1 is encircled by a cingulum as well, which is most pronounced posterolingual to the protocone and on the posterior face of the tooth but remains thin on the anterior face (as in UCMP 9999 and 1549). This condition of the cingulum clearly represents the plesiomorphic state prior to massive enlargement of the lingual cingulum in younger, larger temnocyonines.

Discussion: Temnocyon altigenis Cope is the most dentally plesiomorphic species of 
North American temnocyonines, and also the smallest in body size. The hypodigm was collected from the John Day beds of Oregon; none are known from the Great Plains or elsewhere in North America. Skulls attributable to the hypodigm indicate carnivorans with basilar lengths of $\sim 16$ to $18 \mathrm{~cm}$ (table 7 ).

The dentition of $T$. altigenis shares similarities with the teeth of the late EoceneOligocene amphicyonid Daphoenus. The principal differences are: (a) T. altigenis has all teeth larger than those of Daphoenus vetus of Orellan age despite similar skull size; (b) $T$. altigenis has taller premolars than Daphoenus (excluding $\mathrm{P} 1 / \mathrm{p} 1$ ); (c) the $T$. altigenis $\mathrm{P} 4$ is larger and has a more robust lingually extended protocone relative to Orellan $D a$ phoenus; (d) M1-2 of $T$. altigenis have expanded or swollen lingual cingula not found in Daphoenus; (e) T. altigenis has lost M3 which Daphoenus retains; (f) lower molars of $T$. altigenis lack entoconids, and have an enlarged $\mathrm{m} 1$ hypoconid and only an $\mathrm{m} 2$ protoconid and hypoconid relative to Daphoenus, which has a plesiomorphic amphicyonid m1-2; (g) T. altigenis has lost the $\mathrm{m} 2$ metaconid that Daphoenus retains.

Merriam's (1906) associated skull, mandibles, and partial postcranial skeleton from Logan Butte (UCMP 9999), is here interpreted as a small female of the $T$. altigenis hypodigm. The gracile canines, less swollen snout, less expanded frontal region, and smaller overall skull size are believed to indicate the female morph. Logan Butte is an isolated John Day outlier far distant southwest of Turtle Cove where most other T. altigenis fossils were found. Eventually UCMP 9999 may prove a distinct speciesthe most plesiomorphic North American temnocyonine-but for the present it is placed within $T$. altigenis as its teeth and dental measurements do not merit separation.

Temnocyon altigenis from the John Day beds shares some dental characteristics with European haplocyonine amphicyonids from the Aquitanian Allier Basin localities of StGérand, France. A holotype mandible of Haplocyon elegans (MNHN-SG 395: Bonis, 1966: pl. 3, fig. 4; Viret, 1929: pl. 8, fig. 1) displays teeth and dental measurements much like those of the Logan Butte jaw of T. altigenis (UCMP 9999). The holotype of
Haplocyon crucians (MNHN-SG 404: Viret, 1929: pl. 8, fig. 2), a partial ramus with p2-4, and an $\mathrm{m} 1$ (MNHN-SG 403) are comparable to Cope's holotype of $T$. altigenis (AMNH 6855). This similarity between haplocyonine and temnocyonine dentitions had been previously noted by Viret (1929) and Bonis (1973).

In 1992 I was able to study Aquitanian haplocyonines in Paris through the courtesy of L. de Bonis and L. Ginsburg. Of all haplocyonines, Haplocyon elegans and $H$. crucians from St-Gérand are dentally closest to John Day $T$. altigenis, which is the most plesiomorphic North American species. However, subtle yet evident dental differences distinguish the St-Gérand forms from John Day T. altigenis - although similar in mandibular length, depth and tooth size, $H$. elegans (MNHN-SG 395) is dentally more plesiomorphic than UCMP 9999: (1) its m1 metaconid is not as reduced as in UCMP 9999; (2) the more plesiomorphic $\mathrm{m} 2$ trigonid is taller and wider, with fully developed metaconid, a low talonid with labially placed hypoconid, and an internal talonid shelf. In UCMP 9999 there is no $\mathrm{m} 2$ metaconid, the talonid is nearly equal in height to the trigonid, and the hypoconid nearly fills the talonid, which is not the case in MNHN-SG 395. In all the dental features where UCMP 9999 is more derived than MNHN-SG 395, the small Logan Butte carnivore closely approaches Cope's larger holotype of $T$. altigenis (AMNH 6855), suggesting a plausible male-female relationship between the two John Day fossils.

Finally, the age of the derived Logan Butte Temnocyon altigenis, found in proximity to tuffs dating from $\sim 28.8-29.3 \mathrm{Ma}$, seems in conflict with the probable younger age (within MP29-MN2: 26-20.5 Ma) of the more plesiomorphic Haplocyon elegans jaw from the St-Gérand basin.

\section{Temnocyon subferox, new species Figures 9, 10, 66}

Temnocyon altigenis: Thorpe, 1922: 167-168. Temnocyon altigenis (in part): Hough, 1948: 100101.

TYPE: YPM 10065, nearly complete skull with basicranium but lacking the rostrum 


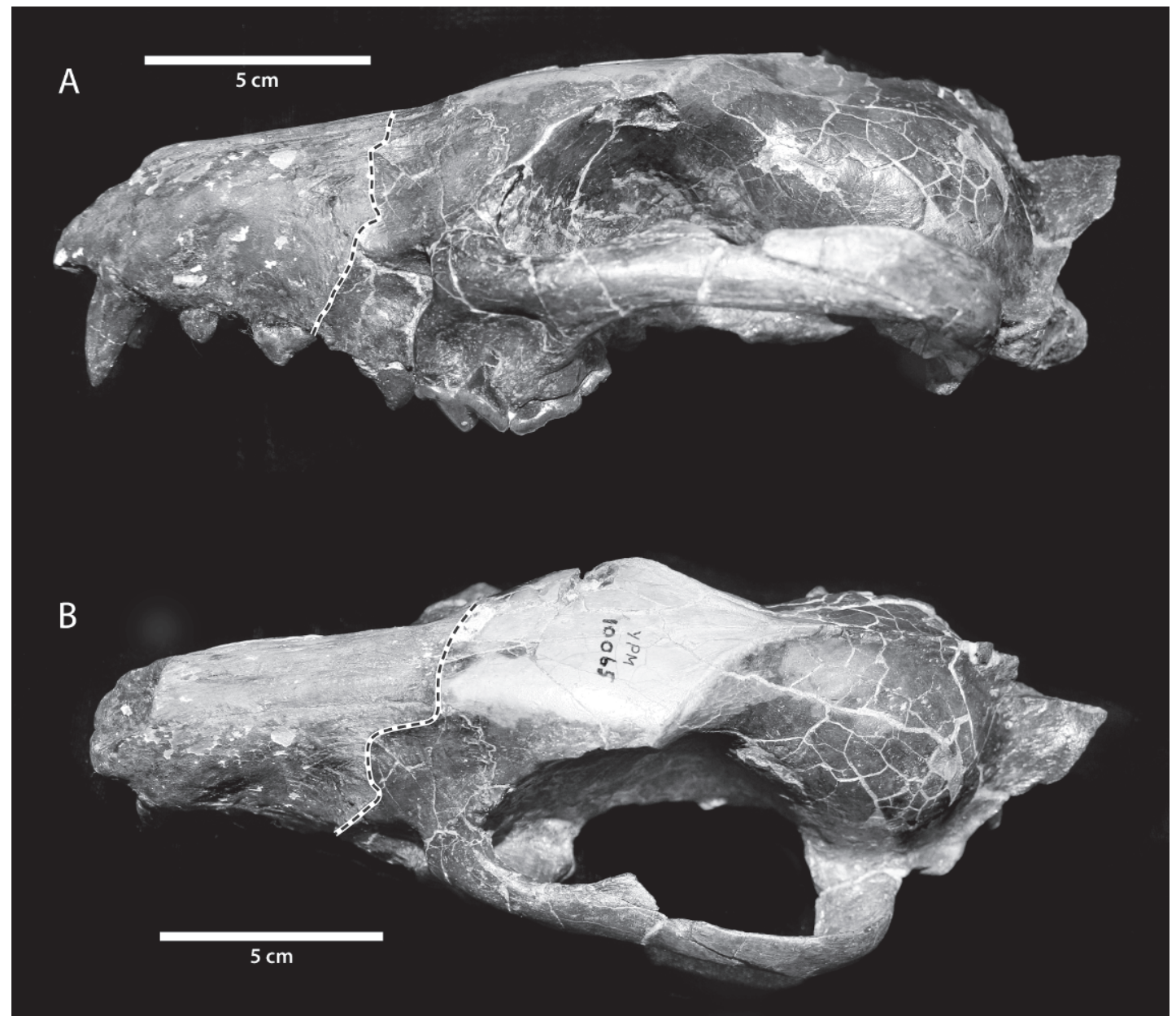

Fig. 9. Temnocyon subferox (YPM 10065), John Day Formation, Oregon. Holotype cranium in (A) lateral and (B) high lateral oblique views. Rostrum restored to the left of dashed line.

anterior to P3; from the John Day Formation, John Day River, Oregon (a catalog entry at the Peabody Museum, Yale University, reads "Middle John Day"); teeth present include right $\mathrm{P} 3-\mathrm{M} 2$, left P4-M2. Collector or date of collection unknown, but cataloged in 1914.

Distribution: Earlier Arikareean, John Day Formation, Oregon.

ETYMOLOGY: From the Latin, sub, for "less than, under" and ferox, "fierce," in the belief that the species precedes Temnocyon ferox.

DiAgnosis: Cranium and teeth intermediate in size (basilar length, $\sim 21 \mathrm{~cm}$ ) between T. altigenis (UCMP 9999, 1549, basilar lengths $\sim 16-18 \mathrm{~cm}$ ) and $T$. ferox (YPM-PU 10787, basilar length, $\sim 26 \mathrm{~cm}$ ) and without strong inflation of the frontal region (table 7). Differs from other species of Temnocyon (except $T$. altigenis) by (a) smaller size and more plesiomorphic P4-M2 in which a marked expansion of $\mathrm{M} 1$ protocone region has not occurred (ratio A/B, 1.44, table 6); (b) P4 sectorial with protocone placed in advance of paracone (more dentally derived species of Temnocyon have protocone directly lingual to paracone). No preprotocrista on M1 (present in T. altigenis). Retains most plesiomorphic auditory bulla of any known temnocyonine (see discussion of Basicranial Anatomy). 
A
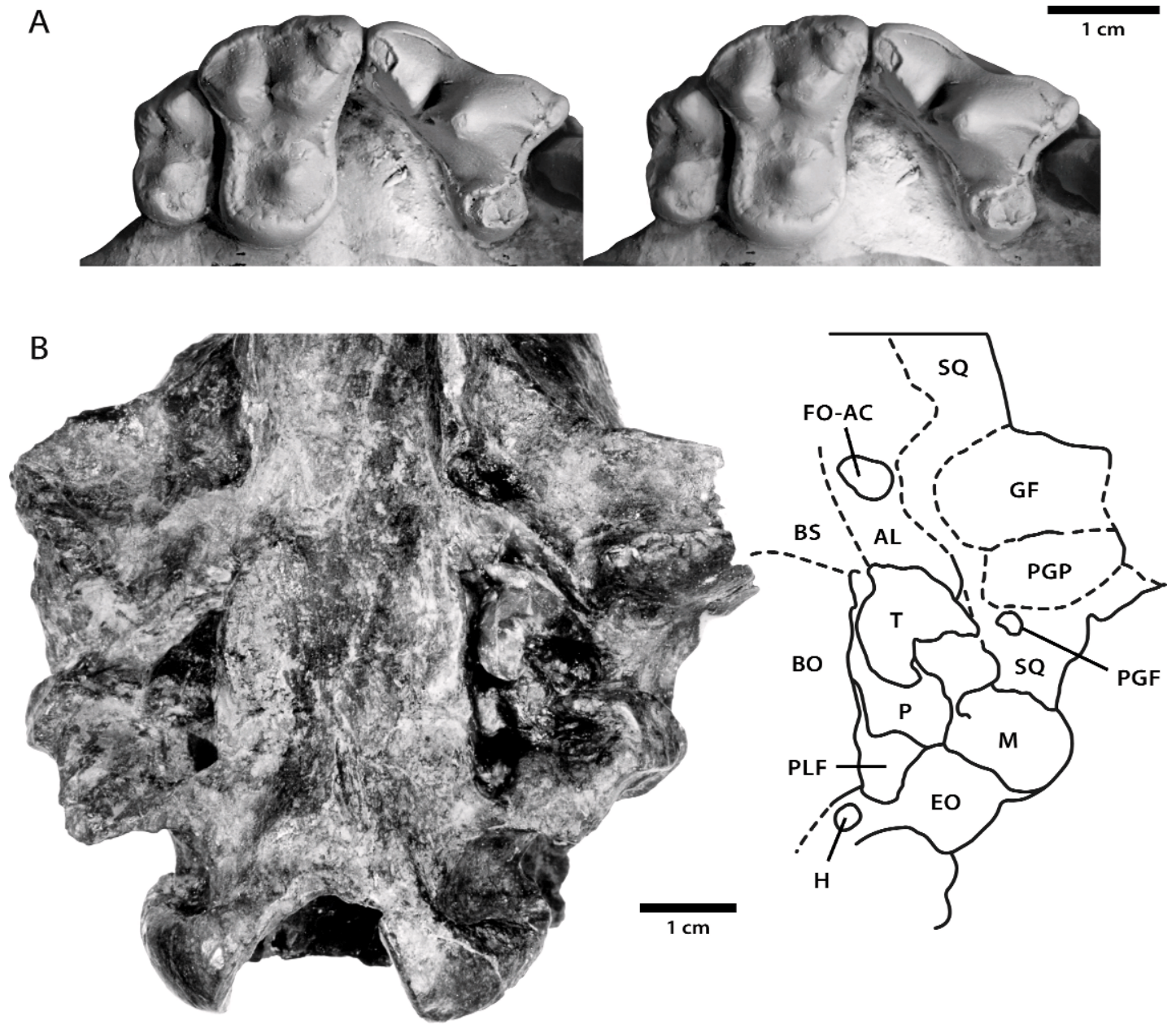

Fig. 10. Holotype of Temnocyon subferox (YPM 10065), John Day Formation, Oregon. A, maxilla with P4-M2; B, basicranium with remnant of ectotympanic bulla (stereopairs with negatives reversed). See figs. 66, 69. For abbreviations, see p. 5.

\section{RefERred Specimens: None.}

DESCRIPTION: The skull was first mentioned and briefly described by Thorpe (1922) in a discussion of doglike canids and amphicyonids in the Marsh collection at Yale. Later, Hough (1948: 101_“'”a specimen in the Peabody Museum, Yale University") mentioned the auditory region and recognized the presence of a remnant of the auditory bulla (she does not cite a catalog number but her description can apply only to YPM 10065). Neither Hough nor Thorpe illustrated the skull. The basicranium shows the deeply embayed basioccipital bone typical of amphicyonids, thought to contain an enlarged inferior petrosal venous sinus. The auditory region is reviewed and illustrated in the section on Basicranial Anatomy.

Although the skull is uncrushed and its form intact, the bone itself is fractured and altered by diagenesis after burial so that anatomical detail is lacking. The dolichocephalic skull has a gracile appearance with slender zygomatic arches and a long postorbital distance (orbital margin to occpital condyle is $14.3 \mathrm{~cm}$ ). The frontal region is not inflated, thus similar to $T$. ferox, contrasting with the expanded frontal region of $T$. fingeruti. As in T. altigenis, the maxilla is slightly depressed above the prominent 
infraorbital foramen. Foramina of the orbital region are as described for $T$. altigenis: an optic foramen, sphenorbital fissure, and anterior foramen for the alisphenoid canal open into the elongate depression that begins $18 \mathrm{~mm}$ anterior to the foramen ovale. The posterior opening of the canal and the foramen ovale share a common fossa. As in UCMP 1549 the foramen rotundum must open internally into the enclosed alisphenoid canal. Despite the loss of the rostrum the palate is preserved from P3 to M2; the cheek teeth seem quite small given the palatal area and skull size (greatest palatal width at P4 $\mathrm{M} 1$ is $6.5 \mathrm{~cm}$; P4-M2 occupy $58 \%$ of this width). The mandibles must have been long and slender because of the modest glenoid fossa for a rather small narrow condyle, the small cheek teeth, and the considerable distance $(\sim 9 \mathrm{~cm})$ from the glenoid fossa to the carnassial.

The left P4-M2 and right P3 survive whereas P1-2, incisors, and canines did not.

P3 is laterally compressed, slightly expanded posteriorly, and is taller than in $T$. altigenis and T. ferox. A fine enamel ridge runs from the principal cusp down the posterior slope to the basal cusp, the latter more prominent than a tiny posterior accessory cusp $2 \mathrm{~mm}$ anterior to the basal cusp. There are weak labial and lingual cingula that meet posteriorly to form the prominent basal cusp. P3 length, $12.9 \mathrm{~mm}$; greatest posterior width, $6.6 \mathrm{~mm}$.

P4 has a well-developed protocone, a sectorial paracone/metastylar blade, and is clearly a shearing carnassial. The metastylar blade is placed at a $45^{\circ}$ angle to the anteroposteriorly aligned paracone. Length of the blade, $8 \mathrm{~mm}$; paracone length, $10.3 \mathrm{~mm}$. The protocone, lingual and slightly anterior to the paracone, is enlarged as is the protocone of $T$. altigenis. In $T$. subferox there is a broad embrasure between P4 and M1 into which the shearing $\mathrm{m} 1$ trigonid fits during carnassial occlusion. Dimensions of this embrasure in T. subferox are similar to those in T. altigenis (UCMP 9999) and represent the plesiomorphic state. Closure of this shearing embrasure between P4 and M1 occurs in the large species of Mammacyon and Delotrochanter where crushing takes precedence over shear.
P4 is encircled by a cingulum that is pronounced at the labial base of the metastylar blade. The cingulum is swollen at the anterolabial corner to form a parastyle, situated $2 \mathrm{~mm}$ anterolabial of the base of the enamel ridge descending the anterior face of the paracone. The protocone is a blunt knoblike cusp separated by a valley from the paracone and would have occluded with the heel of $\mathrm{p} 4$.

M1 is similar to the $T$. altigenis $\mathrm{M} 1$ except that the protocone region is more derived. A well-developed parastyle contacts the P4 metastylar blade. The labial cingulum is thickest at the parastylar region and thins posteriorly yet is still well defined along the entire labial margin of M1. The paracone is somewhat larger than the metacone. The internal faces of paracone-metacone form a vertical shearing surface that descends steeply to an enamel flat forming the lingual half of the tooth. A knoblike protocone is isolated on this enamel flat: no preprotocrista runs from the protocone across the enamel flat to the anterior cingulum as in the more plesiomorphic $T$. altigenis. This differs from $T$. ferox (YPM-PU 10787) that retains not only a pre- but also a weak postprotocrista.

The knoblike M1 protocone and its enamel flat are surrounded by a prominent cingulum, strongly thickened on the lingual margin, slightly less developed on the posterior margin, and thin but distinct anteriorly. Development of a swollen anterolingual M1 cingulum in temnocyonines accompanies loss of the $\mathrm{m} 1$ metaconid during closure of the embrasure between $\mathrm{P} 4$ and M1. There is no metaconule; a paraconule may be represented by a small cingular cusp on the anterior edge of M1 midway between protocone and paracone.

M2 is much smaller than M1 but remains a fully functional quadrate tooth with a weak parastyle. The paracone and metacone are elevated as in M1 but here the metacone is much smaller than the paracone. The lingual half of the tooth is a low enamel platform with a low blunt protocone. The tooth is surrounded by a prominent cingulum, lingually thickened as in M1.

M3 was not present in life: the maxillary border is smooth and unbroken posterior to M2, and there is no evidence of alveoli or roots for M3. 
Discussion: The skull, which is of considerable importance because of the basicranium, has been long ignored except for Hough's (1948) brief mention of its auditory region. It was first described by Thorpe (1922), who placed it in T. altigenis. However, the skull is much larger than the known crania of $T$. altigenis (UCMP 9999, 1549) and exceeds any reasonable upper limit of skull size predicted for the $T$. altigenis sample from the John Day region. Unfortunately, Yale University collection records for the skull do not establish an exact location, a collector, or a date of collection, only that it was cataloged in 1914 as YPM 10065, and that it may have come from the "Middle John Day." Whether the skull was found by collectors employed by O.C. Marsh in the late 19th century is unknown but is a possibility. It is surprising that such a wellpreserved and unusual carnivore did not merit a more detailed description of its site of collection, which suggests it was found during one of the early Yale expeditions when exact locality data were rarely obtained. The stage of evolution of the skull relative to other North American temnocyonines indicates that a late Arikareean assignment is unlikely. An earlier Arikareean age is most probable, postdating the $T$. altigenis hypodigm in the John Day Formation.

The plesiomorphic dentition and weakly inflated frontal region of the skull make it a possible predecessor to T. ferox (YPM-PU 10787) from the "upper John Day beds." The lack of pre- and postprotocristae on M1 in YPM 10065, and their presence in T. ferox, seem to conflict with this view. However, with acquisition of larger samples, protocristae may prove to be variable features on the molars of these carnivorans. The morphological "distance" between T. subferox and $T$. ferox is greater than between skulls of $T$. subferox and $T$. altigenis, suggesting that substantial time intervened between YPM 10065 and $T$. ferox.

The skull of YPM 10065 is important to the determination of the broader relationships of temnocyonines since the basicranium and auditory bulla are preserved and largely undistorted. The bulla of T. subferox represents the most plesiomorphic condition found among temnocyonines. The auditory bulla in North American temnocyonines is known only in $T$. subferox (YPM 10065), in T. fingeruti (NM 280/61), and in Mammacyon obtusidens (ACM 34-41). These bullae are more fully discussed in the section on Basicranial Anatomy.

No mandible was associated with the skull of T. subferox (YPM 10065), and no isolated jaws from the John Day beds occlude satisfactorily, but there are two mandibles of North American temnocyonines that correspond in size: (a) LACM 15908, a partial mandible from the Sharps Formation of South Dakota; (b) LACM 470, a crushed mandible from Kew Quarry, Sespe Formation, Las Posas Hills, California.

The Sharps mandible (LACM 15908) is unlikely to belong to the same species as the holotype skull despite the size correspondence: the $\mathrm{m} 2$ protoconid and hypoconid are placed in the center of the tooth, not on the labial margin as in Temnocyon. The $\mathrm{m} 1$ metaconid of the Sharps jaw is reduced, more than expected for an $\mathrm{m} 1$ that would occlude with the shearing P4 of the holotype skull. This jaw likely represents an early member of the Mammacyon lineage. On the other hand, the Kew Quarry jaw includes a tall p3-p4 that corresponds to the tall P3 in YPM 10065. Here the Kew Quarry mandible is referred to $T$. cf. $T$. subferox pending discovery of associated upper and lower dentitions of the John Day species.

\section{Temnocyon cf. T. subferox Figure 11}

Temnocyon cf. T. altigenis: Stock, 1933b: 35-37, pl. 1 , fig. 6 .

REFERRED SPECIMEN: LACM 470, right mandible with $\mathrm{c}$, single-rooted $\mathrm{p} 1$ alveolus, alveoli of p2, damaged p3-m2, including anterior part of ascending ramus, from Kew Quarry, Las Posas Hills, CIT loc. 126, Sespe Formation, Ventura County, California, collected by Thurston, 1930, early Arikareean.

DESCRIPTION: The crushed and fragmented lower jaw was accurately described and figured by Stock (1933b: 35-37). Premolars are closely spaced but not crowded, and p3-4 are tall, more so than in T. altigenis. The $\mathrm{m} 1$ is larger than any $T$. altigenis carnassial (table 2): both trigonid and talonid are 


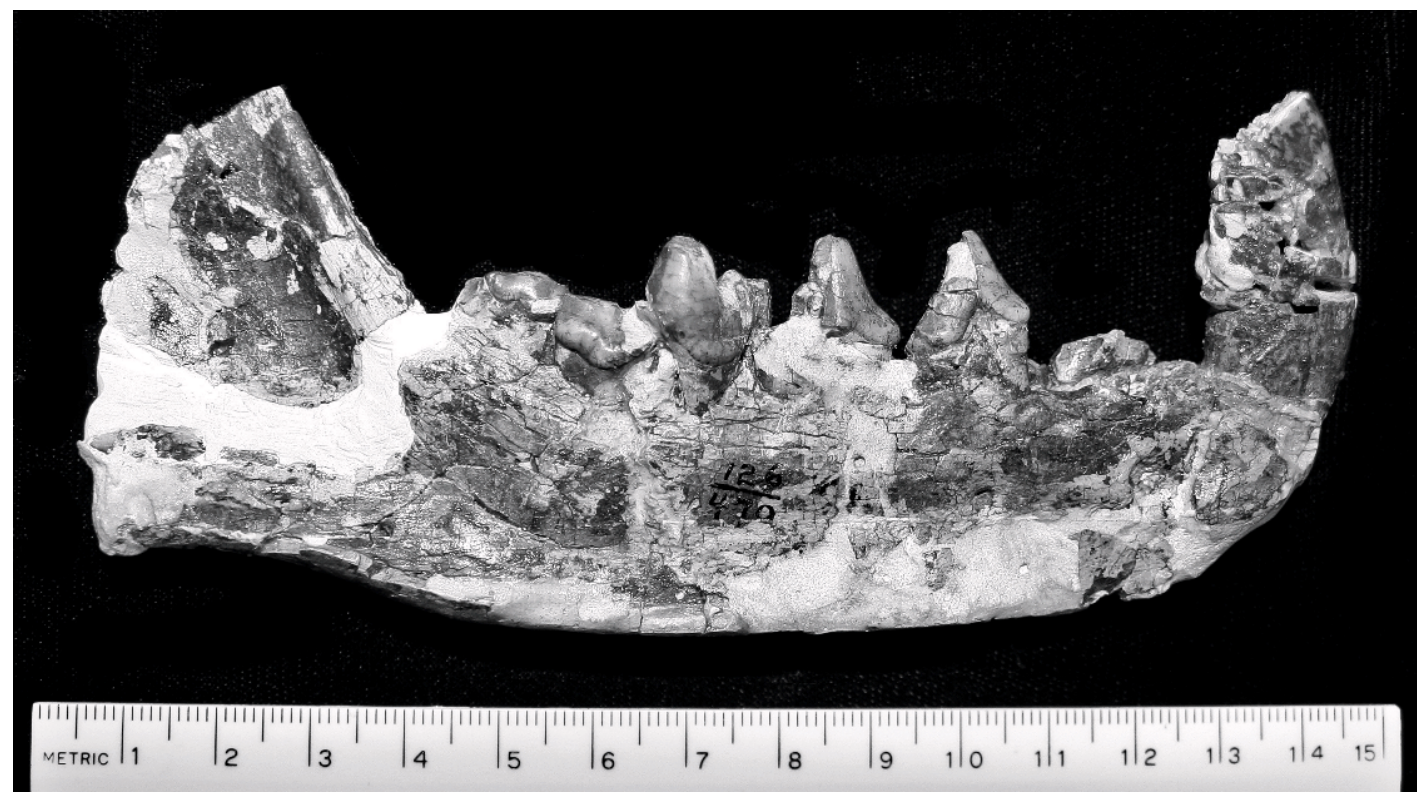

Fig. 11. Temnocyon cf. T. subferox (LACM 470), right mandible with p3-m2, damaged c, p1-2, from Kew Quarry, Sespe Formation, Ventura Co., California. This is the only record of the subfamily in western North America other than fossils from the John Day region.

broadened relative to $T$. altigenis. The $\mathrm{m} 1 / \mathrm{m} 2$ length ratio is estimated at $\sim 1.8$, similar to $T$. ferox, taking into account damage to both molars - there is a relatively short plesiomorphic $\mathrm{m} 2$. The preserved lower teeth (p3$\mathrm{m} 2$ ) are all slightly wider and more robust than these teeth in T. altigenis (table 2). The mandible is only $25 \mathrm{~mm}$ in depth below the hypoconid of $\mathrm{m} 1$, its width much compressed by crushing.

Discussion: The Kew Quarry mandible from the Sespe Formation displays differences in size and proportion of the posterior premolars and molars that argue against its placement in $T$. altigenis. The upper teeth of Temnocyon subferox (YPM 10065) satisfactorily occlude with the teeth of the Kew Quarry jaw, and indicate a carnivore of approximately the same size. However, there is no associated mandible with the holotype skull of T. subferox (YPM 10065) nor is there any other mandible of appropriate size from the John Day beds that can be referred to the skull. The dentary itself is not diagnostic but is quite shallow as would be predicted for $T$. subferox.
An important contrast exists between the Kew Quarry mandible and the holotype mandible of Delotrochanter petersoni n. sp. (CM 1603). CM 1603 belonged to a carnivore only slightly larger than the Kew Quarry animal, yet its p2 is short, with a large posterior and a small anterior root, placed very close together. The Kew Quarry p2 is elongate, and its two roots are of about equal size and spaced well apart. Thus the Kew Quarry carnivore does not approach Delotrochanter in premolar form, since the $\mathrm{p} 2$ is a key derived trait of the latter genus, nor does its $\mathrm{m} 1$ show the straight (as opposed to sinuous) labial cingulum found in Delotrochanter. The Kew Quarry animal cannot be referred to Mammacyon because it lacks shared derived dental traits of that genus: the notched lingual margin of the $\mathrm{m} 1$ talonid and the elongate $\mathrm{m} 2$. It is more likely that the Kew Quarry mandible belongs to a carnivoran similar to the John Day Temnocyon subferox that retained the shearing dentition typical of the Temnocyon lineage. Fossil mammals found with LACM 470 in Kew Quarry favor an early Arikareean age for the 
quarry assemblage (see discussion in Age and Correlation).

Temnocyon ferox Eyerman, 1896 Figures 12-14, 53

Temnocyon ferox Eyerman, 1896: 268-284, pl. 11, figs. 1-9.

Temnocyon ferox: Wortman and Matthew, 1899: 115-118, fig. 3.

Temnocyon ferox: Merriam, 1906: 22-23, 29.

TYPE: PU 10787, as given in Eyerman (1896), a nearly complete articulated skeleton with associated skull and lower jaws, the basicranium badly damaged. Found in the same block with a partial oreodont skeleton, "near Maginnis' ranch, Turtle Cove, John Day river, Upper John Day beds, Oregon," collected by L.S. Davis, 1889. The type is now conserved in the Yale Peabody Museum collection and is numbered YPM-PU 10787.

DisTribution: Mid- or late Arikareean, John Day Formation, John Day valley, Oregon.

Diagnosis: Wolf-sized species of Temnocyon (basilar skull length, $\sim 26 \mathrm{~cm}$ ), distinguished from $T$. altigenis and $T$. subferox by much larger size, from $T$. macrogenys by much smaller size, and from the Mammacyon obtusidens $-M$. ferocior group by retention of the $\mathrm{m} 1$ metaconid and possession of a short $\mathrm{m} 2$ relative to $\mathrm{m} 1$ (ratio $\mathrm{E} / \mathrm{F}, \sim 1.6$ in Mammacyon; $\sim 1.8$ in $T$. ferox). T. percussor is distinguished from $T$. ferox by its taller, broader p3-4 and by its larger more robust m1-2 and M1 (tables 2, 3). T. ferox and $T$. percussor share a similar m1-2 form but $T$. percussor represents a larger species. $T$. fingeruti differs from $T$. ferox in its more elongate, narrower $\mathrm{m} 1$, longer $\mathrm{m} 2$, disproportionate size of M1-2 (small M2 relative to $\mathrm{M} 1$ in $T$. ferox; large M2 in $T$. fingeruti); dental ratios (table 6); and more inflated frontal region.

Referred Specimens: None.

DESCRIPTION: Eyerman described and figured the type specimen of $T$. ferox (1896: 268-279, pl. 11), reporting that it came from the upper John Day beds, Turtle Cove, Oregon, and so I include here only relevant observations to facilitate comparison with other temnocyonine species of similar size.

The skull and associated mandibles are crushed and fragmented, held together by an extremely hard, indurated gray tuff that preserved the articulated skeleton. Sutures and other fine anatomical details are obscured and distorted. The skull has a basilar length of $\sim 26 \mathrm{~cm}$. The snout is of moderate length: preorbital distance, $\sim 10 \mathrm{~cm}$; postorbital $\sim 16 \mathrm{~cm}$. Relative to Canis lupus the preorbital distance is proportionately shorter and the postorbital longer. The frontals are little inflated, much less so than in $T$. fingeruti, a carnivore of about the same size. The basicranium unfortunately is so damaged that no details can be identified.

The dentition reflects the plesiomorphic pattern seen in $T$. altigenis and $T$. subferox, is simply scaled to larger size, differing most notably in the form of M1-2. The $\mathrm{p} 1$ is represented by a single alveolus; $\mathrm{p} 2$ and $\mathrm{p} 3$ are not robust as in Mammacyon and Delotrochanter but rather low as seen in T. altigenis from Logan Butte - they carry no posterior accessory cusps and have thin enamel ridges traversing their anterior and posterior faces; p4 is distinctly larger than p3 and has a labially placed posterior accessory cusp $-\mathrm{p} 4$ has a squared heel with a centrally placed cingulum cusp and is elongate relative to $\mathrm{m} 1$ length. The $\mathrm{ml}$ is a short, rather broad carnassial retaining a slightly reduced metaconid; the $\mathrm{m} 1$ talonid is nearly entirely occupied by the massive hypoconid (there is no entoconid); the hypoconid is much lower in height than the $\mathrm{m} 1$ paraconid. The $\mathrm{m} 2$ is short, a striking feature of the species; $\mathrm{m} 1 / \mathrm{m} 2$ length ratio is $\sim 1.8$. The $\mathrm{m} 2$ trigonid is dominated by a large protoconid and the talonid by a hypoconid, both labially placed - there is no metaconid and only an extremely reduced paraconid; the trigonid width is $8 \mathrm{~mm}$, and the talonid narrows to a width of $6.6 \mathrm{~mm}$. The $\mathrm{m} 1$ hypoconid and $\mathrm{m} 2$ protoconid-hypoconid form a linear series of three blunt, crushing cusps.

The upper premolars are also lowcrowned, gradually increasing in height from P1-3. Only P3 has a posterior accessory cusp, very small, somewhat labial in position above a slightly expanded heel with a squared posterior border. Although the upper carnassials are damaged, the metastylar blade was apparently short and the protocone modestly enlarged. M1 still retained a parastyle, and a prominent cingulum surrounded 


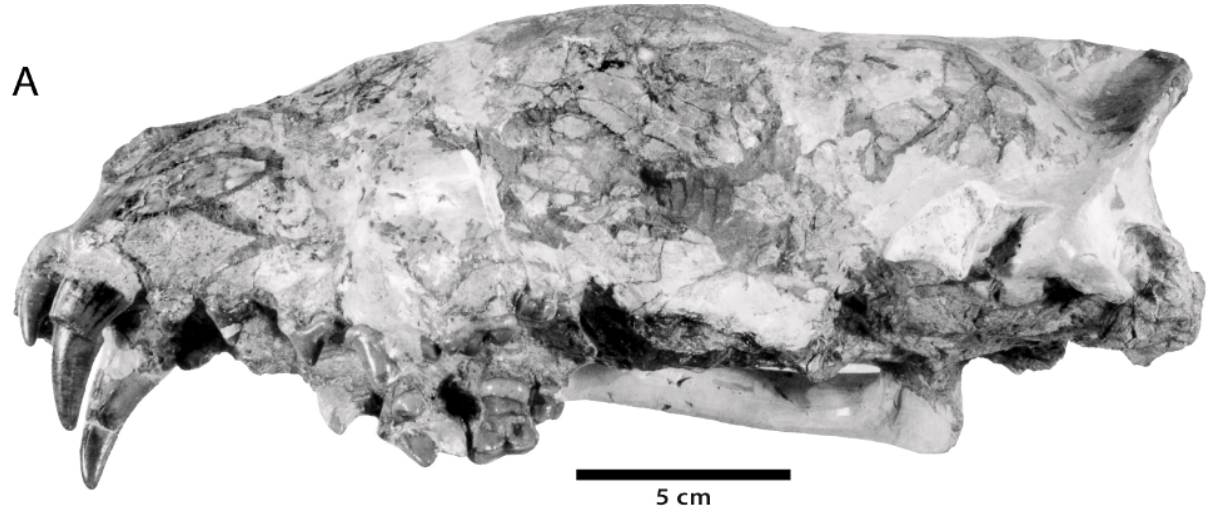

B
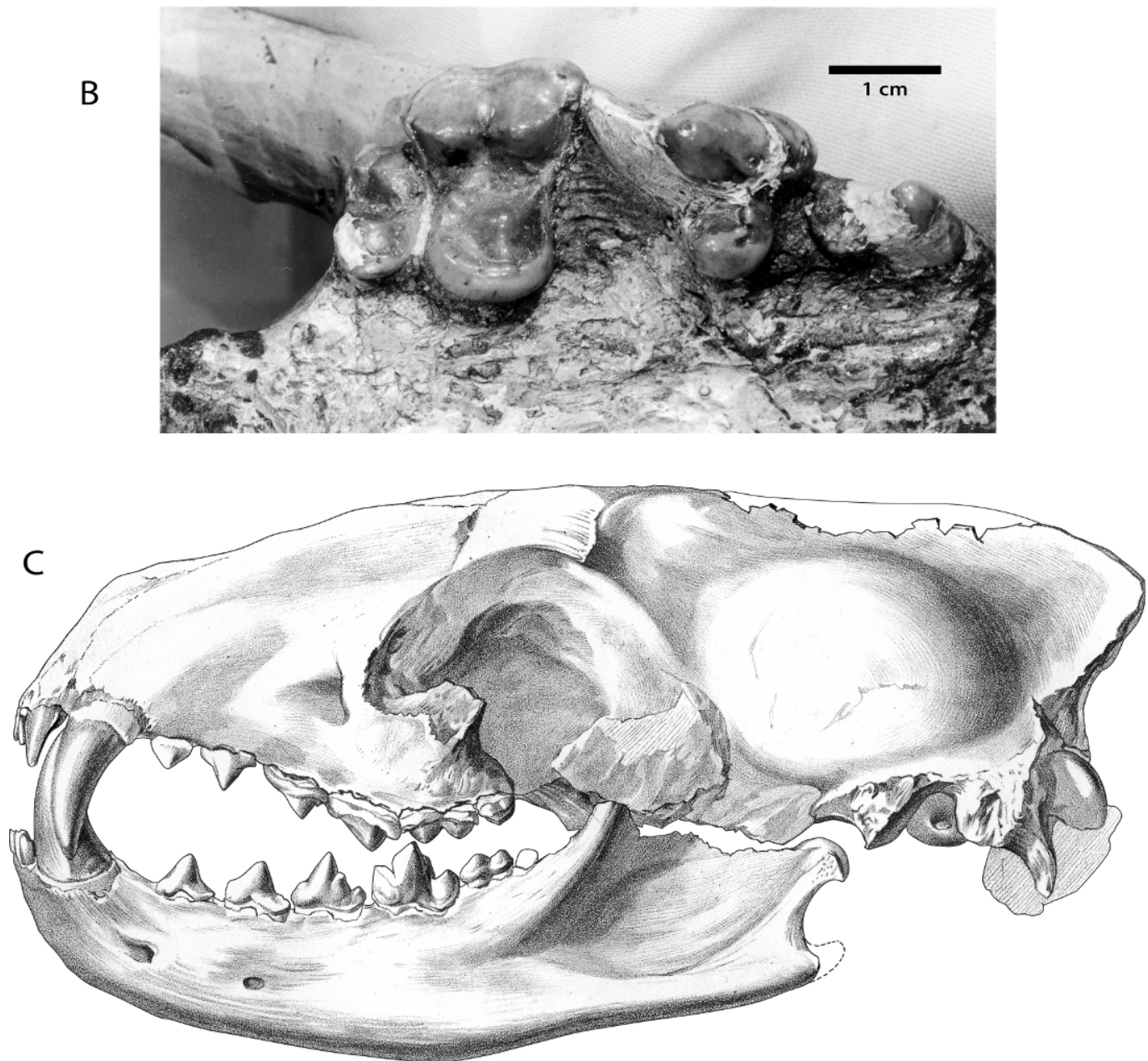

Fig. 12. Holotype of Temnocyon ferox Eyerman (YPM-PU 10787), from “near Maginnis' ranch, Turtle Cove, John Day river, Upper John Day beds, Oregon.” A, Cranium in lateral view; B, maxilla with P3-M2 (white plaster fills voids in teeth); C, Eyerman's (1896) restoration of the holotype cranium and mandible. Note crushing and fragmentation of the cranium in (A). 


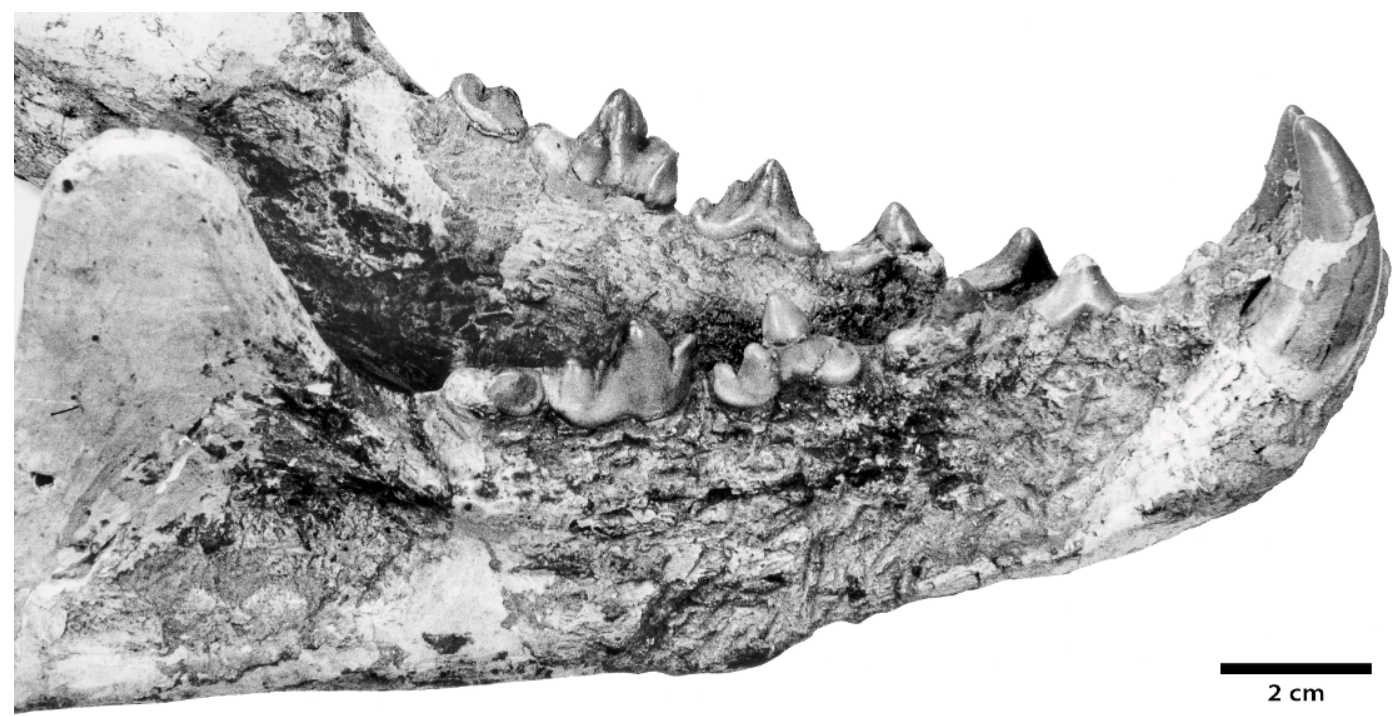

Fig. 13. Holotype mandibles of Temnocyon ferox Eyerman (YPM-PU 10787), with both canines and left and right p2-m2. Mandibular bone is heavily fractured. Associated forelimb, figure 53.

the tooth; the lingual cingulum was thickened, enlarging the protocone region, more so than in T. subferox. M1 retains both preand postprotocristae and the protocone is situated almost exactly in the center of the expanded lingual half of the tooth. M2 is much smaller than M1 and has markedly reduced the metacone; M3 is absent.

Relative to the wolf the upper and lower canines are larger whereas the incisors are the same size. Each lower incisor shows a single accessory cusp (Nebenzacke) on its labial margin.

A partially articulated postcranial skeleton, including the limbs, fore- and hind feet, was found in association with the skull and mandibles and was described by Eyerman (1896). Although difficult to free from the indurated matrix, the skeleton was prepared to demonstrate its limb proportions and digitigrade paraxonic fore- and hind feet. The limbs are discussed in the section on Postcranial Osteology.

Discussion: Temnocyon ferox is distinguished from $T$. altigenis and $T$. subferox by larger size, similar to a living wolf, but shares with those species a plesiomorphic temnocyonine dentition. These three species probably form a morphocline in which body size increases through time. T. ferox, however, is the first species in this lineage to show specialization of its carnassials and molars, while still retaining simple low premolars that distinguish this species from $T$. percussor, $T$. macrogenys, and the species of Mammacyon and Delotrochanter that have larger more developed premolars. The presence of the $\mathrm{m} 1$ metaconid and short $\mathrm{m} 2$ are diagnostic features of the molars distinguishing $T$. ferox from temnocyonines of similar size such as Mammacyon obtusidens (which has no $\mathrm{ml}$ metaconid and a larger, elongate $\mathrm{m} 2$ ) and Temnocyon fingeruti. T. ferox can be distinguished from $T$. fingeruti using M1-2: the $T$. ferox M1 shows a more developed lingual cingulum and M2 is much reduced whereas in $T$. fingeruti the M1 shows only modest expansion of the lingual cingulum and M2 is large. However, the M1 lingual cingula of both $T$. ferox and $T$. fingeruti are much less developed relative to the hypertrophied lingual cingula of Mammacyon and Delotrochanter.

Upper carnassials of $T$. ferox are damaged but appear to be sectorial teeth like those of $T$. fingeruti; however, $\mathrm{P} 4$ has a prominent protocone more lingually situated than in $T$. subferox.

The teeth of Temnocyon ferox are similar to the available teeth of $T$. percussor (p3-m2, 

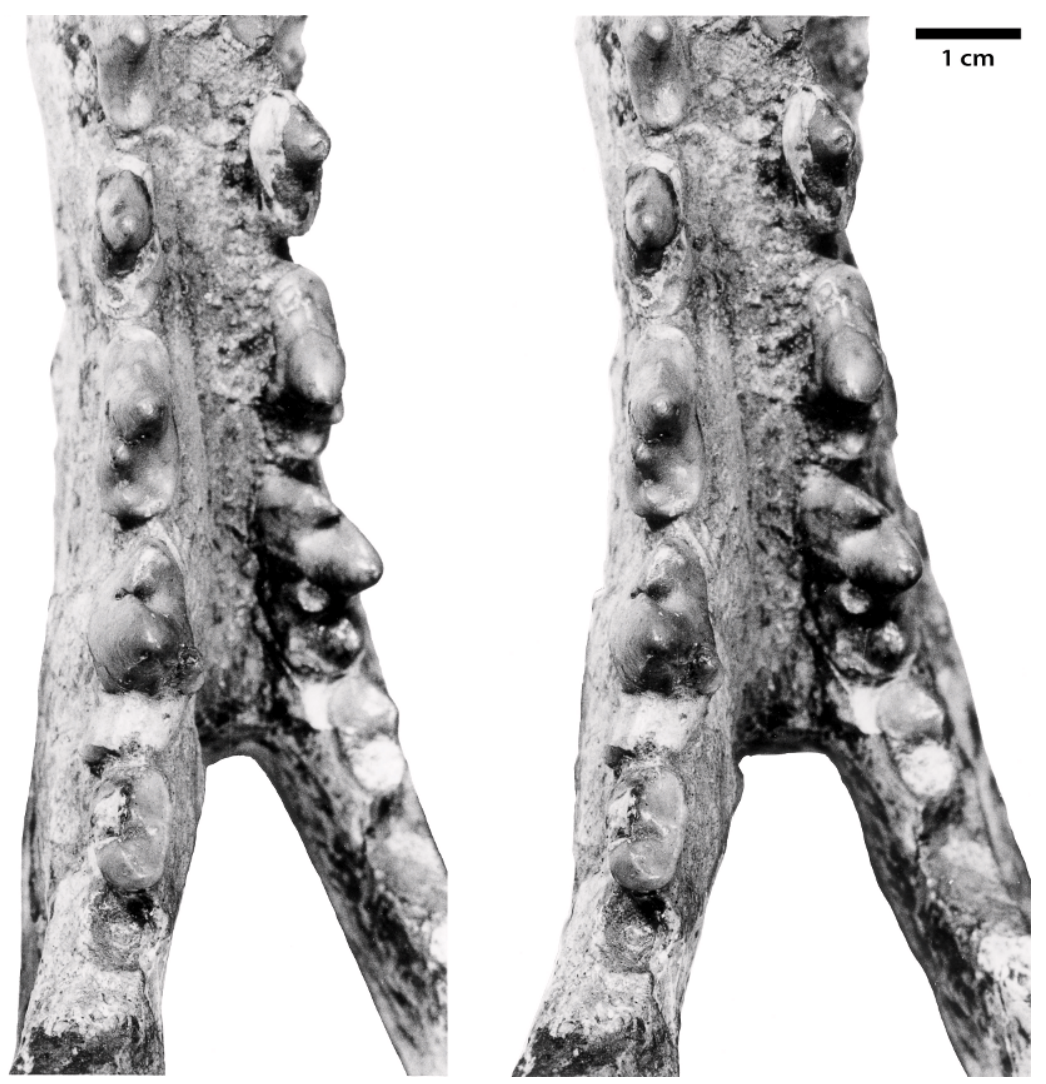

Fig. 14. Occlusal view of the holotype mandibles of Temnocyon ferox Eyerman (YPM-PU 10787), with left p2-4, m1-2, right p3-4, m1-2. An m1 metaconid is evident on both carnassials (stereopair).

M1). The size increase from $T$. ferox to $T$. percussor is characterized by development of a taller p3-4 and more robust $\mathrm{m} 1-2$ in $T$. percussor.

Temnocyon ferox is one of the few temnocyonines for which there is a confirmed association of the cranium and an articulated postcranial skeleton. Eyerman (1896) was aware of the evident disproportion between skull and limbs: the skull was larger than that of the average wolf yet the limbs were noticeably shorter. Limb elongation is nonetheless present, although not to the degree seen in the wolf. When compared with the limb and foot skeleton of the cursorial wolf, T. ferox shows a number of parallel adaptations (see Postcranial Osteology).

Forelimb elongation in Temnocyon ferox is evident relative to the plesiomorphic forelimb of T. altigenis and Daphoenus. As in the wolf, the forelimb of $T$. ferox exhibits a narrow distal humerus with reduced medial epicondyle, a closely apposed distal ulna and radius (i.e., articular process of the ulna reduced to a smooth planar facet pressed against the distal radius), and a digitigrade paraxonic forefoot with narrow carpus (metacarpals 2 and 5 short; metacarpal 1 reduced). In the hind foot there is a narrow elongated tarsus; long paraxonic metatarsals 3-4; shorter metatarsals 2 and 5; and metatarsal 1 a thin rodlike bone $45 \mathrm{~mm}$ in length (not as reduced as the minute triangular nubbin, $1 \mathrm{~cm}$ in length, that is the vestige of the first metatarsal of the wolf). Paraxonic metapodials of the fore- and hind foot of the wolf are $\sim 2$ to $2.5 \mathrm{~cm}$ longer than those of $T$. ferox. The lengthened radius and ulna and the long paraxonic metacarpals are responsible for the more elongate forelimb of the wolf. 


\section{Temnocyon percussor Cook, 1909} Figure 15

Temnocyon percussor Cook, 1909: 266, 271, fig. 3.

TYPE: AMNH 81005, associated right and left partial mandibles, left $\mathrm{p} 3-\mathrm{m} 2$, right $\mathrm{p} 1$, $\mathrm{p} 4, \mathrm{~m} 2$, roots or alveoli of $\mathrm{p} 2-3, \mathrm{~m} 1$, and a partial $\mathrm{m} 3$ alveolus, a doubtfully associated right upper canine, comprising Cook's (1909) type of Temnocyon percussor, found "about one-half mile west of Agate, Nebraska, in the Lower Harrison beds ....", Sioux County, Nebraska (see Discussion for additional information on site of collection). Cook's figure of the type is a composite based on both mandibles, although this is not plainly stated in his publication.

Distribution: Late Arikareean, upper Arikaree Group, Sioux County, Nebraska.

Diagnosis: Differs from T. altigenis and $T$. subferox in larger size and from $T$. macrogenys in much smaller size. Distinguished from $T$. ferox by taller differently proportioned p3-4 and by dimensions of $\mathrm{m} 1-$ 2 and M1 that together exceed the size attributable to a $T$. ferox population (tables 2, 3). $T$. percussor differs from $T$. fingeruti in having a taller more robust, somewhat longer p3-4, shorter $\mathrm{m} 1-2$, and no $\mathrm{m} 2$ metaconid. M1 lingual cingulum better developed in $T$. percussor relative to $T$. fingeruti.

ReFerRed Specimens: (1) AMNH 81054, right m1, American Museum-Cook Quarry (Hunt, 1972), 2 mi north of the Agate Spring Quarries, basal Anderson Ranch Fm., Sioux County, Nebraska, H. Cook, August 1909; (2) AMNH 81047, right M1, American Museum-Cook Quarry, basal Anderson Ranch Fm., Sioux County, Nebraska, H. Cook, July 1908.

DESCRIPTION: AMNH 81005-Cook (1909: 266) only briefly described this individual but presented an accurate illustration of the dentition. This illustration posterior to p3 is based on the left mandibular fragment, and anterior to $\mathrm{p} 3$ on the anterior part of the right mandible. It is not possible to estimate jaw depth since the lower border of the mandible has been broken away along the length of the horizontal ramus. However, an estimate of mandibular length, based on length of toothrow (c-m2, $110.9 \mathrm{~mm})$, compares with the mandibular length of Eyerman's type of $T$. ferox (c-m2, $102 \mathrm{~mm}$ ), an observation complemented by the similar premolar spacing in both animals.

The p1 measures $8.4 \mathrm{~mm}$ in length, $5.0 \mathrm{~mm}$ in width. It is a small, single-rooted peglike tooth situated on the jaw margin anterointernal to the anterior root of $\mathrm{p} 2$. The main cusp is anteriorly inclined, and there are no accessory cusps.

The $\mathrm{p} 2$ is not preserved in either mandible; the alveolar measurements of length and width are 14.8 and $7.2 \mathrm{~mm}$. The anterior root is more labially placed than the posterior root, the tooth being directed outward, a trait also seen in several other temnocyonines.

The p3 measures $15.9 \mathrm{~mm}$ in length, $7.8 \mathrm{~mm}$ in width. There are no posterior accessory or basal cingulum cusps. The tooth in lateral view is nearly an equilateral triangle, the posterior slope being only slightly longer than the anterior slope. Weak enamel ridges run down the anterior and posterior slopes; there is slight development of a lingual and posterior cingulum that is even less well defined labially.

The p4 measures $19.7 \mathrm{~mm}$ in length, $9.0 \mathrm{~mm}$ in width. It has the same form as p3, only larger and taller, with the addition of a prominent posterior accessory cusp and a shelflike heel at the rear of the tooth. The posterior accessory cusp is situated about half the distance down the posterior slope and is labial in position. A weak cingulum is present on the lingual and posterolabial faces of $\mathrm{p} 4$. A small cingular cusp also occurs on the shelflike heel of $\mathrm{p} 4$ where the posterior enamel ridge descends to meet it.

The $\mathrm{m} 1$ measures $23.5 \mathrm{~mm}$ in length, $10.5 \mathrm{~mm}$ in width. Trigonid length, $16.2 \mathrm{~mm}$; talonid length, $7.3 \mathrm{~mm}$. The trigonid appears somewhat inflated: paraconid and metaconid are of about equal height, the taller protoconid elevated only $\sim 1.5 \mathrm{~mm}$ above the main p4 cusp. The metaconid is present, reduced, and situated on the posterolingual corner of the massive protoconid about half the distance to its base. The hypoconid is the only talonid cusp: it is centrally positioned, and occupies nearly all the talonid. A cingulum is developed on labial and lingual margins of the talonid. On the posterior slope of the hypoconid there 

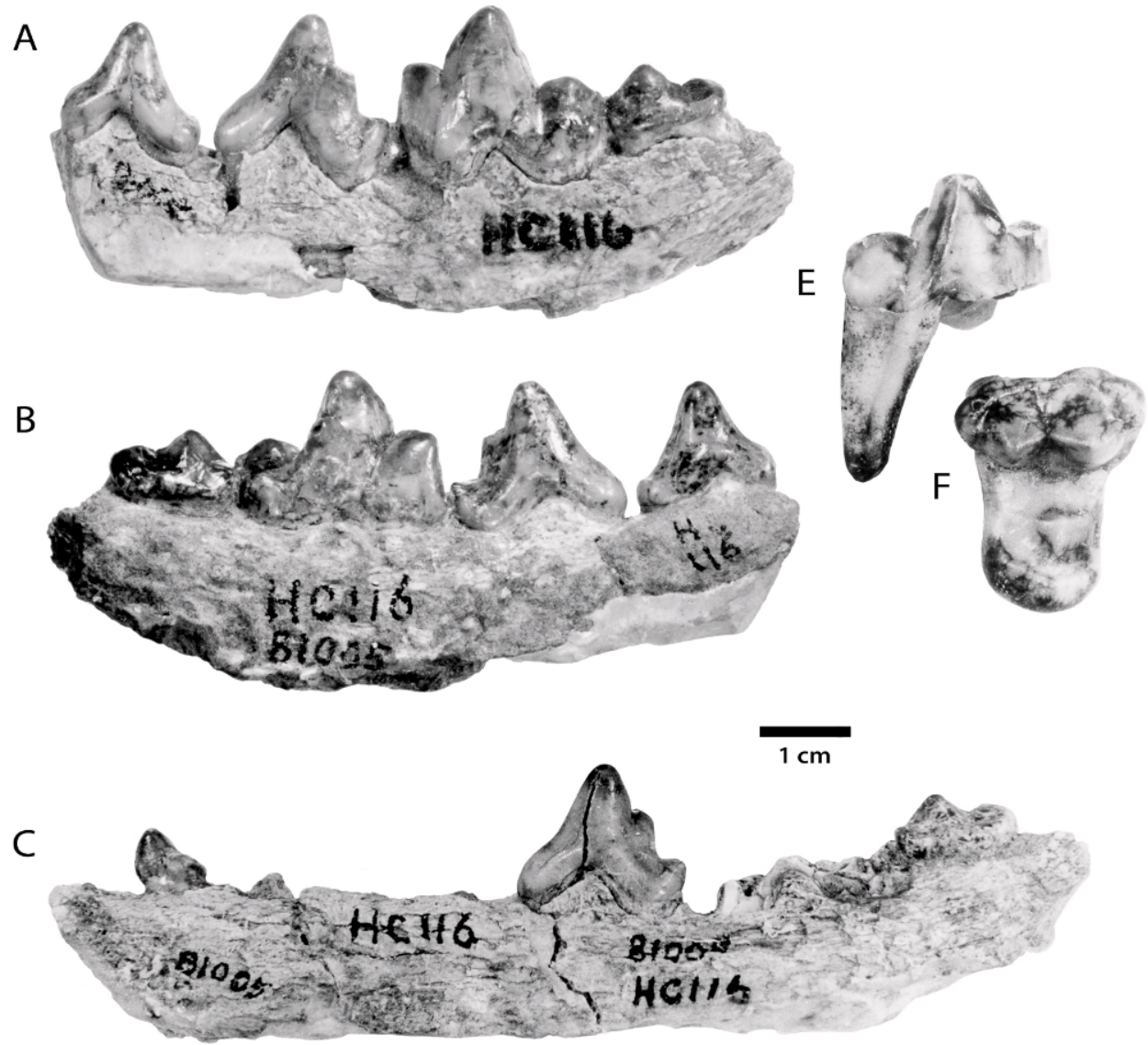

D

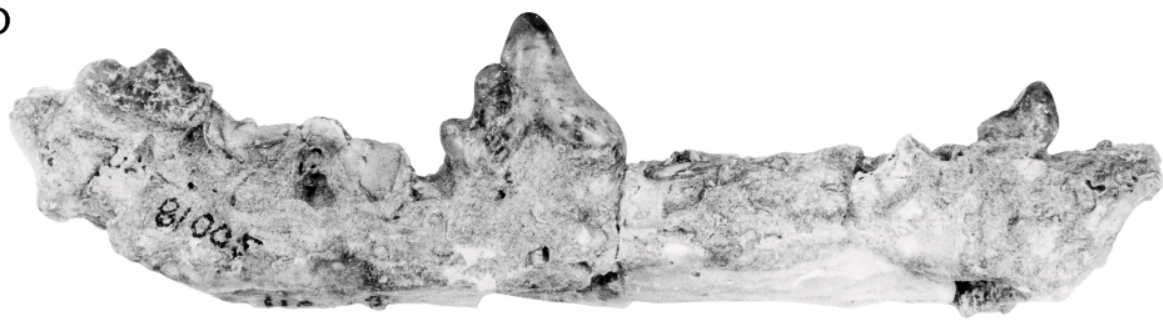

Fig. 15. Temnocyon percussor Cook, Niobrara River valley, Sioux Co., Nebraska. Holotype (AMNH 81005) left partial mandible with $\mathrm{p} 3-\mathrm{m} 2(\mathbf{A}, \mathbf{B})$ and right mandibular fragment with $\mathrm{p} 1, \mathrm{p} 4$, and $\mathrm{m} 2$ (C, D) from $0.5 \mathrm{mi}$ west of Agate Ranch headquarters, Harrison Formation, Sioux Co., Nebraska. A, D, labial and B, C, lingual views. Referred right $\mathrm{m} 1$ (E, AMNH 81054) and right M1 (F, AMNH 81047) from AMNH-Cook Quarry, basal Anderson Ranch Formation. Cook's 1909 drawing of the holotype is a composite of the two mandibular fragments (A to D) illustrated here, both from the same individual.

is a tiny cusp apparently derived from the cingulum.

The $\mathrm{m} 2$ measures $13.9 \mathrm{~mm}$ in length, $9.0 \mathrm{~mm}$ in width. The form of the tooth is most like $\mathrm{m} 2$ in YPM-PU 10787 (T. ferox) and differs from the elongate $\mathrm{m} 2$ of Mam- macyon. The prominent $\mathrm{m} 2$ protoconid is the same height as the $\mathrm{m} 1$ hypoconid. These two cusps, aligned in series with the much smaller hypoconid of $\mathrm{m} 2$, are low, blunt, crushing instruments. A low paraconid occupies the anterolingual corner of $\mathrm{m} 2$. A low ridge 
descends the protoconid to the lingual margin of $\mathrm{m} 2$. The $\mathrm{m} 2$ talonid is occupied solely by the low hypoconid placed directly behind the much larger protoconid. There is no entoconid.

The isolated upper canine measures $12.5 \mathrm{~mm}$ in labiolingual width at the enamel base; anteroposterior length, $17.2 \mathrm{~mm}$; height, $61.2 \mathrm{~mm}$. The tooth is recurved and exhibits a flat wear surface, $\sim 25 \mathrm{~mm}$ in length, $6 \mathrm{~mm}$ in width, on the anterointernal face near the tip. The tooth is badly cracked, probably from postmortem drying prior to burial.

AMNH 81054-This isolated right $\mathrm{m} 1$ compares well with Cook's type m1 (AMNH $81005)$ but exhibits more wear. Although a vertical shear facet is evident on the labial face of the protoconid-paraconid, the tips of the protoconid, paraconid, and hypoconid are blunted by apical wear, suggesting mastication of hard material. This tooth measures $24.2 \mathrm{~mm}$ in length, $10.8 \mathrm{~mm}$ in width. The $\mathrm{m} 1$ talonid of AMNH 81054 is nearly identical to that of the holotype $\mathrm{m} 1$, including the cingular swelling on the posterior slope of the hypoconid.

Because they retain the $\mathrm{m} 1$ metaconid, $T$. percussor carnassials are easily confused with those of Daphoenodon superbus, the amphicyonid that occurs with $T$. percussor in the American Museum-Cook Quarry. In $T$. percussor, however, the hypoconid fills almost the entire talonid, but in Daphoenodon the hypoconid occupies only the labial talonid surface, and does not encroach on a narrow lingual talonid shelf. Isolated teeth in the American Museum-Cook Quarry demonstrate the presence of three beardogs (Temnocyon percussor, Daphoenodon superbus, Ysengrinia americana) at the site.

AMNH 81047-This isolated M1 was also found in the American Museum-Cook Quarry. Although not associated with other material of $T$. percussor, it has the form and predicted cusp morphology that correspond to mandibular teeth of the holotype. The tooth is an enlarged version of the M1 of $T$. altigenis and $T$. ferox, measuring $20.9 \mathrm{~mm}$ in length, $27.9 \mathrm{~mm}$ in width; hence it lacks the extremely swollen lingual cingulum found in Mammacyon and Delotrochanter. The paracone and metacone are conspicuously elevated above the lingual half of the tooth, forming a vertical shear surface. The paracone is somewhat larger than the metacone; both cusps are bordered by a sharply defined labial cingulum continuous with a prominent parastyle. The protocone is centrally situated on a flat enamel platform, and is less knoblike, more crescentic in form than in Mammacyon. A long preprotocrista runs from the protocone to the anterior cingulum, and a short low postprotocrista extends from protocone to posterior cingulum, similar in this respect to M1 of $T$. ferox.

The plesiomorphic form of the $T$. percussor M1 (AMNH 81047) is unique in the late Arikareean; the older Mammacyon lineage and contemporary Delotrochanter have more derived upper molars in which the protocone region forming the lingual half of M1 is more expanded, primarily due to the more swollen lingual cingulum. In AMNH 81047 the anteroposterior length of the protocone region is quite narrow relative to the length of the labial margin of the tooth (table 5), and its anterior cingulum is plesiomorphic (as in $T$. altigenis) in contrast to the enlarged cingulum of Mammacyon. The narrow M1 protocone region and the lack of a swollen anterior cingulum indicate the presence of a metaconid on the mandibular carnassial, and so AMNH 81047 cannot be referred to Mammacyon or Delotrochanter in which the $\mathrm{m} 1$ lacks a metaconid.

Discussion: Temnocyon percussor is restricted to upper Arikaree Group sediments in western Nebraska, and has never been found outside of the Niobrara River valley near Agate in Sioux County. The species is more advanced in dental traits than the John Day holotype of $T$. ferox: $T$. percussor has broader, more robust teeth, taller premolars (p3-4), and a much larger yet still plesiomorphic M1. Although the two species are similar in dental features, the Great Plains T. percussor has a slightly longer $\mathrm{m} 2$ than found in the John Day T. ferox (ratio $\mathrm{E} / \mathrm{F}$ is $\sim 1.7$ in AMNH 81005 , $\sim 1.8$ in YPM-PU 10787, table 6). Eyerman's type (YPM-PU 10787) of T. ferox represents a smaller individual than $T$. percussor and a less evolved dental stage, suggesting an older age for the John Day carnivore.

Cook (1909) was aware that the holotype, found by him in 1906, was dentally similar to 
the John Day $T$. ferox yet represented a larger carnivore with different p3-4 proportions. The M1 later found by Cook in 1908 is reasonably referred to $T$. percussor, its large size and form in agreement with the m1-2 of the holotype mandible.

If Cook (1909) correctly attributed the holotype of Temnocyon percussor (AMNH $81005)$ to the Syndyoceras level or "quarry" one-half mile west of Agate, then the holotype material comes from the Harrison Formation about $40-50 \mathrm{ft}(12-15 \mathrm{~m})$ below the upper contact of the formation with the Anderson Ranch beds. The isolated molars (AMNH 81054, 81047) come from the American Museum-Cook Quarry in the basal Anderson Ranch Fm., about $50 \mathrm{ft}$ stratigraphically higher than Cook's AMNH 81005. The Syndyoceras level is late Arikareean in age and occurs in proximity to the Agate Ash, initially 21.3 Ma (KA 481, Evernden et al., 1964), now more recently dated by the ${ }^{40} \mathrm{Ar} /{ }^{39} \mathrm{Ar}$ method at $\sim 22.9 \mathrm{Ma}$ (Izett and Obradovich, 2001). The similarity of the teeth of $T$. percussor and $T$. ferox suggests a relationship: although the age of T. ferox is uncertain (see Age and Correlation), a date older than $22.9 \mathrm{Ma}$ is supported by its less advanced dentition relative to the more robust teeth of $\mathrm{T}$. percussor.

The presence of $T$. percussor (with $\mathrm{m} 1$ metaconid) in western Nebraska in both the Harrison Formation and basal Anderson Ranch beds in the Agate area, and the occurrence of large Delotrochanter oryktes (without $\mathrm{ml}$ metaconid) in these same two formations, also in the Agate area, demonstrates that the temnocyonine dentition was evolving at different rates in these two contemporary lineages. This had been difficult to prove given the fact that two or more temnocyonine species rarely occur in proximity in the same rock unit. However, based on fossils in this study, two temnocyonine genera had already lost the $\mathrm{m} 1$ metaconid prior to the late Arikareean (Mammacyon, LACM 9194; Delotrochanter, CM 1603); hence these represent more derived dentitions relative to a geologically younger Temnocyon percussor that retains its $\mathrm{m} 1$ metaconid and plesiomorphic M1 into the late Arikareean interval. If $T$. percussor directly precedes $T$. macrogenys, which is probable, then Temno- cyon maintains this plesiomorphic dental pattern in the Great Plains until its extinction at the end of the Arikareean.

\section{Temnocyon fingeruti, new species} Figures 16-19, 68

TYPE: NM 280/61, a complete skull and lower jaws in articulation, the rostrum offset $\sim 3 \mathrm{~cm}$ from the posterior cranium by sediment deformation after burial; both left and right $\mathrm{I} 1-3, \mathrm{C}, \mathrm{P} 1-4, \mathrm{M} 1-2$ and left i3, c, p2-4, m1-3, right c, p1-4, m1-3, from the Haystack Valley Member (revised), John Day Formation, Oregon, Lower Beardog Section, E1/2, NE4, SW4, SW4, sec. 27, T8S, R25E, Kimberly 7.5-minute quadrangle, from $96 \mathrm{ft}$ stratigraphic level in appendix 1-6, Hunt and Stepleton (2004: 81); $62 \mathrm{ft}$ above a radioisotopically dated horizon at $\sim 23.8 \mathrm{Ma}$.

Distribution: Latest Oligocene, late midArikareean, John Day Formation, Wheeler County, Oregon.

ETYMOLOGY: The species name recognizes Michael Fingerut, who discovered and collected the holotype in the Balm Creek drainage, north-central Oregon.

Diagnosis: Wolf-sized species of Temnocyon (basilar skull length $\sim 25 \mathrm{~cm}$ ), distinguished from $T$. altigenis and $T$. subferox by much larger size, from $T$. macrogenys by smaller size; differs from similarly sized $T$. ferox by greater inflation of the frontal paranasal sinuses (relative to braincase width, table 7) and by different form and proportions of $\mathrm{p} 4-\mathrm{m} 2$ and M1-2 (tables 2, 3), including a more lingually extended M1-2 with less expansion of M1 protocone region (ratio A/B, table 6), a much larger M2 and $\mathrm{m} 2$, a longer $\mathrm{m} 2$ (ratio $\mathrm{E} / \mathrm{F}$ ), and by a more robust, wider $\mathrm{p} 4$. Temnocyon fingeruti differs from $T$. percussor in its much smaller M1 (in the upper dentition of $T$. percussor only M1 survives), more elongate $\mathrm{m} 1-2$, stronger $\mathrm{m} 1$ metaconid, and larger, rectangular $\mathrm{m} 2$ with vestigial metaconid and more developed paraconid, and by the $\mathrm{p} 4 / \mathrm{m} 1$ ratio $(0.78$ in $T$. fingeruti vs. 0.84 in both $T$. percussor and $T$. ferox). Temnocyon fingeruti differs from $T$. altigenis, T. subferox, and probably $T$. ferox in $\mathrm{P} 4$ proportions (ratio $\mathrm{C} / \mathrm{D}$, table 6); $\mathrm{P} 4$ is not known in $T$. percussor and T. macrogenys. 


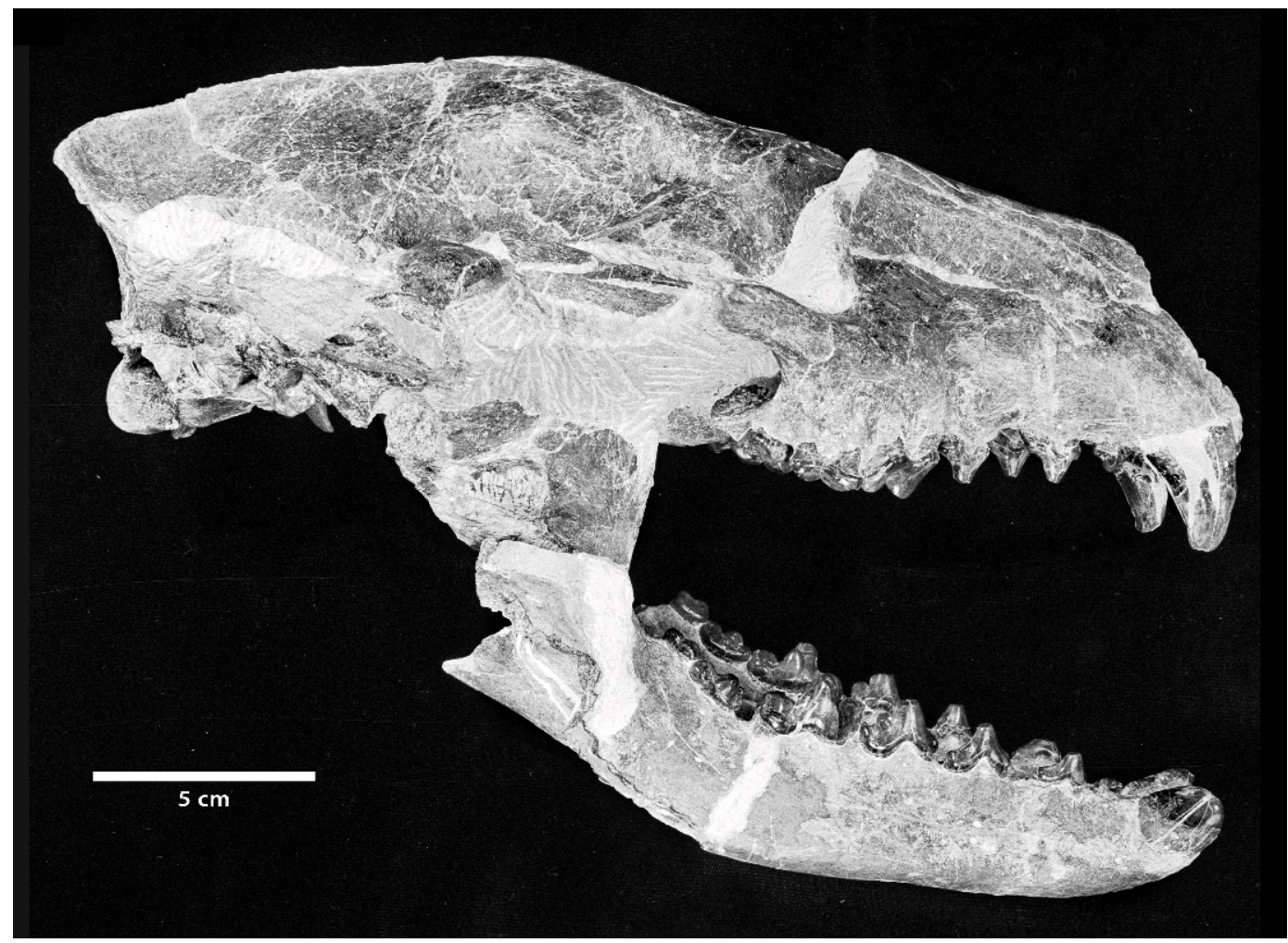

Fig. 16. Holotype cranium and mandibles of Temnocyon fingeruti (NM 280/61), from Balm Creek, Haystack Valley Member (revised), John Day Formation, Wheeler Co., Oregon. This skull was found $62 \mathrm{ft}$ $(\sim 19 \mathrm{~m})$ above a tuffaceous horizon dated to $\sim 23.8 \mathrm{Ma}$ (Hunt and Stepleton, 2004).

\section{Referred Specimens: None.}

DESCRIPTION: The skull of NM 280/61 is elongate (basilar length, $25 \mathrm{~cm}$, table 7) as are the known skulls of $T$. ferox and $T$. subferox but differs from the short, broad skull of Delotrochanter oryktes. Cranial size and proportions are similar to those of $T$. ferox except for the much greater frontal sinus inflation and entirely different form of $\mathrm{P} 4-\mathrm{M} 2$ and $\mathrm{p} 4-\mathrm{m} 2$ in $T$. fingeruti. Despite smaller size, a narrower snout and clearly dissimilar dentition, the profile of NM 280/61 compares with the skull form of Mammacyon ferocior. NM 280/61 approximates a large male wolf (Canis lupus) in rostral proportions and palatal dimensions but shows a longer postorbital cranium with broader basicranium, greater frontal sinus inflation, and smaller braincase volume. Although the teeth are similar in occlusal dimensions to those of a wolf, NM 280/61 has larger canines, more robust premolars, with a proportionately smaller shearing $\mathrm{m} 1$ and a longer $\mathrm{m} 2-3$ crushing platform. As with other John Day crania, sutures and anatomical detail are obscured by diagenetic alteration of bone. The orbital region preserves the orbital foramina nested in the elongate depression previously descibed for $T$. altigenis (UCMP 1549). An orbital foramen, sphenorbital fissure, and anterior opening for the alisphenoid canal (the foramen rotundum opening internally into the canal) are situated as in that plesiomorphic species, and it is apparent that this anatomical pattern is common to all temnocyonines where the orbital region has been preserved. The basicranium and auditory region are exceptional and are discussed in the section on Basicranial Anatomy.

The mandible is gracile and slender (depth beneath $\mathrm{m} 1,32 \mathrm{~mm}$; below p2, $27 \mathrm{~mm}$ ) with toothrow length $(\mathrm{p} 1-\mathrm{m} 3)$ of $110 \mathrm{~mm}$. These teeth are worn, indicating a mature but not aged individual; the canines, particularly the 


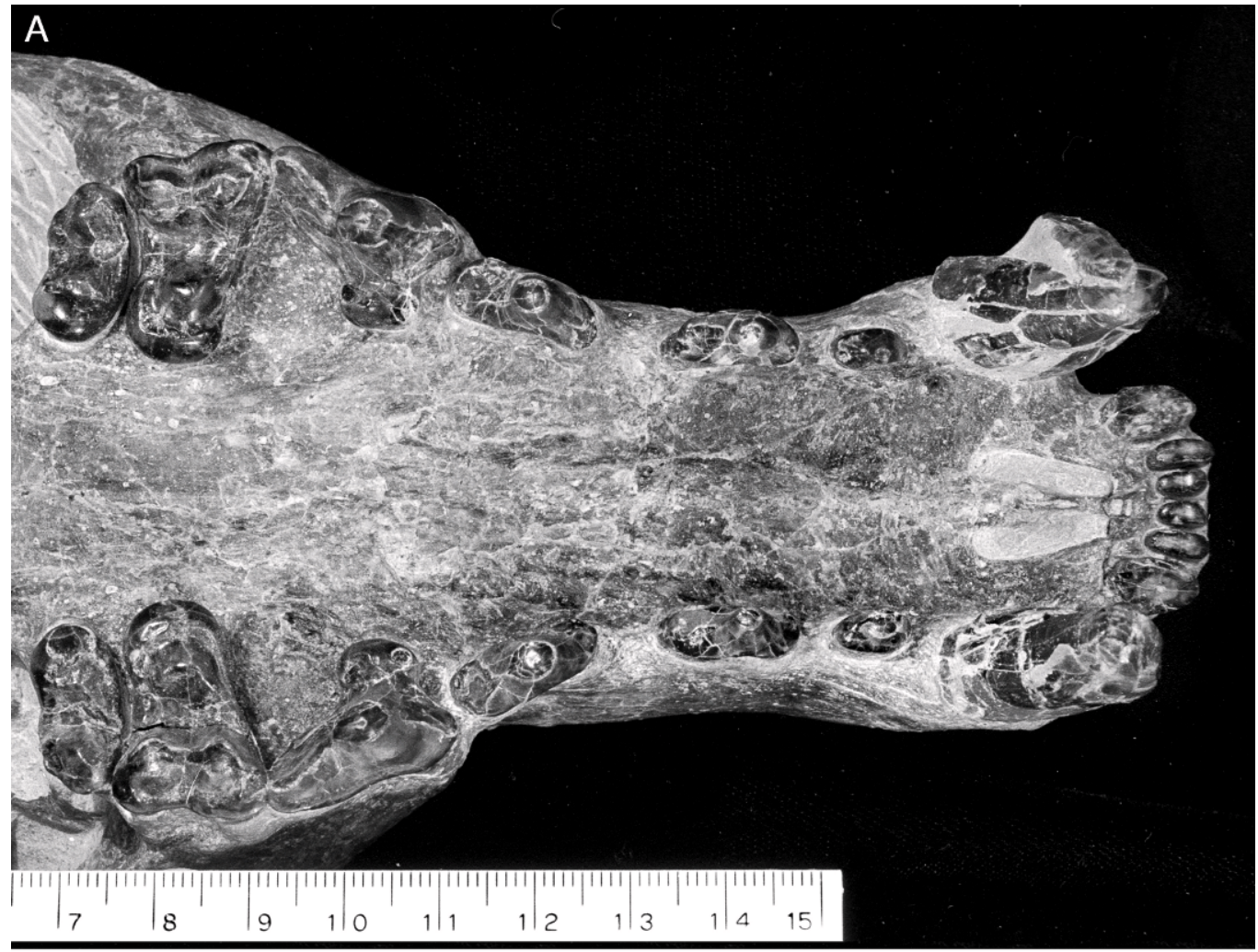

B

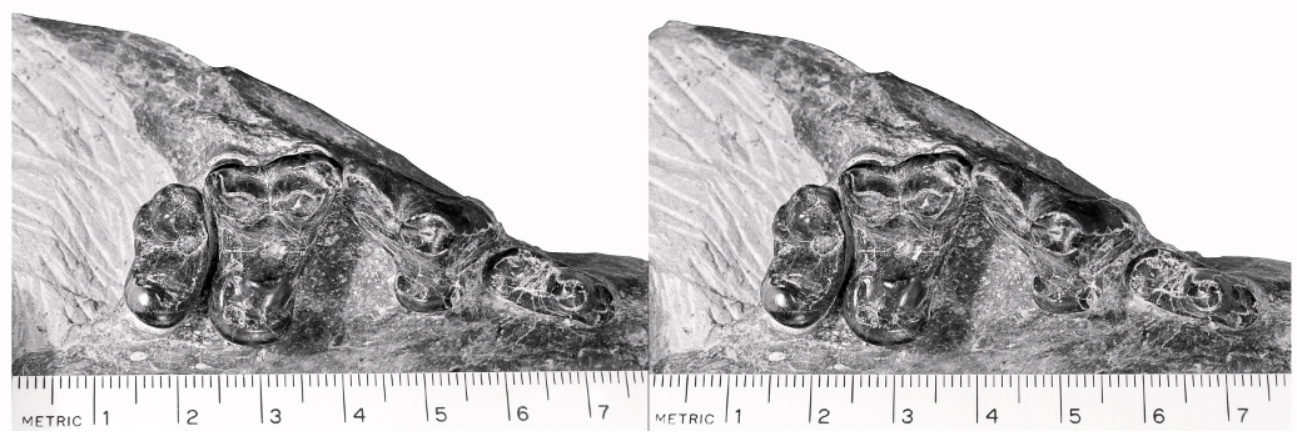

Fig. 17. Holotype palate and upper dentition (A, left and right I1-3, C, P1-M2; B, stereopair with right P3-M2) of Temnocyon fingeruti (NM 280/61), Balm Creek, Haystack Valley Member (revised), John Day Formation, Wheeler Co., Oregon. Note occlusal wear on P3-M2.

lower pair, reflect some damage, with the right lower canine beveled to a rounded stub suggesting it had been broken and smoothed by abrasion during life.

Lower incisors of temnocyonines rarely survive but are preserved in $T$. fingeruti. The i1-3 were quite small; there is little room $(\sim 1 \mathrm{~cm})$ for them between the canines. During feeding these incisors would have been of little use. A somewhat larger i3 (length, $6.4 \mathrm{~mm}$; width, $3.7 \mathrm{~mm}$ ) contrasts with i2 (length, $5.9 \mathrm{~mm}$; width, $2.9 \mathrm{~mm}$ ) represented only by a broken root. There is no evidence of il that if present was placed in front of and below i2.

The canine measures $\sim 19 \mathrm{~mm}$ in length, $\sim 10 \mathrm{~mm}$ in width, measured at the enamel base; the symphyseal width is narrow, only 


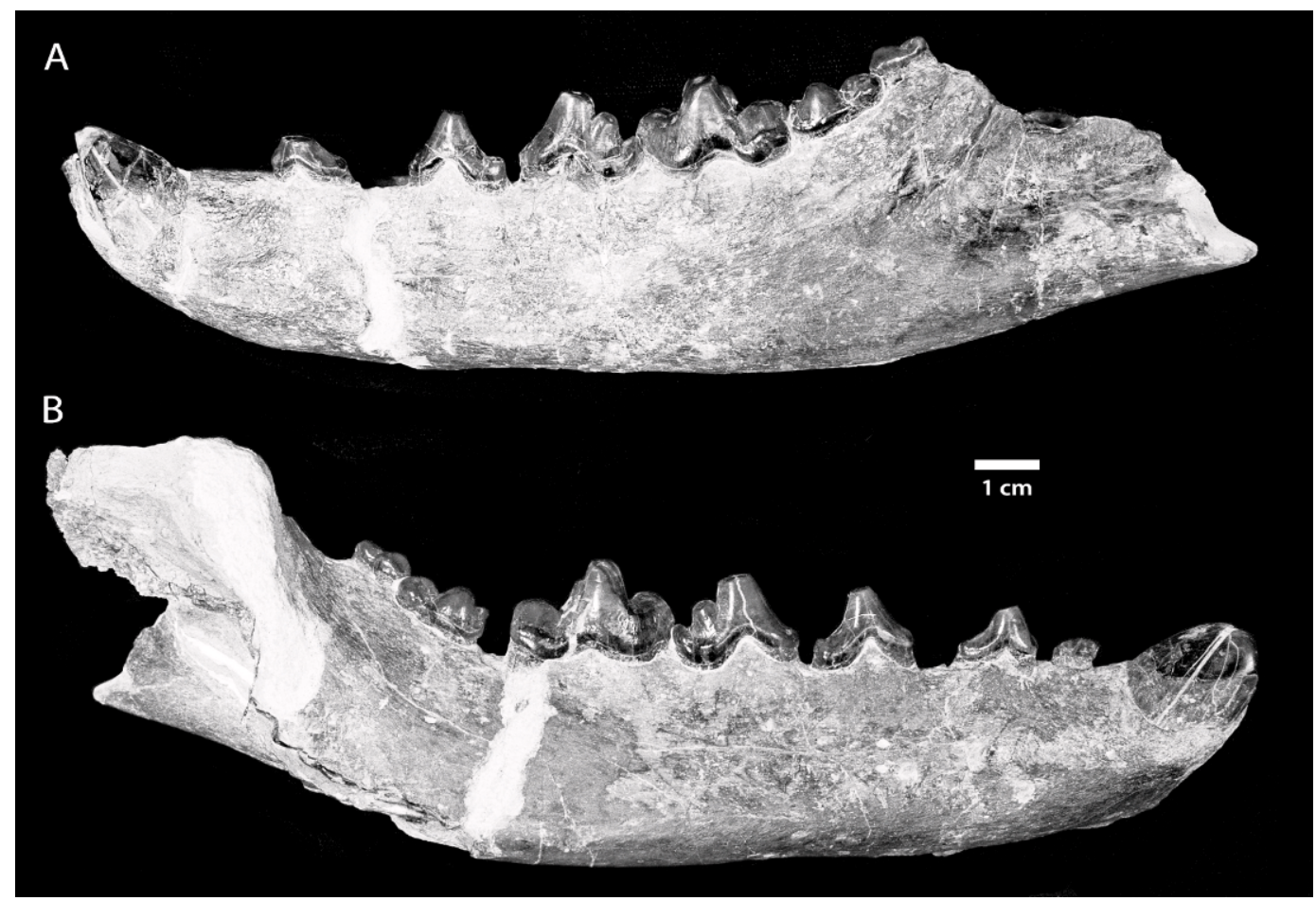

Fig. 18. Holotype left (A) and right (B) mandibles of Temnocyon fingeruti (NM 280/61), from Balm Creek, Haystack Valley Member (revised), John Day Formation, Wheeler Co., Oregon, both in labial view (left c, p2-m3; right c, p1-m3).

$30 \mathrm{~mm}$ measured across the base of the canines

The $\mathrm{p} 1$ is a small, peglike tooth (length, $6.9 \mathrm{~mm}$; width, $4.0 \mathrm{~mm}$ ) and is much worn.

The p2 (length, $12.1 \mathrm{~mm}$; width, $5.6 \mathrm{~mm}$ ) is much larger than $\mathrm{p} 1$ with its posterior slope somewhat longer than the anterior slope. A thin enamel ridge travels down both the anterior face to the anterolingual corner and the posterior face to the posterolabial cingulum. There are no accessory cusps.

The p3 (length, $15.3 \mathrm{~mm}$; width, $6.6 \mathrm{~mm}$ ) is a larger replica of $\mathrm{p} 2$ with a small posterior cingular shelf and a tiny basal cusp; the shelf is indented by wear on the left p3, less so on the right. There are no evident accessory cusps.

The p4 (length, $19.3 \mathrm{~mm}$; width, $8.7 \mathrm{~mm}$ ) is quite long relative to $\mathrm{p} 3$. There is a prominent labially situated posterior accessory cusp above a cingular shelf.

The principal cusps of p2-4 are worn flat by apical abrasion. The p2-3 are not tall relative to those in the large durophagous species of Mammacyon and Delotrochanter. They compare with p2-4 of $T$. altigenis but are much larger teeth.

The $\mathrm{m} 1$ (length, $24.7 \mathrm{~mm}$; width, $10.6 \mathrm{~mm}$ ) is a narrow, shearing carnassial that in this individual shows apical wear on trigonid and talonid cusps. Although the mandible of $T$. fingeruti and the wolf are of similar size, $\mathrm{m} 1$ is much smaller and the premolars larger in the beardog. The paraconid is mesially advanced to form a shear plane with the tall protoconid. A prominent metaconid is situated posterolingual to the protoconid. The talonid is filled by a large hypoconid; this cusp does not attain the height of the paraconid as in Mammacyon and Delotrochanter. A sinuous labial cingulum is present on the talonid but subdued on the trigonid. There is no entoconid yet a very narrow lingual talonid shelf occurs.

The elongate $\mathrm{m} 2$ (length, $14.8 \mathrm{~mm}$; width, $8.9 \mathrm{~mm}$ ) displays a low paraconid anterolingual to the taller, rather blunt, labial protoconid; a small metaconid is present. 

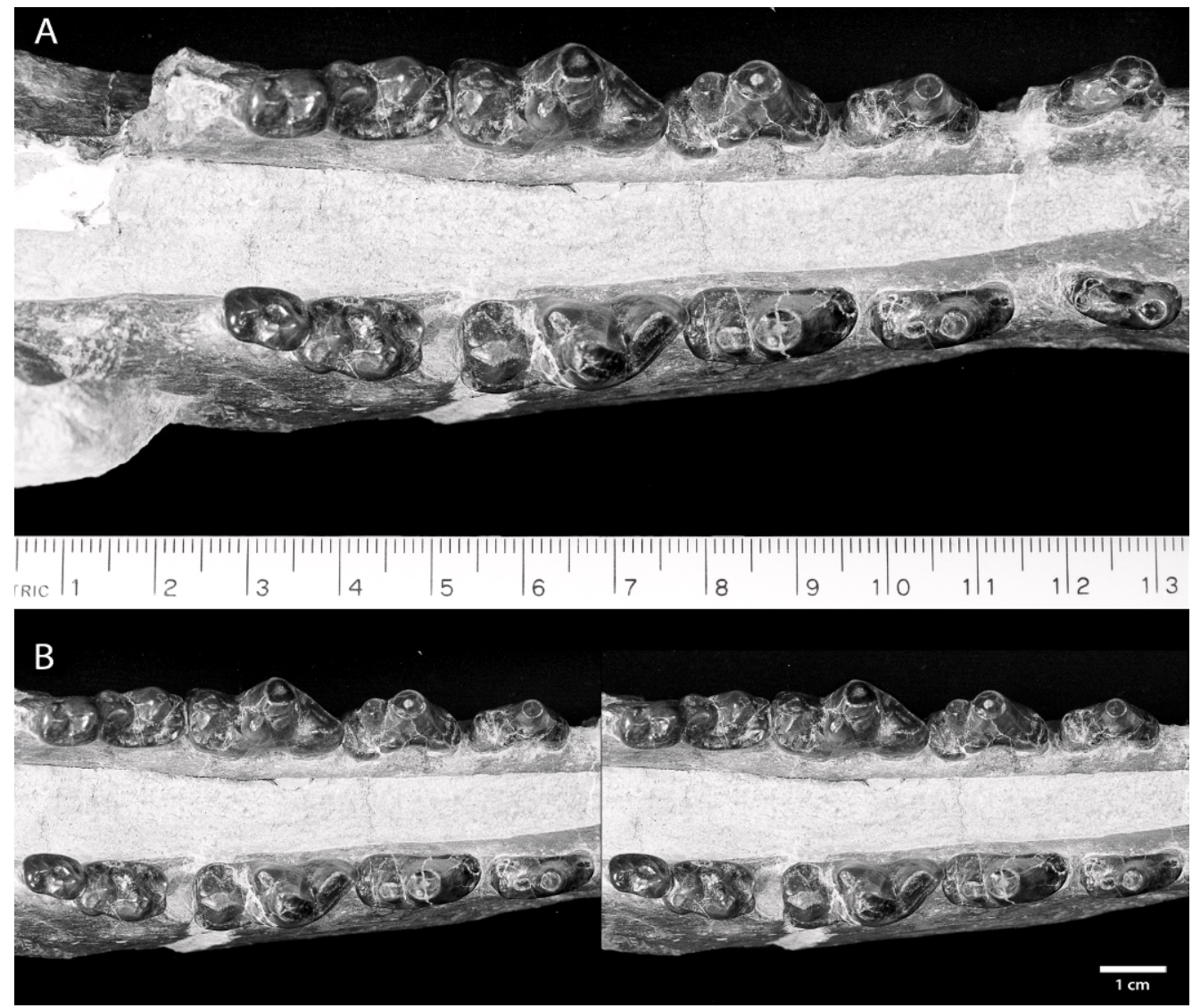

Fig. 19. Occlusal views of the mandibular dentition of the holotype of Temnocyon fingeruti (NM 280/ 61). Balm Creek, Haystack Valley Member (revised), John Day Formation, Wheeler Co., Oregon. A, left and right $\mathrm{p} 2-\mathrm{m} 3 ; \mathbf{B}$, stereopair of $\mathrm{p} 3-\mathrm{m} 3$. Note apical wear on premolars and carnassials.

The $\mathrm{m} 2$ talonid has a low, more centrally placed hypoconid; there is no entoconid.

The rectangular $\mathrm{m} 3$ (length, $9.8 \mathrm{~mm}$; width, $7.1 \mathrm{~mm}$ ) has a distinct trigonid somewhat elevated above the talonid. The protoconid is connected by a curvilinear ridge to a very small metaconid. A low hypoconid is the only talonid cusp. A cingulum surrounds both the $\mathrm{m} 2$ and $\mathrm{m} 3$.

The upper dentition is one of the most complete among temnocyonines. Both toothrows are intact: width of the transverse incisor row, $24.7 \mathrm{~mm}$; width between canines, $24.9 \mathrm{~mm}$; a narrow palate between $\mathrm{P} 1-2$ $(25.9 \mathrm{~mm})$ widens between P3-4 $(36.8 \mathrm{~mm})$, and reaches its maximum breadth $(59 \mathrm{~mm})$ between the embrasures of the P4-M1 pair. Palatal length measured from I1 along the midline to the posterior border of the palate is $13 \mathrm{~cm}$. Toothrow length from $\mathrm{P} 1-\mathrm{M} 2$ is $92.1 \mathrm{~mm}$ (P2-4, $58.7 \mathrm{~mm}$; M1-2, $27.3 \mathrm{~mm})$.

I1 (length, $5.5 \mathrm{~mm}$; width, $2.4 \mathrm{~mm}$ ) and $\mathrm{I} 2$ (length, $6.5 \mathrm{~mm}$; width, $2.7 \mathrm{~mm}$ ) are quite small, their apices worn flat. I3 is larger (length, $10.0 \mathrm{~mm}$; width, $5.4 \mathrm{~mm}$ ), heavily worn to a stub. There are short diastemata between $\mathrm{I} 3$ and the canine $(4.8 \mathrm{~mm})$, between C-P1 (3.6 mm), P1-2 (3.9 mm), P2-3 $(7.0 \mathrm{~mm})$, and P3-4 $(2.0 \mathrm{~mm})$. The small $\mathrm{I} 3$ of $T$. fingeruti contrasts in size with the huge I3s of D. oryktes and M. ferocior. Wear on the upper incisors of $T$. fingeruti shows that they occluded with i1-3 in a grasping or nipping role.

The canine (length, $17.3 \mathrm{~mm}$; width, $12.3 \mathrm{~mm}$, measured at enamel-dentine contact) is broken and worn, but it was more robust than a wolf canine from a similarly sized skull. 
$\mathrm{P} 1$ is a small peglike tooth (length, $7.6 \mathrm{~mm}$; width, $4.7 \mathrm{~mm}$ ) with a low vertical anterior face and a posterior slope lacking accessory cusps.

P2 is a larger triangular tooth (length, $13.4 \mathrm{~mm}$; width, $5.7 \mathrm{~mm}$ ) with a posterior slope slightly longer than the anterior face. There are no accessory cusps.

P3 is somewhat larger (length, $16.1 \mathrm{~mm}$; width, $7.0 \mathrm{~mm}$ ) than $\mathrm{P} 2$ with anterior and posterior faces as in $\mathrm{P} 2$ but having a broader heel than P2. Heavy wear on the posterior slope prevents identification of an accessory cusp but it was probably not present.

P4 is a short carnassial (length, $22.0 \mathrm{~mm}$; width, $15.4 \mathrm{~mm}$ ) with a prominent shear plane beveling the lingual faces of paracone and metastylar blade. A blunt protocone is situated directly lingual to the paracone. The posterior half of the protocone occluded against the $\mathrm{m} 1$ paraconid, evidenced by an elliptical wear facet, whereas the anterior face of the protocone was abraded by the $\mathrm{p} 4$ accessory cusp. Labial and lingual cingula are present but the anterior face of $\mathrm{P} 4$ and the adjacent heel of P3 were deeply worn by the principal and accessory cusps of the large p4.

The principal cusps of P1-3 exhibit flat apical wear facets. This blunting of cusps also occurred on the M1 paracone and metacone (with minor apical wear on M2 paracone) and the paracone and metastylar blade of P4. P4 wear included a shear component that extended posteriorly along the lingual faces of the M1 paracone-metacone and M2 paracone, evidenced by shear facets on these molars.

M1 (length, $17.1 \mathrm{~mm}$; width, $22.4 \mathrm{~mm}$ ) retains a plesiomorphic occlusal form little different from that of $T$. altigenis. The paracone and slightly smaller metacone are bordered by a labial cingulum with developed parastyle. The cingulum thins on the margins of $\mathrm{M} 1$ at the level of the protocone basin but then thickens to form a prominent posterolingual cingulum around the protocone, which does not equal the strongly swollen M1 lingual cingula observed for Mammacyon and Delotrochanter. The protocone is situated near the anterior margin of the tooth and is more sharp-crested and less bunodont. A preprotocrista runs anterolabially from the protocone to the anterior cingulum, and a short weak postprotocrista intersects the posterior cingulum.

M2 (length, $9.6 \mathrm{~mm}$; width, $17.4 \mathrm{~mm}$ ) is smaller and of a different form than M1; the anterior margin is convex, the posterior concave. The paracone is much larger than the low reduced metacone yet the lingual face of the two cusps forms a vertical shear plane. The labial and anterior sides of M2 are bordered by a cingulum that thickens to form a wide lingual swelling. A minute protocone situated in the center of an enamel flat retains an anterolabially directed preprotocrista and a tiny postprotocrista. The posterior margin of $\mathrm{M} 2$ is worn by the anterior face of $\mathrm{m} 3$ since there is no M3.

In $T$. fingeruti, crushing/shearing occlusion was accomplished by $\mathrm{p} 4-\mathrm{m} 2$ and P3-M2. More anterior teeth served to grasp the food and, via the action of the tongue, passed it back to the carnassials and molars.

DisCUSSION: The skull and mandibles of NM 280/61 represent one of the bestpreserved North American temnocyonines. The species preserves the most wolflike dentition of any temnocyonine and exhibits an attritional dental wear pattern much like that known for Canis lupus. Despite some crushing of the skull that collapsed the zygomata and shifted the rostrum laterally relative to the frontal region, the cranium, teeth, and basicranial anatomy are exceptional. NM 280/61 demonstrates that a plesiomorphic temnocyonine dental pattern continued in the Pacific Northwest to very near the Oligocene-Miocene boundary, currently placed at 23.03 Ma (Gradstein et al., 2004). Because NM 280/61 occurs only $\sim 20 \mathrm{~m}$ above a radiometric date of $23.8 \mathrm{Ma}$, its stratigraphic level places it in the latest Oligocene.

NM $280 / 61$ is the stratigraphically youngest John Day temnocyonine yet discovered; whether Great Plains early Miocene temnocyonines such as T. macrogenys and Delotrochanter existed in the Pacific Northwest is not known. Absence of early Miocene temnocyonines in the John Day beds could simply reflect the more limited representation of sediments of that age, which are often unfossilferous. However, large daphoenine and amphicyonine beardogs have been found in early Miocene John Day strata of early Hemingfordian age (Borocyon, Amphicyon: 
A

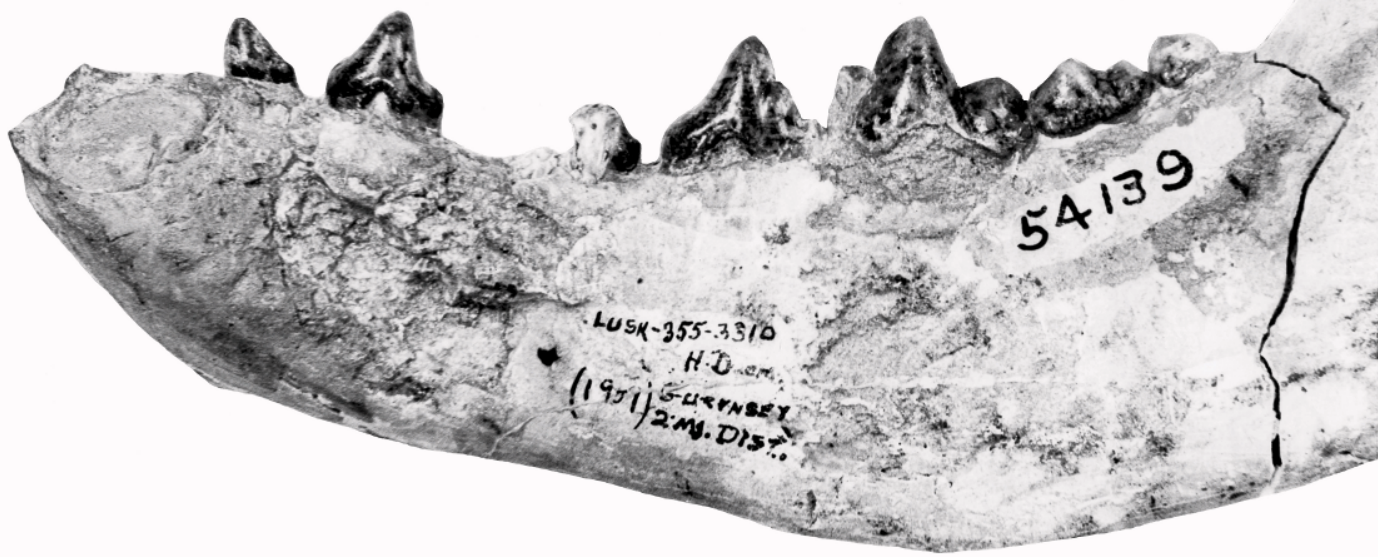

B

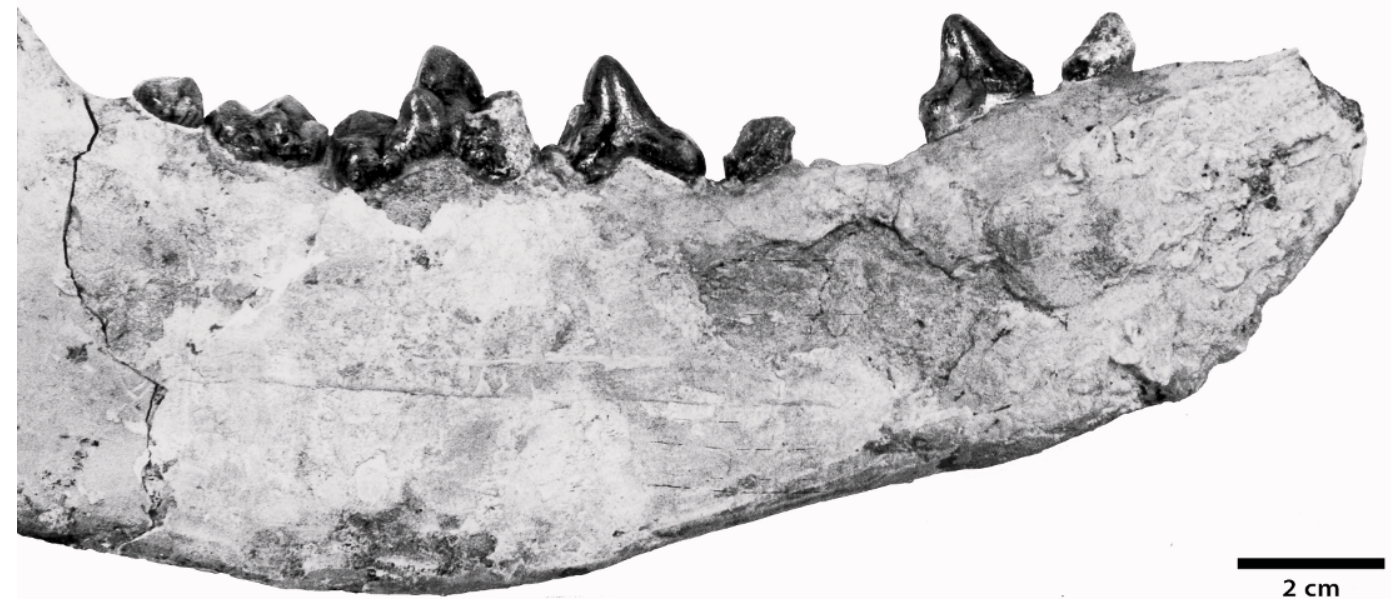

Fig. 20. Holotype mandible of Temnocyon macrogenys (F:AM 54139), with left p1-2, p4-m3 (pathologic p3), Anderson Ranch Formation, 2-Mile District, near Guernsey, Platte Co., Wyoming. This is the largest and youngest species of Temnocyon. A, labial and $\mathbf{B}$, lingual views.

Hunt and Stepleton, 2004), suggesting that they replaced the temnocyonines.

\section{Temnocyon macrogenys, new species}

Figures 20, 21

TYPE: F:AM 54139, left mandible with canine alveolus, p1-2, broken roots of pathologic p3, complete p4-m3, with most of the ascending ramus, articular condyle, and angular process preserved; also two partial metapodials and a fragmentary astragalus, from the Anderson Ranch Fm., "High Daemonelix zone," 2-Mile District of Charles Falkenbach, near Guernsey, Platte County, Wyoming, collected by C. Falkenbach, 1939.

Distribution: Latest Arikareean, Anderson Ranch Fm., Platte County, Wyoming.

ETYMOLOGY: From the Greek, macro, "long," and genys, "jaw," in reference to the large, elongate mandible of the terminal species of the Temnocyon lineage. 

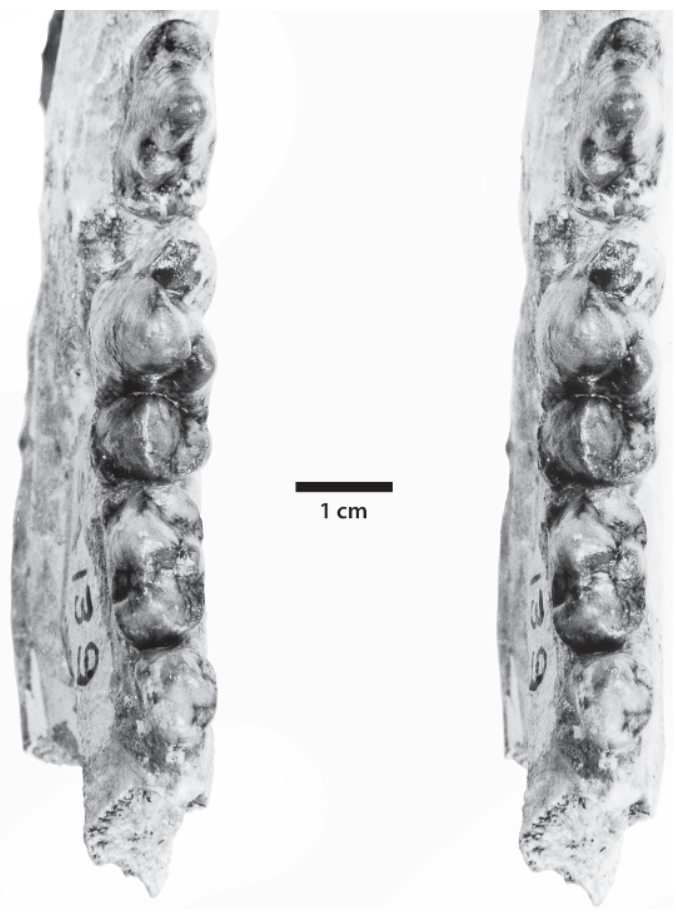

Fig. 21. Occlusal steropair of the holotype dentition ( $\mathrm{p} 4-\mathrm{m} 3)$ of Temnocyon macrogenys (F:AM 54139). Note presence of $\mathrm{m} 1$ and $\mathrm{m} 2$ metaconids.

DiAGNOSIS: Largest species of Temnocyon (basilar length, $\sim 30 \mathrm{~cm}$, table 7), and the only large temnocyonine in which the plesiomorphic cusp pattern of the lower teeth is retained: $\mathrm{ml}$ shear maintained; metaconids present on $\mathrm{m} 1-2 ; \mathrm{m} 1 / \mathrm{m} 2$ ratio, 1.62 , the lowest among Temnocyon species (table 6). Depth of mandible below $\mathrm{m} 1, \sim 50 \mathrm{~mm}$; below p2, $46 \mathrm{~mm}$. Mandibular dental measurements highest values among species of Temnocyon: length of toothrow, p1-m3, $135 \mathrm{~mm}$; lengths in $\mathrm{mm}$ of $\mathrm{p} 2,16.6$; $\mathrm{p} 4$, 22.1; m1, 28.2; m2, 17.4 (table 2).

RefErred Specimens: None.

DESCRIPTION: The nearly complete mandible lacks only part of the ventral border of the horizontal ramus and small sections from the labial and lingual sides. From the anterior limit of the jaw to the posterior face of the articular condyle is $\sim 26 \mathrm{~cm}$; this is a large carnivore with estimated basilar skull length of $30 \mathrm{~cm}$, thus the largest known temnocyonine. The articular condyle and angular process are in close proximity: from the center of the condyle to the process is $24 \mathrm{~mm}$. The distance from the tip of the coronoid process to the articular condyle is $77 \mathrm{~mm}$; from tip of coronoid to base of angular process is $106 \mathrm{~mm}$. The coronoid process is gently recurved posteriorly, with a shallow depression on its lingual face, and a moderately deep masseteric fossa on the buccal face. The articular condyle, mandibular foramen, and coronoid and angular processes are configured as in Canis lupus. Except for the much greater size and mandibular depth of the beardog, the form of the jaw is similar to that of the wolf. As in other temnocyonines, the anterior border of the ascending ramus is gently inclined so that m2-3 are slightly elevated and tilted forward on the edge of the ramus. Depth of the mandible below p2 is $46 \mathrm{~mm}$, beneath $\mathrm{m} 1$ $\sim 50 \mathrm{~mm}$, thus differing from Delotrochanter oryktes (ACM 4804) for which the same measurements, respectively, are 46 and $42 \mathrm{~mm}$, and for Mammacyon obtusidens (LACM 9194), 38 and $35 \mathrm{~mm}$. The mandibular depth beneath $\mathrm{m} 1$ for $T$. macrogenys is nearly twice that of an average wolf.

The mandibular symphysis was united by strong binding ligaments; there is no evidence of symphyseal fusion. The symphysis is widest near its posterior edge. The greatest anteroposterior length is $\sim 56 \mathrm{~mm}$; greatest dorsoventral height $\sim 37 \mathrm{~mm}$. The upper part of the symphysis (a rectangular area $22 \mathrm{~mm}$ in length, $11 \mathrm{~mm}$ in width) is smoother and less rugose than the ventral portion and represents the attachment of a compressible fibrocartilage pad like that described by Scapino (1981; Hunt, 2009). This indicates a flexible mandibular symphysis in T. macrogenys that facilitates close registration of the carnassials during the bite, as in the wolf (fig. 50F).

None of the lower incisors are preserved, however the extremely narrow space between the symphysis and canine alveolus shows that they would have been very small teeth.

The large canine alveolus measures $26.5 \mathrm{~mm}$ in length, $20.7 \mathrm{~mm}$ in width, with the long axis of the ellipse directed anteriorly and somewhat laterally. There is no intervening space between the canine and p1, their alveolar borders nearly in contact. 
Premolars (p2-4) are not crowded and are separated by $2-3 \mathrm{~mm}$ diastemata; they are not shortened or posteriorly widened as in Delotrochanter but are relatively narrow, tall yet robust, thus representing a scaled-up version of the premolars of $T$. percussor.

The single-rooted $\mathrm{p} 1$ measures $10.6 \mathrm{~mm}$ in length, $7.3 \mathrm{~mm}$ in width. It has the form of an oblate cone, anteriorly inclined, whose posterior face has been slightly depressed. There are no accessory or basal cusps. A fine enamel ridge runs from the principal cusp down the posterior slope to the cingulum.

The p2 measures $16.6 \mathrm{~mm}$ in length, $8.5 \mathrm{~mm}$ in width. In lateral view it approximates an equilateral triangle; there are thin anterior and posterior enamel ridges but no posterior accessory cusp. There is a moderately developed heel with a very small, low basal cusp.

The p3 is represented only by the posterior basal part of the tooth. The tooth was either abnormally triple-rooted, or there was a supernumerary single-rooted premolar inserted in front of a normal p3, this latter alternative more probable. The three alveoli occur in anteroposterior sequence, with a total alveolar length of $24.9 \mathrm{~mm}$. This is longer than $\mathrm{p} 4$. If a normal p3 was present, its length based on alveoli would be $\sim 18 \mathrm{~mm}$.

The p4 measures $22.1 \mathrm{~mm}$ in length, $10.4 \mathrm{~mm}$ in posterior width, $8.5 \mathrm{~mm}$ in anterior width. There is a prominent, labially placed posterior accessory cusp. The posterior border of the tooth is squared and produced as a shelf with a small basal cusp situated below the posterior accessory cusp. Height of p4 is much greater than the $\mathrm{m} 1$ paraconid, and I suspect that were p3 present, it also would exceed the paraconid in height.

Length of the premolar series (p1-4) is $\sim 82 \mathrm{~mm}$. However, because this measurement includes an abnormality (p3), it probably represents a maximum value for the species.

The $\mathrm{m} 1$ measures $28.2 \mathrm{~mm}$ in length and a talonid width of $13 \mathrm{~mm}$. Length of the trigonid is $\sim 20 \mathrm{~mm}$, the talonid $\sim 9.5 \mathrm{~mm}$, emphasizing that the trigonid dominates the tooth and the talonid is not enlarged. The metaconid is well developed; this is the only large temnocyonine in which the metaconid survives. The short talonid is dominated by a large, labially situated hypoconid, directly behind the protoconid. The labial face of the asymmetric hypoconid descends abruptly to the cingulum but the lingual face is more gradually inclined, sloping to the medial edge of the talonid (there is a small lingual talonid shelf). The apex of the hypoconid is an anteroposteriorly aligned ridge that curves posterolingually to become the posterior edge of the talonid. There is weak swelling on the lingual talonid shelf that appears to be a vestigial entoconid.

The $\mathrm{m} 2$ measures $17.4 \mathrm{~mm}$ in length, with a talonid width of $10.0 \mathrm{~mm}$, and a trigonid width of $10.4 \mathrm{~mm}$. The trigonid is low but higher than the talonid. There is an anterolabial cingulum; the large protoconid is the most prominent cusp and is connected by a smoothly curving ridge to the low, broad paraconid. The small knoblike metaconid lies lingual to the protoconid and is separated from it by a slight constriction. The hypoconid is the only talonid cusp and is labial in position. The talonid surface descends gradually from the hypoconid to the lingual margin.

The $\mathrm{m} 3$ measures $10.7 \mathrm{~mm}$ in length, $\sim 8.5 \mathrm{~mm}$ in width. The only prominent cusp is a conical protoconid, somewhat anterior to the center of the tooth, flanked lingually by weak enamel ridges descending to barely discernible vestigial paraconid and metaconid swellings. The talonid is much reduced and shows only a vestige of the hypoconid as a swelling on the posterior face of the protoconid.

The toothrow measures as follows: anterior border of canine alveolus to $\mathrm{m} 3,160.9 \mathrm{~mm}$; p1-m3 length, $135.0 \mathrm{~mm} ; \mathrm{p} 1-\mathrm{m} 2$ length, $125.4 \mathrm{~mm}$; m1-3 length, $55.5 \mathrm{~mm}$.

DISCUSSION: Temnocyon macrogenys is the largest North American species of the genus and it retains the metaconid on $\mathrm{m} 1-2$. The $\mathrm{m} 1$ remains a shearing carnassial (i.e., a tall, shearing trigonid and low talonid), and the premolars, although robust, are tall, relatively narrow teeth. These dental features indicate a large predatory carnivore with a more sectorial dentition than found in Mammacyon and Delotrochanter. When compared to the mandibular dentition of the wolf, the canine, premolars, and $\mathrm{m} 2-3$ of $T$. macrogenys are much larger whereas the carnassial 
is the same length, although a broader tooth. The beardog has incorporated the carnassial as an integral part of a crushing dental battery made up of premolars and posterior molars, while still retaining some shearing ability.

The dentition of $T$. macrogenys can be derived from that of $T$. percussor, and there is a particularly strong similarity in cusp pattern to AMNH 81005, Cook's type of the species. This opinion is supported by $\mathrm{m} 1-2$ structure and similar $\mathrm{m} 1 / \mathrm{m} 2$ length ratios of 1.62 and 1.69 in AMNH 81005 and F:AM 54139 (table 6). Temnocyon macrogenys seems the lineal descendant of $T$. percussor from the Niobrara River valley at Agate National Monument.

Temnocyon macrogenys (F:AM 54139) comes from the Anderson Ranch beds about 2 mi south of Guernsey, Wyoming; in this district and throughout northwest Nebraska and southeast Wyoming the formation includes widespread flat geomorphic surfaces representing level, early Miocene grasslands (Hunt, 1990). These surfaces are densely packed with fine root casts (rhizoliths) and are cemented by silica derived from diagenesis of volcanic glass shards and unstable minerals in these fine-grained tuffaceous sandstones. Charles Falkenbach, who collected the mandible of $T$. macrogenys, used the term "High Daemonelix zone" for these silica-cemented geomorphic surfaces, although they have no relationship to rodent burrows first termed "Daimonelix" many years previously by E.H. Barbour (1892). Evidence that Falkenbach in fact collected the mandible from one of the geomorphic surfaces of the Anderson Ranch Formation can be seen in the sediment adhering to the mandible that includes the small siliceous rootlets and pale reddish-brown sand typical of these grassland surfaces. Temnocyon macrogenys was found within one of these siliceous paleosols. Fossil mammals in the Childs Frick collection from the "High Daemonelix" level of the Guernsey collecting district are similar to mammals of the Niobrara Canyon local fauna from the stratotype area of the Anderson Ranch Formation (Niobrara Canyon, Sioux County, Nebraska) and establish the age of $T$. macrogenys as latest Arikareean.
Rudiocyon, new genus

Type Species: Rudiocyon amplidens, new species.

INCLUDED SPECIES: Only the type species.

DISTRIBUTION: Early or mid-Arikareean of Oregon.

ETYMOLOGY: From the latinized Greek, kyon, for "dog," and for Rudio Creek, the locality in north-central Oregon where the holotype was discovered.

Diagnosis: Differs from Temnocyon by absence of the $\mathrm{m} 1$ metaconid; from Mammacyon and Delotrochanter by a small, short $\mathrm{m} 2$ relative to $\mathrm{m} 1$ (table 6 , ratio $\mathrm{E} / \mathrm{F} \sim 1.9$ ); and from Delotrochanter by a narrow, compressed p4 (not posteriorly broad). See tables $1-2$.

Discussion: The genus includes a single species represented by a partial mandible with massive teeth $(\mathrm{p} 4-\mathrm{m} 2)$ that define the taxon. A small $\mathrm{m} 2$ in Rudiocyon (table 6, ratio $\mathrm{E} / \mathrm{F}, \sim 1.9$ ) precludes assignment to Mammacyon (table 6, ratio E/F, 1.57-1.6), a genus defined by a large, elongate $\mathrm{m} 2$. Nonetheless, the genus may have evolved from an earlier less derived species that gave rise to both Mammacyon and Rudiocyon. Similarity to cheek teeth of $T$. ferox suggests a possible alternative derivation for $R$. amplidens. Rudiocyon amplidens is considered somewhat younger than the age of the Deep Creek tuff $(27.9 \pm 0.57 \mathrm{Ma})$; the probable site of collection occurs $10-15 \mathrm{~m}$ above a local ash on Rudio Creek identified as a correlative of the Deep Creek tuff.

Rudiocyon amplidens, new species Figures 22, 23

Temnocyon large species: Stock, 1933b: 36.

TYPE: LACM 480, partial left mandible with $\mathrm{p} 4-\mathrm{m} 2$, right $\mathrm{m} 2$, right $\mathrm{p} 4$ protocone, and a partial braincase, from the John Day Formation, CIT loc. $31,1.5$ to $2 \mathrm{mi}$ south of the Johnson Ranch [now Tom Campbell Ranch] at the mouth of Rudio Creek, from gray beds exposed on the east side of Rudio Creek, south of the North Fork of the John Day River, Grant County, Oregon, collected by E.L. Furlong $(\sim 1930)$.

DisTRIBUTION: Early or mid-Arikareean, John Day Formation, Grant County, Oregon. 

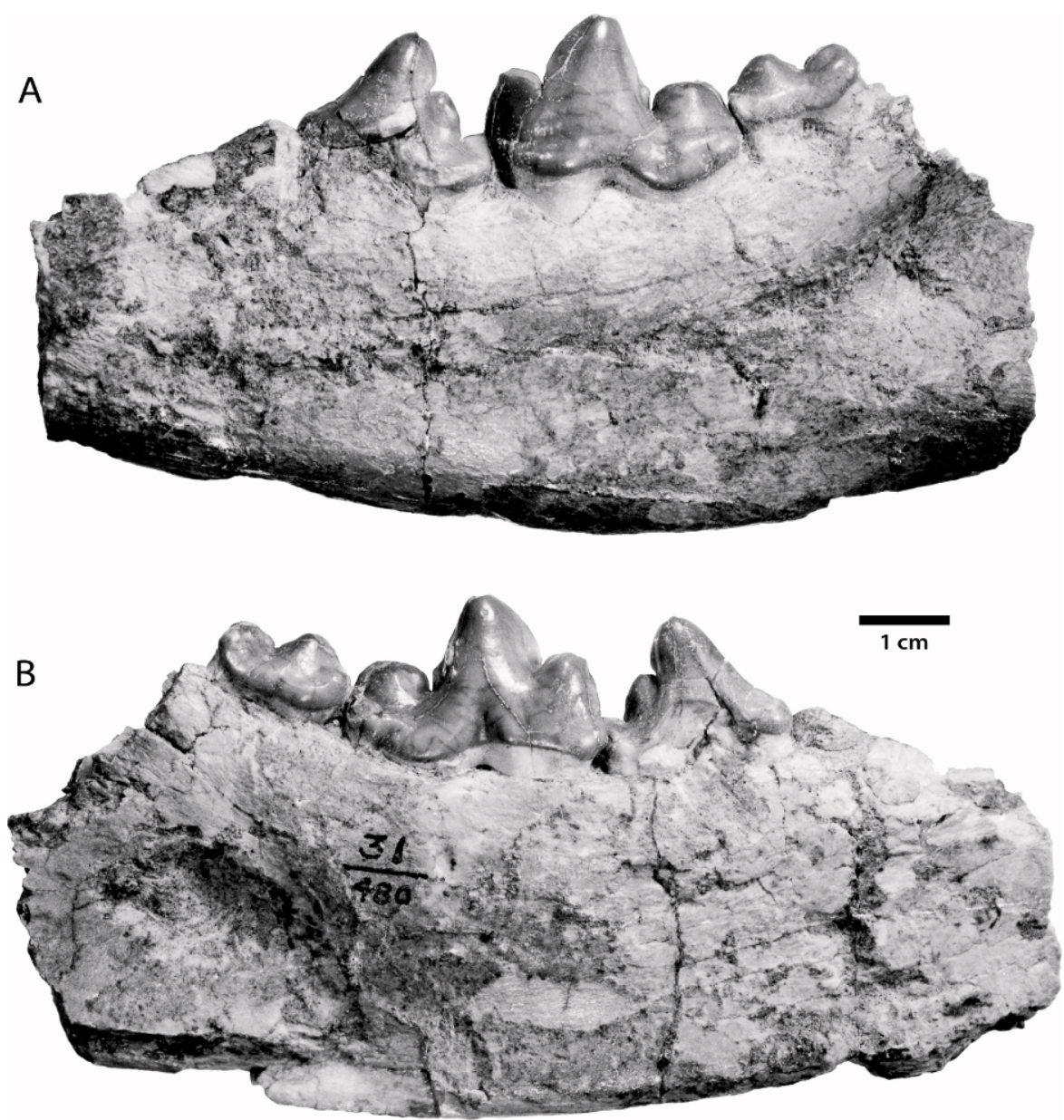

Fig. 22. Holotype mandible of Rudiocyon amplidens (LACM 480), with left p4-m2, probably from $1.5 \mathrm{mi}$ south of the Johnson Ranch, from gray beds exposed on the east side of Rudio Creek, Kimberly Member, John Day Formation, Grant Co., Oregon. A, labial and B, lingual views. This is the largest John Day temnocyonine.

ETYMOLOGY: From the Latin, amplus, "large," and dens, "tooth," in reference to the robust teeth in this species, the largest of the John Day temnocyonine beardogs.

DiAgNosis: Largest John Day temnocyonine species, $\mathrm{m} 1$ length, $28.7 \mathrm{~mm}, \mathrm{~m} 1$ without metaconid thereby distinguished from Temnocyon; $\mathrm{m} 1$ hypoconid centrally placed on talonid, no entoconid; m1 labial cingulum sinuous, not straight as in Delotrochanter; p4 narrower than in Delotrochanter and Mammacyon ferocior but similar in this respect to M. obtusidens, T. ferox, and T. macrogenys. Relatively short $\mathrm{m} 2(\mathrm{E} / \mathrm{F}$ ratio, $\sim 1.9$, the highest value for any temnocyonine), not elongate as in Mammacyon, with blunt protoconid and hypoconid the principal cusps, aligned one behind the other along the midline of $\mathrm{m} 2$; small $\mathrm{m} 2$ paraconid occupies anterointernal corner; no metaconid or entoconid. Mandible deep below m1-2 (43 $\mathrm{mm})$, more so than in any other John Day temnocyonine.

RefERred SPECIMENS: None.

DESCRIPTION: The partial mandible (length, $\sim 114 \mathrm{~mm}$ ) retains $\mathrm{p} 4-\mathrm{m} 2$. The dorsal border of the jaw is damaged anterior to $\mathrm{p} 4$ but has alveoli for p3. Depth of mandible: $\sim 36 \mathrm{~mm}$ below $\mathrm{p} 3 ; 37 \mathrm{~mm}$ below the posterior root of $\mathrm{p} 4 ; 40 \mathrm{~mm}$ below the $\mathrm{m} 1$ 


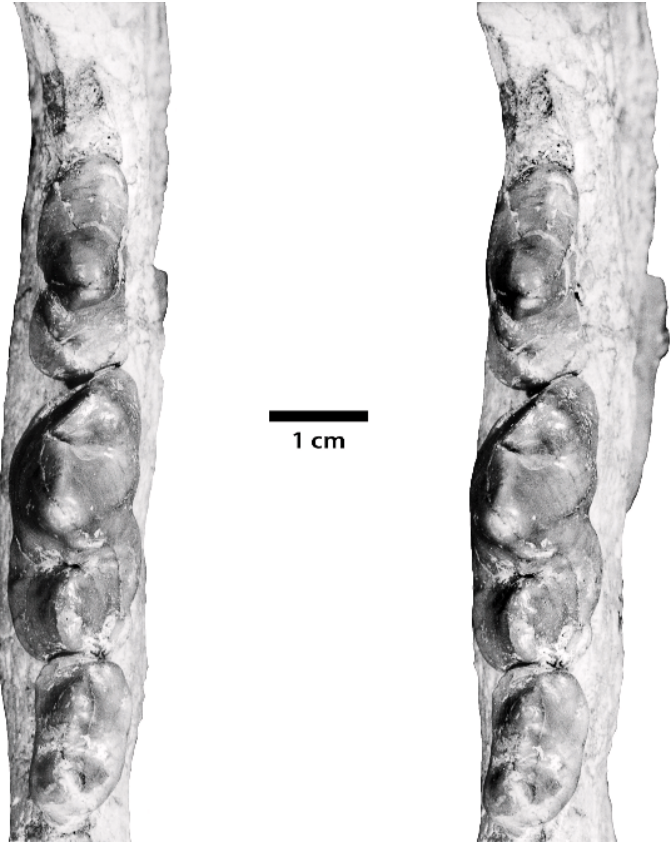

Fig. 23. Occlusal stereopair of the holotype dentition (p4-m2) of Rudiocyon amplidens (LACM 480). Note absence of $\mathrm{m} 1$ and $\mathrm{m} 2$ metaconids and narrow compressed $\mathrm{p} 4$.

protoconid; and $43 \mathrm{~mm}$ below the anterior root of $\mathrm{m} 2$; the anterior masseteric fossa is present below the $\mathrm{m} 2$ talonid.

The $\mathrm{p} 4$ is narrow and similar in form to the p4 of Mammacyon obtusidens and Eyerman's type of $T$. ferox. The tooth is tall, the principal cusp $5 \mathrm{~mm}$ higher than the $\mathrm{m} 1$ paraconid. A fine enamel ridge on the anterior slope intersects the cingulum. A large labially situated posterior accessory cusp occurs above a small basal cusp. The anterior $(8.1 \mathrm{~mm})$ and posterior $(10.0 \mathrm{~mm})$ widths of p4 demonstrate a narrow $\mathrm{p} 4$ in Rudiocyon, which compares with these $\mathrm{p} 4$ widths of $M$. obtusidens $(7.4,9.7 \mathrm{~mm})$.

The $\mathrm{m} 1$ measures $28.7 \mathrm{~mm}$ in length, $13.2 \mathrm{~mm}$ in width at the base of the protoconid, $11.8 \mathrm{~mm}$ in talonid width, and lacks both a metaconid and entoconid. This is a massive carnassial, the protoconid much taller than the flanking paraconid and hypoconid. The hypoconid is as large as the paraconid and nearly equal in height, indicating the important role played by this pestlelike cusp in crushing. It occupies the center of the talonid, rather than the more labial placement seen in $T$. macrogenys. Anterior to the blunt hypoconid is a small vertical swelling of enamel on the posterior face of the protoconid. It measures $2.4 \mathrm{~mm}$ in width, $3.7 \mathrm{~mm}$ in height. Above and lingual to this swelling is a thin enamel ridge also situated on the posterior face of the protoconid. This is not a vestige of the metaconid but rather a remnant of a thin protoconid crest that in a plesiomophic $\mathrm{m} 1$ forms an incisure with the metaconid. It remains as a low narrow ridge in temnocyonines that have recently lost the metaconid, and is absent in species that have long been without this cusp. A sinuous (not straight as in Delotrochanter) cingulum surrounds the base of the tooth on the labial side and on the posterior half of the lingual side, but is indistinct on the lingual side of the trigonid. The lingual cingulum medial to the hypoconid contains a small notch.

The $\mathrm{m} 2$ is not elongate and narrows posteriorly, differing from Mammacyon: greatest trigonid width is $9.1 \mathrm{~mm}$, talonid width $8.4 \mathrm{~mm}$. The protoconid and smaller hypoconid, both blunt crushing cusps, are anteroposteriorly aligned with the $\mathrm{m} 1$ hypoconid. There is variation in the cusp placement of right and left $\mathrm{m} 2$ : the left $\mathrm{m} 2$ shows these two cusps centrally placed, whereas the right $\mathrm{m} 2$ shows them closer to the labial margin - it is possible that the latter tooth represents another individual. There is no $\mathrm{m} 2$ metaconid or entoconid. However, as in other large temnocyonine species, the anterolabial cingulum of the $\mathrm{m} 2$ trigonid is protuberant.

The right $\mathrm{P} 4$ protocone, the only remnant of the upper dentition, is similar in size and blunt conical form to that cusp in large species of Mammacyon. It measures $10.9 \mathrm{~mm}$ in anteroposterior width and compares closely with the protocone of ACM 34 41, the holotype of $M$. obtusidens. The protocone was encircled by a thickened cingulum.

DISCUSSION: Rudiocyon amplidens is a carnivore about the same size as Mammacyon ferocior or Delotrochanter oryktes, and is somewhat smaller than T. macrogenys. Thus, the species was one of the larger North American temnocyonines. The $\mathrm{m} 1 / \mathrm{m} 2$ length ratio of $R$. amplidens $(\sim 1.9)$ distinguishes it 
from M. ferocior (1.6), T. macrogenys ( $\sim 1.6)$, and the species of Delotrochanter $(\sim 1.6-1.7)$. In addition, its $\mathrm{p} 4$ is not as broad as the $M$. ferocior $\mathrm{p} 4$, nor does it have an $\mathrm{m} 1$ metaconid as in T. macrogenys. Delotrochanter oryktes and $D$. major also differ from $R$. amplidens in having a short, posteriorly wide p4 in contrast to the more narrow p4 of Rudiocyon.

In its $\mathrm{p} 4-\mathrm{m} 1$, in the form of the mandible, but particularly the $\mathrm{P} 4$ protocone, $R$. amplidens shows an evident similarity to Mammacyon. However, M. obtusidens has a longer $\mathrm{m} 2$ and a much smaller $\mathrm{m} 1$ than $R$. amplidens, and $M$. ferocior has a boader $\mathrm{p} 4$ and a much more elongate $\mathrm{m} 2$.

Mammacyon mandibular dentitions are distinguished by the elongate $\mathrm{m} 2$ and are known only from the Arikareean of the Great Plains. Because the only evidence of Mammacyon in the John Day basin is a maxilla (LACM 5386) from Haystack Valley, the nature of $\mathrm{m} 2$ in that species cannot be determined. $T$. altigenis is the only temnocyonine where $\mathrm{m} 2$ variation can be estimated and the fossils are not from a single stratigraphic horizon. The variation in $\mathrm{m} 2$ length in the $T$. altigenis sample indicates that the hypodigm has a range of 1.67-1.83 for the $\mathrm{m} 1 / \mathrm{m} 2$ length ratio (table 6). Yet the difference between the $\mathrm{m} 1 / \mathrm{m} 2$ length ratio of $R$. amplidens (1.89) and those of M. obtusidens-M. ferocior (1.57-1.6) exceeds that range. LACM 480 cannot be included in Mammacyon unless the genus is more broadly defined to include more pronounced variation in dental proportions, particularly with regard to $\mathrm{m} 2$.

A partial braincase accompanies the lower jaw and presumably was collected with it. It is remarkable how similar most temnocyonine skulls are in braincase width, a proxy for volume of the cranial cavity (table 7): five of the larger species all measure from 62 to $67 \mathrm{~mm}, R$. amplidens among them. The braincase of LACM 480 cannot be compared with temnocyonines with inflated frontal paranasal sinuses because the frontal region anterior to the braincase was not preserved.

The $\mathrm{p} 4-\mathrm{m} 2$ of Rudiocyon shows similarities to these same teeth in T. ferox. These include the squared posterior heel and cusp pattern of $\mathrm{p} 4$; the form of $\mathrm{m} 1$, which suggests that the reduced metaconid in $T$. ferox could have finally been lost in LACM 480; and the occlusal form of the relatively short $\mathrm{m} 2$ in both species. LACM 480 came from gray tuffaceous sandstone of the Kimberly Member along Rudio Creek a short distance above a supposed correlative ash of the Deep Creek tuff, dated elsewhere at $\sim 27.9 \mathrm{Ma}$. If this age for the Rudio Creek ash is correct, it would appear to be a much older carnivore than $T$. ferox, which is a smaller and possibly much younger species, and in this case an ancestordescendant relationship would be unlikely. However, if the correlative ash along Rudio Creek, identified by Fisher (Fisher and Rensberger, 1972: 14) as the Deep Creek tuff in fact represents a much younger undated ash-fall event, then the relative ages of $R$. amplidens and T. ferox are unspecified.

\section{Mammacyon Loomis, 1936}

TyPe SPECIES: Mammacyon obtusidens Loomis, 1936.

INCLUDED SPECIES: Mammacyon obtusidens Loomis, 1936; M. ferocior, new species.

Distribution: Early Arikareean of Oregon; early to mid-Arikareean of South Dakota; mid- or early late Arikareean of southeastern Wyoming.

Diagnosis: Distinguished from Temnocyon by absence of the $\mathrm{m} 1$ metaconid and different $\mathrm{M} 1$ and $\mathrm{P} 4$ proportions (table 6, ratios A/B, C/D); from Temnocyon, Rudiocyon, and Delotrochanter by a more elongate m2 (ratio E/F); and from Delotrochanter by M1 proportions (ratio A/B), by P3/p3 without posterior accessory cusp, by $\mathrm{p} 4$ with labially (not centrally) placed posterior accessory cusp, by a sinuous (not straight) labial cingulum on $\mathrm{m} 1$, and by proportions of p2-4 (short broad p2-3 in Delotrochanter, longer narrow p2-3 in Mammacyon). Mammacyon evolves the most extreme form of crushing P4-M1 of the subfamily. See tables $1-5$.

Discussion: The genus includes temnocyonines that abandon the plesiomorphic form of the cheek teeth and adopt a durophagous crushing dentition involving not only premolars but also the carnassialmolar battery. The large Mammacyon ferocior apparently evolved from the somewhat smaller $M$. obtusidens, both species repre- 
sented by skulls and some postcrania. The genus seems restricted to the Oligocene and ranges in time from the early to midArikareean, possibly continuing into the early late Arikareean but is not known in early Miocene faunas.

Mammacyon obtusidens Loomis, 1936 Figures 24-27, 67

Mammacyon obtusidens Loomis, 1936: 44 47, fig. 1. Mammacyon obtusidens: Macdonald, 1963: 219. Mammacyon obtusidens: Macdonald, 1970: 63. Temnocyon percussor: Macdonald, 1970: 61-62.

TYPE: As given in Loomis (1936: 44), but modified as follows: skull with well-preserved basicranium and dentition, axis vertebra, humerus, radius, both ulnae, four metapodials, tibia, partial scapula, two isolated canines, and an astragalus (ACM 34 41), found "in the summer of 1934 in the lower Miocene Rosebud formation on Porcupine Creek, South Dakota, just above the concretionary layer, or about 100 feet above the base of the beds." Additional information is found in Macdonald (1963: 157, 219) as to the type locality, "Amherst College Museum Rosebud 2, Monroe Creek Formation or Harrison Formation." The locality producing the holotype is in the lower Arikaree Group and is of Oligocene age.

DISTRIBUTION: Early to mid-Arikareean: lower Arikaree Group, Wounded Knee area, ACM Rosebud 2, Shannon County, South Dakota; lower Arikaree Group, LACM loc. 1964, Wounded Knee area, Shannon County, South Dakota; John Day Formation, CIT loc. 29, Wheeler County, Oregon.

Diagnosis: Distinguished from $M$. ferocior by smaller size of cranium (basilar length: M. obtusidens, $25.5 \mathrm{~cm}$; M. ferocior, $28 \mathrm{~cm}$, table 7), postcrania, and mandibular dentition (toothrow length, $\sim 98$ vs. $120 \mathrm{~mm}$, table 2), including $\mathrm{m} 1-\mathrm{m} 2$ lengths (M. obtusidens, 24.4, $15.5 \mathrm{~mm}$; M. ferocior, 27.7, $17.3 \mathrm{~mm}$ ) and by a much narrower p3-4 width in $M$. obtusidens. The two species differ in P4 and M1 dental ratios $\mathrm{A} / \mathrm{B}$ and $\mathrm{C} / \mathrm{D}$ (table 6 ).

REFERRED SPECIMENS: (1) LACM 9194, left mandible with canine, p1 alveolus, p2$\mathrm{m} 2, \mathrm{~m} 3$ alveolus, isolated right lower canine, right mandibular fragment with $\mathrm{m} 1$ talonid and $\mathrm{m} 2$ roots, right mandibular fragment with anterior root of $\mathrm{p} 4$ and its posterior alveolus, from LACM loc. 1964, Wounded Knee area, "Monroe Creek Formation," NW4, NW4, sec. 3, T39N, R42W, Shannon County, South Dakota, collected by $\mathrm{H}$. Garbani, June 30, 1964; (2) LACM 5386, partial maxilla with P4-M1, from the John Day Formation, CIT loc. 29, "from a large exposure of green beds on north side of Haystack Valley, Wheeler Co., Oregon."

DESCRIPTION: ACM 34 41-Loomis (1936) only briefly described the upper dentition of this fine skull, and did not mention the wellpreserved basicranium. It is one of only three temnocyonine skulls in which some part of the auditory bulla is preserved, in this case a crescentic anterior portion formed largely or entirely by the ectotympanic (see Basicranial Anatomy).

The left maxilla retains the canine, $\mathrm{P} 2-\mathrm{M} 2$; on the right, I3, P2-M2. An alveolus for a single-rooted $\mathrm{P} 1$ is present on the right, but other alveoli are distorted.

The upper canine, blunted at the tip from wear, measures $\sim 45 \mathrm{~mm}$ in length from the tip to the enamel base on the labial face. There is no evident wear groove produced by the lower canine. At the enamel base the canine measures $22.1 \mathrm{~mm}$ in anteroposterior length and $14.1 \mathrm{~mm}$ in width.

The alveolus of P1 measures $8.7 \mathrm{~mm}$ in length, 5.4 in width, and has been slightly distorted by crushing.

P2 measures $18.5 \mathrm{~mm}$ in length, the width anterior to the main cusp is $6.8 \mathrm{~mm}$, and the width posterior to this cusp is $7.7 \mathrm{~mm}$. A long posterior slope descends from the main cusp in contrast to the shorter anterior face, both devoid of accessory or cingular cusps. On all upper teeth the cingula are slightly developed basal swellings without sharp or distinct edges. On both P2 and P3 a weak, thin, enamel ridge runs from the main cusp anterolinguad to the cingulum on the anterior slope, and a similar ridge on the posterior slope runs to the posterolabial cingulum.

$\mathrm{P} 3$ is an enlarged version of P2, measuring $20.3 \mathrm{~mm}$ in length; width anterior to main cusp, $8.2 \mathrm{~mm}$; width posterior to this cusp, $10.6 \mathrm{~mm}$. P3 is somewhat more robust than P2 and much more expanded at its base posterior to the main cusp. There are no accessory or cingular cusps. The anterior and 


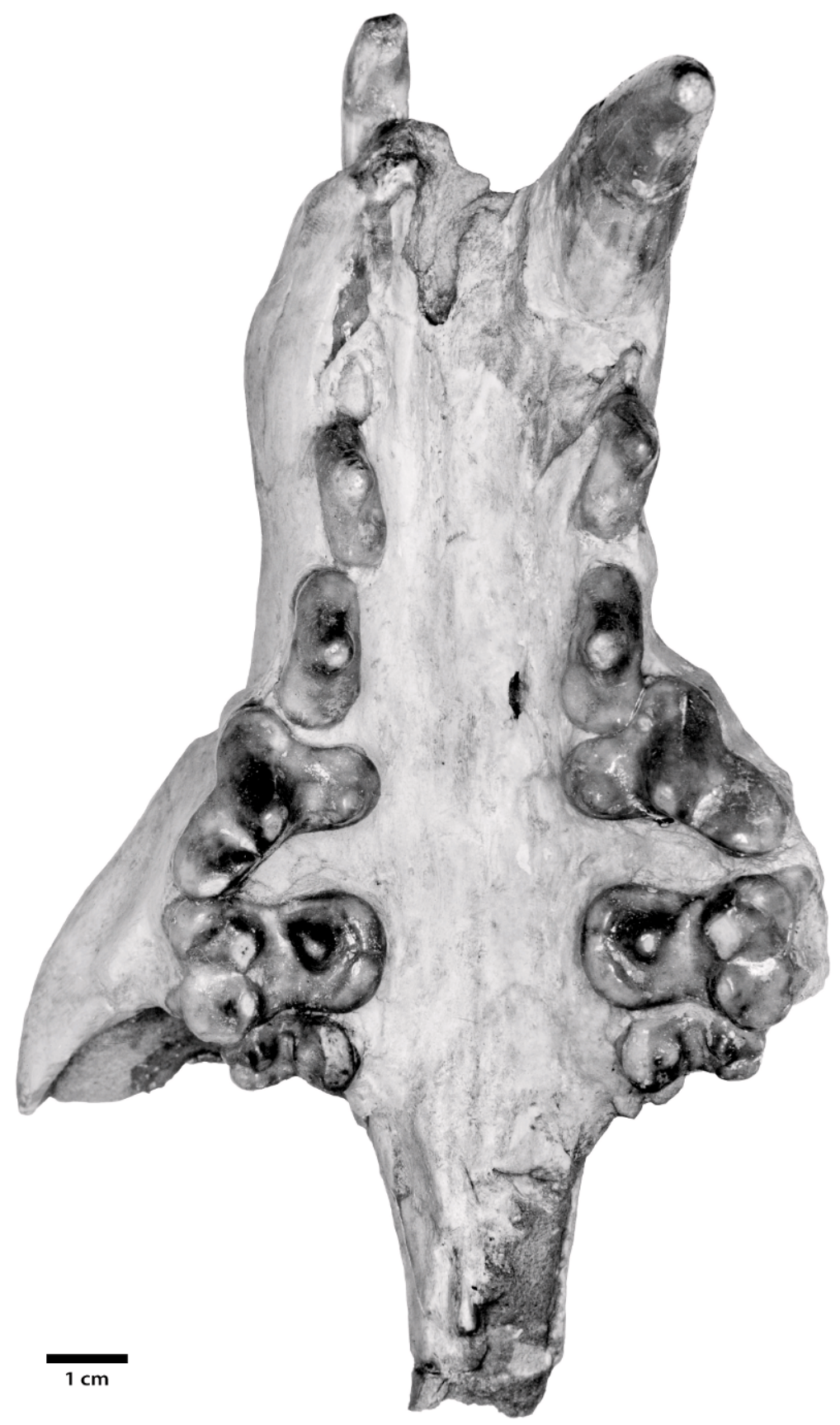

Fig. 24. Holotype rostrum of Mammacyon obtusidens (ACM 34-41) with right I3, P2-M2, left C, P2M2, from the lower Arikaree Group, Porcupine Creek, Shannon Co., South Dakota. This is one of the earliest durophagous temnocyonines. Focal point of the crushing dentition is centered on the P4-M1 pair. See figs. $67,69$. 

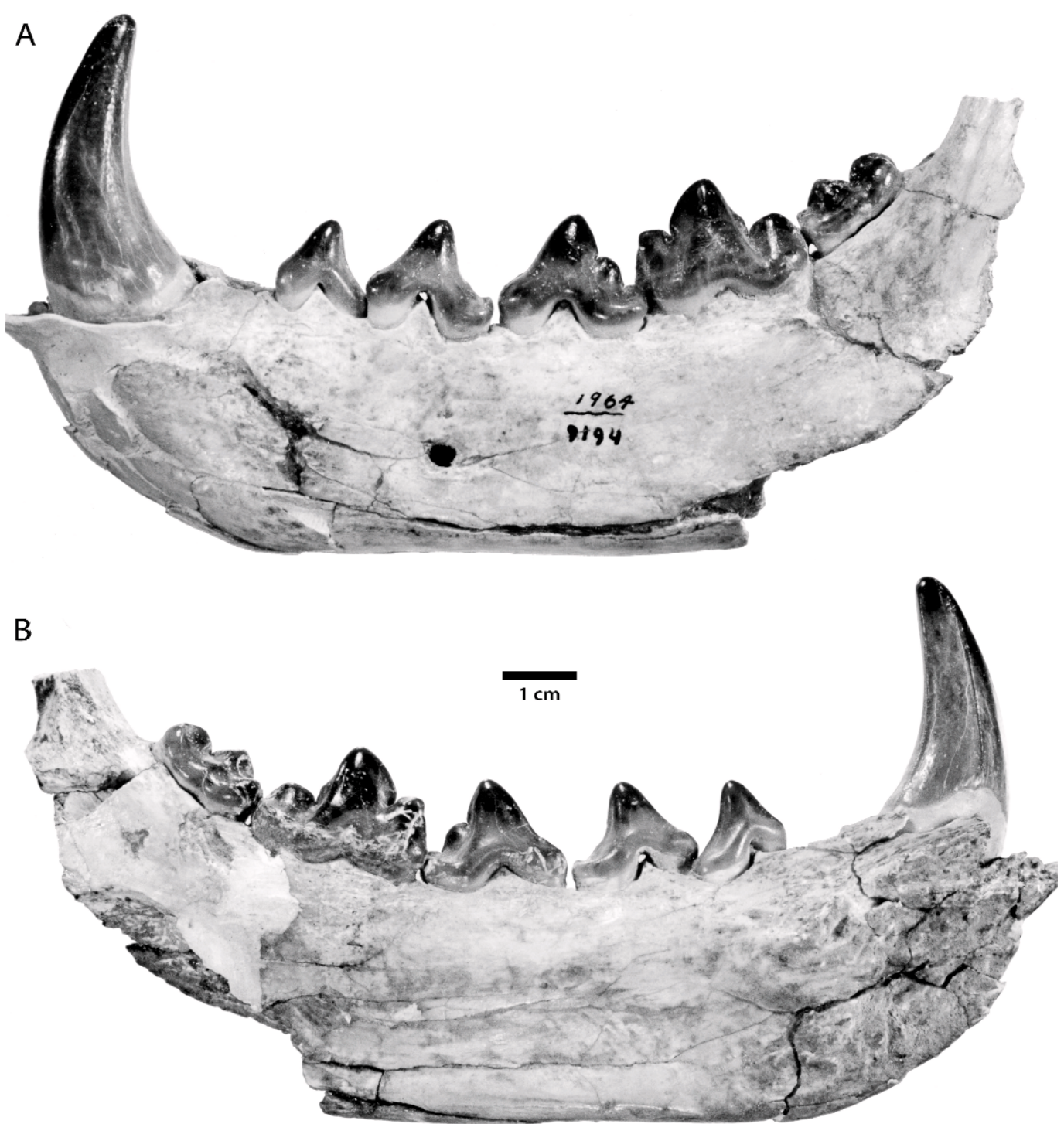

Fig. 25. Referred mandible of Mammacyon obtusidens (LACM 9194) with left canine, p2-m2, LACM loc. 1964, lower Arikaree Group, Wounded Knee area, Shannon Co., South Dakota. A, labial and B, lingual views.

posterior faces of $\mathrm{P} 3$ are more nearly equal in length, and the tip of the main cusp shows flat apical wear.

P4 is a robust, massive tooth; M. obtusidens is the first of the larger temnocyonines to develop this crushing carnassial. P4 has a short metastylar blade, an anteroposteriorly elongate stout paracone, and a greatly enlarged protocone that crushes against the p4 heel. Shear is still accomplished to some degree by the lingual surfaces of the paracone and metastylar blade. The metastylar blade is directed outward at a $50^{\circ}$ angle from the anteroposterior axis of the paracone. The blade measures $10.5 \mathrm{~mm}$ in length; the paracone measures $18.4 \mathrm{~mm}$ from the carnassial notch to its anterior base. A weak enamel ridge runs down the anterointernal face of the paracone to end in a tiny cingular cusp. Directly lingual to the paracone is the 

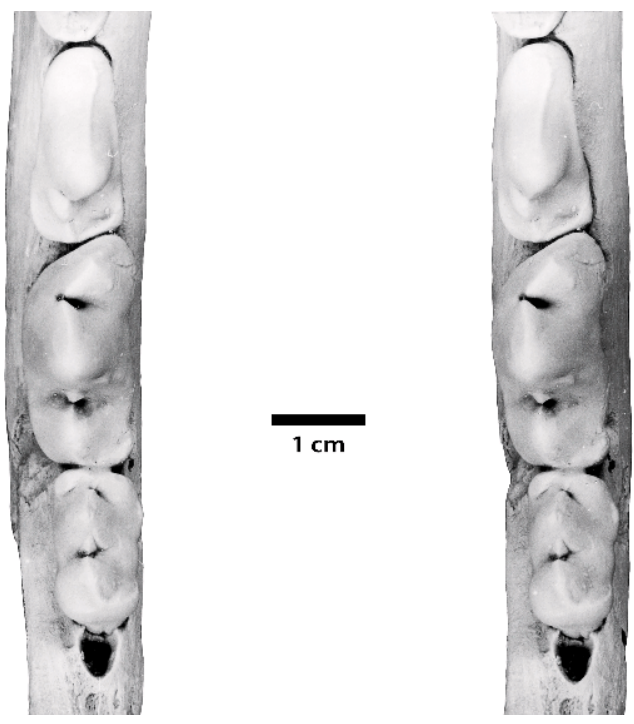

Fig. 26. Occlusal stereopair of the mandibular dentition (p4-m2) of Mammacyon obtusidens (LACM 9194). Note absence of $\mathrm{m} 1$ and $\mathrm{m} 2$ metaconids.

blunt, knoblike protocone: the protocone is separated from the paracone by a broad valley. Anteroposterior length of the protocone is $11 \mathrm{~mm}$; greatest width of $\mathrm{P} 4$ at the level of the protocone is $21.5 \mathrm{~mm}$. Only a narrow embrasure $(\sim 7 \mathrm{~mm}$ in length) remains between $\mathrm{P} 4$ and $\mathrm{M} 1$ to receive the trigonid of $\mathrm{m} 1$, and a similarly reduced space also occurs in $M$. ferocior.

M1 measures $20.4 \mathrm{~mm}$ in length, $28.2 \mathrm{~mm}$ in width. In $M$. obtusidens the tooth comprises a labial part dominated by the paraand metacone, and an enlarged lingual half created by swelling of the lingual cingulum around the broad protocone region. Between the lingual and labial parts of the tooth is a prominent constriction, giving the tooth a "waist" at the level of the protocone basin. The paracone is somewhat larger than the metacone; the parastyle, swollen labially and ventrally downturned, is more pronounced than the metastyle. Here, as in other large temnocyonines, M1 has a "folded" appearance as if the entire labial half were inwardly rotated toward the lingual half about an anteroposterior axis through the protocone basin. The protocone is centrally situated in a flat expanse of enamel. A preprotocrista runs from the protocone to the anterior cingulum but there is no postprotocrista nor para- and metaconules. A heavy swollen lingual cingulum, about equally developed throughout its extent, surrounds the protocone region.

M2 measures $10.5 \mathrm{~mm}$ in length, $17.9 \mathrm{~mm}$ in width. It is much smaller than M1 and fits into the concavity on the posterior margin of the larger molar. The paracone is much larger than the abbreviated metacone, but only slightly taller. The stylar shelf and labial cingulum external to the paracone are better developed than these features labial to the metacone as a result of the reduction of the metacone. The protocone basin occurs at the constricted "waist" of the tooth, and here also, as for M1, the labial half of M2 is rotated or "folded" inward. The protocone is a small, low blunt cusp protruding from the enamel flat forming the lingual half of the tooth. It is surrounded by a swollen cingulum, which is considerably worn. M3 was absent; there is no alveolus and there is no place on the maxilla posterior to M2 for an M3.

The associated limb and vertebral elements are similar in form to skeletal elements of Mammacyon ferocior (F:AM 27562) from north of Keeline, Wyoming. Comparisons of the ulna, humerus, astragalus, and scapula show no differences other than size. The limb elements of $M$. ferocior, in association with its mandible, indicate a species larger than $M$. obtusidens (ACM 34-41).

LACM 9194 Only the complete left mandible is described here; the two isolated jaw fragments and canine only duplicate structure observable in the more complete lower jaw. LACM 9194 was initially described as Temnocyon percussor by Macdonald (1970: 61-62).

The jaw is short and massive. Depth under the main cusp of $\mathrm{p} 2$ is $38.4 \mathrm{~mm}$, and $35.9 \mathrm{~mm}$ below the $\mathrm{m} 1$ protoconid. Premolars and molars are large, robust teeth; the molars, especially $\mathrm{m} 2-3$, are conspicuously tilted forward on the curvilinear margin of the ascending ramus. The inclined $\mathrm{m} 2-3$ are characteristic of temnocyonines, consequently M2 is often dorsally elevated relative to M1 to accommodate this configuration of the lower molars. Such an M2 is present in the holotype (ACM 34-41). The unworn teeth indicate a mature young adult. 
The canine is a large, recurved tooth, $38.9 \mathrm{~mm}$ in height from tip to enamel base, measured on the labial face. Its anteroposterior width is $19.1 \mathrm{~mm}$ measured at the base of the enamel; its labiolingual width is $12.6 \mathrm{~mm}$. A wear groove produced by the upper canine begins near the tip on the posterior surface, continues down the posterior slope, trending slightly labiad, eventually terminating about $9.5 \mathrm{~mm}$ above the enamel base on the posterolabial face. Two fine enamel ridges traverse the tooth from tip to enamel base: the first courses down the center of the lingual face, the second traverses the posterolingual face.

The single alveolus for $\mathrm{p} 1$, although crushed, measures $\sim 8 \mathrm{~mm}$ in length, $6.2 \mathrm{~mm}$ in width. Elongation of the large alveolus suggests that the tooth was directed anterolabially.

The p2 measures $14.4 \mathrm{~mm}$ in length, $5.8 \mathrm{~mm}$ in anterior width, and $6.4 \mathrm{~mm}$ in posterior width. There are no accessory or cingular cusps. A fine enamel ridge descends the somewhat steeper anterior face to the anterolingual corner of the tooth, and a similar ridge occupies the posterior face, ending at the posterolabial corner.

The p3 measures $17.7 \mathrm{~mm}$ in length, $6.4 \mathrm{~mm}$ in anterior width, and $7.8 \mathrm{~mm}$ in posterior width. There are no accessory cusps, but there is a small basal cusp situated at the center of the posterior cingulum. A thin enamel ridge descends the anterior face to the anterolingual corner; a second ridge traverses the posterior face to the basal cingulum cusp.

The p4 measures $20.4 \mathrm{~mm}$ in length, $7.5 \mathrm{~mm}$ in anterior width, and $9.7 \mathrm{~mm}$ in posterior width. A large posterior accessory cusp is labially situated half the distance down the posterior slope. A small basal cusp on the posterior cingulum lies below the posterior accessory cusp. A fine enamel ridge follows the anterior slope and ends in the anterolingual corner as in p2-3, but a posterior ridge is largely obscured by development of the large posterior accessory cusp.

The bases of P3 and p3-4 are posteriorly widened but this is less pronounced relative to $M$. ferocior or D. oryktes teeth where such widening of the posterior base is strongly developed.

The $\mathrm{ml}$ measures $24.4 \mathrm{~mm}$ in length, $11.4 \mathrm{~mm}$ in posterior trigonid width, and $10.9 \mathrm{~mm}$ in greatest talonid width. Trigonid length is $17.4 \mathrm{~mm}$. This is a robust, short, blunt-cusped carnassial that has lost the metaconid, although a small wear facet on the labial face of the protoconid shows that paraconid-protoconid shear is retained. The short, swollen paraconid blade is angled inward and is much lower in height than the principal cusp of $\mathrm{p} 4$. The protoconid is compressed to form a blade running forward and downward to form the incisure with the paraconid. A short enamel ridge $4 \mathrm{~mm}$ in length descends the posterior surface of the protoconid to form the incisure with the hypoconid, a massive blunt cusp placed directly behind the protoconid and centrally situated on the talonid. There is also a low enamel swelling on the posterolingual wall of the protoconid that represents the vestige of the incisure once shared with the metaconid. Its presence indicates that the metaconid has probably been lost relatively recently in this lineage. There is no entoconid. The $\mathrm{m} 1$ has a swollen, weakly differentiated cingulum, most evident on the labial side where it is sinuous: it rises below the protoconid, descends at the protoconid-hypoconid incisure, and rises again beneath the hypoconid (in contrast, the labial $\mathrm{ml}$ cingulum is straight in Delotrochanter). At the posterolingual corner of the $\mathrm{m} 1$ talonid, the cingulum is slightly enlarged, creating a marked indentation of the cingulum anterior to this swelling (also found in M. ferocior).

The elongate $\mathrm{m} 2$ is diagnostic of the Mammacyon lineage in the Great Plains. Its length is $15.5 \mathrm{~mm}$; greatest trigonid width, $9.6 \mathrm{~mm}$; greatest talonid width, $8.7 \mathrm{~mm}: \mathrm{m} 2$ has a rectangular occlusal outline. The labially placed protoconid is the largest cusp. There is no metaconid but a small, distinct paraconid occupies the anterolingual corner of $\mathrm{m} 2$. The only talonid cusp is a low, blunt, somewhat labially situated hypoconid. There is no entoconid. The pronounced inclination of $\mathrm{m} 2$ (and $\mathrm{m} 3$ ) on the edge of the ascending ramus of the mandible, tilted forward nearly $30^{\circ}$ from the horizontal, further emphasizes the short toothrow and massive quality of the teeth.

The $\mathrm{m} 3$ is represented by a single alveolus, length $4.7 \mathrm{~mm}$, width $4.1 \mathrm{~mm}$, placed close against the posterior edge of $\mathrm{m} 2$.

Length of the toothrow from $\mathrm{p} 2-\mathrm{m} 2$ is $86.2 \mathrm{~mm}$; from the base of the enamel on the 


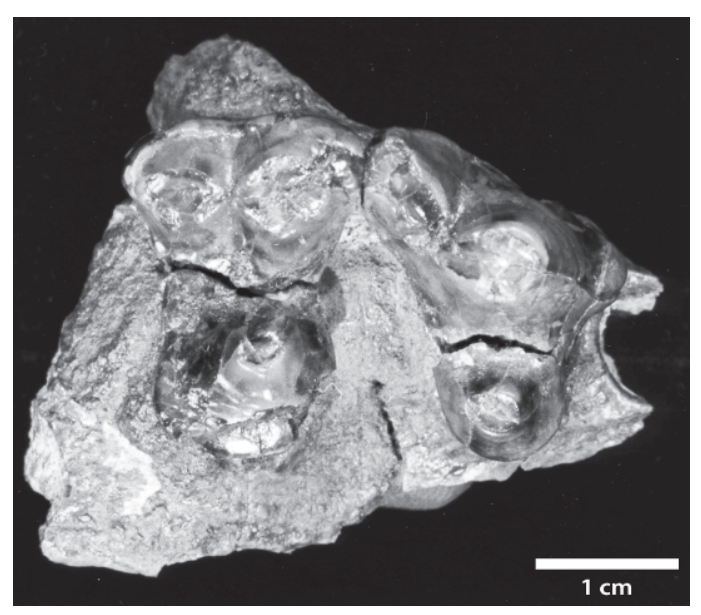

Fig. 27. Referred maxilla of Mammacyon obtusidens (LACM 5386) with right P4-M1, Turtle Cove Member, John Day Formation, Haystack Valley, Wheeler Co., Oregon. Note apical wear on all cusps, indicating crushing action of P4-M1.

posterior face of the canine to the anterior rim of $\mathrm{m} 3$ alveolus is $98.3 \mathrm{~mm}$; from anterior rim of $\mathrm{p} 1$ alveolus to posterior rim of $\mathrm{m} 3$ alveolus is $\sim 99 \mathrm{~mm}$.

LACM 5386-I refer to M. obtusidens a partial maxilla with right $\mathrm{P} 4-\mathrm{M} 1$ and the alveolus for the posterior root of $\mathrm{P} 3$, from CIT Locality 29, Haystack Valley, Wheeler County, Oregon. It was found among unidentified material in the collection of the Los Angeles County Museum and has not been previously described. The teeth are most similar in form to ACM 34-41 (M. obtusidens) and F:AM 54134 (M. ferocior). This is the only specimen from the John Day beds assigned to Mammacyon; it represents a smaller individual than the holotype of $M$. obtusidens and is closer in size to LACM 9194.

The alveolus (greatest width, $8.2 \mathrm{~mm}$ ) for the posterior root of P3 is very large, indicating a posteriorly broad premolar at least $9 \mathrm{~mm}$ in width. This alveolus indicates that P3 was closely set against the base of P4 as in the holotype.

P4 measures $21.8 \mathrm{~mm}$ in length, $18.2 \mathrm{~mm}$ in greatest width, and is characterized by the short yet robust metastylar blade relative to the large paracone and protocone. Metastylar blade length is $8.1 \mathrm{~mm}$; width of the blade is $7.4 \mathrm{~mm}$. The upper carnassial is nearly as wide as long, and shows blunted cusps with pronounced apical wear (there is only a weak vertical shear facet on the lingual face of the paracone-metastylar blade). The enormous protocone is responsible for the width of $\mathrm{P} 4$ : it extends as far toward the midline of the palate as does the M1. An enlarged protocone is characteristic of Mammacyon; in Delotrochanter the P4 protocone does not extend as far toward the midline. A slightly swollen cingulum surrounds $\mathrm{P} 4$, and is somewhat more defined around the base of the metastylar blade than elsewhere on the tooth. A conspicuous valley separates the large blunted paracone from the much lower knoblike protocone.

M1 measures $17.8 \mathrm{~mm}$ in length, $24.8 \mathrm{~mm}$ estimated transverse width (the anterolingual cingulum is broken), and $13.1 \mathrm{~mm}$ in anteroposterior width of the protocone region. The form of the tooth is comparable to M1 of ACM 34-41. The embrasure for $\mathrm{m} 1$ between P4 and M1 is much reduced as in the holotype, thus there was probably no $\mathrm{m} 1$ metaconid. In addition, the M1 of LACM 5386 shows the "folded" appearance in which the labial half of the tooth is rotated inward toward the lingual half as in ACM 34-41. The knoblike protocone of M1 was isolated within the broadened protocone region and surrounded by a swollen lingual cingulum; a weak preprotocrista runs from protocone toward the anterior cingulum but no postprotocrista is apparent. Paracone, metacone, and protocone of M1 are blunt cusps with flat apical wear surfaces. The paracone and metacone were once tall cusps but wear has reduced their height so that evidence of vertical shear on their lingual faces is equivocal. In mature individuals mastication emphasized the processing of hard food items, also suggested by the blunt, knoblike protocones of both $\mathrm{M} 1$ and $\mathrm{P} 4$.

A vestige of the labial M2 alveolus indicates that the tooth was small and fitted tightly against the posterior margin of M1 in the same location as the holotype.

Discussion: Mammacyon obtusidens is the oldest species that can be confidently attributed to the genus. The maxilla (LACM 5386) from the John Day Formation of Haystack Valley, Oregon, can be conservatively dated 
at younger than $28.7 \mathrm{Ma}$ based on its probable site of collection close above the Picture Gorge ignimbrite; an age estimate for the locality falls in the interval from $\sim 28$ to 28.7 Ma. The first appearance of M. obtusidens in the Great Plains is based on the referred mandible (LACM 9194) from the "Monroe Creek Formation" of the Wounded Knee area in southwestern South Dakota. The holotype cranium and associated postcranials (ACM 34-41) were attributed to the "Monroe Creek or Harrison Formation" and are also part of the Wounded Knee fauna of Macdonald (1963, 1970). However, a reliable correlation of these rock units with the type Monroe Creek and Harrison formations of Hatcher (1902a) north of the town of Harrison in northwest Nebraska has not been established, and the mammalian fauna from the "Monroe Creek" and "Harrison" of the Wounded Knee area lacks agediagnostic species found in the stratotype Harrison Formation in Sioux County. The Wounded Knee fauna from the "Monroe Creek-Harrison" interval in South Dakota is an early to mid-Arikareean fauna (see Age and Correlation), hence the holotype of $M$. obtusidens is assigned to the late Oligocene the species had attained the specialized durophagous dental traits typical of the genus at least by the earlier late Oligocene, and this dental trend continued in the Great Plains with $M$. ferocior.

The M. obtusidens mandible (LACM 9194) is from the same Wounded Knee locality as the canid Enhydrocyon pahinsintewakpa, the most plesiomorphic species of its genus (Wang, 1994: 90); this locality (LACM 1964) occurs near the base of the "Monroe Creek" unit and in close proximity to the Sharps Formation, which includes leptauchenine oreodonts in the same area (Macdonald, 1963: 162). These mammals document an early Arikareean age for the stratigraphic level that yielded the mandible of $M$. obtusidens.

This conclusion is supported by the stratigraphic position of the descendant of $M$. obtusidens, the larger terminal species of the lineage, M. ferocior. Mammacyon ferocior from the Pine Ridge of Niobrara County, north of Keeline, Wyoming, is a species of larger size in which derived dental features of the M. obtusidens holotype become further accentuated. Thus, in $M$. ferocior the teeth are similar in form but larger, more massive, with even greater emphasis on the crushing function of the cheek teeth. The fauna from north of Keeline is considered here to be intermediate in age between the Wounded Knee "Monroe Creek" fauna and the fauna of the stratotype Harrison Formation in northwest Nebraska.

The mandibular fragment (LACM 15908) attributed in this study to cf. Mammacyon from the Sharps Formation of South Dakota was collected stratigraphically below and $\sim 4 \mathrm{mi}(6.4 \mathrm{~km})$ north of the locality that produced the referred $M$. obtusidens mandible (LACM 9194). It possibly represents the earliest record of Mammacyon in the Great Plains. It has reduced the $\mathrm{m} 1$ metaconid to a vestigial remnant and shows the robust teeth and thick mandible that would be expected in the ancestor of M. obtusidens. However, LACM 15908 lacks the elongate $\mathrm{m} 2$ relative to $\mathrm{m} 1(\mathrm{~m} 1 / \mathrm{m} 2$ length ratio, $\sim 1.7)$ common to M. obtusidens and M. ferocior and is too incomplete to permit confident referral to the genus. The $\mathrm{m} 2$ protoconid and hypoconid are centrally situated, a character of Mammacyon and Delotrochanter; these cusps are labially placed in Temnocyon.

\section{Mammacyon ferocior, new species Figures 28-31}

TYPE: Right partial mandible with i3 root, $\mathrm{c}-\mathrm{m} 3$, and associated limb elements and vertebrae: atlas, caudal vertebra, sacrum, glenoid of scapula, left humerus, distal right humerus, both ulnae, rib fragments, left metacarpal 2, proximal left and right metacarpal 3, innominate fragments, partial left femur, left tibia, proximal right tibia, both calcanea, left astragalus, proximal right astragalus, right navicular, both cuboids, left ectocuneiform, right metatarsal 2, left distal metatarsal 3, proximal right metatarsal 5 (reduced), from ?Harrison Formation, north of Keeline, Niobrara County, Wyoming, collected by Charles Falkenbach, 1931 (F:AM 27562).

DistRIBUTION: Mid- or early late Arikareean, Arikaree Group, Niobrara County, Wyoming. 
A

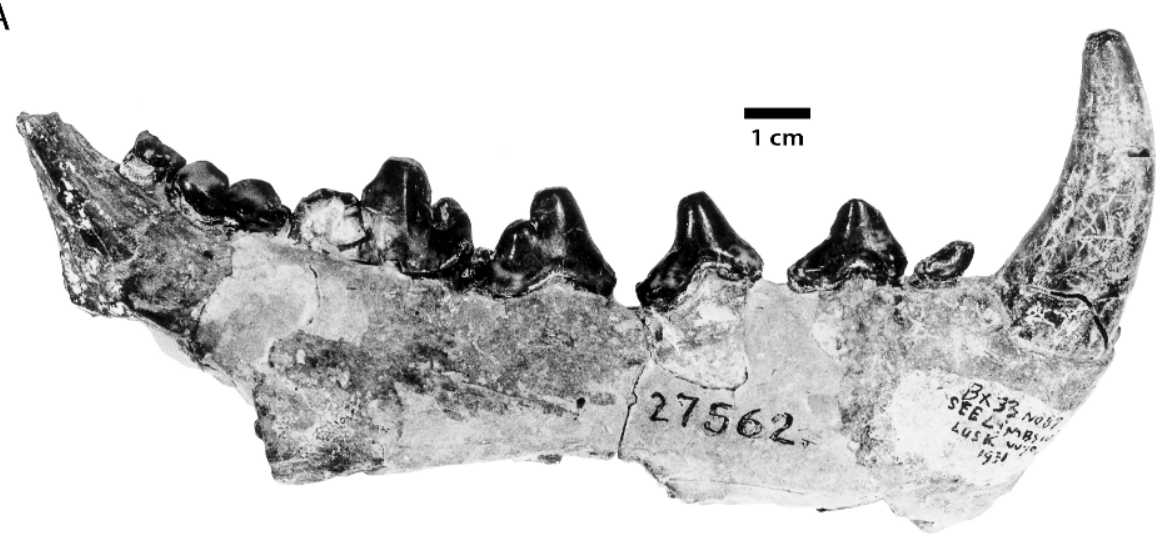

B

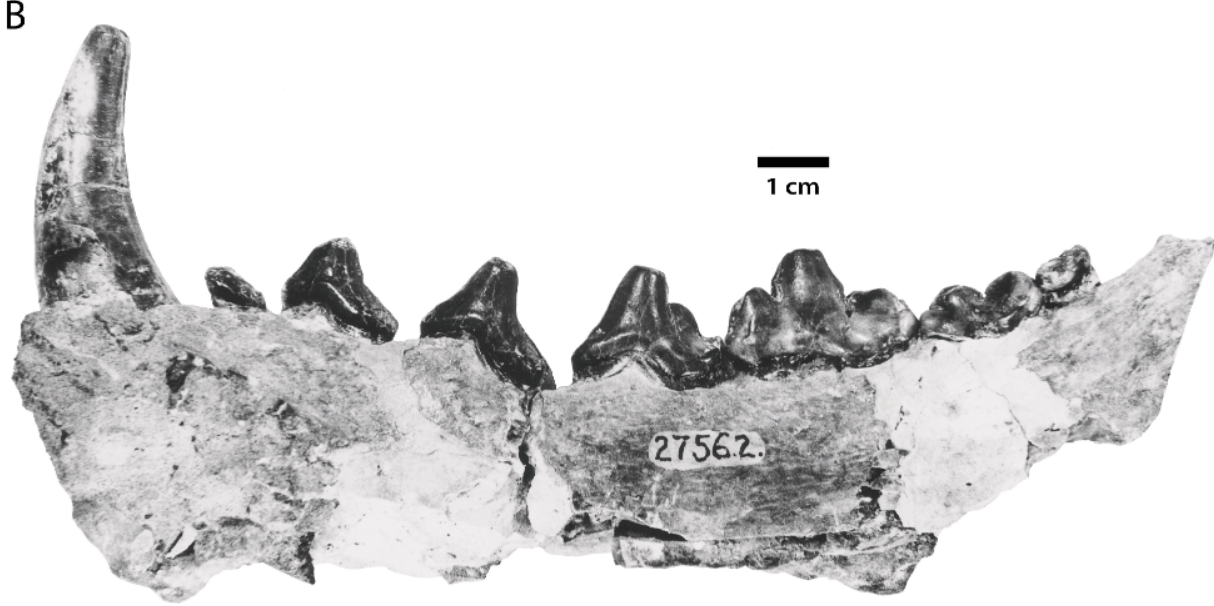

Fig. 28. Holotype mandible of Mammacyon ferocior (F:AM 27562) with right canine, p1-m3, from the Arikaree Group, north of Keeline, Niobrara Co., Wyoming. The large crushing p4 nearly equals the carnassial in size. A, labial and $\mathbf{B}$, lingual views.

ETYMOLOGY: From the Latin, ferocior, "particularly fierce," in allusion to the large size and presumed disposition of this predator.

DiAgNosis: Largest species of the Mammacyon lineage, thus sharing the same dental characters of form and proportion as $M$. obtusidens but distinguished by larger size. Dental ratio $\mathrm{A} / \mathrm{B}, 1.23$; ratio $\mathrm{C} / \mathrm{D}, 1.13$ (table 6), lower than all Temnocyon species. Ratio C/D (1.13), lowest of all temnocyonines. Distinguished from other large temnocyonines such as $R$. amplidens by an elongate $\mathrm{m} 2$ (ratio E/F: 1.6 in M. ferocior, $\sim 1.9$ in $R$. amplidens); from $T$. ferox, $T$. percussor, $T$. fingeruti, and $T$. macrogenys by absence of the $\mathrm{m} 1$ metaconid; from $T$. macrogenys by much smaller size; and from Delotrochanter oryktes and $D$. major by a $\mathrm{p} 4$ with labially placed posterior accessory cusp (centrally placed in Delotrochanter). M. ferocior $\mathrm{p} 4$ posteriorly broader than in $M$. obtusidens. Cranium with greatly inflated frontal sinuses relative to small braincase volume (table 7).

REFERRED SPECIMEN: F:AM 54134, a skull with poorly preserved basicranium yet in other features complete and uncrushed. This is the largest known North American temnocyonine skull (basilar length, $28 \mathrm{~cm}$ ). Upper dentition with alveoli for six incisors, two canines, left $\mathrm{P} 1-3$, right P2-3; complete right P1, P4-M2 (P4 damaged), and left P4-M2; M3 not present in the species. From the ?Harrison Formation, north of Keeline, Niobrara County, 

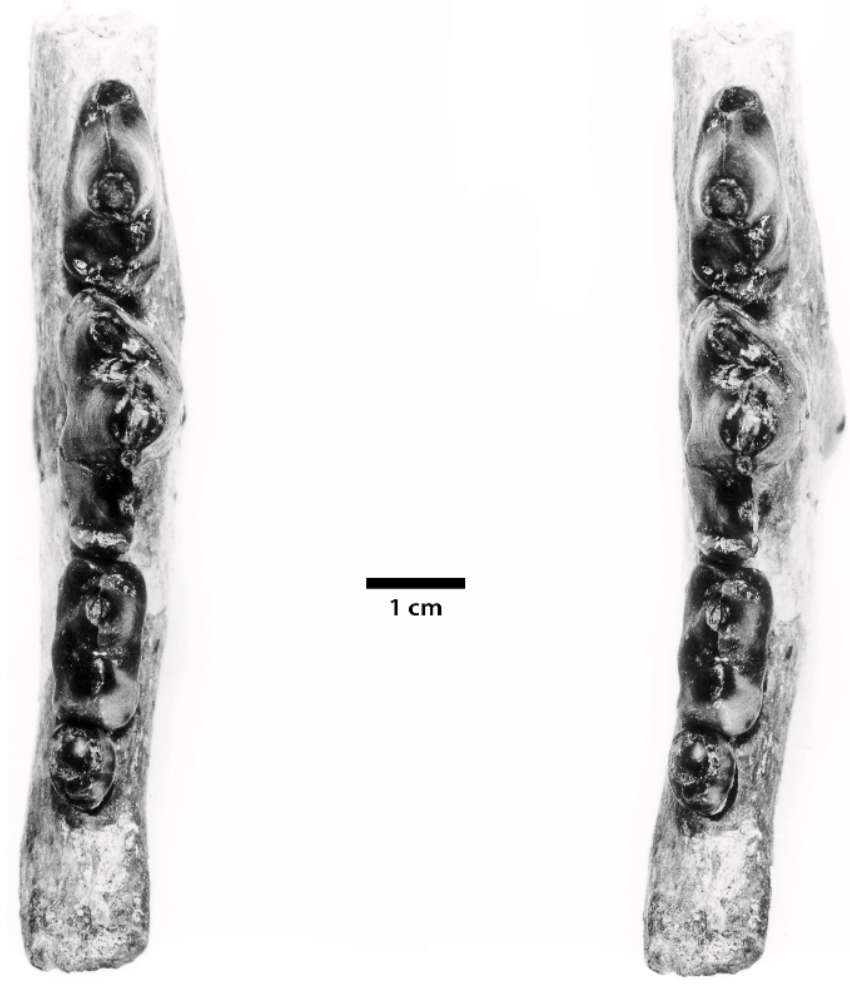

Fig. 29. Occlusal stereopair of the mandibular dentition (p4-m3) of Mammacyon ferocior (F:AM 27562). Note absence of $\mathrm{m} 1$ and $\mathrm{m} 2$ metaconids, apical wear on $\mathrm{p} 4-\mathrm{m} 2$ cusps, a labial shear facet on $\mathrm{m} 1$ protoconid-paraconid, and the broad p4 (compare fig. 23).

collected by C. Falkenbach in 1944, from a stratigraphic level "high in the formation" in this area.

DESCRIPTION: FAM 27562-The depth of the mandible (estimated at $\sim 44 \mathrm{~mm}$ ) is uncertain because the ventral border of the horizontal ramus is damaged. Length of toothrow from the posterior border of the canine alveolus to the posterior limit of $\mathrm{m} 3$ is $126.2 \mathrm{~mm}$. The mandibular symphysis extends from the anterior canine border almost to the posterior border of $\mathrm{p} 2$, having a greatest length of $48.8 \mathrm{~mm}$ and depth of $36.3 \mathrm{~mm}$.

Lower canine height is $47.5 \mathrm{~mm}$ above the labial alveolar border. The tooth is grooved on its posterolabial face by the upper canine, identical to the similarly positioned groove in LACM 9194 (M. obtusidens). At the enamel base the canine measures $14 \mathrm{~mm}$ in width, $20.3 \mathrm{~mm}$ in anteroposterior length, and is somewhat posteriorly recurved. In addition to the groove worn by the upper canine, there is a deep elliptical wear facet on the anterolingual face produced by the I 3 which is much larger than I1-2 based on alveolar dimensions.

The $\mathrm{p} 1$ is a small, peglike tooth that measures $9 \mathrm{~mm}$ in length, $5.9 \mathrm{~mm}$ in width. The main cusp is anteriorly placed as in all temnocyonines, with a long posterior slope and no accessory or cingular cusps.

The $\mathrm{p} 2$ is much larger than $\mathrm{p} 1$, measuring $17.9 \mathrm{~mm}$ in length, $8.1 \mathrm{~mm}$ in greatest width posterior to the main cusp. There are no accessory or cingular cusps. The posterior face is longer and more gently inclined relative to the more vertical anterior face. Fine enamel ridges are present on both anterior and posterior faces and, as in $M$. obtusidens, the anterior ridge descends to the anterolingual cingulum whereas the posterior ridge runs to the posterolabial cingulum. The tooth itself is angled outward; that is, the 
anterior $\mathrm{p} 2$ root is more labial in position than the posterior root. A somewhat swollen cingulum is more defined along the lingual bases of p2, p3, and p4 relative to its less pronounced labial expression.

The $\mathrm{p} 3$ is simply a taller, larger example of p2; it measures $19.3 \mathrm{~mm}$ in length, $9 \mathrm{~mm}$ in width. There are no accessory or cingular cusps despite the broadened heel of $\mathrm{p} 3$ relative to $\mathrm{p} 2$. Thin enamel ridges run down the anterior and posterior faces to the barely discernible cingulum, the anterior ridge contacting the anterolingual corner, the posterior touching the posterolabial corner where the cingulum is better developed along the posterior margin.

The p4 is more massive and robust than p3. It measures $21.9 \mathrm{~mm}$ in length, $10.7 \mathrm{~mm}$ in width. A large posterior accessory cusp occurs about halfway between the tip of the main cusp and the crown base. It lies labial not only to the main cusp but also to the basal cusp occupying the center of the broad posterior shelf of $\mathrm{p} 4$. The main cusp of $\mathrm{p} 4$ is nearly as tall and robust as the protoconid of $\mathrm{m} 1$. Both p3 and p4 are particularly tall premolars; their principal cusps are each $\sim 4 \mathrm{~mm}$ taller than the $\mathrm{m} 1$ paraconid.

Flat apical wear facets are present on the principal cusps of $\mathrm{pl}-4$ and on the $\mathrm{ml}$ protoconid.

The $\mathrm{ml}$ measures $27.7 \mathrm{~mm}$ in length, $\sim 13 \mathrm{~mm}$ in width (the labial talonid is lost). The carnassial is large and robust yet appears rather low and almost dwarfed relative to the tall, massive premolars. The metaconid is absent. Both protoconid and paraconid are massive, broad cusps, the protoconid showing strong apical wear. However, carnassial shear is evidenced by a near-vertical facet on the labial face of the paraconid-protoconid. The paraconid, placed anterolingual to the protoconid, has not rotated into a position directly anterior to the protoconid as in carnivorans with highly developed carnassial shear. The hypoconid is large, blunt, centrally placed on the talonid, and the entoconid is absent. The cingulum is not well defined and appears only as a vague swelling around the base of the tooth. However, a prominent swelling of the enamel occurs at the posterolingual corner of $\mathrm{ml}$ and represents a small cingular shelf; anterior to this swelling on the lingual margin of the talonid, the base of $\mathrm{m} 1$ is indented or "notched." Both the cingular swelling and indentation also occur in $M$. obtusidens.

The $\mathrm{m} 2$ measures $17.3 \mathrm{~mm}$ in length, $10.3 \mathrm{~mm}$ in width. This is the longest North American temnocyonine $\mathrm{m} 2$, yet the $\mathrm{m} 1$ of this same individual is exceeded in length by the $\mathrm{m} 1$ of three other species (T. macrogenys, $D$. oryktes, $R$. amplidens). A low, blunt protoconid occupies the center of the trigonid; a hypoconid of nearly equal height lies directly behind the protoconid in the center of the talonid. There is neither metaconid nor entoconid. A vestigial paraconid appears as a low platform at the anterolingual corner of $\mathrm{m} 2$.

The $\mathrm{m} 3$ is a small, oval tooth with minimal surface relief. It measures $8.6 \mathrm{~mm}$ in length, $7.2 \mathrm{~mm}$ in width. Because the enamel is damaged, cusp pattern is uncertain; however, a low protoconid was the principal cusp and a small, reduced talonid is present.

FAM 54134 - The skull is largely uncrushed and the largest known for the subfamily. It displays "bearlike" proportions reflected in the swollen muzzle, inflated frontal region, heavy zygomatic arches, and pronounced sagittal and lambdoid crests. The upper teeth represent the most highly specialized durophagous dentition developed by a temnocyonine, a crushing dentition unlike that of bears (Ursinae). The locus of crushing in the upper teeth of F:AM 54134 involves P3-M1/p4-m2 whereas in living ursine bears the $\mathrm{M} 1-\mathrm{M} 2 / \mathrm{m} 1-\mathrm{m} 3$ serve this function.

Basilar length of skull is $280 \mathrm{~mm}$ comparable in size to adult male Ursus americanus. The braincase is proportionately small relative to overall skull size; in fact the expanded frontal sinuses appear to have had a volume greater than the cranial cavity (table 7 ). The secondary palate is long $(14 \mathrm{~cm})$ and narrow for a skull of this length: palatal width measured across the M1s is $8.7 \mathrm{~cm}$ whereas only $3 \mathrm{~cm}$ of this is occupied by the palatal bone between the teeth, with the remainder taken up by the enlarged molars. The tall, narrow infraorbital foramen (height, $18 \mathrm{~mm}$; width, $9 \mathrm{~mm}$ ), opens on the maxilla above the upper carnassial. The orbitotemporal region is long: postorbital length is $\sim 19 \mathrm{~cm}$, preorbital $\sim 12.5 \mathrm{~cm}$. The left orbital region 

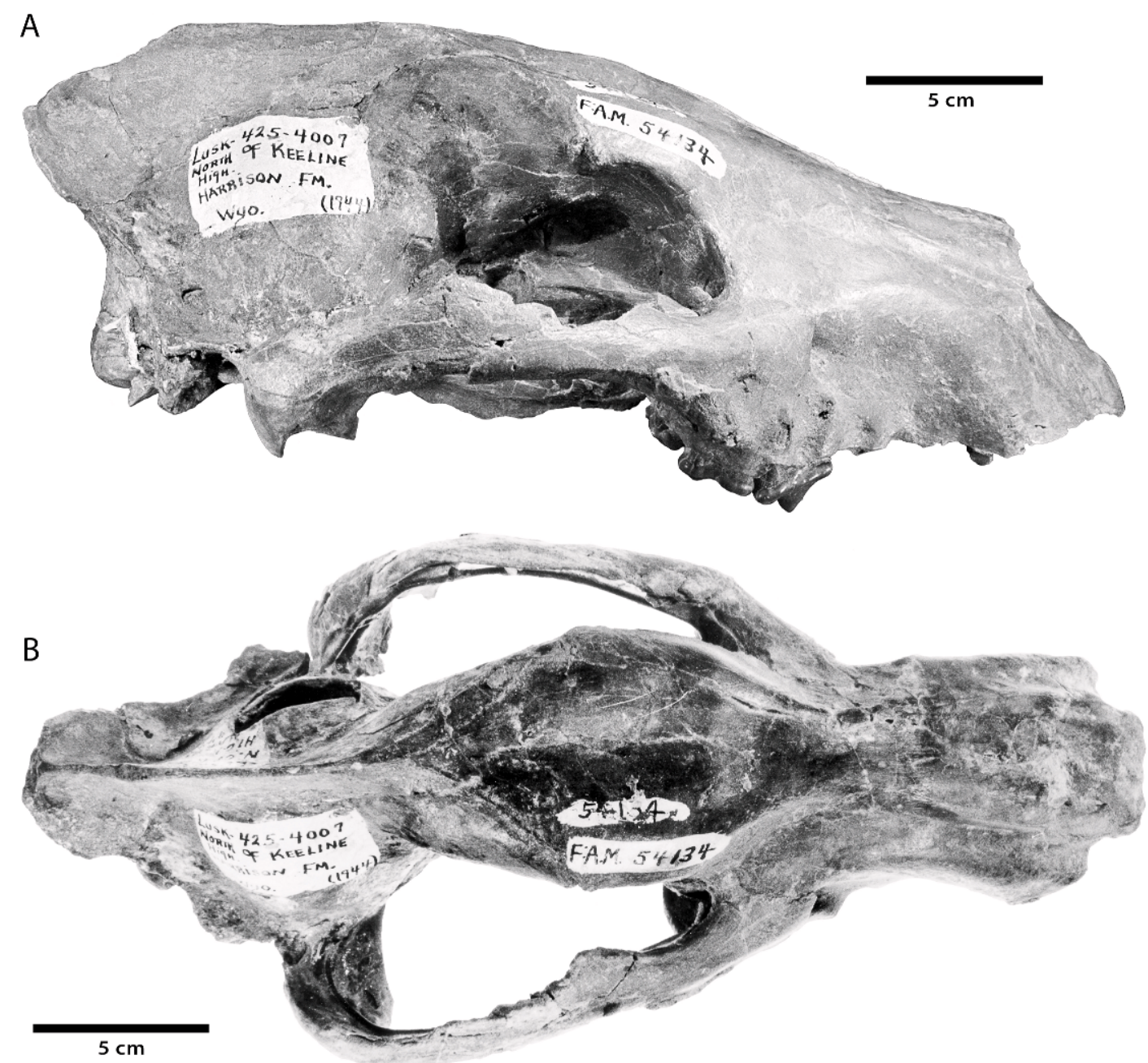

Fig. 30. Cranium of Mammacyon ferocior (F:AM 54134) in (A) right lateral; (B) dorsal; and (C; opposite page) left lateral (restored) views, from the Arikaree Group, north of Keeline, Niobrara Co., Wyoming, showing (B) width of the frontal paranasal sinuses relative to braincase volume.

preserves the elongate depression in alisphenoid and orbitosphenoid bones for the optic foramen, sphenorbital fissure, and anterior aperture of the alisphenoid canal. The canal is $20 \mathrm{~mm}$ in length; its posterior opening shares a common fossa with the foramen ovale. The foramen rotundum opens internally into the canal as in other temnocyonine crania.

The basicranium is foreshortened: the length from the common fossa for the posterior opening of the alisphenoid canal and the foramen ovale to the ventral notch of the foramen magnum (an estimate of basicranial length) is only $5.5 \mathrm{~cm}$, approximately one-fifth the basilar skull length. Although the basicranium is damaged there is an evident similarity to the $M$. obtusidens basicranium (ACM 34-41). Enough of the basicranial axis is preserved to show that, on the right side, the margin of the basioccipital was deeply excavated for an enlarged inferior petrosal venous sinus. This is the most pronounced development of the sinus in any temnocyonine skull and is related to the large size of $M$. ferocior. The sinus includes a deep central pocket also seen in Temnocyon altigenis (UCMP 9999), penetrating $13 \mathrm{~mm}$ into the basioccipital. 


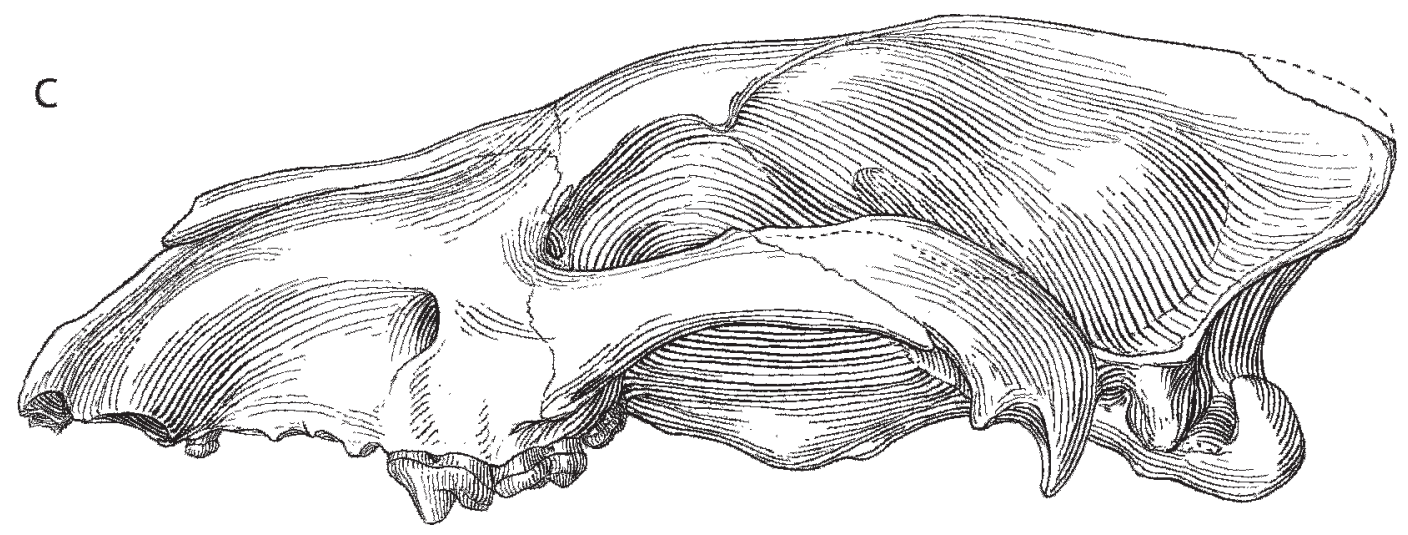

Fig. 30. Continued.

The morphology of the upper dentition is comparable to ACM 34-41, however the Keeline skull has larger, more robust teeth, a massive P3-M2 crushing dental battery, close-spaced P2-4 (no diastemata), huge canines, and a full complement of incisors with large I3.

Incisor alveoli show that the upper incisors became larger from I1 to I3: I1 alveolus measures $9.1 \mathrm{~mm}$ in length, $4 \mathrm{~mm}$ in width; I2 alveolus, $11.2 \mathrm{~mm} \times 6.1 \mathrm{~mm}$; I3 alveolus, $11.5 \mathrm{~mm} \times 10 \mathrm{~mm}$. There is a diastema of $\sim 9 \mathrm{~mm}$ between $\mathrm{I} 3$ and the canine alveolus. The canine alveolus measures $24 \mathrm{~mm} \times$ $15 \mathrm{~mm}$; the maxilla surrounding the canine roots is swollen to accommodate the large canines, indicating a male individual.

The upper premolars were somewhat crowded judging from the placement of P13 alveoli. This is not the crowding seen in many young amphicyonids since the wear on cheek teeth shows F:AM 54134 to be a mature adult. As is the case in the mandible, P2 is angled outward and shows the effect of crowding more than any other tooth, its posterior alveolus more lingual than the anterior. This degree of crowding also occurs in the upper teeth of M. obtusidens (ACM 3441) and must be characteristic of large species of Mammacyon.

$\mathrm{P} 1$ is a small rounded peg $(7.6 \mathrm{~mm}$ in length, $6.4 \mathrm{~mm}$ in width) preserved only on the right side close behind the large canine. The alveoli for P2-3 measure $18.6 \mathrm{~mm}$ by $9.4 \mathrm{~mm}$, and $21.1 \mathrm{~mm}$ by $13.4 \mathrm{~mm}$, respectively. The larger posterior alveolus common to each of these premolars shows that both $\mathrm{P} 2$ and P3 were posteriorly broad, especially P3.

The enormous $\mathrm{P} 4$ with its short metastylar blade and massive paracone and protocone represents the culmination of the trend toward a crushing dentition within the genus. Its $26 \mathrm{~mm}$ length is almost equalled by its $23.1 \mathrm{~mm}$ width. Length of the metastylar blade is $10 \mathrm{~mm}$; length of paracone including the parastylar region is $17.4 \mathrm{~mm}$. The embrasure between the protocones of $\mathrm{P} 4$ and $\mathrm{M} 1$ for the $\mathrm{m} 1$ trigonid is reduced to $8.5 \mathrm{~mm}$ in anteroposterior length, notably less than the anteroposterior lengths of the protocones themselves ( $\mathrm{P} 4$ protocone, $12 \mathrm{~mm}$; M1 protocone, $17.4 \mathrm{~mm}$ ) so that very little of the lower carnassial could have been inserted into this space. Occlusion of the $M$. ferocior mandible (F:AM 27562) with the upper teeth of the skull demonstrates that the $\mathrm{m} 1$ protoconid is arrested at the level of the lingual cingulum of $\mathrm{M} 1$ by the narrow embrasure; the $\mathrm{m} 1$ paraconid and hypoconid also act as enamel stops against $\mathrm{P} 4$ and the M1 protocone basin. Thus, although some shear occurred between upper and lower carnassials, particularly in unworn teeth, a specialized crushing action was the dominant occlusal mode. Following an initial shearing stroke as the mandible brought the lower carnassial into contact with the upper teeth, the final phase of occlusion between $\mathrm{p} 4-\mathrm{m} 2$ and P3-M2 must have been mortar and pestle crushing employing the lingually expanded P4-M1 protocones. Ratios A/B and $\mathrm{C} / \mathrm{D}$ (table 6) are the lowest in the genus, and 

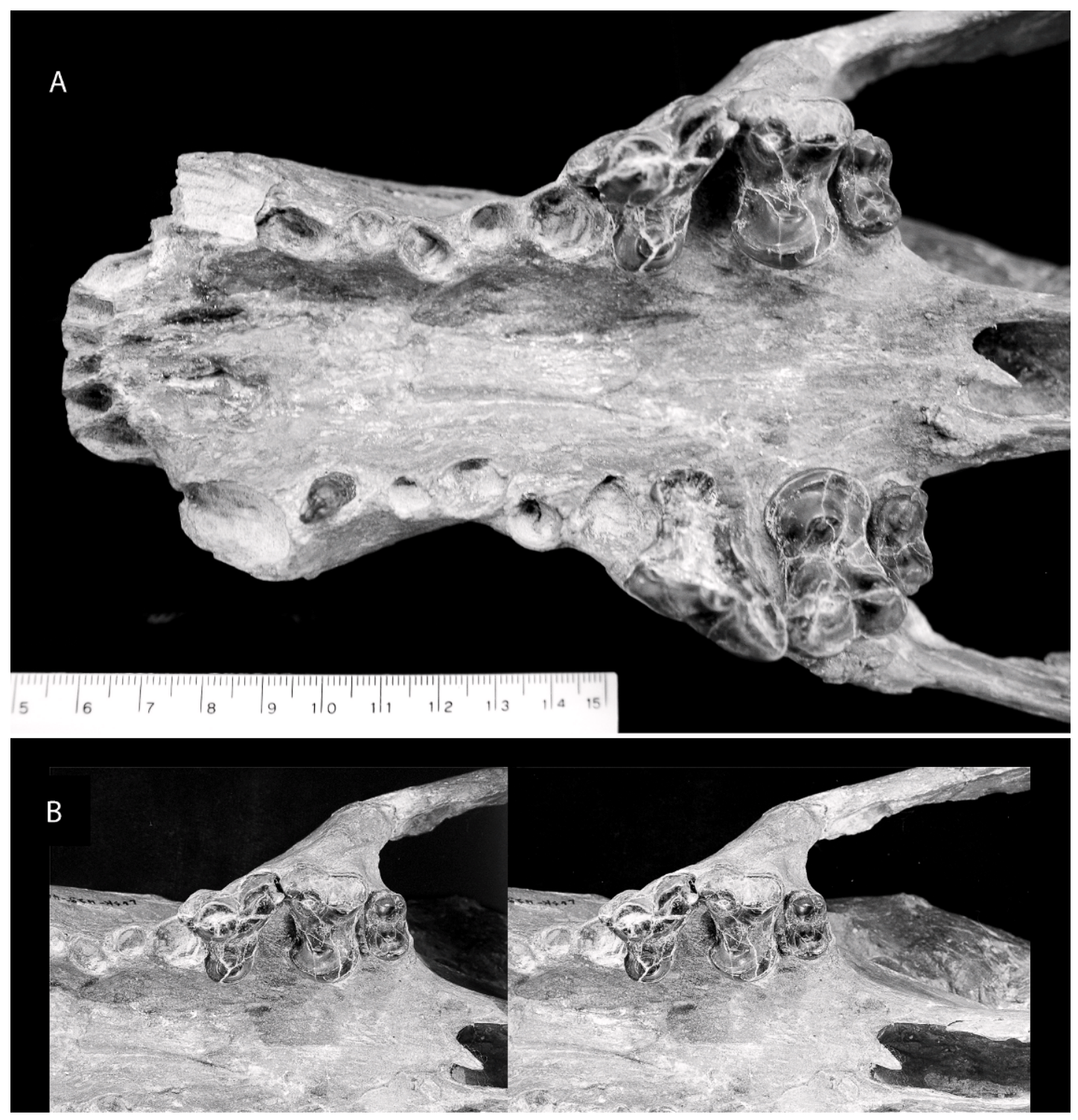

Fig. 31. Mammacyon ferocior (F:AM 54134) rostrum (A) in palatal view with right and left P4-M2, right P1, and alveoli for I1-3, C, P2-3 , from the Arikaree Group, north of Keeline, Niobrara Co., Wyoming. Stereophotos (B) of crushing P4-M2. This is the largest species of Mammacyon, and represents the climax of durophagy in the genus.

are related to the development of a crushing occlusion in $M$. ferocior.

M1 measures $21.4 \mathrm{~mm}$ in length, $29.8 \mathrm{~mm}$ in width. Despite its enormous size, it retains the characteristic temnocyonine configuration in which an expanded protocone region is separated from the enlarged labial half of the tooth by a prominent constriction at the level of the protocone basin. The paracone is slightly larger than the metacone. These two cusps are labially bordered by a cingulum, which is more pronounced labial to the paracone and is continuous with a small parastyle at the anterolabial corner of M1. Although the cusps are worn, in all respects they appear as in $M$. obtusidens. The large 
protocone is situated in the center of a broad enamel platform more developed than in any other temnocyonine species. The enamel platform is surrounded by an expanded lingual cingulum. A preprotocrista extends from the protocone toward the anterior cingulum, and a weak vestige of a postprotocrista also appears on the surface of the enamel platform trending toward the posterior cingulum. There are no para- or metaconules. Lateral to the protocone itself is a deep protocone basin that receives the $\mathrm{m} 1$ hypoconid much as pestle fits against mortar.

M2 is rectangular in occlusal outline with its long axis oriented transversely; it measures $10.8 \mathrm{~mm}$ in length, $17.4 \mathrm{~mm}$ in width, and is much smaller than M1. The paracone is much larger than the metacone. A strong labial cingulum borders only the paracone; the metacone cingulum is weak. The paracone-metacone region forms an elevated labial rim that overlooks the flat protocone region. The centrally situated protocone on this enamel flat is but a reduced version of the same cusp on M1. Wear has reduced the protocone to a flat surface nearly coplanar with the enamel flat on which it rests.

M3 was no longer present in this species. The maxilla terminates abruptly behind M2 in smooth bone indicating that in life there was no tooth posterior to M2.

Length of the upper toothrow from the posterior border of the canine alveolus to the posterior border of M2 is $104.2 \mathrm{~mm}$. Length of the left P1-3 based on an alveolar measurement is $\sim 51 \mathrm{~mm}$. Greatest length of $\mathrm{P} 4-\mathrm{M} 2$ is $55.7 \mathrm{~mm}$.

Discussion: Although the mandible (F:AM 27562) and skull (F:AM 54134) here assigned to Mammacyon ferocior were not associated, the teeth in the mandible not only correspond in size and form to the upper teeth but also occlude perfectly. The collector, Charles Falkenbach, did not provide exact locality data for these fossils, but we know that they were derived from the same general locality north of Keeline, Wyoming, from gray volcaniclastic fine-grained sandstone of the Arikaree Group. Recent geologic study of the area north of Keeline and examination of the fossils previously collected from the area by the Frick Laboratory suggest that the fauna including $M$. ferocior can be considered as mid- to early late Arikareean in age. The fauna lacks a number of mammalian species that typify the late Arikareean (Ar3) Harrison Formation fauna of Sioux County to the east (see Age and Correlation). Although a radioisotopic age is not available for the $M$. ferocior hypodigm, faunal relationships suggest that the species is older than $\sim 23 \mathrm{Ma}$. Mammacyon has not been found in any known latest Arikareean (Ar4) fauna.

Associated limb elements and vertebrae were collected with the $M$. ferocior mandible (F:AM 27562) in 1931; they are alike in form but larger in size than the postcranials associated with the genoholotype of Mammacyon (ACM 34-41). Additional limb and foot bones (F:AM 107758) collected by Falkenbach in 1950 "from brownish sandstone 15 feet below highest exposure, west end, north of Keeline, Wyo." belong to a large temnocyonine and also possibly represent limb elements of $M$. ferocior. Included are a humerus (length, $234 \mathrm{~mm}$; width of distal end, $50.3 \mathrm{~mm}$ ), partial scapula (only the glenoid and adjacent blade), distal ?tibia, distal ?radius, and two elongate metapodials. M. ferocior retained a postcranial skeleton much like (if not identical to) $M$. obtusidens, indicative of a digitigrade cursorial gait in which the forelimb was characterized by a narrow distal humerus, a lengthening of radius and ulna with limited ability for pronation/supination, and an elongate tarsus and carpus (see Postcranial Osteology). These are the first large Cenozoic carnivorans to achieve a limb skeleton modified for a digitigrade stance, restricted fore-aft limb excursion, and a striding cursorial gait. This recommends a behavioral mode in which a cursorial habit was coupled with durophagous feeding, an ecology to some extent paralleling spotted hyaenids (Crocuta) in the Old World.

None of the other very large North American temnocyonine species (Temnocyon macrogenys, Delotrochanter major, Rudiocyon amplidens) are known from skulls, although Delotrochanter oryktes is represented by a substantial partial cranium (UNSM 47800) from the carnivore dens at Beardog Hill, Agate National Monument. The skull of $M$. ferocior (F:AM 54134) is the most complete cranium of a large temnocyonine and demonstrates that the terminal species of the 
Mammacyon lineage possessed a rather ursidlike profile, strong inflation of the frontal sinuses relative to volume of the cranial cavity, a broad rostrum swollen around the large canine alveoli, and a robust dentition with cheek teeth adapted for crushing bone, fibrous sinew, and muscle.

\section{cf. Mammacyon}

Figure 32

Sunkahetanka pahinsintewakpa (in part): Macdonald, 1970: 60 (LACM 15908 was initially placed in the canid genus Sunkahetanka).

REFERRED SPECIMEN: Fragment of mandible with left $\mathrm{m} 1-2$, posterior part of $\mathrm{p} 4$, and alveolus for m3 (LACM 15908), Sharps Formation, LACM loc. 1872, south of Wolf Ranch, NE1/4, sec. 15, T40N, R42W, Shannon County, South Dakota, collected by J. Harksen, July 1963.

DistRIBUTION: Early Arikareean, Sharps Formation, Wounded Knee area, South Dakota.

Comments: A small temnocyonine slightly larger than $T$. altigenis and with more derived m1-2; LACM 15908 has a more robust $\mathrm{ml}$ (length, $20.5 \mathrm{~mm}$; width, $9.9 \mathrm{~mm}$ ) relative to the $T$. altigenis hypodigm $(\mathrm{m} 1$ length, $17.4-19.5 \mathrm{~mm}$; 1 width, 7.7-9.3 mm); $\mathrm{m} 1$ metaconid more reduced relative to $T$. altigenis (metaconid is a small vestigial cusp on posterolingual slope of protoconid); $\mathrm{m} 2$ not elongate $(\mathrm{m} 1 / \mathrm{m} 2$ length ratio, $\sim 1.7)$ thus differs from $M$. obtusidens-M. ferocior (m1/ $\mathrm{m} 2$ length ratios, $1.57,1.6) ; \mathrm{m} 2$ protoconid and hypoconid in anteroposterior alignment and more centrally situated than these cusps in T. altigenis; posterior base of $\mathrm{p} 4$ only slightly broadened, and posterior accessory cusp labially (not centrally) placed; small m3 present; thick, robust dentary below molars. Lacks an enamel swelling at base of $\mathrm{m} 1$ posterolingual to protoconid (present in Delotrochanter petersoni, a carnivore of about the same size).

DESCRIPTION: The fragmentary mandible of LACM 15908 is about the same depth $(28 \mathrm{~mm})$ below the $\mathrm{ml}$ as Cope's type of Temnocyon altigenis $(29 \mathrm{~mm})$, however, the jaw is thicker and the teeth are larger and more robust (mandibular depth below $\mathrm{m} 2$ is similar, $\sim 31 \mathrm{~mm}$ in both species). Delotro- chanter petersoni, smallest species of its genus, has a depth below $\mathrm{m} 1$ of $\sim 33 \mathrm{~mm}$; although of about the same size as LACM 15908, its $\mathrm{m} 1$ lacks the metaconid and differs in the form of the principal cusps and cingulum. Only the posterior part of $\mathrm{p} 4$ is preserved in LACM 15908, anchored in the jaw by the posterior root. This tooth has both a basal cusp and a labially placed posterior accessory cusp. The posterior border of $\mathrm{p} 4$ fits tightly against the base of the $\mathrm{ml}$ paraconid. The posterior part of $\mathrm{p} 4$ is only somewhat widened, and could be transitional between the plesiomorphic laterally compressed $\mathrm{p} 4$ of $T$. altigenis and the posteriorly broad $\mathrm{p} 4$ of $M$. obtusidens.

The $\mathrm{m} 1$ is a small, well-worn carnassial. The placement of the three trigonid cusps is similar to their position in AMNH 6855, Cope's holotype of $T$. altigenis, however the metaconid is more reduced in LACM 15908. The cusps are more worn than in AMNH 6855 , and apical wear is pronounced on all $\mathrm{m} 1$ cusps but not present on $\mathrm{m} 2$. The broadened talonid of $\mathrm{m} 1$ bears a large, rounded hypoconid, nearly centrally situated; lingual to the hypoconid the enamel surface slopes downward to a narrow shelf lacking an entoconid. The labial $\mathrm{ml}$ cingulum is sinuous, not straight as in D. petersoni.

The $\mathrm{m} 2$ is not elongated as in M. obtusidens $-M$. ferocior. The centrally placed, low, blunt protoconid is the largest cusp; a vestigial paraconid is indicated only by the slightly elevated anterolingual corner of the tooth; there is no metaconid. The hypoconid is lower than the protoconid, is placed directly behind it, and is the sole talonid cusp. The $\mathrm{m} 2$ paraconid is not as pronounced as in $M$. obtusidens-M. ferocior, hence LACM 15908 lacks the anteriorly extended $\mathrm{m} 2$ trigonid of the latter two species, formed by the paraconid and a protrusion of the anterolabial corner of the tooth. However, the $\mathrm{m} 2$ of LACM 15908 could structurally precede the more elongate $\mathrm{m} 2$ of $M$. obtusidens. A single alveolus for $\mathrm{m} 3$ is present.

The masseteric fossa terminates anteriorly under the posterior part of $\mathrm{m} 2$, and the forward inclination of $\mathrm{m} 2-3$ on the edge of the ascending ramus of the mandible is evident in LACM 15908 exactly as in Mammacyon obtusidens. 

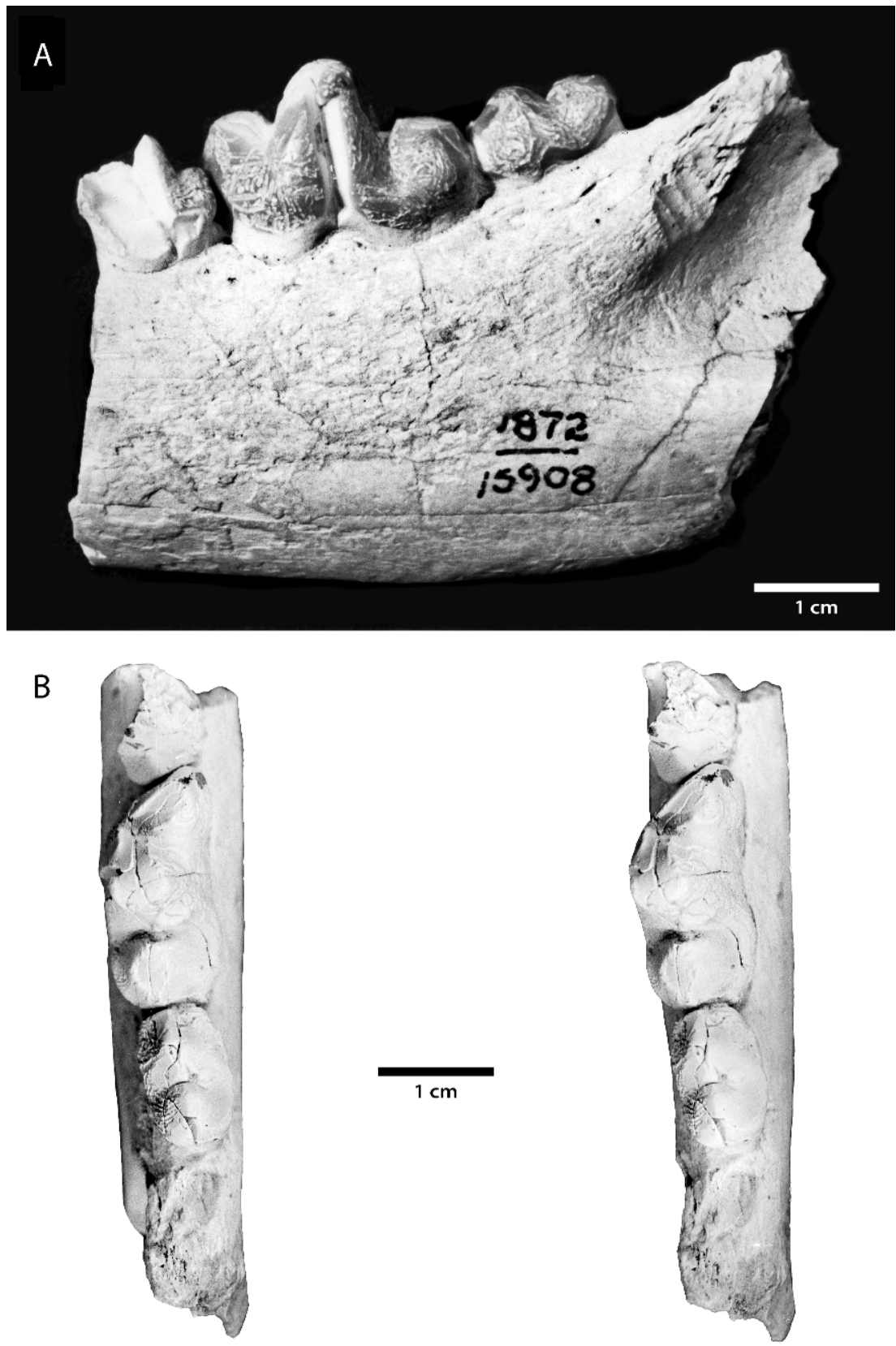

Fig. 32. Tentatively referred mandibular fragment of Mammacyon (LACM 15908) with left m1-2 and partial p4, LACM loc. 1872, Sharps Formation, Shannon Co., South Dakota. A, labial view; B, occlusal stereopair. Note apical wear on m1 cusps.

Discussion: This mandibular fragment, originally identified as a canid, is the earliest evidence of the Temnocyoninae described from the Cenozoic of the North American midcontinent. LACM Locality 1872 occurs in the Sharps Formation with an estimated age of between 28.8 and $29.4 \mathrm{Ma}$ (Tedford et al., 1996, 2004; Macdonald, 1970). The mandible represents a temnocyonine more specialized in its dentition than fossils of 
Temnocyon altigenis from the John Day beds of Oregon. T. altigenis (UCMP 9999) from Logan Butte is certainly older than $\sim 28.9 \mathrm{Ma}$, the date obtained on an ash bed near the top of the John Day Formation at the butte, and more likely falls near 29.2-29.3 Ma if collected near dated tuffs at the base of Logan Butte. UCMP 9999 and LACM 15908 could be approximately contemporaneous species, although a somewhat younger age for LACM 15908 seems more probable.

The teeth of LACM 15908, despite small size, have a robust quality much like the larger durophagous temnocyonines of the later Arikareean. The absence of its anterior premolars makes referral to a genus difficult because the short, wide premolars of Delotrochanter are diagnostic relative to more plesiomorphic premolars of Mammacyon and Temnocyon. Lack of the elongate $\mathrm{m} 2$ that distinguishes the Mammacyon lineage prevents certain referral to that genus but the shorter $\mathrm{m} 2$ of LACM 15908 could represent the ancestral state. The labial $\mathrm{m} 1$ cingulum appears to be slightly sinuous, a trait present in Mammacyon, differing from the straight labial cingulum of Delotrochanter. Referral of LACM 15908 to Temnocyon altigenis is not appropriate because of the strong reduction of the $\mathrm{m} 1$ metaconid and the deep mandible and broader teeth, indicating a more derived carnivore. More complete material of the Sharps temnocyonine will be necessary to establish its identity.

\section{Delotrochanter, new genus}

TyPe SPECIES: Delotrochanter oryktes, new species.

INCLUDED SPECIES: Delotrochanter petersoni, new species; $D$. oryktes, new species; $D$. major, new species.

Distribution: Mid- and late Arikareean of northwest Nebraska; latest Arikareean of Nebraska-Wyoming boundary in vicinity of the Niobrara River.

ETYMOLOGY: From the Greek, delos, for "evident," and trochanter, "runner," to emphasize the cursorial nature of these carnivores.

Diagnosis: Distinguished from Temnocyon by absence of the $\mathrm{m} 1$ metaconid; by a centrally placed $\mathrm{m} 2$ protoconid and hypo- conid; and by proportions of $\mathrm{P} 4$ and $\mathrm{M} 1$ (table 6, ratios A/B, C/D); from Mammacyon by a short, less elongate skull, by shorter broad p2-3 and less elongate $\mathrm{m} 2$ (ratio E/F); and from Rudiocyon by a more elongate $\mathrm{m} 2$ (ratio E/F). See tables 1-5.

DisCussion: The genus includes temnocyonines that abandon the plesiomorphic form of the cheek teeth and adopt a crushing durophagous dentition different from that of Mammacyon in proportions of the carnassial-molar battery. Delotrochanter petersoni appears to be a mid-sized ancestral species evolving to the large $D$. oryktes and the even larger $D$. major. The genus ranges in time from the midto latest Arikareean but is not certainly known in the early Arikareean interval.

\section{Delotrochanter petersoni, new species} Figure 33

Family Canidae, gen. et sp. indet: Peterson, 1907: 33-34, fig. 6. (The year of publication usually cited for this paper is 1906; however, a printed erratum in a copy in the American Museum's Osborn Library establishes March 21, 1907, as the publication date.)

TyPE: CM 1603, associated lower jaws, with only the left canine, $\mathrm{p} 1$, and $\mathrm{m} 1$ preserved. Also included under the same catalog number are the M1 protocone, the anterolabial corner of left P4, a metastylar fragment of right $\mathrm{P} 4$, a premolar, and four canine fragments. The Carnegie Museum field label records the holotype from the "middle Monroe Creek beds," head of Warbonnet Creek, Sioux County, Nebraska, collected by O.A. Peterson and party, May 1904, but was reported in Peterson's publication (1907: 24) as "from the upper Monroe Creek horizon."

DistRIBUTION: ?Mid-Arikareean, Arikaree Group, near head of Warbonnet Creek, Sioux County, Nebraska.

ETYMOLOGY: The species name recognizes the paleontologist Olaf Peterson who collected the holotype in northwest Nebraska in 1904.

DiagnOSIS: Smallest recognized species of Delotrochanter with $\mathrm{m} 1$ length of $22.3 \mathrm{~mm}$; differs in size from the much larger $D$. oryktes and D. major. Distinguished from Temnocyon and Mammacyon by nearly straight (not sinuous) labial cingulum on $\mathrm{m} 1$ and by short, 
A

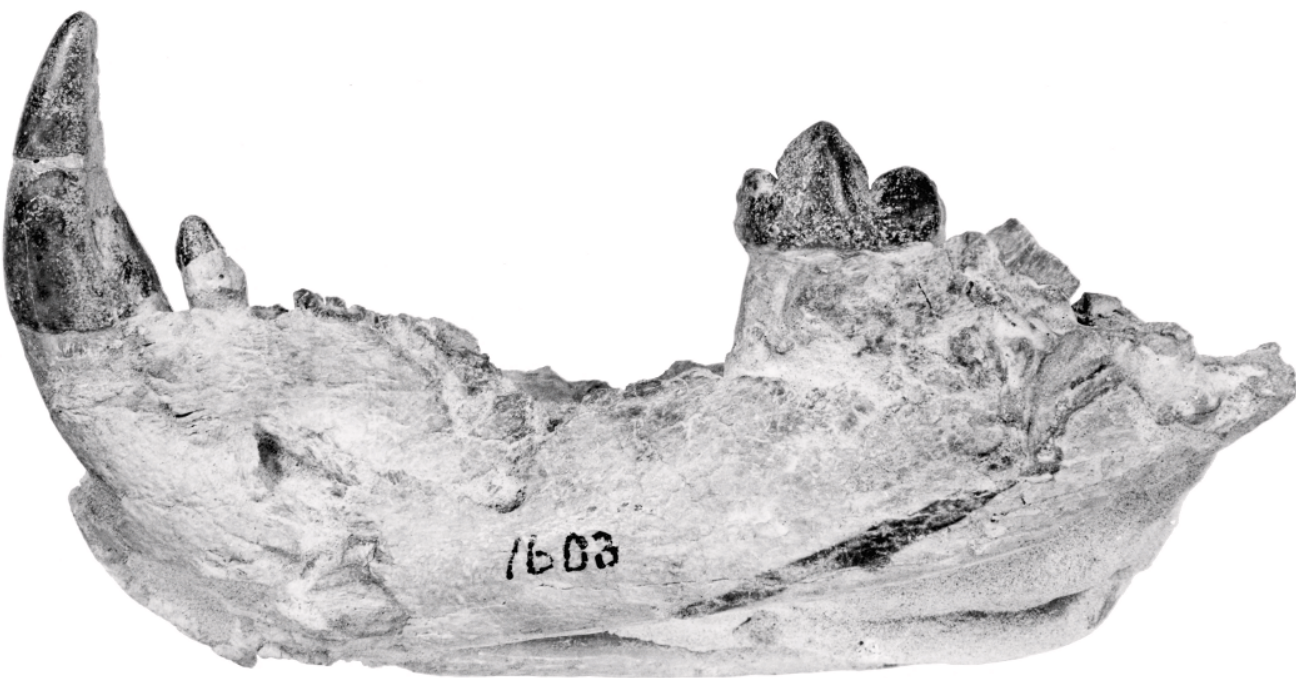

B

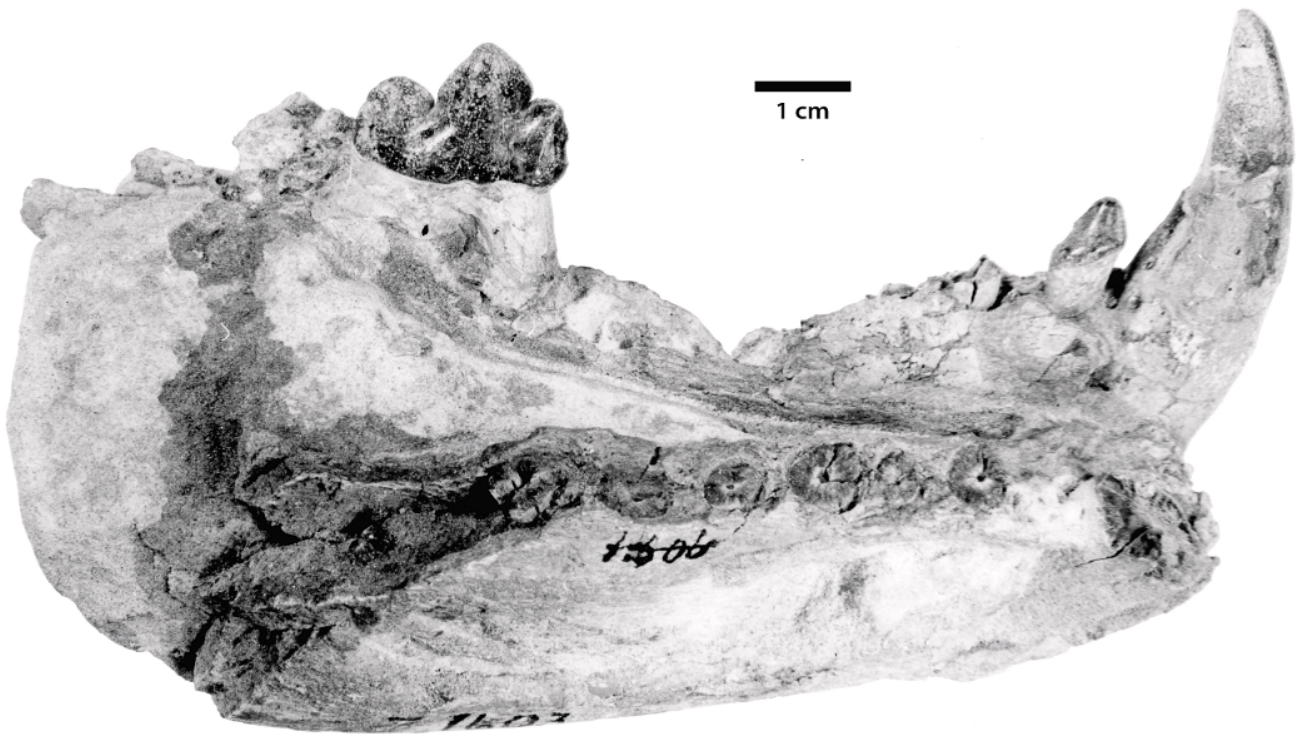

Fig. 33. Holotype mandibles of Delotrochanter petersoni (CM 1603), with left canine, $\mathrm{p} 1$ and $\mathrm{m} 1$, and alveoli for p2-p4, from the Monroe Creek beds (fide Peterson, 1907), head of Warbonnet Creek, Sioux Co., Nebraska. A, labial view and B, high oblique lingual view of left mandible and the alveoli of right mandible. The $\mathrm{ml}$ lacks a metaconid.

posteriorly broad p2-3. Differs from Temnocyon by absence of $\mathrm{m} 1$ metaconid; by its $\mathrm{m} 1$ paraconid-protoconid-hypoconid triad low, blunt, not specialized for shear and in direct anteroposterior alignment; and from Rudiocyon by much smaller size.
Referred Specimens: None.

DESCRIPTION: The canine measures $33.3 \mathrm{~mm}$ in height from tip to enamel base on the labial face, $12.0 \mathrm{~mm}$ in width, and $16.0 \mathrm{~mm}$ in length at the enamel base. A wear groove is developed on the 
posterolabial surface by the action of the upper canine.

The p1 measures $7.7 \mathrm{~mm}$ in length, $5.6 \mathrm{~mm}$ in width. It is a simple, conical tooth with an anteriorly placed main cusp and no accessory cusps.

Only roots of p2-4 are present, however they demonstrate that the premolars were closely spaced but not crowded. Labial placement of the anterior root of p2 suggests that the front of the tooth was rotated slightly outward. An important dental trait of Delotrochanter petersoni is that p2-3 are short with small-diameter anterior roots, a specialization of the anterior premolars also found in Delotrochanter oryktes and D. major, thus a defining characteristic of the genus. In Mammacyon and Temnocyon, p2-3 are elongate teeth with anterior roots of larger diameter.

The $\mathrm{m} 1$ measures $22.2 \mathrm{~mm}$ in length, $11.3 \mathrm{~mm}$ in greatest width (at protoconid), and $10 \mathrm{~mm}$ in transverse width across the hypoconid. There is no metaconid; the paraconid is short and robust, much lower than the protoconid, with a paraconid blade $3.7 \mathrm{~mm}$ in length. The wide, robust protoconid is $10.1 \mathrm{~mm}$ in length measured between the incisures it forms with the paraconid and hypoconid. Its talonid is dominated by a massive, blunt, centrally placed hypoconid that functions as a crushing cusp when applied to the protocone basin of M1. From the hypoconid-protoconid incisure to the rear of the talonid is $7.6 \mathrm{~mm}$. An indistinct cingulum surrounds the base of $\mathrm{m} 1$, but this cingulum on the labial side is nearly straight, not sinuous, and is a key feature linking $D$. petersoni to $D$. oryktes.

The $\mathrm{m} 2$ was not preserved and its size cannot be accurately determined since both mandibles have been damaged in this area. Peterson (1907: 34, fig. 6) in his description of the specimen stated that "judging from the specimen, $\mathrm{m} 2$ was of considerable size." Peterson figured two alveoli for the roots of $\mathrm{m} 2$ : the anterior alveolus is represented by a root, and the posterior alveolus by a circular depression where a root tip once existed. Estimating the length of $\mathrm{m} 2$ from these two alveolar remnants gives an $\mathrm{m} 2$ length of $\sim 13 \mathrm{~mm}$, and an $\mathrm{m} 1 / \mathrm{m} 2$ ratio of $\sim 1.7$, similar to that of D. oryktes (ratio E/F, 1.69, table 6).
Little can be said concerning the four isolated canine fragments that accompany CM 1603. However, these fragments and the intact canine in the mandible show that the canines are large teeth relative to the dimensions of the mandible.

The fragment of the anterolabial corner of the left P4 indicates that the upper carnassial had a slightly swollen basal cingulum, and that a fine enamel ridge ran from the tip of the paracone to a point just medial to the anterolabial corner, a typical feature of temnocyonines. In addition, the paracone was a low, blunt cusp as are the $\mathrm{m} 1$ cusps. This tooth fragment is configured as in Delotrochanter where the anterolabial corner is not anteriorly extended as it is in large Mammacyon. A fragment of the metastylar blade of the right $\mathrm{P} 4$ shows that the blade was short and broad, measuring $9 \mathrm{~mm}$ in length, about $8.2 \mathrm{~mm}$ in width. It compares well with the metastylar blade of $D$. oryktes (ACM 4804). An indistinct cingulum surrounds the blade. The fragment is similar in size to the fragmentary P4 metastylar blade of $T$. ferox (YPM-PU 10787) but is more robust. In fact, the narrow blade of $T$. ferox represents a more sectorial carnassial.

A fragment of the left M1 protocone shows that the protocone region was already anteroposteriorly widened. The protocone fragment measures $12.5 \mathrm{~mm}$ in anteroposterior width but in life the tooth was wider since the posterior part of the thickened lingual cingulum is missing. The M1 protocone of CM 1603 was knoblike and isolated in an enamel flat surrounded by an expanded lingual cingulum.

The depth of the mandible below $\mathrm{m} 1$ is $32.8 \mathrm{~mm}$ and below $\mathrm{p} 2$ is estimated at $30 \mathrm{~mm}$. This is a rather shallow jaw relative to its thickness (12.9 mm below $\mathrm{m} 1$ ).

Note that Peterson's figure (1907: fig. 6) gives CM 1506 for this specimen, whereas his text reads CM 1603: this last is the correct catalog number and is the only number on the specimens. The specimen labels show that the mandibles initially were given CM 1506 and the isolated teeth fragments assigned CM 1505; all this material later was united under CM 1603.

Discussion: This mandible, collected in 1904, was the first record of Temnocyoninae 
in the North American midcontinent, and was believed by Peterson (1907) to be a canid (within the broader meaning of that term as used at that time, i.e., canids and amphicyonids). The few intact teeth present in the left mandible (canine, p1, m1) made identification difficult. However, the following traits suggest that this is the earliest North American representative of Delotrochanter:

(1) absence of $\mathrm{m} 1$ metaconid, straight labial cingulum on $\mathrm{m} 1$, and large centrally placed $\mathrm{m} 1$ hypoconid filling the talonid; (2) short p2-3, with small-diameter anterior roots and largerdiameter posterior roots; (3) unexpanded anterolabial corner of $\mathrm{P} 4$ like that of $D$. oryktes; low, short P4 metastylar blade; (4) slender, shallow horizontal ramus of the mandible.

Fine-grained gray volcaniclastic sandstone adheres to the mandibles, leaving no doubt as to the sediment in which the fossil was found. Along the Pine Ridge escarpment in Sioux County near the head of Warbonnet Creek, this matrix is typical of the Arikaree Group, and indicates gray volcaniclastic sandstone exposures of the middle and upper part of the escarpment. Peterson's confusing attribution to "middle" Monroe Creek (on field labels) and later on, "upper" (in his published article), at least indicates that CM 1603 came from beds stratigraphically between the lower Arikaree fluvial sandstones at the base of the Pine Ridge and the eolian Harrison Formation sandstones forming the upper part of the escarpment, but prevents an exact stratigraphic designation.

The Pine Ridge escarpment immediately east of Warbonnet Creek includes the stratotypes for the Monroe Creek Formation and Harrison Formation of Hatcher (1902a) at Monroe Creek Canyon. Because Peterson did not attribute the fossil to the Harrison Formation, one can be reasonably confident that CM 1603 did not come from that rock unit as understood by Peterson and Hatcher (i.e., the upper $\sim 200 \mathrm{ft}$ of the Pine Ridge Arikaree escarpment). Hatcher in 1902 described the Monroe Creek Formation as "300 feet of very light-colored, fine-grained, not very hard, but firm and massive sandstones." Based on Peterson's published attribution to "upper Monroe Creek," one would predict that CM 1603 came from fine-grained gray tuffaceous sandstones of the Pine Ridge escarpment $\sim 200-400 \mathrm{ft}$ below the terminal paleosol of the Harrison Formation (Hunt, 1985). These sandstones exhibit large-scale eolian cross-strata, in which CM 1603 was possibly found, that constitute much of the middle part of the Pine Ridge stratigraphic section in Sioux County from Monroe Creek west to Warbonnet Creek. Fossil mammals are rarely encountered in these beds.

Previously I attributed the temnocyonine here named Delotrochanter petersoni to an early Arikareean chronofauna (Hunt, 1985: 192) but Peterson's (1907: 24) "upper Monroe Creek" allocation, which places CM 1603 in association with the oreodonts Promerycochoerus and Phenacocoelus, cannot be ruled out and suggests a younger age. It is at least certain $D$. petersoni occurs in a fauna older than that typical of the Harrison Formation of Peterson. This is supported by the size relationship of $D$. petersoni to its presumed descendant, D. oryktes. The latter species occurs in the Harrison Formation in the Niobrara River valley at Agate National Monument, and its predecessor, D. petersoni, is of the smaller size and dental features one would predict in "middle to upper Monroe Creek" sediments of the Pine Ridge.

Delotrochanter oryktes, new species Figures 34-39

"The major part of a skeleton of Daphoenodon
superbus Peterson ...": Loomis, 1910: 298.

TYPE: ACM 4804, partial skull with right I2-3, C, P1-2, P4-M2, and left I2-3, C (partial), P1-2, P4-M1, labial half of M2; right mandible with $\mathrm{c}, \mathrm{p} 4-\mathrm{m} 2$; left mandible with c, p2-4, m1-2; and much of the postcranial skeleton, from the Harrison Formation, Stenomylus Quarry, Agate Fossil Beds National Monument, Sioux County, Nebraska, collected by F.B. Loomis, 1908.

Distribution: Late Arikareean, Harrison Formation and basal Anderson Ranch Formation, Agate Fossil Beds National Monument, Sioux County, Nebraska.

ETYMOLOGY: From the Greek, oryktes, for "digger" or "excavator," in allusion to the discovery of one of the individuals of the species in a burrow.

Diagnosis: Distinguished from $D$. petersoni by larger size (D. petersoni $\mathrm{m} 1$ length, 


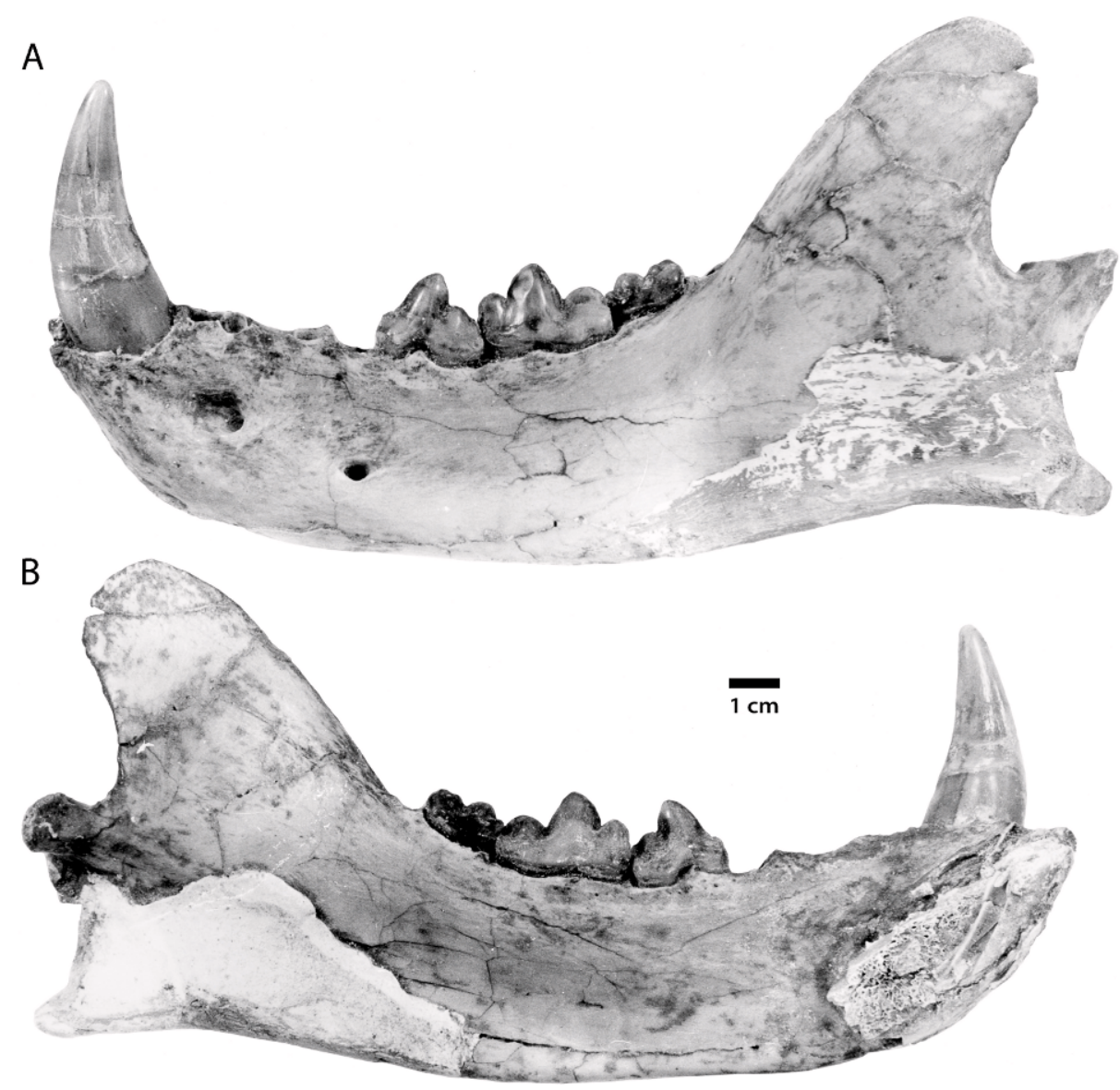

Fig. 34. Holotype mandible of Delotrochanter oryktes (ACM 4804) with left canine, p4-m2, alveoli of p1-3, from Stenomylus Quarry, Harrison Formation, Agate Fossil Beds National Monument, Sioux Co., Nebraska. A, labial and $\mathbf{B}$, lingual views. Male individual found with baculum.

$22.3 \mathrm{~mm}$; D. oryktes $\mathrm{m} 1$ length, $27.1 \mathrm{~mm}$ ). Dentition clearly antecedent to that of the much larger D. major (tables 2, 3), but not as massive and robust. Differs from Temnocyon by loss of the $\mathrm{m} 1$ metaconid and by short, posteriorly wide p2-3 and P2-3; from Mammacyon by a posterior accessory cusp on $\mathrm{p} 3$, a large centrally placed posterior accessory cusp on $\mathrm{p} 4$, and by a smaller P4 with lingually abbreviated protocone region; and from Rudiocyon by the form of $\mathrm{p} 4$.

REFERRED SPECIMENS: (1) UNSM 47800 (field no. 8-81), partial skull with left P2-M2, lingual half of right $\mathrm{M} 1$, right $\mathrm{I} 2-3$, and petrosal fragment; associated left calcaneum, left metatarsals 2-4, left metacarpals 3-5 with proximal phalanx and 2 sesamoids, left mag- num; found in place within a burrow, Carnegie Quarry 3, Beardog Hill den site, Agate Fossil Beds National Monument, Sioux County, Nebraska, collected September 14, 1981, by J. Kaufman and R.M. Hunt (UNSM field no. 9-81 was given to the fifth metacarpal, found near the skull, presumably from the same individual); (1a) CM 1589b, right metatarsal 5, Carnegie Quarry 3, Beardog Hill den site, collected by O.A. Peterson, 1904-1905, probably the same individual as UNSM 47800; (2) YPM-PU 24872, left calcaneum, removed from Princeton University quarry block (now YPM-PU 12213), Princeton Expedition of 1914, loc. 1002A, Carnegie Hill waterhole bonebed, Agate Fossil Beds National Monument, Sioux County, Nebraska. 


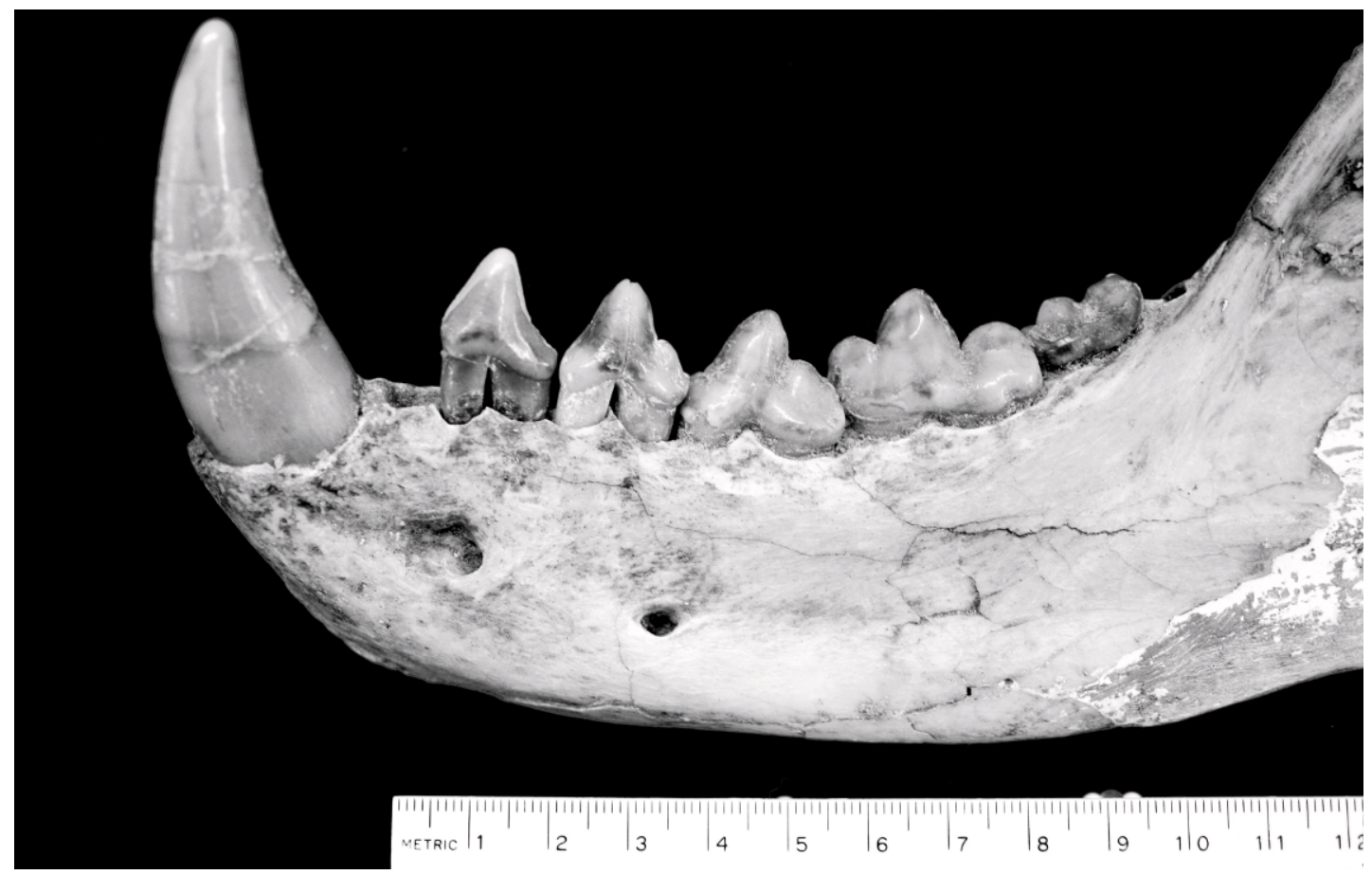

Fig. 35. Holotype mandible of Delotrochanter oryktes (ACM 4804) with left canine, p2-m2 (p2-3 inserted in mandibular alveoli to demonstrate small diameter of anterior roots).

DESCRIPTION: Both individuals referred to this species (ACM 4804, UNSM 47800) come from Agate Fossil Beds National Monument, Sioux County, Nebraska, and were collected 73 years apart. ACM 4804, designated here as the holotype, includes a nearly complete skeleton discovered by Loomis at Stenomylus Quarry in 1908. It was originally referred to Daphoenodon superbus: Loomis (1910) did not recognize it as a temnocyonine, a group almost unknown at that time. A second individual (UNSM 47800) is represented by a skull (fig. 37) and bones of the fore- and hind feet, found within a carnivore burrow (front cover) during the reopening of Carnegie Quarry 3 by the University of Nebraska in 1981 (Hunt et al., 1983; Hunt, 1990: 106107).

The mandible and lower dentition are known in ACM 4804 but were not recovered with UNSM 47800. The following description is based on ACM 4804; it is selected here as the holotype of the species because of the association of maxillary and mandibular dentition with the postcranial skeleton (see
Postcranial Osteology). Appropriate comparisons are made with the larger derivative species, D. major, known only from teeth.

The mandible is deep yet thin, with a distinctive recurved coronoid process and a wide $(35.8 \mathrm{~mm})$ articular condyle. The anterior margin of the ascending ramus curves gradually downward beneath the rear molars so that $\mathrm{m} 2-3$ are forwardly inclined as in several other temnocyonines. The nearly uniform depth of the horizontal ramus is demonstrated by similar measurements beneath $\mathrm{m} 1(45.7 \mathrm{~mm})$ and $\mathrm{p} 2(41 \mathrm{~mm})$. Length of the mandible measured from the symphysis (between the first incisors) and the posterior surface of the articular condyle is $205 \mathrm{~mm}$.

Lower incisors did not survive in either individual referred to this species. Alveoli for i1-3 are present in the left mandible of ACM 4804: the single alveolus for i3 (width, $4.5 \mathrm{~mm}$ ) shows that it was the largest of the lower incisors. A smaller i2 alveolus is situated medial to i3, and a very small il alveolus is placed slightly internal and ventral to i2. 


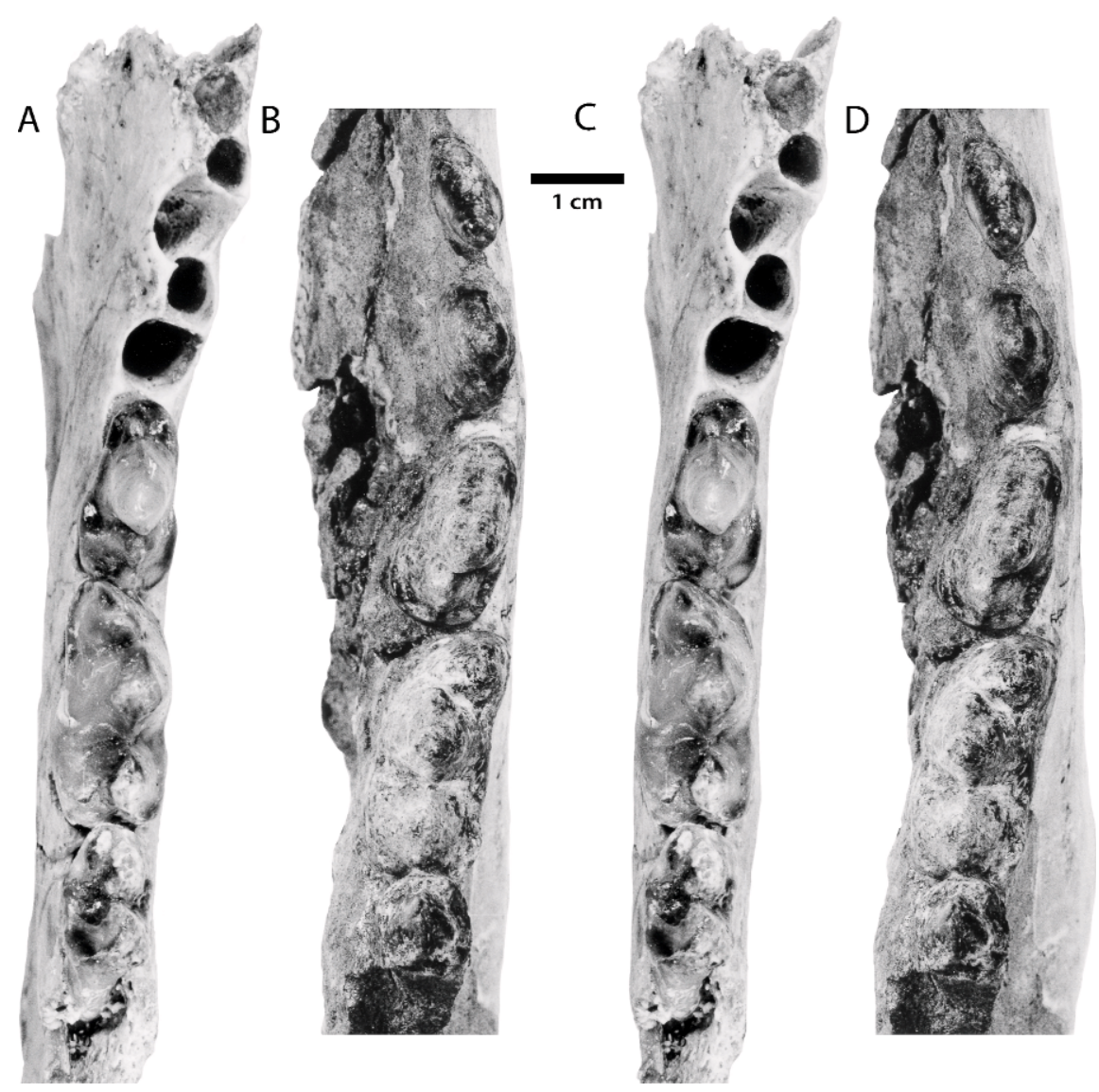

Fig. 36. Occusal stereopairs of the holotype mandibles of (A, C) Delotrochanter oryktes (ACM 4804) and (B, D) Delotrochanter major (F:AM 27561). D. oryktes, right p4-m2, alveoli of p1-3; D. major, left p2$\mathrm{m} 2$. Note absence of $\mathrm{m} 1$ metaconids and relative anterior and posterior alveolar diameters of $\mathrm{p} 2$ in $D$. oryktes. The $\mathrm{p} 4-\mathrm{m} 2$ are crushing teeth in both species.

The left lower canine of ACM 4804 is not as strongly recurved as in some species of Temnocyon (UCMP 9999, YPM-PU 10787). Canine height from the base of the enamel to the unworn tip on the labial side is $36.8 \mathrm{~mm}$. Length and width measured at the base of the enamel are $18.5 \mathrm{~mm}$ and $12.5 \mathrm{~mm}$, respectively. A pronounced enamel ridge runs from the tip to the enamel base on the posterior edge, and a second ridge travels down the anterolingual face. Although the $\mathrm{m} 1$ of a wolf is about the same size as the $D$. oryktes $\mathrm{m} 1$, the beardog canine is much larger.

The $\mathrm{p} 1$ is not preserved in ACM 4804; the single large alveolus measures $8.2 \mathrm{~mm}$ in length, $6 \mathrm{~mm}$ in width, and is crowded between the canine and $\mathrm{p} 2$ alveoli, and is in contact with both. Closely spaced alveoli are common to the entire lower toothrow. The slight crowding of premolar alveoli is due to the youth of this carnivore (all teeth are only in early wear).

The $\mathrm{p} 2$ is a tall, yet anteroposteriorly short, double-rooted tooth, $14.9 \mathrm{~mm}$ in length, $8.2 \mathrm{~mm}$ in greatest width. There is no posterior accessory cusp. The anterior face is steeply inclined and is traversed by a fine enamel ridge that extends from tip to anterolingual cingulum. The posterior face is more gradually inclined with an enamel ridge running from tip to posterolabial cingulum. The anterior root of $\mathrm{p} 2$ is much smaller (length, $4.9 \mathrm{~mm}$ ) than the robust posterior root (length, $8.5 \mathrm{~mm}$ ), a distinguishing trait of the species. 

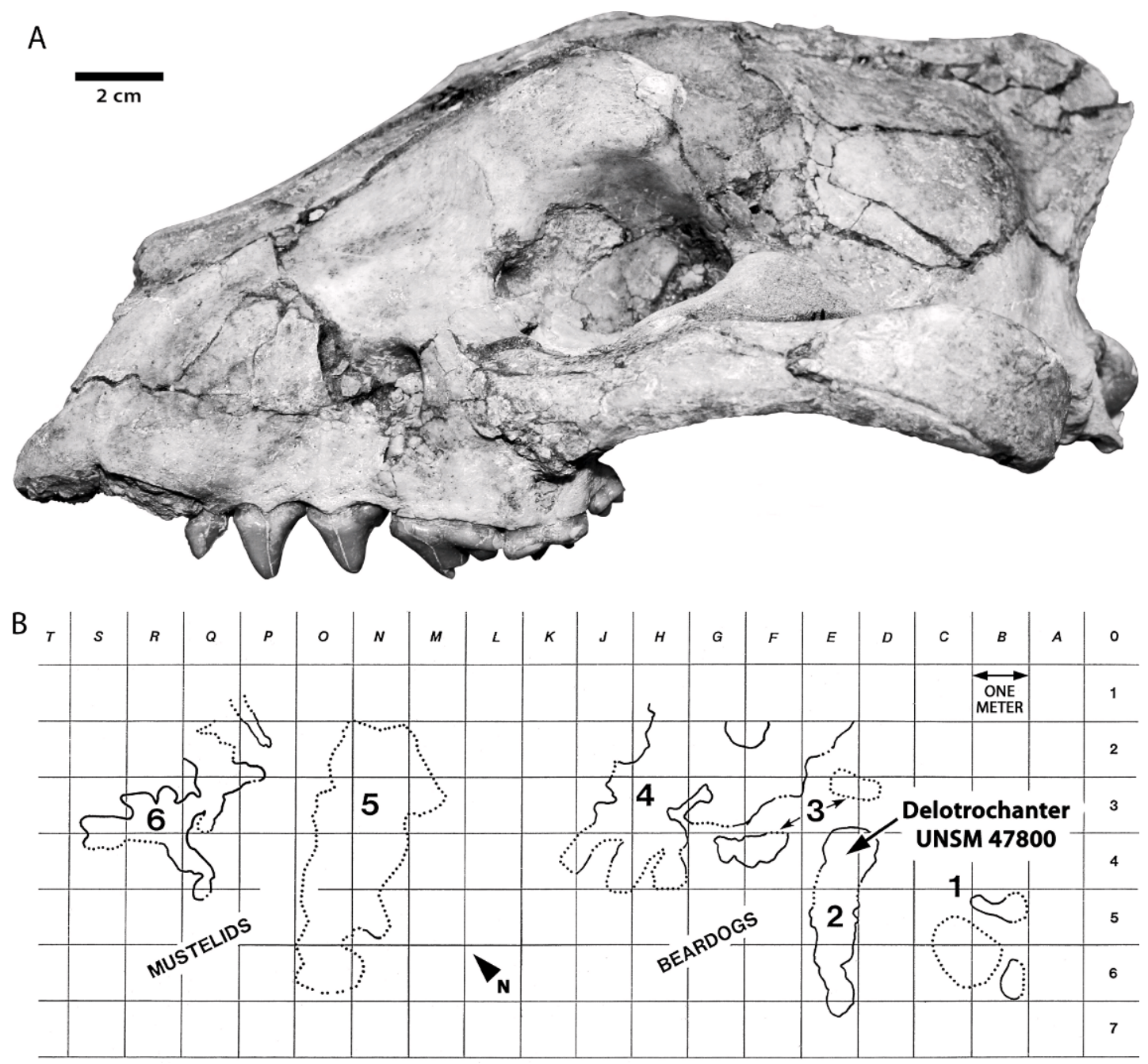

Fig. 37. A, Delotrochanter oryktes (UNSM 47800), cranium with P1-M2 of presumed female from carnivore den, Beardog Hill, Agate Fossil Beds National Monument, Sioux Co., Nebraska. The short, deep hyenalike skull is unique among temnocyonines. B, Plan map of dens showing location of burrow (den 2) that contained the skull and foot bones of D. oryktes (UNSM 47800). The beardog Daphoenodon superbus was the principal occupant of dens 1,3, and 4; mustelids were found in dens 5 and 6 .

The p3 measures $16.6 \mathrm{~mm}$ in length, $9.4 \mathrm{~mm}$ in posterior width, and $6.9 \mathrm{~mm}$ in anterior width. The tooth is short and posteriorly wide, which is evident when compared with the respective dimensions of p3 in Mammacyon ferocior $(19.3 \mathrm{~mm}, 9.0 \mathrm{~mm}, 6.8 \mathrm{~mm})$. There is a posterior accessory cusp, somewhat labially placed. A slightly swollen basal cingulum is more pronounced on the lingual and posterior sides. Just as for $\mathrm{p} 2$, the anterior root is smaller than the posterior root.
The p4 is robust, with a wide heel, measuring $21.0 \mathrm{~mm}$ in length, $10.8 \mathrm{~mm}$ in posterior width, and is much larger than $\mathrm{p} 3$. Its form is diagnostic of the genus, notably the large posterior accessory cusp centrally placed on an expanded heel behind the principal cusp. Delotrochanter is the only temnocyonine that has evolved a centrally placed posterior accessory cusp on p4. In Temnocyon and Mammacyon the accessory cusp is labially placed. 


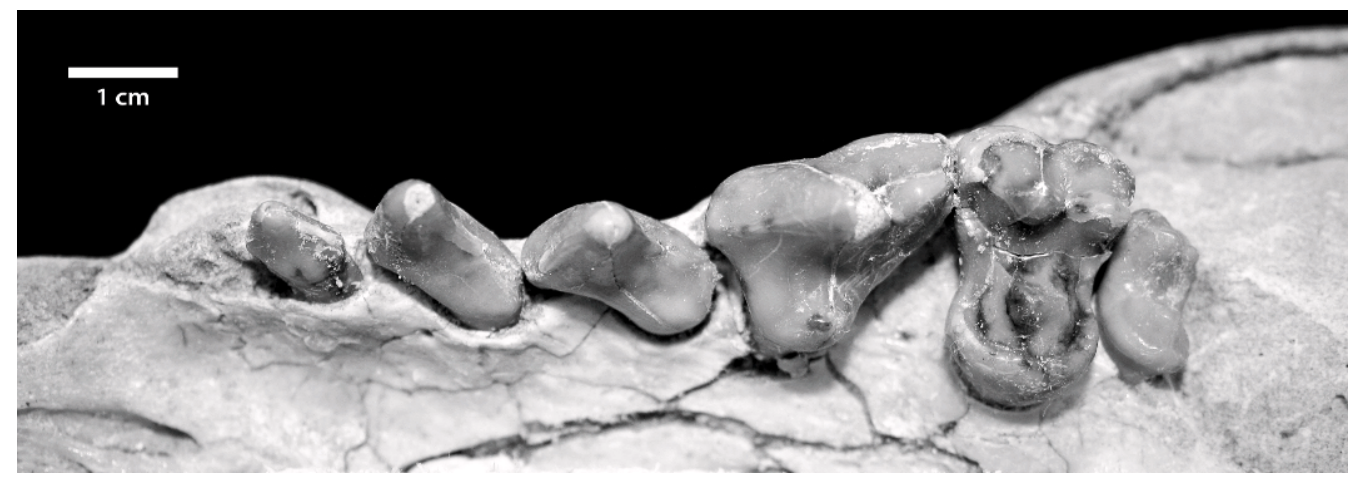

Fig. 38. Left maxilla of the Delotrochanter oryktes cranium (UNSM 47800) with P1-M2, presumed female, Beardog Hill, Agate Fossil Beds National Monument, Sioux Co., Nebraska. The crushing P4-M1 is more gracile than these teeth in the male (ACM 4804, fig. 39).

The height of the principal cusps of $\mathrm{p} 2-4$ is pronounced, so much so that the linear serial alignment of the premolar cusps is continued along the toothrow by the principal cusps of $\mathrm{m} 1$ and $\mathrm{m} 2$, and this cusp alignment is further emphasized by the elevation of $\mathrm{m} 2$ 3 on the rising margin of the ascending ramus.

The $\mathrm{m} 1$ is a crushing carnassial, $27.1 \mathrm{~mm}$ in length, $12.7 \mathrm{~mm}$ in greatest width, formed by three aligned bunodont cusps, the paraconid-protoconid-hypoconid. There is no metaconid or entoconid. The thickened labial cingulum is essentially straight, not sinuous as in Temnocyon and Mammacyon. The hypoconid is centrally placed on the talonid and in labial view is as tall as the

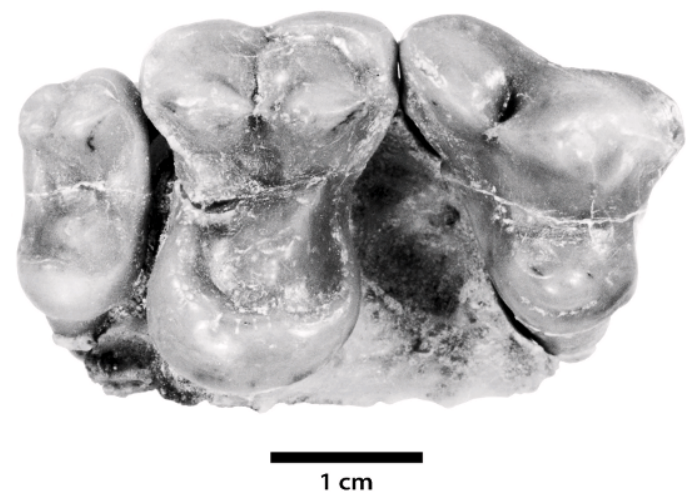

Fig. 39. Right maxilla with P4-M2 of Delotrochanter oryktes (ACM 4804, male), Stenomylus Quarry, Harrison Formation, Agate Fossil Beds National Monument, Sioux Co., Nebraska. paraconid (as in Mammacyon but not Temnocyon). The nearly equal development of hypoconid and paraconid flanking the protoconid creates a profile typical of large species of Mammacyon and Delotrochanter, but a somewhat larger hypoconid in Delotrochanter emphasizes the cusp alignment adapted for crushing.

The $\mathrm{m} 2$ is rectangular in occlusal view, measuring $16.0 \mathrm{~mm}$ in length, $10.0 \mathrm{~mm}$ in greatest width $(\mathrm{m} 1 / \mathrm{m} 2$ length ratio, $\sim 1.7$, table 6). The protoconid and hypoconid are placed in direct anteroposterior alignment behind the $\mathrm{m} 1$ hypoconid. These three cusps are about the same height and form a crushing battery posterior to the carnassial blade. There is a low vestigial paraconid. The $\mathrm{m} 2$ is not as elongate (relative to $\mathrm{m} 1$ length) as in Mammacyon, but the cusps of $\mathrm{m} 2$ are centrally placed as in that genus. Hence, one of the hallmarks of Delotrochanter is the central placement of all cusps from $\mathrm{p} 4$ to $\mathrm{m} 3$ (with slight lingual diversion of the $\mathrm{ml}$ paraconid).

The $\mathrm{m} 3$ is not preserved but is represented in ACM 4804 by a single large alveolus, length $5.3 \mathrm{~mm}$, width $5 \mathrm{~mm}$.

In ACM 4804, p1-m3 length is $104.5 \mathrm{~mm}$; p2-m2 length, $89.6 \mathrm{~mm} ; \mathrm{p} 1-4$ length, $59.7 \mathrm{~mm}$; m1-3 length, $48.2 \mathrm{~mm}$.

The skull of ACM 4804 was damaged during preparation and mounting of the specimen at Amherst College shortly after it was collected in 1908. With the aid of Drs. Margery and Walter Coombs, we were able to recover the skull and restore part of the 
rostrum and palate and a few basicranial fragments, including the right petrosal and a partial basioccipital.

The central incisors (I1-2) of ACM 4804 are much smaller than I3. I1 is not preserved in ACM 4804, however the alveolus measures $9.3 \mathrm{~mm}$ in length, $4.1 \mathrm{~mm}$ in width. I2 is present with a vertical anterior face, a sloping posterior surface, and a prominent auxiliary cusp (Nebenzacke) on its lateral margin. I2 is $9.8 \mathrm{~mm}$ in length, $5.7 \mathrm{~mm}$ in width at the enamel base. I3 is a large, recurved caniniform tooth measuring $23.2 \mathrm{~mm}$ in height from tip to posterolabial enamel border, $13.1 \mathrm{~mm}$ in length, $10.1 \mathrm{~mm}$ in width at the base of the enamel. I3 has a thin enamel ridge from tip to posterolabial base and another on the lingual face from tip to enamel base. I2-3 in UNSM 47800 show no differences from those incisors in ACM 4804.

The upper canine measures $37.9 \mathrm{~mm}$ in height from its posterolabial enamel base to its unworn tip. Length and width at the base of the enamel are 19.3 and $13.4 \mathrm{~mm}$. An enamel ridge runs from the tip to the enamel base on the posterior surface; a second ridge runs from tip to base on the anterolingual surface.

$\mathrm{P} 1$ is a small, conical tooth $9.4 \mathrm{~mm}$ in length, $6.9 \mathrm{~mm}$ in greatest width. There is a single principal cusp and no accessory cusp. The principal cusp is placed forward of center, and from this cusp a fine enamel ridge extends down both the anterior and posterior faces of the tooth.

$\mathrm{P} 2$ is much larger than $\mathrm{P} 1$, measuring $15.8 \mathrm{~mm}$ in length, $8.7 \mathrm{~mm}$ in posterior width (in UNSM 47800, P2 measures $15.9 \mathrm{~mm}$ and $8.0 \mathrm{~mm}) . \mathrm{P} 2$ is tall, triangular in lateral view, with a vertical, nearly rectilinear anterior face and a more gradually sloping posterior face. Of importance is the small anterior root relative to the larger posterior root, a diagnostic feature of Delotrochanter, indicating that the shortening of $\mathrm{p} 2$ in the lower jaw is reciprocated in the upper dentition. Alveolar length of the P2 anterior root is $5.6 \mathrm{~mm}$; posterior root, $10.0 \mathrm{~mm}$; length of the roots themselves are, respectively, 5.2 and $8.8 \mathrm{~mm}$. The posterior heel of $\mathrm{P} 2$ is widened and a weak accessory cusp is labially placed low on the broad heel. Thin enamel ridges are present on the anterior and posterior faces of $\mathrm{P} 2$, running to the respective anterolingual and posterolabial corners.

P3 is lost from the skull of ACM 4804 but is present in UNSM 47800 (length, $18.2 \mathrm{~mm}$; width, $9.8 \mathrm{~mm}$ ) where it is about the same height as P2 but posteriorly wider with a small accessory cusp slightly labially situated on the posterior slope.

P4 measures $21.4 \mathrm{~mm}$ in labial length, $18.8 \mathrm{~mm}$ in greatest transverse width across the protocone. This massive tooth has a short metastylar blade $9 \mathrm{~mm}$ in length that forms a moderately developed shear surface with the large paracone. Small vertical wear facets are developed on the lingual faces of metastylar blade and paracone but the predominant crushing mode of occlusion is evidenced in this young individual by bluntcusp wear on the paracone. As in the larger temnocyonines, the rounded blunt protocone is enlarged for crushing but is not as massive as in species of Mammacyon. The protocone in Delotrochanter does not extend as far toward the midline of the palate as it does in Mammacyon, and does not reach the lingual margin of M1. P4 length is $22.8 \mathrm{~mm}$ and width is $17.9 \mathrm{~mm}$ in UNSM 47800, too young an individual to develop shear facets on $\mathrm{P} 4$.

M1 measures $17.7 \mathrm{~mm}$ in length of the labial margin, $25.4 \mathrm{~mm}$ in greatest transverse width, and $14.7 \mathrm{~mm}$ in anteroposterior width of the protocone region. In UNSM 47800, M1 length is $17.5 \mathrm{~mm}$; greatest width is $23.9 \mathrm{~mm}$; and width across the protocone is $14.1 \mathrm{~mm}$, thus a smaller molar relative to the M1 in ACM 4804. An M1 that is constricted at the level of the protocone basin so that the tooth has a "waist" is typical of Delotrochanter and Mammacyon. The labial half of M1 is formed by a prominent, yet rather blunt, paracone and somewhat smaller metacone bordered by a labial cingulum thickened in the parastylar region. The lingual faces of the paracone and metacone form a vertical shear surface but these cusps are lower and shear is not as developed as in large species of Temnocyon. The low protocone is isolated within an enamel platform, creating a flat crushing surface surrounded by a muchthickened lingual cingulum. A preprotocrista runs from the protocone to the anterior 
cingulum at the base of the paracone but there is no postprotocrista. On the M1s of both ACM 4804 and UNSM 47800 the lingual cingulum thins abruptly at the level of the protocone basin. The lingual cingulum of UNSM 47800 is not as developed as in ACM 4804.

M2 is a rectangular tooth, much smaller than M1, measuring $9.3 \mathrm{~mm}$ in labial length, $17.4 \mathrm{~mm}$ in greatest width (M2 length, $8.9 \mathrm{~mm}$; width, $15.3 \mathrm{~mm}$ in UNSM 47800). The paracone is much larger than the strongly reduced metacone, both bordered by a labial cingulum thickened in the parastylar region. The lingual faces of para- and metacone form a low shear surface that continues the paracone- metacone shear plane of M1 (this plane less evident in UNSM 47800 in which M2 is more reduced). The M2 protocone is a low, blunt cusp isolated on an enamel platform surrounded by a slightly thickened lingual cingulum. There is no evidence of M3 although that part of the maxilla where M3 would occur is not preserved. However, UNSM 47800 has an intact maxilla in which M3 is certainly absent.

The skull (UNSM 47800) found in 1981 within a burrow at Beardog Hill, Agate Fossil Beds National Monument preserves the left P1-M2 (figs. 37-38). This is the only known skull of Delotrochanter. The left side of the skull and upper dentition are largely intact, whereas the right side was destroyed by plant roots that invaded the burrow. The skull is remarkably similar in form to the skull of the hyena, Crocuta crocuta. Both skulls are broad and rather short with laterally extended zygomatic arches and large temporal fossae indicating well-developed temporal jaw musculature. Both have blunt, short snouts of similar length: the preorbital proportion of skull length in UNSM 47800 is $40 \%$ and in the hyena $35 \%$. UNSM 47800 differs from Crocuta in possessing a more inflated frontal region and more massive snout with larger canines. The infraorbital foramen of UNSM 47800 is much larger than this foramen in the hyena, suggesting a more developed neurovascular supply to the nasal region. The braincase of UNSM 47800, despite the rather short skull, is the largest of any known temnocyonine (table 7).
The upper teeth are extremely similar in form to those of ACM 4804 but are somewhat smaller and more gracile. $\mathrm{P} 4$ is longer and its protocone not as developed, and the M1-2 are smaller, not as hypertrophied as in ACM 4804. The crushing function of $\mathrm{P} 4-\mathrm{M} 2$ is better developed in ACM 4804. ACM 4804 is a male (a baculum was found with the skeleton) and, based on the gracile teeth, UNSM 47800 could be a female. Sexual dimorphism is common among amphicyonids and it would not be surprising to find it present in temnocyonines. Dimorphism in temnocyonine species is difficult to demonstrate because of the lack of multiple individuals from a single locality.

Discussion: Delotrochanter is defined on the basis of the holotype dentition and skeleton of D. oryktes (ACM 4804) supplemented by information derived from the individual (UNSM 47800) found in the carnivore dens at Agate National Monument. These two individuals are clearly closely related and are assigned here to a single species, diagnosed by short, posteriorly wide premolars (p2-4, P2-3) with centrally (not labially) placed posterior accessory cusp on $\mathrm{p} 4$. These premolars differ from the longer premolars and labially placed p4 posterior accessory cusp found in Temnocyon and Mammacyon. Although the p4 of Mammacyon ferocior is broader than that of $M$. obtusidens, the posterior accessory cusp in both species remains labial in position. Also, Delotrochanter oryktes does not have as prominent a protocone on $\mathrm{P} 4$ as in Mammacyon nor is its $\mathrm{m} 2$ as elongate; and it lacks the $\mathrm{m} 1$ metaconid found in Temnocyon. These differences, however, are most readily observed in relatively complete dentitions: isolated teeth will in many instances be difficult to assign.

The mandible of ACM 4804 is only $\sim 2 \mathrm{~cm}$ longer than that of a mature female Alaskan wolf (ZM 17459: mandibular length, $18.5 \mathrm{~cm}$; basilar length, $22 \mathrm{~cm}$ ); yet mandibular depth and the height of the coronoid process are much greater and the canine, premolars, and $\mathrm{m} 2$ are conspicuously larger and more robust. The $\mathrm{m} 1$ is about the same length, but is a wider, blunt-cusped tooth, its protoconid-paraconid lacking the sharp edges seen on the $\mathrm{m} 1$ shearing blade of the wolf. 

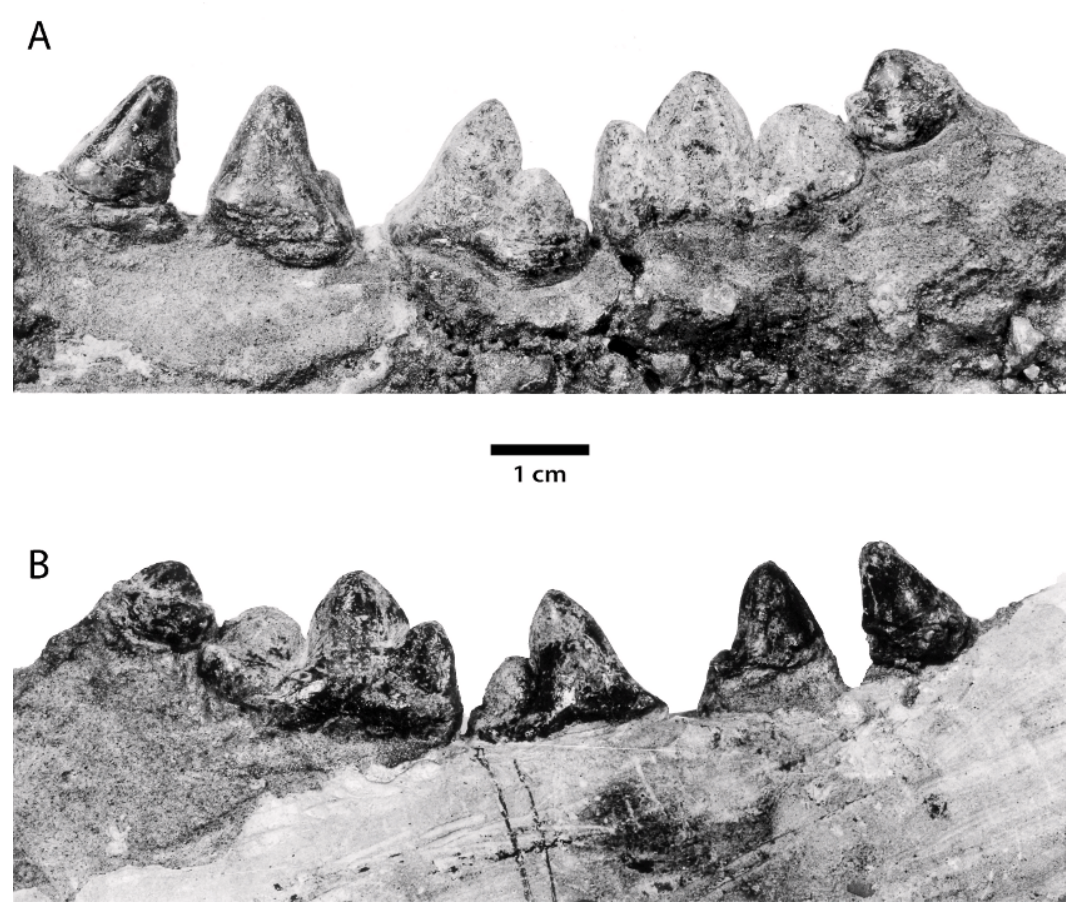

Fig. 40. Holotype dentition of Delotrochanter major (F:AM 27561), left p2-m2 (p2, p3, and m2 damaged), Anderson Ranch Formation, near Van Tassell, Niobrara Co., Wyoming. A, labial and B, lingual views.

The feeding strategy of $D$. oryktes relied on powerful jaw musculature applied to a deep, rigid mandibular "beam" carrying the heavy, blunt premolar and molar crushing dentition with enormous canines.

The four individuals of $D$. oryktes from Agate National Monument occur at three superposed stratigraphic levels: (1) ACM 4804 , the holotype, was found $\sim 12-15 \mathrm{~m}$ above the two principal camel-producing horizons at Stenomylus Quarry in the Harrison Formation (a second individual, ACM 4804A, a juvenile, was found with ACM 4804 but is known only from postcranials); (2) The calcaneum (YPM-PU 24872) indicates the presence of $D$. oryktes in the Agate waterhole bonebed (basal Anderson Ranch Fm.), which occurs stratigraphically between the levels of ACM 4804 and UNSM 48700; (3) The adult (UNSM 47800) discovered in the carnivore dens at Beardog Hill (Hunt et al., 1983: fig. 1, den 2, burrow C) also occurs in the basal Anderson Ranch beds (the dens are excavated into the waterhole bonebed). The amount of time intervening between these stratigraphic levels remains uncertain. The age of ACM 4804 is approximated by the Agate Ash, recently redated at $\sim 22.9 \mathrm{Ma}$ (Izett and Obradovich, 2001).

Despite its younger stratigraphic age, UNSM 47800 is the smaller, more gracile animal relative to ACM 4804. Given the baculum found with ACM 4804, the size difference between UNSM 47800 and ACM 4804 is more likely due to sexual dimorphism and not relative stratigraphic position.

The postcranial skeleton of ACM 4804 is discussed under Postcranial Osetology.

Delotrochanter major, new species Figures 36, 40-42

TYPE: F:AM 27561, right and left lower canines; partial p2-3, complete p4-m1, m2 trigonid, all of the left side; right $\mathrm{p} 3-\mathrm{m} 1$; an upper canine, right $\mathrm{P} 2-4$, maxilla fragment with right $\mathrm{I} 1-3$, left $\mathrm{I} 1-2$, and right $\mathrm{P} 1$ in matrix, from the Anderson Ranch Formation, collected by Paul Miller in 1927 from 

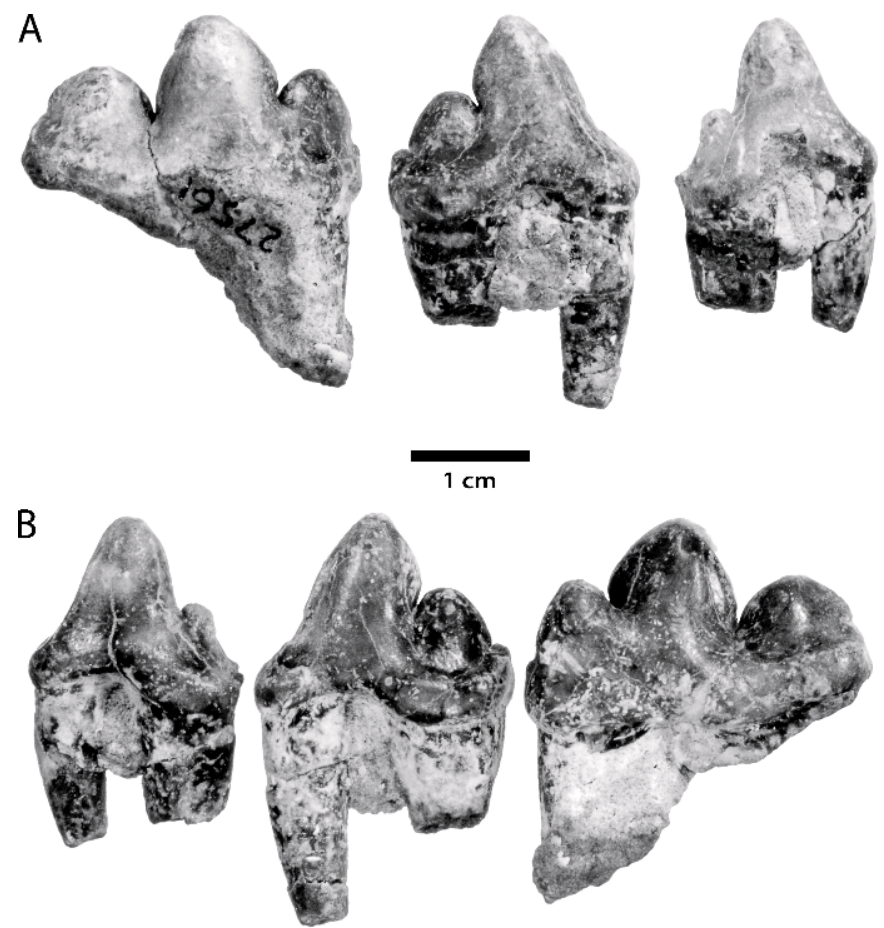

Fig. 41. Holotype dentition of Delotrochanter major (F:AM 27561), right p3-m1, Anderson Ranch Formation, near Van Tassell, Niobrara Co., Wyoming. A, labial and B, lingual views. Note large p4 relative to the carnassial in this terminal species of Delotrochanter.

the vicinity of Van Tassell, Niobrara County, Wyoming.

DisTRIBUTION: Latest Arikareean, Anderson Ranch Formation, near Van Tassell, Niobrara County, Wyoming.

ETYMOLOGY: From the Latin, major, "greater," in reference to the large size of the terminal species of this genus.

Diagnosis: Distinguished from $D$. petersoni by larger size ( $\mathrm{m} 1$ length: D. petersoni, $22.3 \mathrm{~mm}$; D. major, $28.0 \mathrm{~mm}$ ). All D. major teeth are larger and more robust than the equivalent teeth of its predecessor $D$. oryktes (tables 2, 3). Differs from Temnocyon by loss of the $\mathrm{m} 1$ metaconid and by short, posteriorly wide p2-3 and P2-3; from Mammacyon by a posterior accessory cusp on $\mathrm{p} 3$, a large centrally placed posterior accessory cusp on $\mathrm{p} 4$, and by a smaller P4 with lingually abbreviated protocone region; from Rudiocyon by the form of $\mathrm{p} 4$.

REFERRED SPECIMENS: None.

DESCRIPTION: Neither mandible of $D$. major (F:AM 27561) survived. The dentition is embedded in series in sediment without mandibular bone supporting the teeth. Thus only D. oryktes (ACM 4804) and D. petersoni demonstrate the form of the mandible in Delotrochanter.

In F:AM 27561, the left lower canine measures $36.6 \mathrm{~mm}$ in height from the slightly worn apex to the labial enamel-dentine junction (estimated unworn height, $\sim 40 \mathrm{~mm}$ ); length and width at the base of the enamel are respectively $18.4 \mathrm{~mm}$ and $12.8 \mathrm{~mm}$. The posterolabial surface is grooved by the upper canine; a second wear facet made by I3 occurs at the base of the anterolingual face. In other respects the tooth is similar to ACM 4804.

The $\mathrm{p} 1$ is not preserved, and only the main cusp of the left $\mathrm{p} 2$ remains; this indicates a tall principal cusp - there are no evident differences from p2 of ACM 4804.

The p3 measures $17.7 \mathrm{~mm}$ in length, $10.2 \mathrm{~mm}$ in greatest width, and is nearly identical to ACM 4804 except in its larger size and greater posterior width. A centrally placed posterior accessory cusp is present. 
A
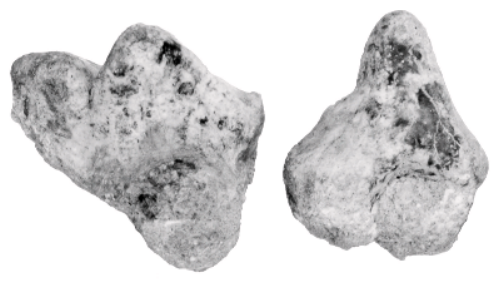

B
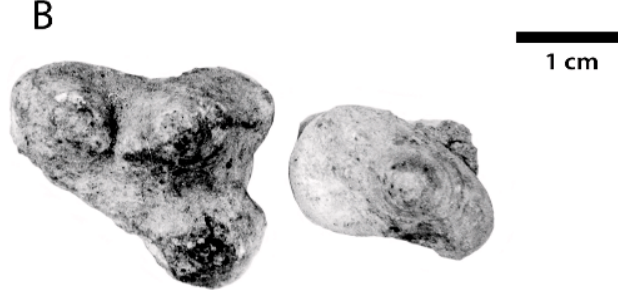

$1 \mathrm{~cm}$
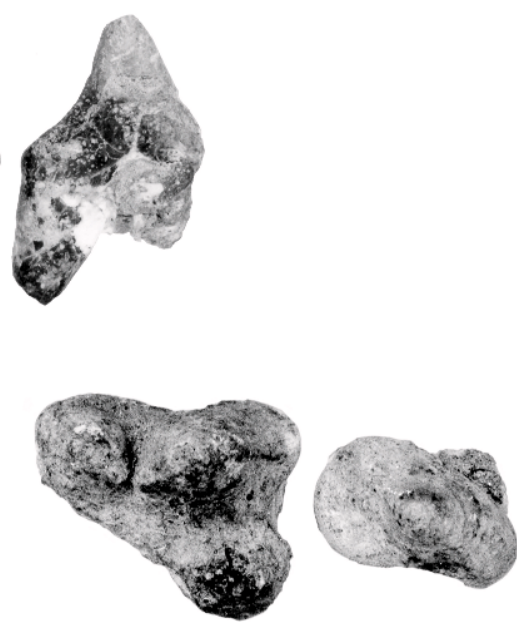

Fig. 42. Holotype maxillary teeth of Delotrochanter major (F:AM 27561). A, lingual view of right P2-4. B, stereopair of right P3-4; enamel was etched by plant roots.

The p4 measures $21.6 \mathrm{~mm}$ in length, $9.2 \mathrm{~mm}$ in anterior width, $12.3 \mathrm{~mm}$ in posterior width; its posterior accessory cusp is very large, centrally placed, and surrounded by a welldefined cingulum, which becomes less conspicuous anteriorly on both lingual and labial sides. The heel of $\mathrm{p} 4$ is much wider than in ACM 4804 as is true for p3.

The $\mathrm{m} 1$ is similar in all respects to that of ACM 4804 but is more massive and robust, measuring $28.0 \mathrm{~mm}$ in length, $14.1 \mathrm{~mm}$ in greatest width. Although these lower carnassials were undoubtedly capable of limited shear (vertical wear facets occur on the paraconid-protoconid blade), the premolars, $\mathrm{m} 2-3$, and $\mathrm{m} 1$ functioned primarily as crushing instruments. The $\mathrm{m} 1$ hypoconid and the protoconid of $\mathrm{m} 2$ are blunt, low cusps, and in this species could have served no role other than crushing.

The $\mathrm{m} 2$ is represented only by the trigonid. It is similar to the $\mathrm{m} 2$ trigonid of $D$. oryktes but is more massive, having a very large, blunt protoconid and small vestigial paraconid with a strong labial cingulum; there is no metaconid. Trigonid width is $10.6 \mathrm{~mm}$. Based on similarity of the cheek teeth in F:AM 27561 and ACM 4804, the complete $\mathrm{m} 2$ of D. major was a larger version of the $\mathrm{m} 2$ in $D$. oryktes.

The $\mathrm{m} 3$ was not preserved but would have been present.

I1-I2 are of equal size and similar cusp form. Both have a vertical anterior face and a curvilinear posterior surface, and both possess prominent auxiliary cusps (Nebenzacken) on their lateral margins as in $D$. oryktes. I 2 measures $9.9 \mathrm{~mm}$ in length, $5.6 \mathrm{~mm}$ in width; I1 measures $9.1 \mathrm{~mm}$ in length, $5 \mathrm{~mm}$ in width. The large I 3 measures $22.8 \mathrm{~mm}$ in height, $13.3 \mathrm{~mm}$ in length, and about $10 \mathrm{~mm}$ in width at the enamel base. There is a wear groove on the posterolabial face of I3 made by the upper canine.

P1 has the same subconical form as in ACM 4804 and measures $9.4 \mathrm{~mm}$ in length by $6.9 \mathrm{~mm}$ in width.

$\mathrm{P} 2$ is much larger than P1; it is tall, subtriangular in labial view, with nearvertical anterior and more inclined posterior faces, and measures 17.0 by $9.0 \mathrm{~mm}$. The heel of P2 is broad; the thin enamel ridge on the posterior slope ends in a minute cingular cuspule at the posterolingual corner.

P3 is tall, triangular in lateral view, and posteriorly broad, measuring $18.7 \mathrm{~mm}$ in length, $11.9 \mathrm{~mm}$ in posterior width. The posterior face has a small, labially situated, posterior accessory cusp. P3 has fine enamel ridges on its anterior and posterior faces; the anterior ridge terminates at the anterolingual margin of these teeth; the posterior ridge at the posterolabial corner. The expansion of the heel of both P2 and P3 is more pronounced than in D. oryktes.

P4 measures $23.5 \mathrm{~mm}$ in length, $19.8 \mathrm{~mm}$ in width across the protocone, and is similar 
in form to the P4 of ACM 4804 but is larger and slightly more robust. The metastylar blade is blunt as is the protocone; both are essentially unworn, and the slightly worn paracone shows only a flat apical wear facet. Vertical shear, although possible, appears to have been secondary to a crushing action.

The upper molars of $D$. major were not recovered, but based on the remaining teeth they would be similar in form yet somewhat larger than M1-2 of D. oryktes.

DisCUSSION: F:AM 27561 differs from $D$. oryktes in larger size and in the greater accentuation of many defining features of the cheek teeth. Not only are its teeth larger but cingula are more pronounced, the cusps more massive, and p3-4 and $\mathrm{P} 2-3$ are posteriorly broadened. The defining dental traits of Delotrochanter are evident and indicate that $D$. major is clearly derived from D. oryktes. Paul Miller, the collector, reported that F:AM 27561 came from the "vicinity of Van Tassell," Wyoming. Near the town of Van Tassell only the Harrison Formation and the Anderson Ranch beds outcrop in the area where Miller worked. Fortunately, sediment adhering to F:AM 27561 shows the pale reddish-brown patina of the Anderson Ranch sandstones. The advanced features of its dentition indicate that Miller may have obtained F:AM 27561 stratigraphically high in the Anderson Ranch beds in the stratotype area of the formation in the Niobrara Canyon (see Hunt, 2002b: 35-39), which is in proximity to the town of Van Tassell. F:AM 27561 is of latest Arikareean age and represents the youngest occurrence of Delotrochanter. More than 80 years of exploration of Anderson Ranch Formation outcrops in northwest Nebraska and Wyoming have failed to yield additional remains of this rare temnocyonine since Miller's fortunate discovery.

The stratigraphic levels that produced $D$. oryktes are well documented, and the horizon that yielded $D$. major can be reliably estimated. The stage of evolution of these two species of Delotrochanter, which occur in late to latest Arikareeean time, can be contrasted with that of Mammacyon. The occurrence of the terminal and largest species, $M$. ferocior, preceded the earliest occurrence of $D$. oryktes in the Harrison Formation at Stenomylus Quarry. Thus, the Mammacyon lineage reached its apex at a time before $23 \mathrm{Ma}$, when the coeval species of Delotrochanter must have been a much smaller carnivore in the same geographic region.

\section{DENTITION AND FEEDING: APPEARANCE OF DUROPHAGOUS AMPHICYONIDS}

The teeth of the geologically oldest temnocyonine, Temnocyon altigenis, resemble the teeth of the dentally plesiomorphic beardog Daphoenus vetus; both are small carnivores of similar size. T. altigenis differs, however, in its larger carnassials, taller premolars, smaller $\mathrm{m} 2$, and lack of M3. During the midCenozoic, the temnocyonine dentition departed from this plesiomorphic condition. In the wolf-sized Temnocyon fingeruti, a hypercarnivorous pattern was retained, and was scaled to formidable size in the largest species of the genus, T. macrogenys. Alternatively, a crushing dental battery also arose from the plesiomorphic type, and attained its maximum development in the large species of Mammacyon and Delotrochanter.

DentiTION: The upper cheek teeth (P3M2) best show this progressive shift in dental pattern (fig. 43). In Temnocyon altigenis (UCMP 9999, fig. 4A) and $T$. subferox (YPM 10065, figs. 10A, 43A) the shearing carnassial retains a bladelike form with the protocone advanced in the anterior direction, leaving a large embrasure between $\mathrm{P} 4$ and M1 for the lower carnassial. This is the primitive amphicyonid condition, also common to primitive arctoid and cynoid carnivorans. M1 is essentially a triangular tooth in occlusal view, its lingual half somewhat broader than in Daphoenus, and flanked by a small elliptical M2. M3 is lost in all temnocyonines, unlike most daphoenine and amphicyonine beardogs. P3 remains a narrow premolariform tooth.

In younger species of Temnocyon a subtle change in the cheek teeth has taken place. In Temnocyon ferox (fig. 43B), body size has increased and the form of P4 and M1 has been modified. A shearing carnassial is still present, yet the tooth is wider and the protocone retracted posteriorly and enlarged relative to $T$. altigenis and T. subferox. M1 is less triangular, more quadrate in form, and 

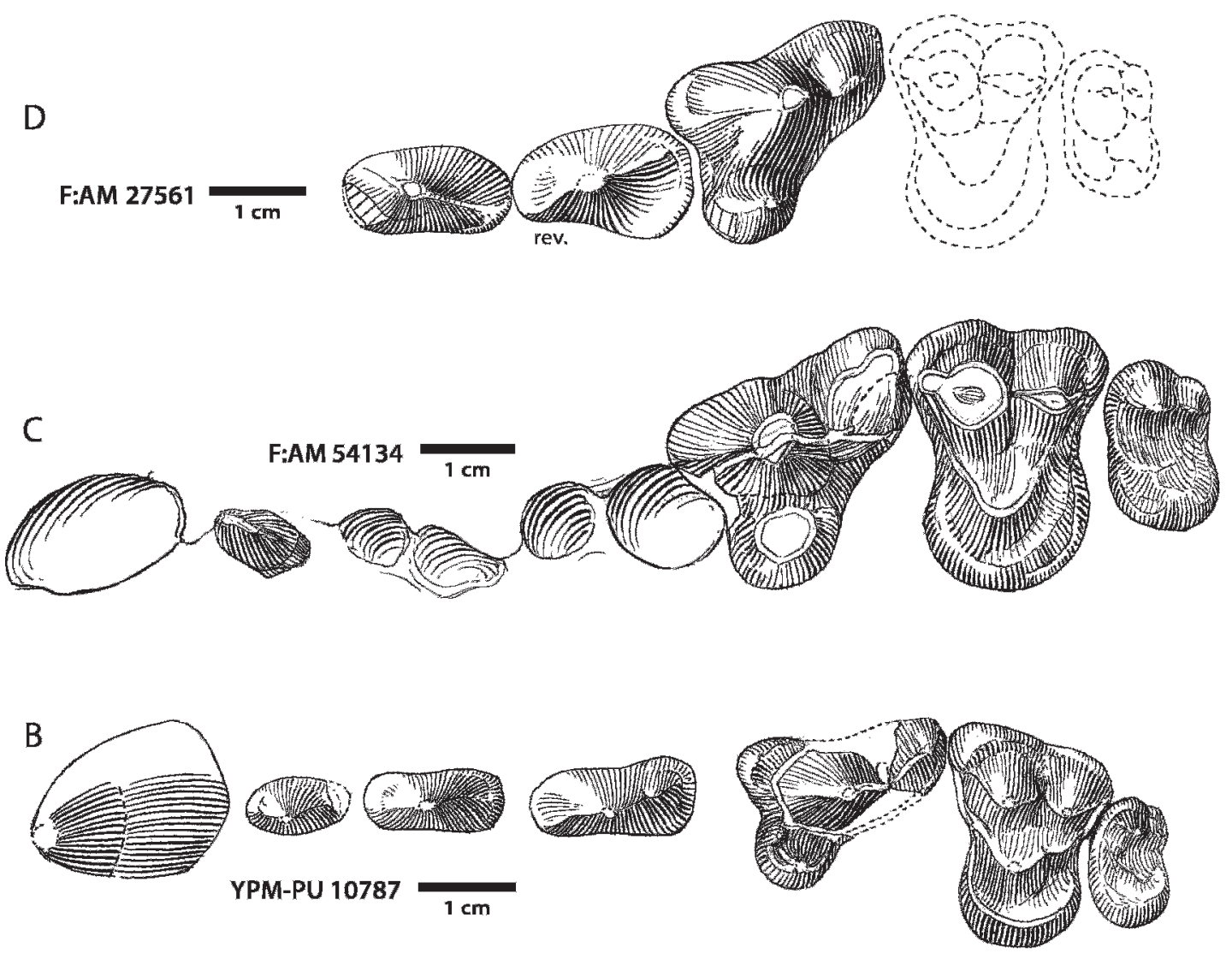

A

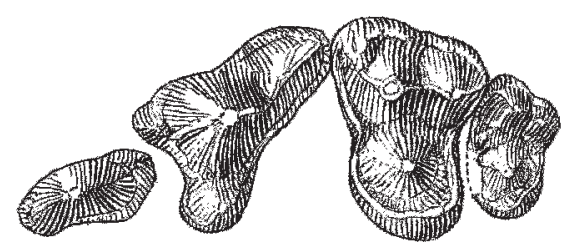

Fig. 43. Maxillary dentitions showing the development of a durophagous dental battery in temnocyonines: A, Temnocyon subferox; B, Temnocyon ferox; C, Mammacyon ferocior; D, Delotrochanter major.

the protocone region has begun to expand, although the P4-M1 embrasure remains fully functional. A shearing dental battery is still evident. M1 of $T$. percussor (fig. 15F) could be derived from the smaller T. ferox $\mathrm{M} 1$, and is lengthened lingually, whereas the M1 of $T$. fingeruti is little different from a scaled-up M1 of the Logan Butte T. altigenis. The M1 of $T$. fingeruti remains a relatively plesiomorphic molar (fig. 17).

The terminal species, T. macrogenys, displays enormous cheek teeth but the carnassial and $\mathrm{m} 2$ do not adopt the more modified occlusal form found in Mammacyon and Delotrochanter. The $\mathrm{m} 1$ and $\mathrm{m} 2$ of T. macrogenys retain metaconids and labially placed hypoconids (figs. 21, 44C), primitive features lost in the other genera (figs. 44A, B).

Species of Temnocyon remain dentally closer to the plesiomorphic dentition than other temnocyonines. On this basis they have been grouped together. The progressive size increase in these species as they undergo a gradual transformation of dental pattern over time lends support to this paraphyletic classification. 
A

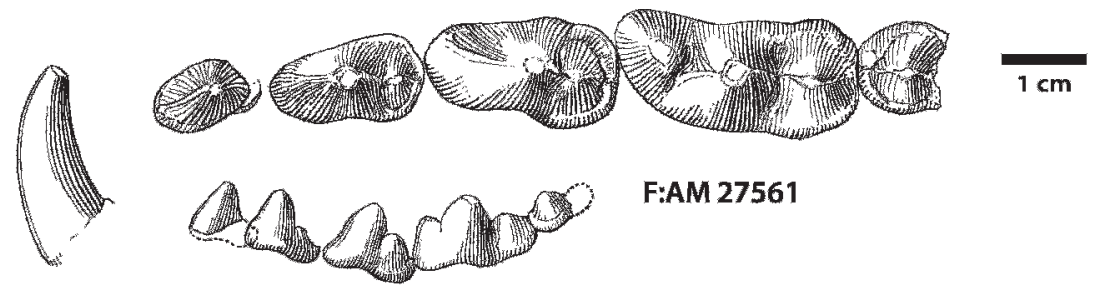

B
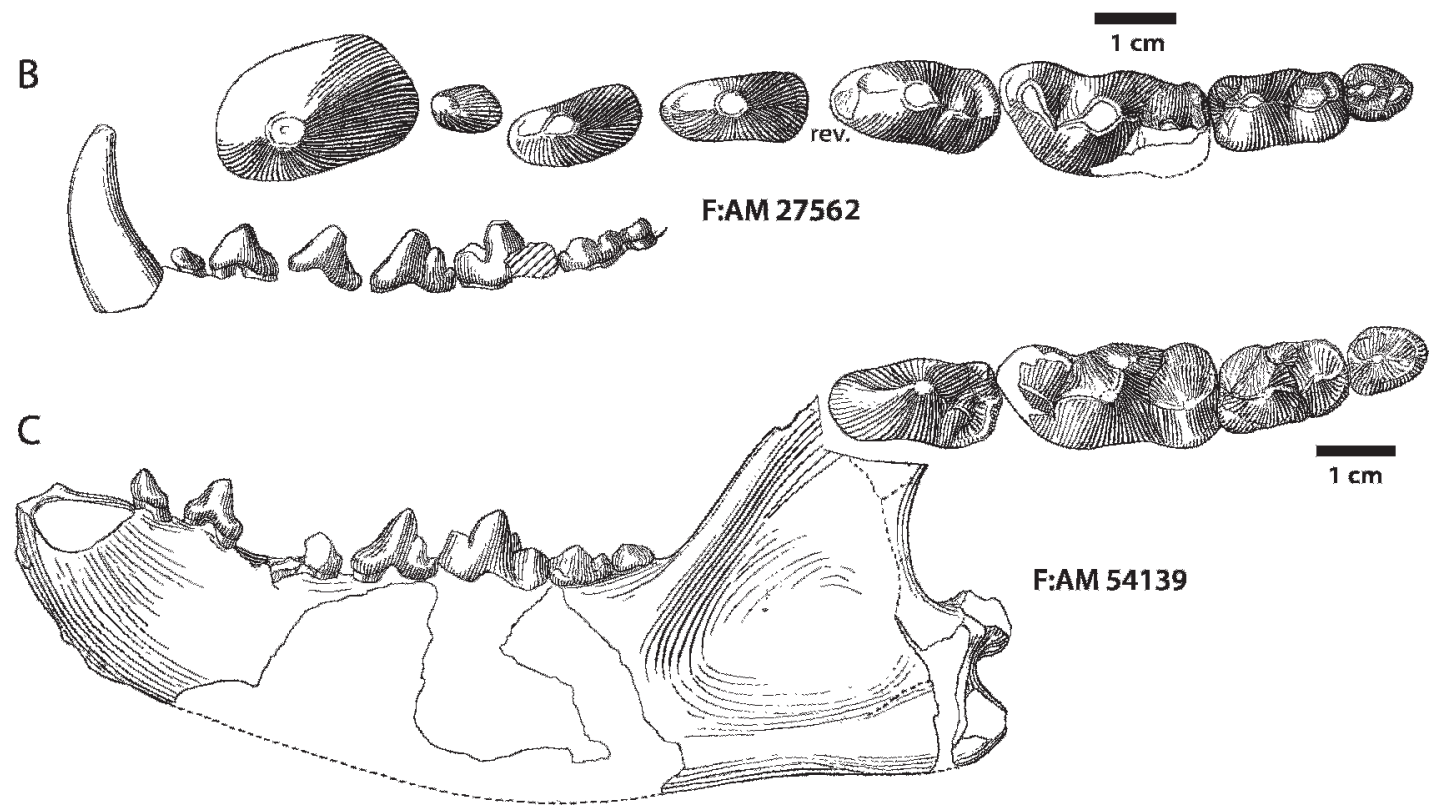

Fig. 44. Mandibular dentitions of the three terminal species of the genera Temnocyon, Mammacyon, and Delotrochanter: A, Delotrochanter major, F:AM 27561; B, Mammacyon ferocior, F:AM 27562; C, Temnocyon macrogenys, F:AM 54139.

In species of Mammacyon (M. obtusidens, M. ferocior, figs. 24, 27, 31, 43C) where the upper cheek teeth are preserved, the P3-M2 transform from the plesiomorphic state to a full-blown crushing dentition. In $M$. obtusidens some $\mathrm{P} 4$ shear remains, which is much less evident in $M$. ferocior. In these two species the P4 metastylar blade is shortened, the paracone becomes a tall, blunt cone, and the protocone a rounded, broad pestlelike cusp. M1 is now a crushing platform with a broadened lingual half (the protocone region), surmounted by a blunt, knoblike protocone. The P4-M1 embrasure is almost obliterated; hence the lower carnassial in these species chiefly crushes food against the $\mathrm{P} 4$ protocone/M1 lingual platform, although early in life some shear is present. This configuration is complemented by the shape of P3, whose heel widens (relative to species of Temnocyon) to form a platform for occlusion with the main cusp of $\mathrm{p} 4$.

The occurrence of the maxilla of Mammacyon (LACM 5386, fig. 27) in proximity to the dated Picture Gorge ignimbrite $(\sim 28.7 \mathrm{Ma})$ in Haystack Valley, Oregon, demonstrates that a crushing dental pattern had already developed in the early Arikareean, predating many of the less dentally derived species of Temnocyon in the John Day region.

Delotrochanter underwent a similar dental transformation resulting in crushing cheek teeth like those seen in Mammacyon (figs. 38, 39, 43D, 44A, 45A). However, upper cheek 


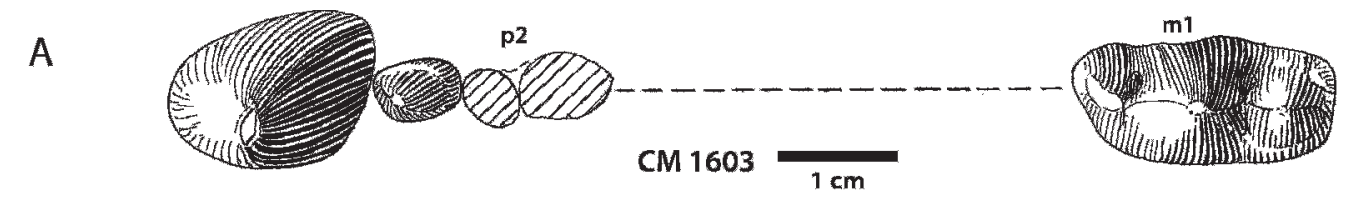

B
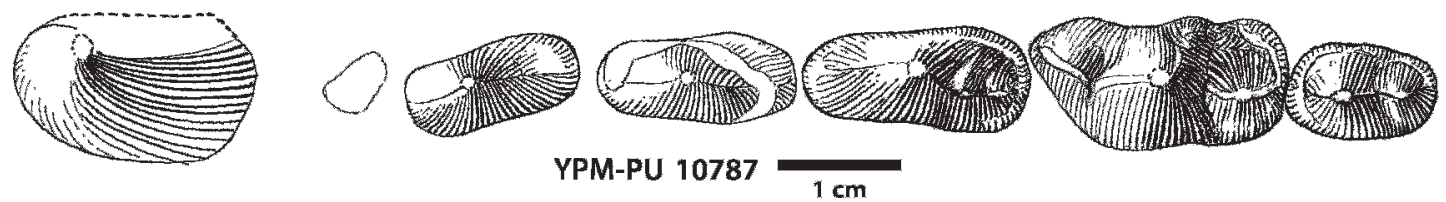

Fig. 45. Comparison of the lower carnassials of Delotrochanter petersoni and Temnocyon ferox, temnocyonines of similar size. The $\mathrm{m} 1$ metaconid has already been lost in $D$. petersoni (A), the earliest species of the genus, but is present in $T$. ferox (B). Note p2 alveolar diameters in (A).

teeth of Delotrochanter are unknown in the geologic record until $D$. oryktes occurs in the Harrison Formation at Agate National Monument, dated at $\sim 22.9 \mathrm{Ma}$. D. oryktes and $D$. major share upper carnassials that duplicate the general form of the Mammacyon $\mathrm{P} 4$, together with the crushing platform on the adjacent P3 (the P4 protocone in Delotrochanter is never quite as developed as in Mammacyon). The Delotrochanter M1 is known only in D. oryktes (figs. 38,39 ) where the lingual half of the tooth is broadened as in $M$. obtusidens but not to the extent evident in Mammacyon ferocior. Nonetheless, the dental batteries of both Delotrochanter and Mammacyon represent the parallel evolution of a type of crushing cheek teeth unknown in other living and extinct Carnivora. These durophagous dental batteries of Mammacyon and Delotrochanter are approached but not equalled by a few dentally similar European haplocyonine beardogs (Peigné and Heizmann, 2003; Bonis, 1973; Hürzeler, 1940; Helbing, 1928).

Measurements of the teeth support recognition of the four temnocyonine genera as distinct dental groups. Dimensions of M1 (fig. 46) reflect the expansion of the protocone region (relative to M1 length) that distinguishes Mammacyon and Delotrochanter from the more plesiomorphic Temnocyon. This same relationship is also evident when graphing M1 length against width (fig. 46). Also, P4 remains a narrower shearing carnassial in Temnocyon species, whereas it becomes a large crushing tooth, broadened by an enlarged protocone, in species of Mammacyon and Delotrochanter (fig. 47).

In the mandible, $\mathrm{m} 1$ dimensions suggest that this carnassial in species of Delotrochanter is slightly broader than in Mammacyon (fig. 48A); the m1s of the geologically youngest species of Temnocyon ( $T$. fingeruti, $T$. percussor, $T$. macrogenys) seem narrow relative to length, reflecting retention of their primary role as shearing carnassials (table 2). Mammacyon obtusidens and $M$. ferocior mandibles are conspicuous for their elongated second molars. This is demonstrated by $\mathrm{m} 2$ length plotted against $\mathrm{m} 1$ length (fig. 48B) compared with the known examples of Delotrochanter and Temnocyon but especially with Rudiocyon.

These genera are also distinguished by premolar dimensions, notably the widths of $\mathrm{p} 2$, p3, and p4 (fig. 49). Invariably, broader premolars differentiate species of Delotrochanter from those of Mammacyon. The large species of Temnocyon generally fall between species of Mammacyon and Delotrochanter, and the dimensions of $\mathrm{p} 2$ and $\mathrm{p} 4$ seem to indicate an evident regression of length on width for Temnocyon species, a trend less obvious for p3. Van Valkenburgh (1989) noted the relationship of broad, robust lower premolars (measured as p4 "roundness") to a diet of meat/bone, a diet less dependent on meat alone.

The teeth of temnocyonines are unlike those of any living carnivore. Whereas the small stem temnocyonine, T. altigenis, differs little in dentition and body size from the plesiomorphic amphicyonid Daphoenus vetus, 
the larger species evolve a unique combination of dental features. Large temnocyonines possess prominent canines and incisors, deep jaws, and broad snouts, features reported to be typical of large living canids that specialize in hunting prey larger than themselves (Van Valkenburgh et al., 2003). When combined with their tall, developed premolars, these traits argue for an ability to grasp and hold large prey. The deep jaws, strong mandibular symphysis, and canines are evidence of the strength and leverage of the bite. Rather blunt carnassials and broad molars add the capability to crush and grind hard food items during mastication.

CANINES: Temnocyonines have prominent canine teeth, capable of stabbing and lacerating. Temnocyon altigenis, the most plesiomorphic species, with a skull much smaller (75\% of basilar length) than that of the living wolf, has already evolved proportionately large upper canines. The upper canine of $T$. altigenis (UCMP 9999) is long and robust (height $83 \%$ and basal area $89 \%$ of that of the wolf), whereas the lower canine falls at $83 \%$ and $62 \%$, respectively.

Van Valkenburgh and Ruff (1987) have reported that the forces involved in the killing bite and handling of large prey are reflected in canine shape. I measured temnocyonine canines and compared this data with values obtained by Gittleman and Van Valkenburgh (1997) for large living carnivores of similar body mass (Canis lupus, Crocuta crocuta, Panthera leo, P. tigris, Ursus arctos). Measurements of height and basal canine diameters were taken on the lower canines of temnocyonines, since these, rather than the upper canines, were more often complete.

Canine bending strength was determined using the formulas of Van Valkenburgh and Ruff (1987) that estimate bending resistance around both the anteroposterior (AP) and mediolateral (ML) axes of the lower canine with canine height incorporated in these calculations: nine temnocyonines, three from each genus, were represented by intact teeth. Bending strength around the mediolateral axis $\left(\mathrm{S}_{\mathrm{y}}\right)$ is commonly greater relative to the anteroposterior axis $\left(\mathrm{S}_{\mathrm{x}}\right)$ in large living carnivores and also in temnocyonines (table 9). Species of Temnocyon show the lowest values, less than those of wolves for the small
$T$. altigenis (the large $T$. macrogenys canine was not preserved). Species of Delotrochanter, regardless of body size, correspond closely to bending strength values of Crocuta, in keeping with the hyenalike skull form of $D$. oryktes. Species of Mammacyon fall between the spotted hyena and the large felids, indicating considerable strength of the lower canines.

Calculated bending strength of the few intact temnocyonine upper canines yielded similar estimates, suggesting comparable stresses to these teeth during predation and feeding. Four species preserve the upper canine (table 9). The small Temnocyon altigenis is similar to the much larger Canis lupus, particularly in resisting force applied to the sides of the canine; $T$. ferox closely parallels Crocuta crocuta in resisting both AP and ML stresses, whereas the upper canines of both Delotrochanter oryktes and Mammacyon obtusidens have $\mathrm{S}_{\mathrm{x}}$ and $\mathrm{S}_{\mathrm{y}}$ values that fall between those of the spotted hyena and the large cats, indicating strong resistance to forces applied at the symphysis.

Furthermore, many of the remaining upper canines, although broken off at the tip, retain the base in the alveolus. A proxy for canine shape was calculated using only the AP and ML diameters measured at the enamel-dentine junction at the base of the upper canine. Van Valkenburgh and Ruff (1987: fig. 3) plotted AP against ML diameters for living canids, felids, and hyaenids. As body size increased, the more mediolaterally compressed canines of large canids diverged from the more robust, less compressed canines of large felids and hyaenids. AP-ML upper canine diameters for temnocyonines plot with large felids and hyaenids, not canids (fig. 50A), suggesting ample resistance of their canines to mediolateral bending stresses. These authors thought that the greater strength of felid canines was related to their killing style, and for hyaenids to their bone-crushing habit. Canines of felidshyaenids may strike bone during the bite, and then "be subjected to large oblique or mediolateral bending stresses" as the prey is subdued (Van Valkenburgh and Ruff, 1987: 391). Thus, both the upper and lower canines of temnocyonines, especially in the larger species, seem well adapted to stresses occurring during prey capture and feeding. 


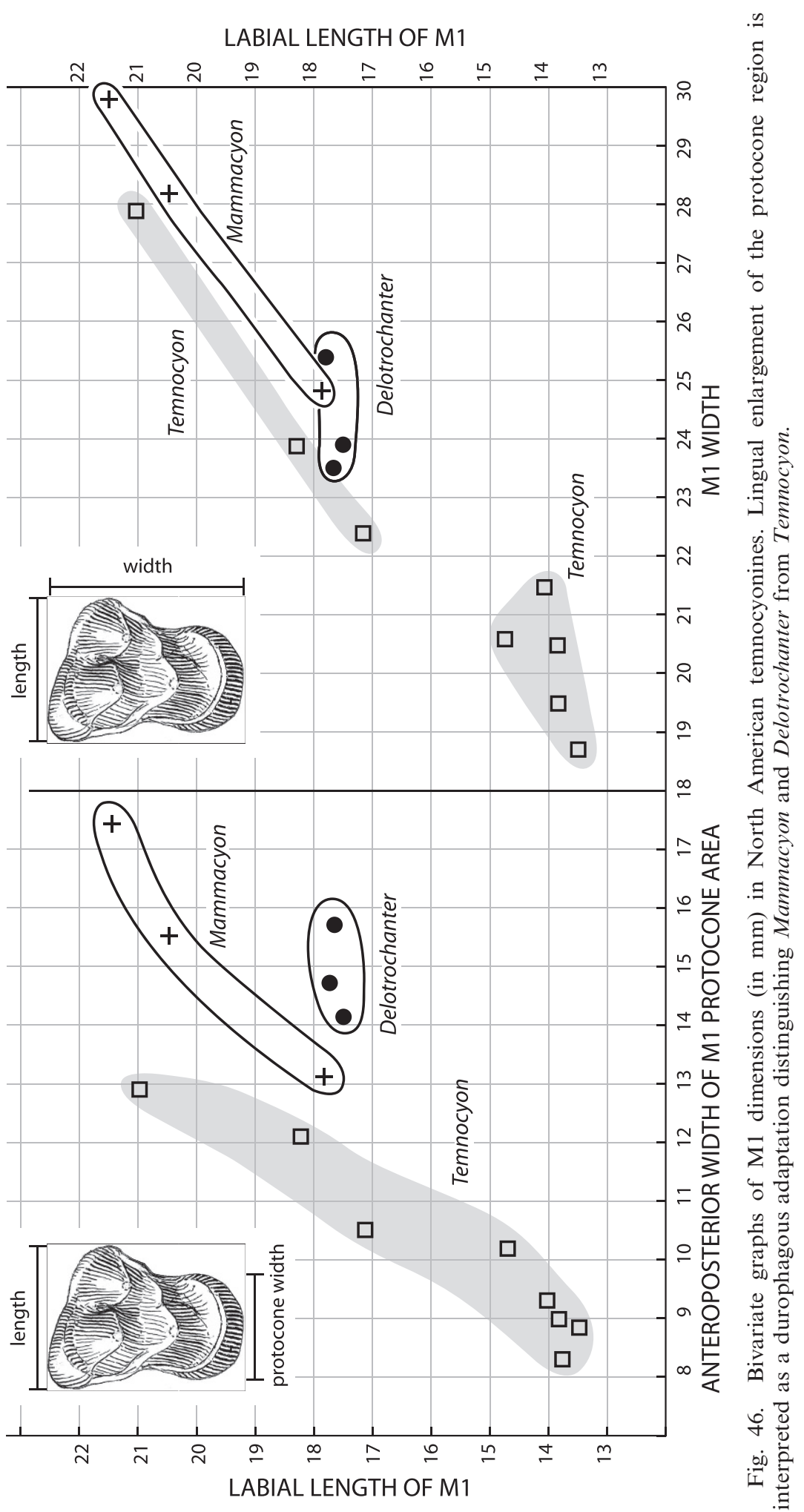




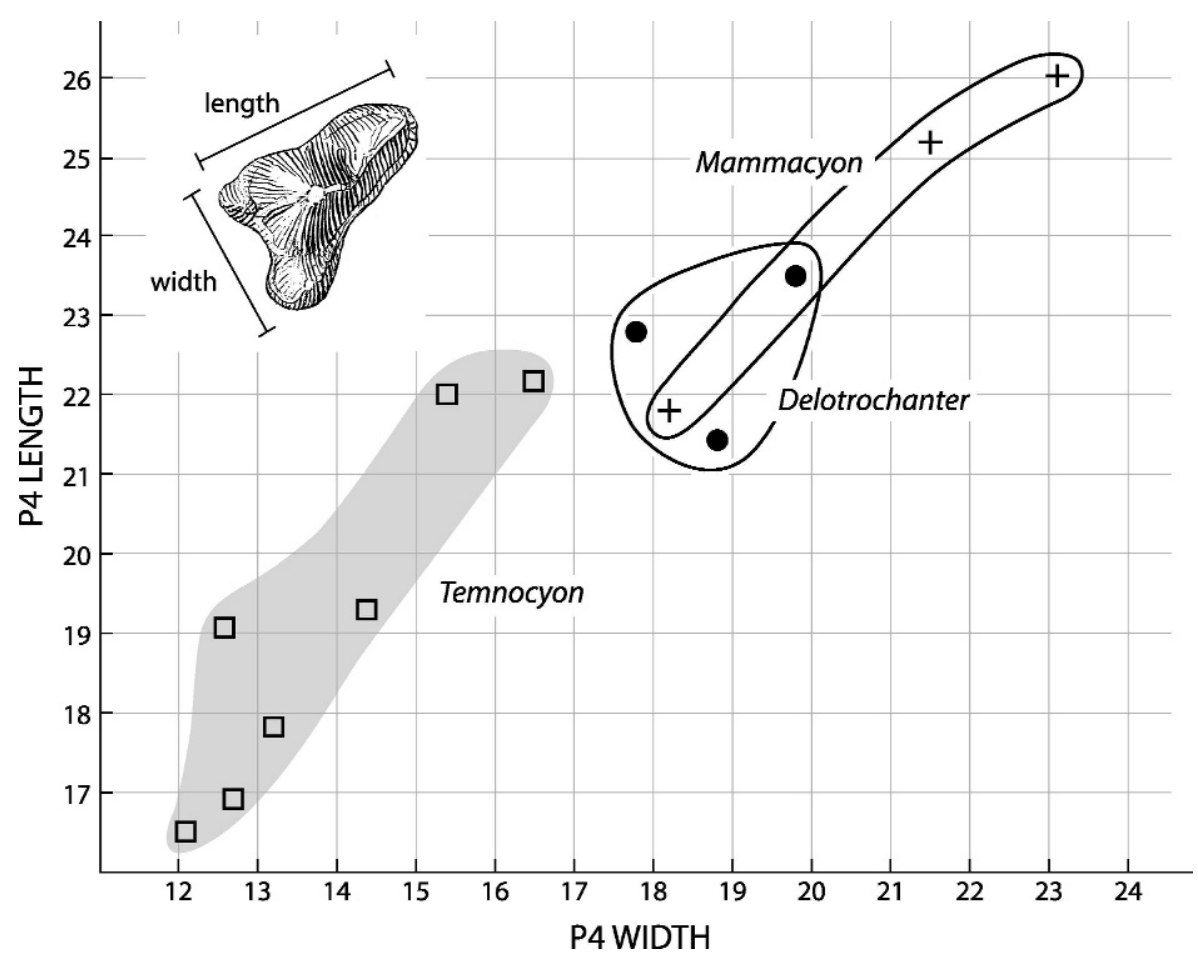

Fig. 47. Bivariate graph of P4 dimensions (in $\mathrm{mm}$ ) of North American temnocyonines. Development of a crushing protocone increases P4 width in durophagous species of Mammacyon and Delotrochanter.

MANDIBLE: Mandibular dimensions of temnocyonines indicate considerable resistance of the jaws to bending stresses arising during mastication of hard materials and to forces applied at the front of the jaws during the kill. Jaws of some large temnocyonines such as Temnocyon macrogenys had apparently developed a parasagittal bending strength at the molars much greater than that of any living canid and similar to that of Panthera leo and Crocuta crocuta.

The resistance of the mandible to forces applied during feeding and prey capture has been examined in living carnivorans using several methods (Biknevicius and Ruff, 1992a, b; Van Valkenburgh and Koepfli, 1993; Biknevicius and Van Valkenburgh, 1996; Therrien, 2005). Biknevicius and Ruff (1992b) modeled the mandible as a hollow beam hinged at the jaw articulation, in which the distribution of cortical bone was calculated from biplanar radiographs. Mandibular cross-sectional geometry was first determined by examining actual cross-sections cut from the jaw, which were found to best approximate a hollow, asymmetrical cortical bone model. Using the radiographs, Biknevicius and Ruff (1992a) then calculated section moduli for canid, felid, and hyaenid mandibles to be used in determining mandibular bending strength. Alternatively, Therrien (2005) modeled the carnivoran mandible as a solid beam, recognizing that the solid beam method overestimates cortical bone crosssectional area, which is better approximated using the method of Biknevicius and Ruff (1992b). Therrien (2005) showed that the solid beam approach, which lends itself to fossil material, could be used to represent relative differences in biomechanical properties along the mandible. Hence, differences among fossil and living species in terms of relative bending resistance along the mandible can be estimated and compared. The method assumes that the amount and distribution of cross-sectional cortical bone in such comparisons are similar, and that the individuals are of approximately the same body mass. 
A

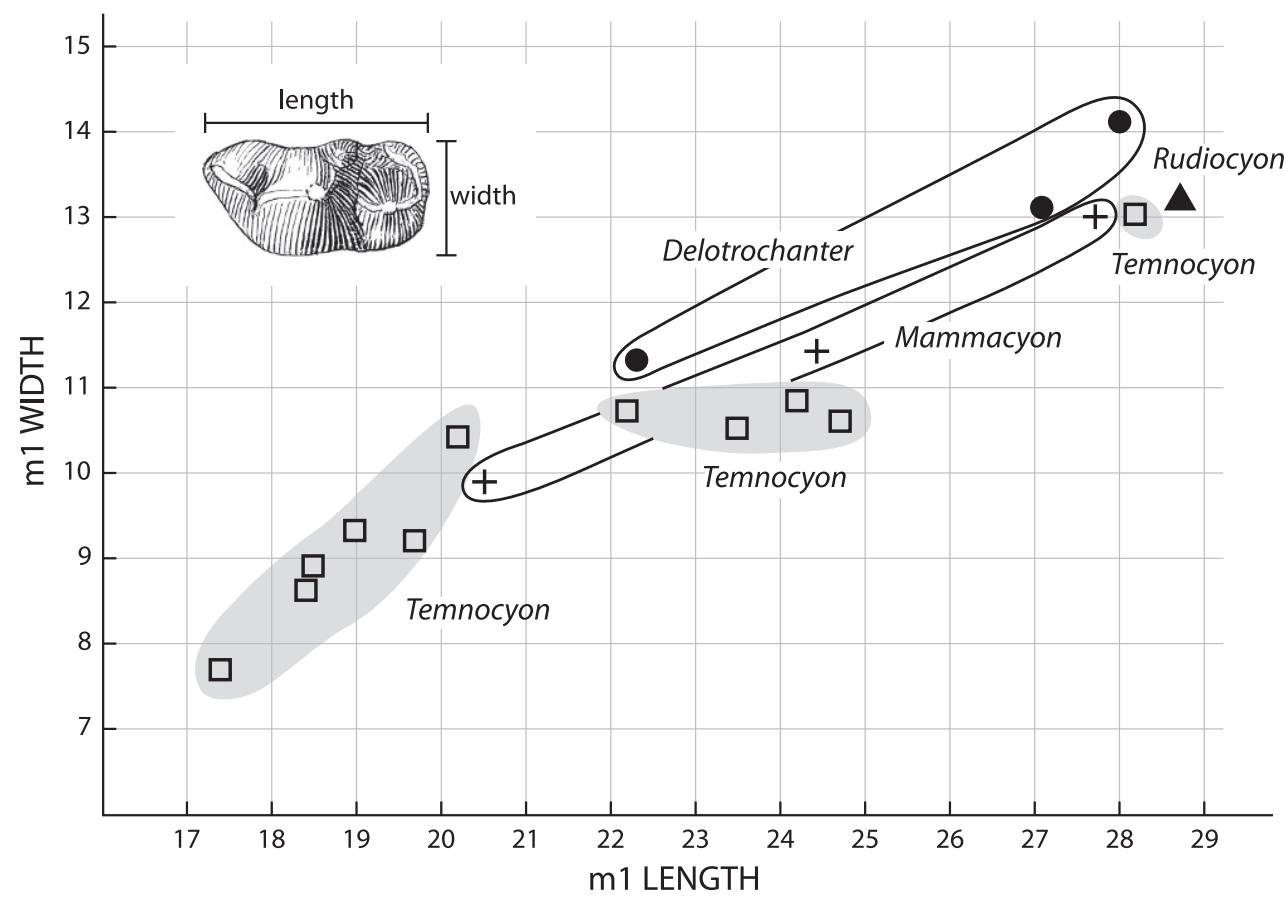

B

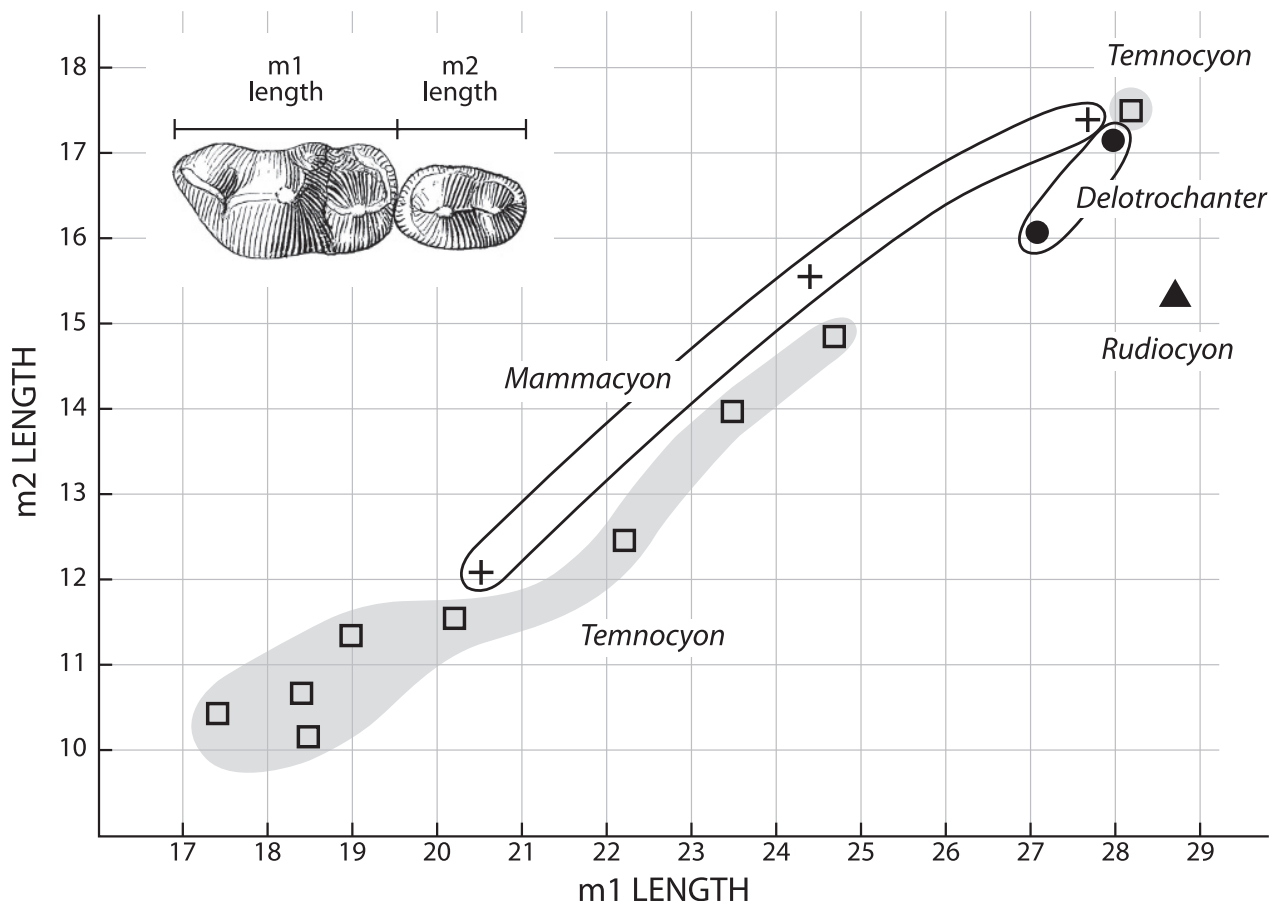

Fig. 48. Bivariate graphs of (A) $\mathrm{m} 1$ dimensions and (B) $\mathrm{m} 1$ length relative to $\mathrm{m} 2$ length (in $\mathrm{mm}$ ) for North American temnocyonines, demonstrating a size increase during the Arikareean. Carnassial size $(>27 \mathrm{~mm})$ for the largest species of the four genera is similar in (A). 
A

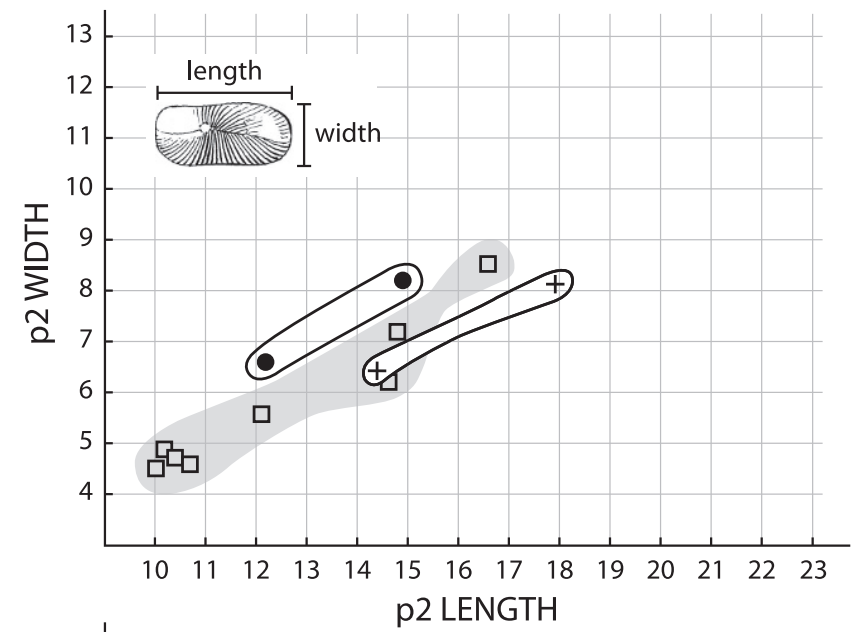

B

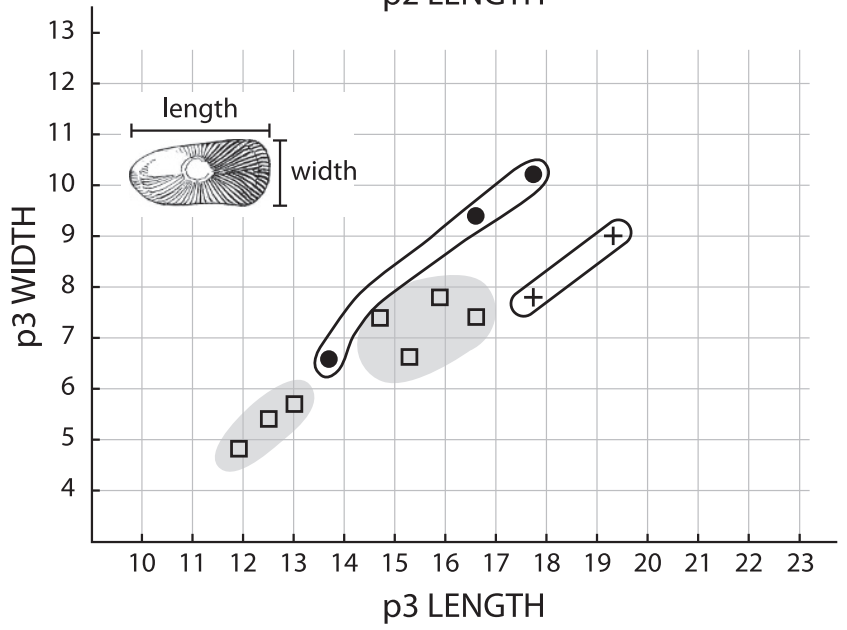

C

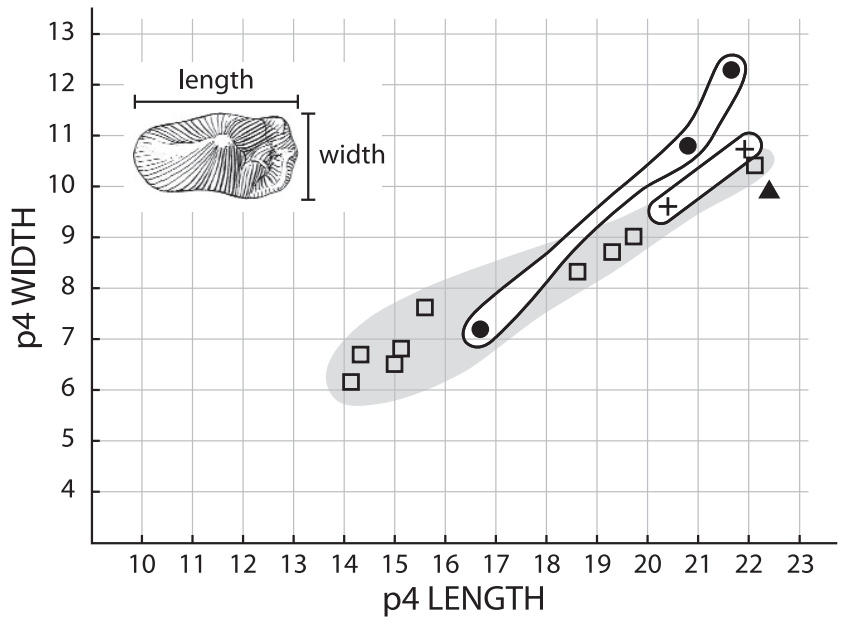

Fig. 49. Bivariate graphs of mandibular premolar dimensions (in $\mathrm{mm}$ ) in North American temnocyonines. A, p2; B, p3; C, p4. Symbols for the genera are as in figure 48 . 
TABLE 9

Dimensions and Bending Resistance of the Upper and Lower Canines of Temnocyonines Relative to Living Carnivorans (in mm)

$\left(S_{\mathrm{x}}=\log _{10}\right.$ estimate of bending strength about anteroposterior axis of the canine; $\mathrm{S}_{\mathrm{y}}=\log _{10}$ estimate of bending strength about mediolateral axis of the canine.

\begin{tabular}{|c|c|c|c|c|c|c|}
\hline & Mus. No. & Length & Width & Height & $\mathrm{S}_{\mathrm{x}}$ & $\mathrm{S}_{\mathrm{y}}$ \\
\hline \multicolumn{7}{|l|}{ LOWER CANINE $^{\mathrm{a}}$} \\
\hline \multirow[t]{3}{*}{ Temnocyon altigenis } & UCMP 9999 & 11.0 & 7.1 & 20.8 & 0.417 & 0.608 \\
\hline & AMNH 6856 & 11.1 & 8.2 & $\sim 24$ & 0.484 & 0.616 \\
\hline & AMNH 6855 & $12.5^{\mathrm{b}}$ & $7.3^{\mathrm{b}}$ & - & & \\
\hline Temnocyon ferox & YPM-PU 10787 & 18.0 & $\sim 11$ & 37.2 & 0.759 & 0.973 \\
\hline Temnocyon fingeruti & NM 280/61 & 19.1 & $\sim 10$ & - & & \\
\hline Temnocyon macrogenys & F:AM 54139 & $23^{\mathrm{b}}$ & $14^{\mathrm{b}}$ & - & & \\
\hline \multirow[t]{2}{*}{ Mammacyon obtusidens } & LACM 9194 & 19.1 & 12.6 & 38.9 & 0.884 & 1.064 \\
\hline & ACM 34-41 & 22.1 & 14.1 & $\sim 45$ & 0.981 & 1.176 \\
\hline Mammacyon ferocior & F:AM 27562 & 20.3 & 14.0 & $\sim 47$ & 0.919 & 1.081 \\
\hline Delotrochanter petersoni & CM 1603 & 16.0 & 12.0 & 33.3 & 0.832 & 0.957 \\
\hline Delotrochanter oryktes & ACM 4804 & 18.5 & 12.5 & 36.8 & 0.887 & 1.057 \\
\hline Delotrochanter major & F:AM 27561 & 18.4 & 12.8 & $\sim 40$ & 0.869 & 1.027 \\
\hline Canis lupus & sample means ${ }^{\mathrm{c}}$ & 13.9 & 9.1 & 25.0 & 0.655 & 0.839 \\
\hline Crocuta crocuta & sample means ${ }^{\mathrm{c}}$ & 14.0 & 12.2 & 27.5 & 0.871 & 0.931 \\
\hline Panthera leo & sample means ${ }^{\mathrm{c}}$ & 21.4 & 15.0 & 37.3 & 1.103 & 1.257 \\
\hline Panthera tigris & sample means ${ }^{\mathrm{c}}$ & 21.3 & 15.8 & 42.1 & 1.093 & 1.223 \\
\hline Ursus arctos & sample means ${ }^{\mathrm{c}}$ & 21.6 & 15.5 & 34.1 & 1.174 & 1.318 \\
\hline \multicolumn{7}{|l|}{ UPPER CANINE $^{\mathrm{a}}$} \\
\hline Temnocyon altigenis & UCMP 9999 & 11.1 & 8.2 & 22.0 & 0.522 & 0.654 \\
\hline Temnocyon ferox & YPM-PU 10787 & 16.6 & $\sim 12$ & 37.3 & 0.799 & 0.940 \\
\hline Mammacyon obtusidens & ACM 34-41 & 22.1 & 14.2 & 48.0 & 0.960 & 1.152 \\
\hline Delotrochanter oryktes & ACM 4804 & 19.3 & 13.4 & 37.9 & 0.953 & 1.112 \\
\hline Canis lupus & sample means ${ }^{\mathrm{c}}$ & 13.7 & 8.3 & 28.0 & 0.520 & 0.737 \\
\hline Crocuta crocuta & sample means ${ }^{\mathrm{c}}$ & 15.1 & 11.2 & 29.6 & 0.798 & 0.928 \\
\hline Panthera leo & sample means ${ }^{\mathrm{c}}$ & 23.1 & 16.7 & 45.1 & 1.147 & 1.288 \\
\hline Panthera tigris & sample means ${ }^{\mathrm{c}}$ & 23.9 & 18.3 & 50.2 & 1.195 & 1.310 \\
\hline Ursus arctos & sample means ${ }^{\mathrm{c}}$ & 21.3 & 15.7 & 36.2 & 1.153 & 1.286 \\
\hline
\end{tabular}

${ }^{\text {a }}$ Length and width of canines measured at the base of the enamel.

${ }^{\mathrm{b}}$ Alveolar measurement.

${ }^{\mathrm{c}}$ Data from Gittleman and Van Valkenburgh (1997: table I), using the average of mean values for males and females.

These studies employed measurements taken from intact dentaries of living species. Temnocyonine mandibles are commonly incomplete, and almost all lack the ascending ramus with its processes and articular condyle that are essential to measurement of dentary length and the calculation of mandibular lever arms used to determine the mechanical advantage of jaw muscles (Van Valkenburgh and Koepfli, 1993; Van Valkenburgh et al., 2003). However, it was possible to approximate bending strength along the length of partial temnocyonine mandibles that preserved undamaged bone beneath the cheek teeth, using the solid beam model and external cross-sectional diameters measured at various points along the toothrow.

Mandibles providing the essential conditions for calculation of bending resistance survived in six temnocyonine species. Measurements were taken from two complete and four partial dentaries (appendix 2): Relative to dentaries in living carnivorans, estimated temnocyonine dentary lengths indicate that the small $T$. altigenis is similar to Canis latrans; Temnocyon ferox, T. fingeruti, and Mammacyon obtusidens approximate Canis lupus; and the large T. macrogenys slightly exceeds Panthera leo, whereas $D$. oryktes is most like Crocuta in form but of greater 
A

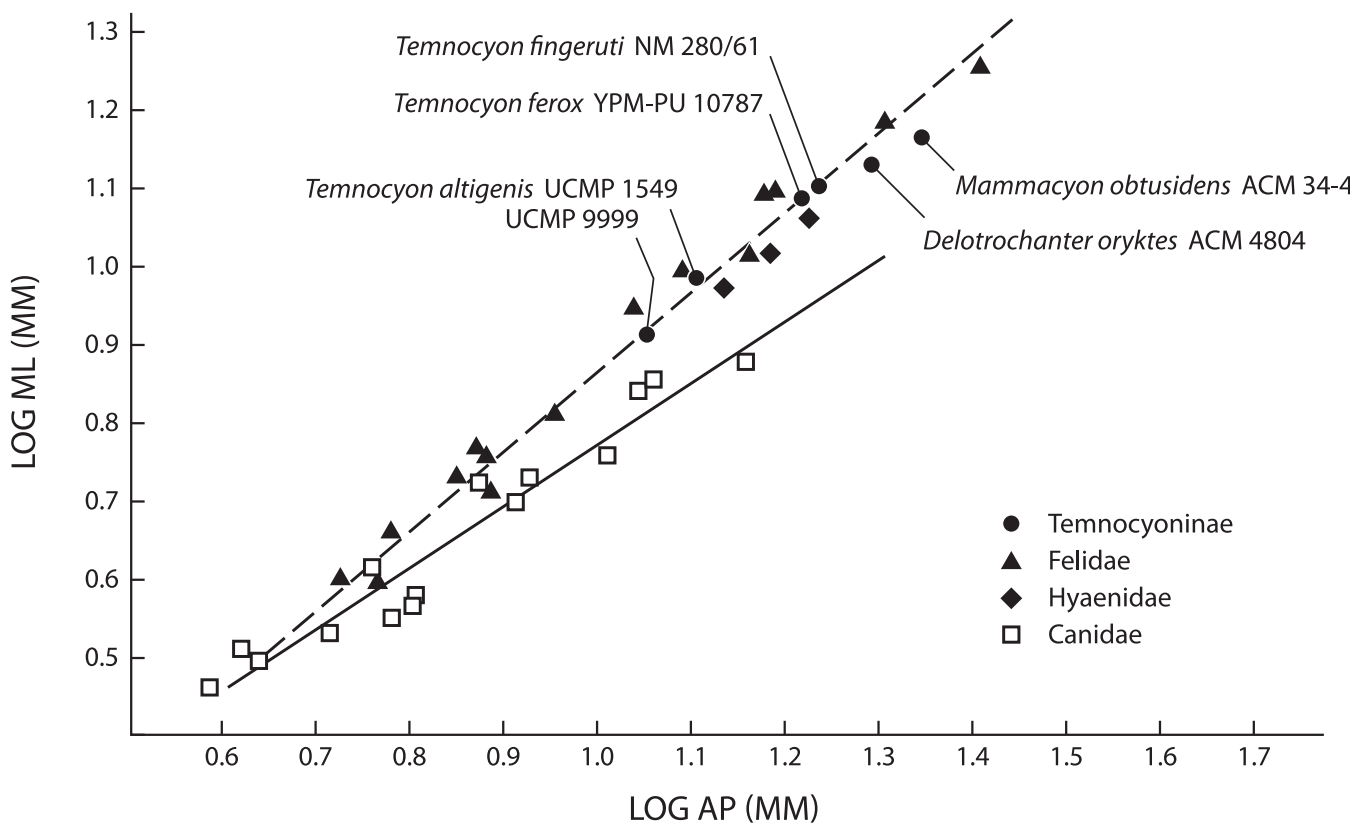

B

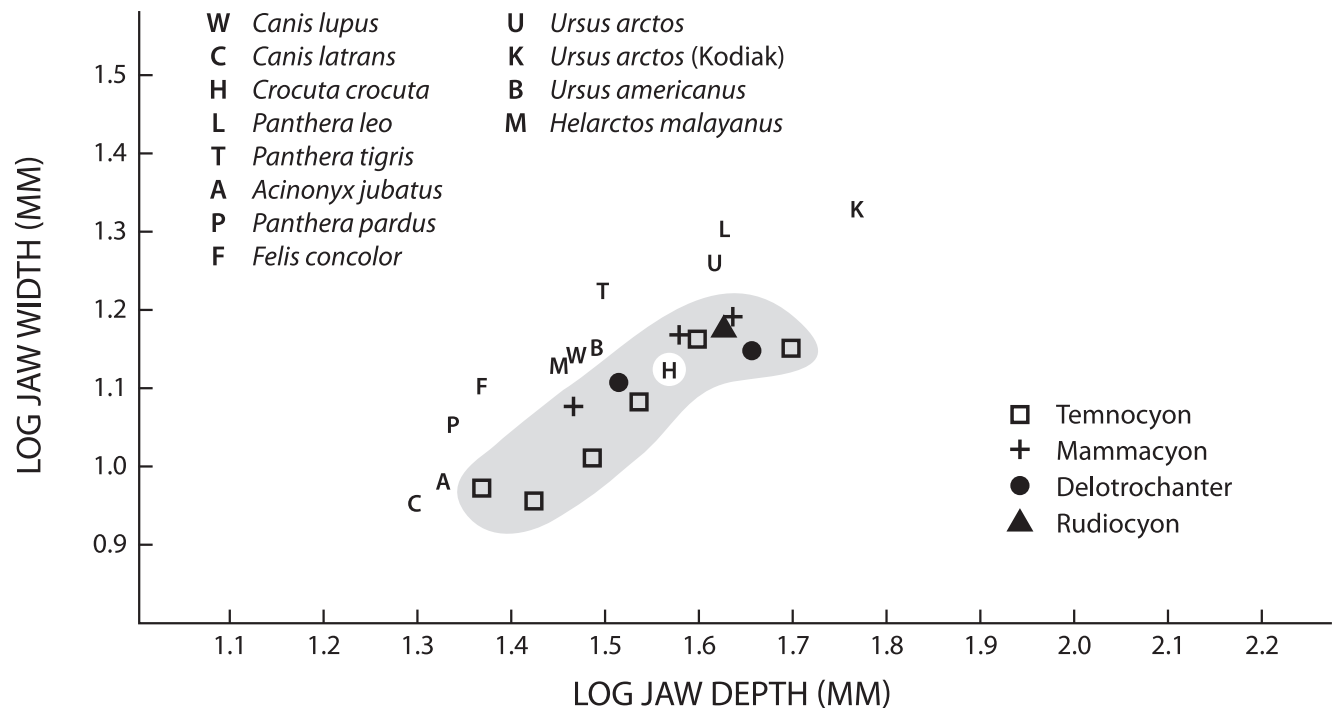

Fig. 50. (A) Log-log plot of upper canine anteroposterior diameter (AP) against mediolateral diameter (ML) as calculated by Van Valkenburgh and Ruff (1987: fig. 3) from samples of living felids, hyaenids, and canids. Temnocyonines plot with felids and hyaenids, not canids; (B) Log-log plot of mandibular depth against width in large living carnivores and temnocyonines (table 10): measured below $\mathrm{m} 1-\mathrm{m} 2$ interdental gap in canids and temnocyonines; below $\mathrm{m} 1$ in felids and Crocuta; below $\mathrm{m} 2$ in ursids.

length. Calculation of bending resistance depends on the length of the working side lever arm (the distance from the point of application of force along the toothrow to the jaw articulation). This length (L) was estimated for the partial dentaries and accurately determined for the two complete jaws. The $\mathrm{m} 1 \mathrm{~m} 2$ interdental gap was selected as the bite locus (point of applied force). Temnocyonines have a proportionately lon- 


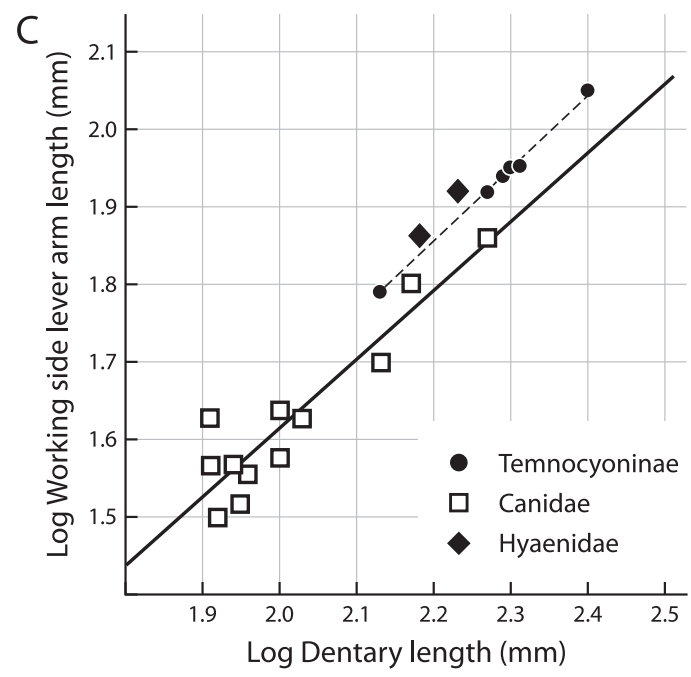

Fig. 50 (continued). (C) Log-log plot of dentary length relative to working side lever arm length (articular condyle to $\mathrm{m} 1 / \mathrm{m} 2$ interdental gap for canids and temnocyonines; to $\mathrm{p} 4 / \mathrm{m} 1$ for hyaenids). Canid-hyaenid data and regression from Biknevicius and Ruff (1992a: fig. 9A).

ger working side lever arm than those of large living canids (fig. 50C). This appears to be the result of lengthened crushing surfaces of molars used to process hard material, a probable adaptation for durophagy.

Many temnocyonines seem to have dorsoventrally deep, labiolingually narrow mandibles. When temnocyonine mandibular width is plotted relative to depth, it is apparent that these beardogs possess deep, narrow mandibles when compared with those of living carnivores of similar body size (fig. 50B). When bite force is applied to the principal cheek teeth during mastication, these temnocyonine mandibles are able to resist substantial dorsoventral bending stress. Jaw depth measured below $\mathrm{m} 1-\mathrm{m} 2$ for large species of Temnocyon ( $\sim 35-53 \mathrm{~mm})$, Mammacyon $(\sim 38-44 \mathrm{~mm})$, and Delotrochanter $(\sim 46 \mathrm{~mm})$ corresponds to, and in some cases exceeds, values $(29.8-43.3 \mathrm{~mm})$ observed for Canis lupus, Panthera leo, Crocuta crocuta, and Ursus arctos at functionally analogous points on the mandible (table 10).

To further explore the relationship between mandibular structure and jaw function, the two intact temnocyonine mandibles (Temnocyon macrogenys, F:AM 54139; Delo- trochanter oryktes, ACM 4804) were compared with a representative canid (Canis lupus), hyaenid (Crocuta crocuta), and felid (Panthera leo), carnivores that approximate the size range of these large temnocyonines (appendix 3). Included here for its heuristic value is the largest known daphoenine amphicyonid, Daphoenodon (Borocyon) robustum, from the early Miocene Runningwater Formation of Nebraska, a carnivore comparable in body size to the large temnocyonines (Hunt, 2009).

The two temnocyonine mandibles were oriented and measured according to Therrien's (2005: 252f.) method of beam analysis. Mandibular depth and width were measured in centimeters with dial calipers at interdental foci between $\mathrm{p} 3 \mathrm{p} 4, \mathrm{p} 4 \mathrm{~m} 1, \mathrm{~m} 1 \mathrm{~m} 2, \mathrm{~m} 2 \mathrm{~m} 3$, and directly behind $\mathrm{m} 3$ (post-m3). Depth of the mandibular symphysis was measured as a vertical posterior to the canine; mandibular width was measured from a point on the labial face of the mandible directly behind the canine to the posterior termination of the symphysis (Therrien, 2005: fig. 2, canine). Working side lever arms were calculated as the distance from the articular condyle to the various interdental points along the mandibular corpus. Dentary length was taken as the distance from articular condyle to the mandibular terminus directly anterior to the canine (Biknevicius and Ruff, 1992a: fig. 1). These measurements on temnocyonine jaws were then compared with sample means for the various species of canids, hyaenids, and felids provided by Therrien (2005: figs. 3-7, appendices 1, 2).

Despite its limitations in overestimating the amount of cortical bone in cross-sections, the solid beam model allowed comparison of relative patterns of bending strength along the mandibles of both the fossil and extant species. Second moments of area (Iy, Ix), which estimate the cross-sectional distribution of cortical bone about the dorsoventral and labiolingual axes, were calculated from the formulas of Therrien (2005: 250). From these were derived the section moduli, $\mathrm{Zx}$ and $\mathrm{Zy}$, which are respective measures of parasagittal and transverse bending strength. These moduli are a reflection of bending moments applied to the mandible during prey capture and feeding.

The bending resistance of a point along the mandible during the bite is a function of the 

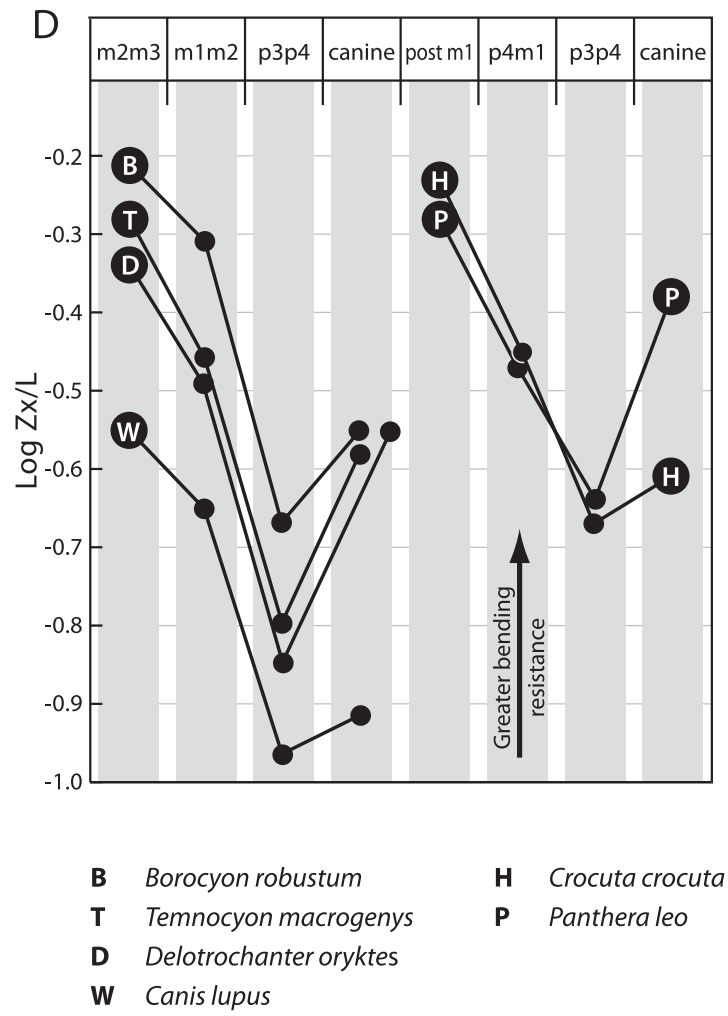
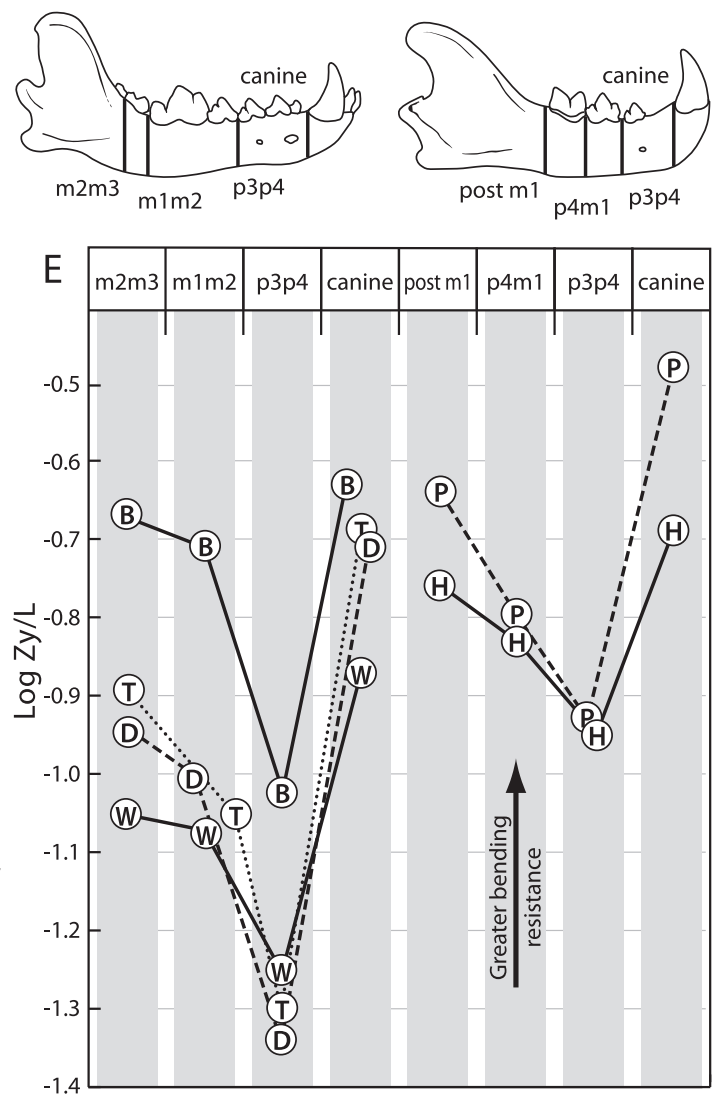

Fig. 50 (continued). (D) Magnitude of dorsoventral force ( $\mathrm{Zx} / \mathrm{L})$ applied at interdental loci along the mandible. $\mathrm{Zx}$, the section modulus, measures parasagittal bending strength relative to length $(\mathrm{L})$ of the working side lever arm. (E) Magnitude of labiolingual force $(\mathrm{Zy} / \mathrm{L})$ applied at interdental loci along the mandible. $\mathrm{Zy}$, the section modulus, measures transverse bending strength relative to length $(\mathrm{L})$ of the working side lever arm. Diagrams of caniform and feliform mandibles show location of linear measurements taken at interdental gaps. Data for canid, felid, and hyaenid from Therrien (2005).

distance (L) from the articular condyle to a particular dental locus, which is then expressed here as a ratio to derive parasagittal $(\mathrm{Zx} / \mathrm{L}$, fig. 50D) or transverse (Zy/L, fig. 50E) bending strength values. These graphs compare patterns of bending strength along the various caniform and feliform mandibular corpora, providing insight into relative bending moments typical of these species.

Living carnivores studied by Therrien (2005: figs. 3-7) typically show parasagittal bending strengths at the various post-canine loci along the mandibular corpus to be greater than transverse values. The temnocyonines and the daphoenine Borocyon robustum show clear parallels here to the large living canids in bending strength values distributed along the mandible, which rise rapidly distad along the mandible from $\mathrm{p} 3 \mathrm{p} 4$ to directly behind $\mathrm{m} 3$. The daphoenine and temnocyonines share with these canids (Canis lupus, Lycaon pictus, Canis rufus) a crushing molar platform (m1 talonid, $\mathrm{m} 2-3$ ) and similar $\mathrm{ZxL}$ and $\mathrm{ZyL}$ force profiles in which maximum bending strength occurs in proximity to the molars at the back of the jaw (figs. 50D, E). These amphicyonids, however, show much greater bending strength at the molars and a longer crushing platform relative to canids studied by Therrien (2005: fig. 6).

The mandibular force profile of Borocyon robustum far exceeds the values for any living canid, and also the extinct Canis dirus (Therrien, 2005: fig. 6). Borocyon robustum is 


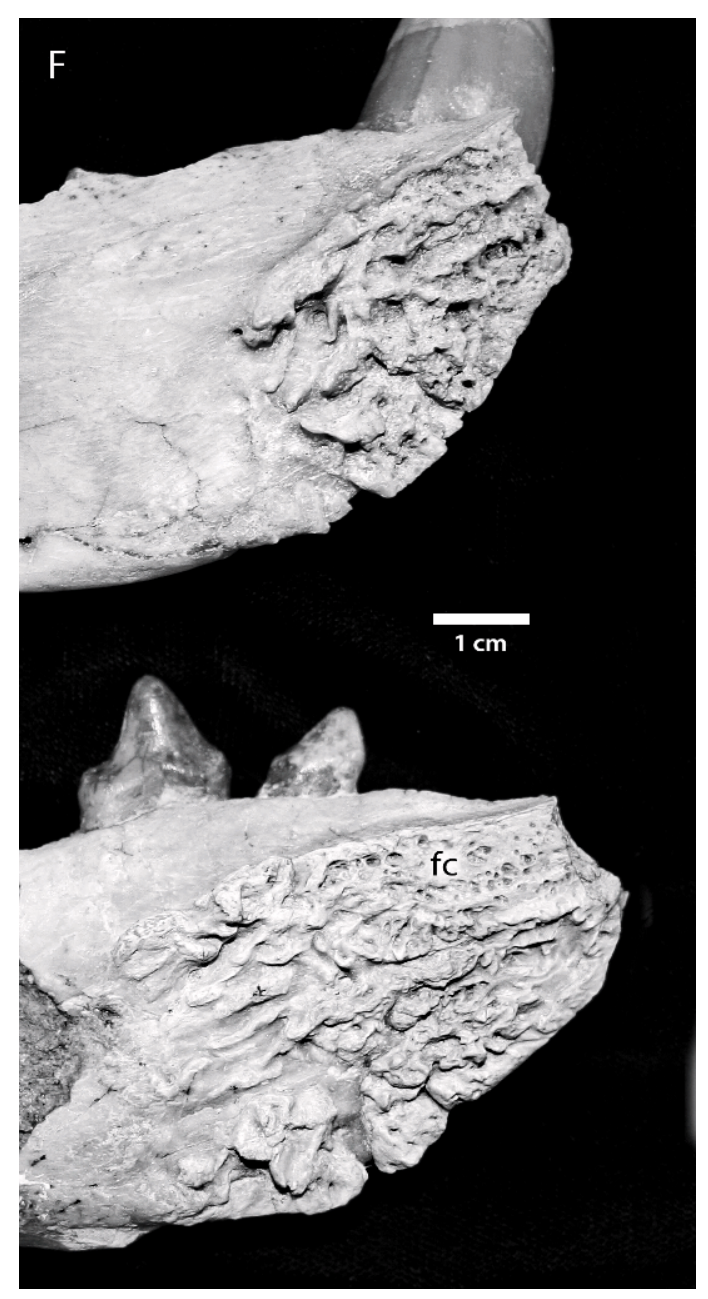

Fig. 50 (continued). (F) Mandibular symphyses of Delotrochanter oryktes (top) and Temnocyon macrogenys (bottom). Interdigitating rugose bone and ligaments strengthen these mandibular symphyses against forces encountered during prey capture and feeding; note area for fibrocartilage pad (fc) in T. macrogenys.

a much larger animal with more massive jaw musculature than a typical wolf, thus the greater bending strength values are likely due in part to the size of this daphoenine. However, resistance to bending at the canines is much greater than in the wolf, evident in the beardog's more strongly buttressed mandibular symphysis (Hunt, 2009: fig. 38), resistant at the canines to both parasagittal and transverse forces applied during prey capture and feeding. Known from its skele- ton to be a cursorial predator, B. robustum appears to have had an ecologic role as a large wolflike hypercarnivore able to easily process bone and other tough fibrous foods (Hunt, 2009).

Higher $\mathrm{Zx} / \mathrm{L}$ and $\mathrm{Zy} / \mathrm{L}$ values for Temnocyon macrogenys and Delotrochanter oryktes reflect their greater body size and more massive jaw musculature relative to the large living canids. The largely parallel patterns of bending resistance along the toothrow, however, indicate a similar distribution of applied force along the mandibular corpus during feeding, except for the canines and mandibular symphysis. $\mathrm{Zy} / \mathrm{L}$ values show temnocyonine mandibles to be stronger at the canines when subjected to transverse stresses, than at the molars, which Therrien (2005) interpreted as an indication of substantial torsion at the symphysis.

Temnocyonines and Borocyon are exceptional in their $\mathrm{Zx} / \mathrm{L}$ and $\mathrm{Zy} / \mathrm{L}$ values for parasagittal and transverse bending strength at the canines/mandibular symphysis. They compare with the spotted hyena (figs. 50D, E), yet cannot match the considerable parasagittal and transverse strength achieved by the lion. The wolf and other large living canids have lower values for canine/symphyseal bending strength, possibly explained by the quick, sharp nipping bites used by social pack-hunters to bring down large prey without the stresses encountered by lion and spotted hyena in capturing and feeding on large ungulates. The reinforced symphysis of these temnocyonines (fig. 50F) and Borocyon, composed of two rugose interlocking mandibular plates joined by strong ligaments, better resists torsional forces than the symphysis of the wolf. The broader, more rectangular form of the $T$. macrogenys and $B$. robustum symphyses is evident in their length/width ratios $(1.51,1.48$, respectively; Mammacyon ferocior, $1.41 ; M$. obtusidens, 1.45) relative to the narrower, elliptical symphyses of Delotrochanter oryktes (2.15) and Crocuta crocuta $(\sim 2.7-2.9)$.

$\mathrm{Zx} / \mathrm{Zy}$ values are a measure of relative bending strength about the sagittal and transverse planes of the mandibular corpus (Biknevicius and Ruff, 1992a: 484), considered by Therrien (2005) as mandibular force profiles. These $\mathrm{Zx} / \mathrm{Zy}$ ratios (fig. $50 \mathrm{G}$, appendix 3) estimate the relative differences 


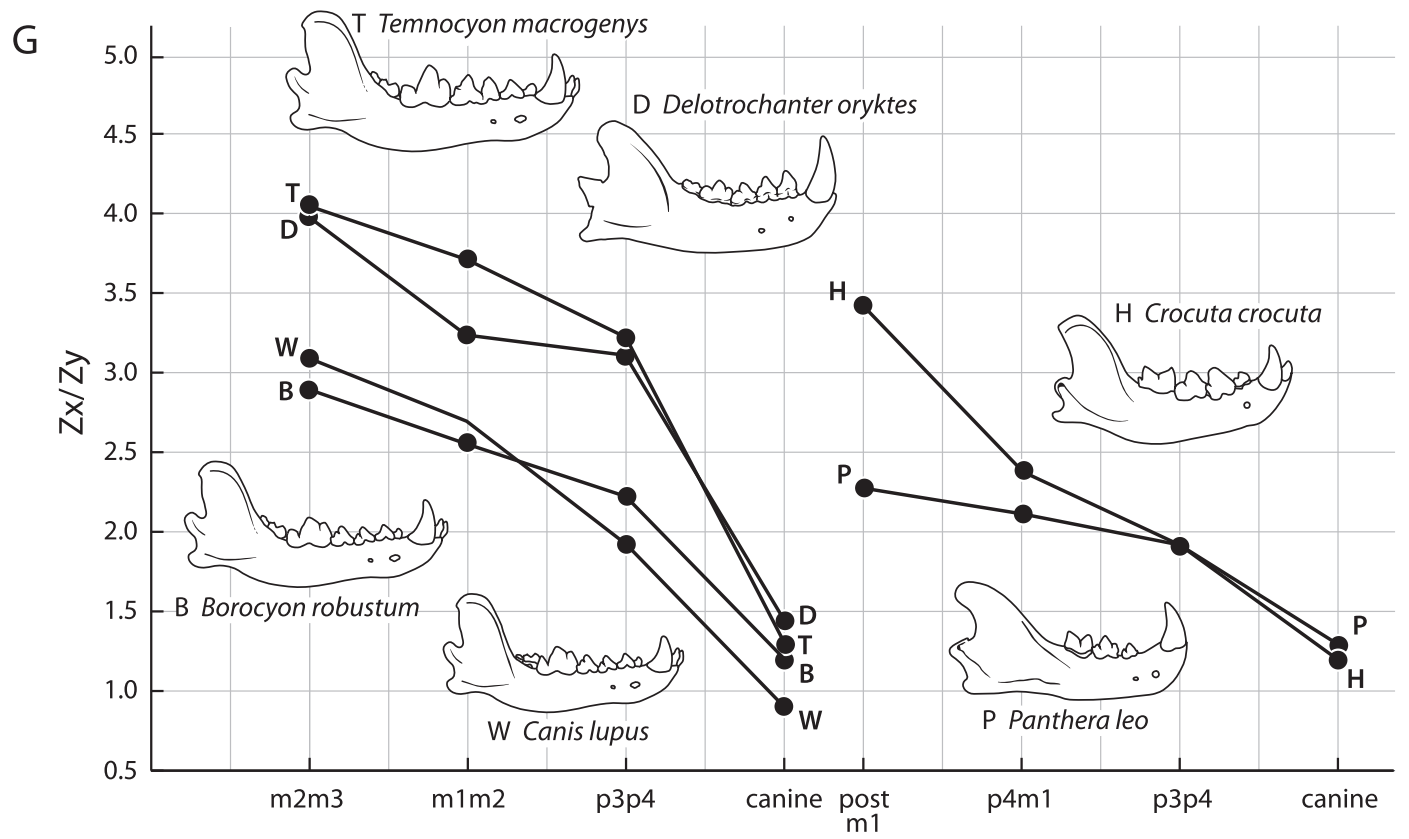

Fig. 50 (continued). (G) Mandibular force profiles ( $\mathrm{Zx} / \mathrm{Zy}$ ) of caniform and feliform carnivorans. Zx/Zy values are nearly all $>1.0$, indicating greater bending resistance to dorsoventral relative to labiolingual stresses applied at mandibular loci during prey capture and food processing. The temnocyonines show exceptional parasagittal bending resistance below the molars that reflects their deep, narrow mandibles at this locus. Zx/Zy canine ratios (1.2 to $\sim 1.5$ ) of the three amphicyonids, Crocuta crocuta, and Panthera leo are comparable, indicating similar resistance to stresses at the mandibular symphysis.

between parasagittal and transverse loadings along a single mandible with the advantage that these patterns can then be compared among carnivoran species. The temnocyonine pattern of $\mathrm{Zx} / \mathrm{Zy}$ ratios along the mandibular corpus indicates the ability to tolerate heavy dorsoventral loading at the molar platform. Thus, temnocyonines combine great strength at the canines and symphysis to hold and dispatch prey with powerful forces exerted at the molar battery to grind and crush hard food material during feeding. Living large canids have been observed chewing hard food items, including bone, at this molar locus (Mech, 1970; Haynes, 1982; Van Valkenburgh, 1996), and temnocyonines also possessed this capability.

Addition of bone (buttressing) is to be expected in the mandibular corpus reinforcing dorsoventral and labiolingual as well as torsional bending strength when strong forces are applied to the teeth during feeding and prey capture. Particularly strong loadings are anticipated where teeth are used to comminute hard, tough foods. In their analysis of living canids and hyaenids, Biknevicius and Ruff (1992a: 497) observed that the location along the mandible of teeth used to chew hard foods (primarily in bone-processing) seemed to determine durophagous adaptations: increased bending strength materialized directly caudal to bone-processing teeth. In temnocyonines, precarnassial teeth seem less involved in masticating bone or other hard food items, evidenced by less apical wear on anterior premolars (P1-2, p1-3), while cusps of P3$\mathrm{M} 2$ and $\mathrm{p} 4-\mathrm{m} 3$ show blunt wear, a situation similar to that known in wolves. The posterior cheek teeth of temnocyonines, notably in the large dentally derived species, were uniquely specialized for crushing and grinding hard material. Bone processing by temnocyonines, relative to living canids, may have been favored by the longer working side lever arm at the molars (fig. 50C) that apparently accommodated a somewhat wider gape.

The two temnocyonines (T. macrogenys, D. oryktes) in which intact mandibles sur- 
TABLE 10

Mandibular Measurements of Temnocyonines and Living Carnivorans (in mm)

\begin{tabular}{|c|c|c|c|}
\hline & Mus. No. & Jaw depth ${ }^{\mathrm{a}}$ & Jaw width \\
\hline \multirow[t]{3}{*}{ Temnocyon altigenis } & AMNH 6855 & 30.7 & 10.3 \\
\hline & AMNH 6856 & 26.8 & 9.0 \\
\hline & UCMP 9999 & 23.3 & 9.2 \\
\hline Temnocyon fingeruti & NM 280/61 & 34.5 & $\sim 12-13$ \\
\hline Temnocyon ferox & YPM-PU 10787 & 39.6 & 14.5 \\
\hline Temnocyon macrogenys & F:AM 54139 & $\sim 50-53$ & 14.2 \\
\hline cf. Mammacyon sp. & LACM 15908 & 29.7 & 11.9 \\
\hline Mammacyon obtusidens & LACM 9194 & $\sim 38$ & 14.5 \\
\hline Mammacyon ferocior & F:AM 27562 & $\sim 44$ & 15.4 \\
\hline Delotrochanter petersoni & CM 1603 & 32.8 & 12.9 \\
\hline Delotrochanter oryktes & ACM 4804 & 45.6 & 14.0 \\
\hline Rudiocyon amplidens & LACM 480 & 43.0 & 15.3 \\
\hline Canis latrans & $\mathrm{N}=12^{\mathrm{b}}$ & $20.3^{\mathrm{c}}$ & $8.9^{\mathrm{c}}$ \\
\hline Acinonyx jubatus & $\mathrm{N}=4$ & 21.6 & 9.7 \\
\hline Panthera pardus & $\mathrm{N}=1$ & 22.0 & 11.2 \\
\hline Felis concolor & $\mathrm{N}=8$ & 23.6 & 12.7 \\
\hline Helarctos malayanus & $\mathrm{N}=1$ & 29.0 & 13.7 \\
\hline Canis lupus & $\mathrm{N}=11$ & 29.8 & 13.8 \\
\hline Ursus americanus & $\mathrm{N}=2$ & 30.9 & 14.1 \\
\hline Panthera tigris & $\mathrm{N}=6$ & 31.8 & 16.8 \\
\hline Crocuta crocuta & $\mathrm{N}=2$ & 36.9 & 13.3 \\
\hline Ursus arctos & $\mathrm{N}=4$ & 41.3 & 18.0 \\
\hline Panthera leo & $\mathrm{N}=3$ & 43.3 & 20.2 \\
\hline Ursus arctos (Kodiak Is.) & $\mathrm{N}=1$ & 59.0 & 21.4 \\
\hline
\end{tabular}

${ }^{\mathrm{a}}$ Measured below $\mathrm{m} 1$ in felids and Crocuta; below $\mathrm{m} 2$ in ursids; below $\mathrm{m} 1-2$ interdental gap in Canis lupus, C. latrans, and temnocyonines.

${ }^{\mathrm{b}} \mathrm{N}$, sample size for living carnivorans.

${ }^{\mathrm{c}}$ If $\mathrm{N}>1$, values are means for living carnivorans.

vived must have differed considerably in external appearance (figs. 20, 34). Although much larger, the elongate mandible of $T$. macrogenys is shaped like that of Canis lupus and indicates a rather long "doglike" skull. Temnocyon macrogenys must have been an enormous wolflike predator with a longlegged striding gait and other predictable cursorial features. The shape of the D. oryktes mandible is hyenalike; the skull short with broad snout and deep zygomata much as in Crocuta, although lacking the wider palate of the hyena. The form of its blunt-cusped cheek teeth are unlike those of living canids and hyaenids, yet doubtless served a crushing function, in agreement with pronounced mandibular buttressing along the ventral margin of the jaw below the cheek teeth. The large species of Delotrochanter appear to be temnocyonines that, to some extent, craniodentally parallelled the bone-crushing hyaenids.

\section{POSTCRANIAL OSTEOLOGY: THE FIRST LARGE CARNIVORAN CURSORS}

In temnocyonine beardogs, lengthening of the limbs and adoption of a more upright stance accompanied by skeletal modifications promoting a more restricted fore-aft motion of the limb and foot are evident adaptations influencing the gait, stride, and energy budget of these archaic carnivorans.

Longer limbs are associated with living cursorial carnivores, particularly the larger canids such as wolves (Canis lupus) and the African hunting dog Lycaon. Here endurance coupled with pack hunting behavior during a prolonged pursuit replaces the hunting strategy of the solitary carnivore that relies on rapid acceleration and attack speed. This capability is manifest in musculoskeletal and physiological adaptations that maximize energy savings. Predatory cursors optimize gaits 
that minimize energy costs (Alexander, 2003). The preferred pursuit gait is a compromise that conserves energy while outlasting the prey-to achieve this, speed, acceleration, maneuverability, and locomotor stability are mutually adjusted within the physiological and structural capability of the carnivore.

Lengthening the limbs, particularly the lower limb and foot, are essential to the endurance strategy, increasing stride and step length. Research on mechanical design in mammals also suggests a benefit to the more upright stance that often accompanies lengthening of the limbs (Biewener, 1989a, b). Energy is further conserved by concentrating muscle mass in the proximal limb segments, thereby reducing the limb's moment of inertia and the energetic cost of locomotion (Myers and Steudel, 1985); thin, distal tendons transmit the force of a much thicker proximally placed muscle while effectively reducing the mass of the lower limb.

Economy of motion is also achieved by confining the limb to a fore-aft path. An indication of restricted fore-aft motion is often evidenced by closely registered joint surfaces in the lower limb segments-this registration can be seen in the hind limb of living cursorial canines in the interlocked fit of astragalus and calcaneum; by close apposition of the metapodials; by pronounced keels on the distal metapodials for the sesamoids and proximal phalanges; and by a deeply grooved astragalar trochlea firmly inserted in the distal tibia-fibula. In the forelimb a more erect stance and fore-aft motion are achieved by parasagittal alignment of the limb in which the scapula functions as the upper mobile segment of the forelimb; by reducing or eliminating angulation at the elbow; by a constrained articulation of the ulna with the humerus favoring fore-aft excursion; by reduced participation of the distal ulna in the carpal joint of the wrist; and by modifications of carpal bones, metacarpals, and phalanges that promote stability during protraction and retraction of the forefoot. In both fore- and hind limb a digitigrade stance allows energy storage in tendons and ligaments supporting the feet (spring mechanisms) - strain energy is thereby stored and released during each stride. A number of these skeletal adaptations are evident in temnocyonines, although in some species not developed to the extent seen in a living cursorial canid such as the wolf.

In living canine cursors and in temnocyonines the potential use of the forelimb in prey capture is sacrificed to the efficient fore-aft gait, a compromise favoring endurance, and accompanied in wolves and African hunting dogs by reliance on pack hunting. Sustained gaits of this type must be powered by aerobic locomotion, and since the metabolic rate of active striated muscle achieves maximum efficiency at a speed of contraction somewhat less than the speed of maximum power output (Alexander, 2003), a gait such as the sustained trot seems well adapted to endurance pursuit in these cursors.

Heglund and Taylor (1988) observed that terrestrial mammals prefer speeds falling in the mid-range of a particular gait such as the trot and gallop. Although the preferred speeds of these mammals increase with body size, stride frequency decreases, accompanied by a mass-specific decrease in energy cost, which suggests that there is an advantage to increasing body size in a cursorial carnivore. Hildebrand (1962) reported that as speed increases, living ungulates and carnivores increase stride length considerably but increase stride frequency only slightly, a plausible strategy for energy conservation. This must be balanced against the cost of acquiring the available (finite) resources necessary to maintain the body mass of a larger animal.

The temnocyonine skeleton represents the earliest experiment by large species within the Order Carnivora at lengthening the limbs (proportionally longer lower limbs and feet), approaching cursorial canids in this regard, as evidenced by the humeroradial and femorotibial length ratios, and by elongation of the metapodials and digits of the feet (tables $8,11,12$ ). The close registration of the joint surfaces of the distal limbs did not progress to the same degree found in cursorial wolves and coyotes, but the first attempts at this are evident in temnocyonine tarsal structure and in the apposition of the metapodials, accompanied by reliance on the paraxonic foot with greatly reduced metapodials 1, 2, and 5. A straight-legged digitigrade stance accompanies these adaptations, marked by less angulation at the elbow 
evidenced in the deep penetration of the head of the ulna into the olecranon fossa of the humerus, creating in some species a perforate fossa of the type seen in living canids. The transversely narrow distal humerus with deep symmetrical olecranon fossa so typical of the erect stance of wolves and coyotes is present even in the earliest temnocyonines. Prominent scars along the shafts of radius and ulna show that these bones were joined by strong interosseous ligaments that in the younger derived species may have limited rotation of the radius on the ulna.

In the larger temnocyonines where the forelimb has survived (Mammacyon obtusidens, M. ferocior, Delotrochanter oryktes), the radius, ulna, and metapodials are lengthened, resulting in an elongate forelimb. Pronationsupination of the forelimb involving rotation of radius on ulna is restricted, yet not to the degree evident in the wolf. Rotation of the radial head in the radial notch of the ulna is not as limited in these beardogs. However, the articulation of the distal ulna with the radius and carpus is as advanced as in the wolf. In both wolf and beardog the radial process of the distal ulna is reduced to a flat articular facet appressed tightly against the radius that permits only limited movement. Whereas some mobility remains in the wrist in the articulation of the proximal carpals (scapholunar, carpal cuneiform) with the radioulna, the rotation of the radius is certainly diminished, indicating restriction of the forelimb to a more fore-aft trajectory. The elongate paraxonic fore- and hind feet, a digitigrade stance, and reduction of the lateral digits in these large temnocyonines further suggest a mobile cursorial predator.

\section{Temnocyonine Postcrania}

Postcranial remains have rarely been found with crania or dentitions of temnocyonines. However, five species are now known to have postcranial elements associated with dentitions (table 8). At least one species in each of the three principal genera recognized in this study is represented by a significant portion of the postcranium.

In the John Day beds of Oregon, Temnocyon altigenis is known from a partial skeleton from Logan Butte (Merriam, 1906) and Temnocyon ferox is represented by the nearly complete skeleton described by Eyermann (1896). This latter species is considerably larger and younger than $T$. altigenis. These two skeletons demonstrate that some cursorial traits retained in T. ferox had already developed in $T$. altigenis, arguably the oldest and most plesiomorphic temnocyonine.

In the Great Plains the postcranial skeleton of Mammacyon is known from limited material belonging to the holotype of $M$. obtusidens and from a more complete skeleton of the larger, more advanced $M$. ferocior. $M$. ferocior represents the terminal species of its lineage and demonstrates the postcranial adaptations that accompanied a robust crushing dentition-this species displaying the most extreme example of durophagy in the Temnocyoninae.

The quarries at Agate Fossil Beds National Monument have produced two individuals of Delotrochanter oryktes, one from Stenomylus Quarry (Loomis, 1910: 298), and the other from the carnivore dens at Beardog Hill (Hunt et al., 1983; Hunt, 1984). These are the only individuals in this genus with associated skeletons, and they reveal the most extreme cursorial modifications of the feet yet recognized in temnocyonines.

Without question the single characteristic distinguishing the temnocyonine skeleton is the change from the primitive skeletal proportions of an early amphicyonid such as Daphoenus to the cursorial stance evident in the limbs and feet of temnocyonines. These altered proportions occur in all three genera and demonstrate a somewhat diachronous yet clearly parallel evolution of cursoriality during the Arikareean NALMA.

Dimensions of the temnocyonine postcranial skeleton (table 8) can be established for two species of Temnocyon, two of Mammacyon, and one species of Delotrochanter. This record of the postcrania in these five species is particularly fortuitous in demonstrating that cursorial modifications in the limbs and feet occur in each of the principal lineages of the subfamily.

Proportions of the forelimb (humerus, radius) are better known than for the hind limb (femur, tibia) because the femur in several cases was not complete or did not 
TABLE 11

Limb Proportions of Temnocyonine, Daphoenine, and Amphicyonine Amphicyonids

\begin{tabular}{|c|c|c|c|c|c|c|c|c|}
\hline Mus. No. & Humerus & Radius & $\mathrm{R} / \mathrm{H}$ & $\mathrm{MC} 4$ & Femur & Tibia & $\mathrm{T} / \mathrm{F}$ & MT4 \\
\hline \multicolumn{9}{|l|}{ TEMNOCYONINAE } \\
\hline \multicolumn{9}{|l|}{ Temnocyon altigenis } \\
\hline UCMP 9999 & $159^{\mathrm{a}}$ & $\sim 132$ & 83.0 & & & & & \\
\hline \multicolumn{9}{|l|}{ Temnocyon ferox } \\
\hline YPM-PU 10787 & 206 & 186 & 90.3 & 71.6 & 244 & 222 & 91.0 & 84.3 \\
\hline \multicolumn{9}{|c|}{ Mammacyon obtusidens } \\
\hline ACM 34-41 & 217 & $\sim 205$ & 94.5 & & & $\sim 239$ & & 85.0 \\
\hline \multicolumn{9}{|l|}{ Mammacyon ferocior } \\
\hline F:AM 27562 & 247 & $227^{\mathrm{b}}$ & 91.9 & & $\sim 275$ & 265 & 96.4 & \\
\hline \multicolumn{9}{|c|}{ Delotrochanter oryktes } \\
\hline ACM 4804 & 220 & 210 & 95.4 & & 246 & 228 & 92.7 & 88 \\
\hline $\mathrm{ACM} 4804 \mathrm{~A}^{\mathrm{juv}}$ & & 166 & & & 207 & & & \\
\hline UNSM 47800 & & & & 83.9 & & & & 91.0 \\
\hline \multicolumn{9}{|l|}{ DAPHOENINAE } \\
\hline \multicolumn{9}{|l|}{ Daphoenus vetus } \\
\hline F:AM 25451 & 142 & 119 & 83.8 & & & & & 62.4 \\
\hline USNM 17847 & 160 & 125 & 78.1 & & & & & \\
\hline F:AM 76206 & 159 & 125 & 78.6 & & $\sim 180$ & & & \\
\hline AMNH 11857 & 165 & 138 & 83.6 & & & 178 & & \\
\hline F:AM 50329 & 168 & 129 & 76.8 & & 193 & 172 & 89.1 & \\
\hline CM 492 & 185 & 135 & 73.0 & & 201 & 179 & 89.0 & \\
\hline FMNH P12021 & & 140 & & & 197 & 178 & 90.3 & \\
\hline FMNH P12138 & $\sim 155$ & $\sim 119$ & 76.7 & $54.4^{\mathrm{c}}$ & $\sim 175$ & 156 & 89.1 & 56.6 \\
\hline FMNH UM746 & $\sim 170$ & 135 & 79.4 & & & $\sim 180$ & & \\
\hline F:AM 63343 & & 131 & & 47 & 187 & & & \\
\hline PU 11423 & & & & & 197 & & & \\
\hline PU 12588 & 163 & & & & & & & \\
\hline \multicolumn{9}{|c|}{ Daphoenus hartshornianus } \\
\hline F:AM 76529 & & & & & 152 & $\sim 142$ & 93.4 & 52.3 \\
\hline FMNH UM488 & $\sim 112$ & $\sim 93$ & 83.0 & & 143 & 135 & 94.4 & \\
\hline \multicolumn{9}{|c|}{ Daphoenus sp. (Chadronian) } \\
\hline CM 951 & & & & & 142 & 137 & 96.4 & \\
\hline FMNH PM8694 & 136 & 109 & 80.1 & & & & & \\
\hline UNSM 26171 & 132 & 108 & 81.8 & & $\sim 158$ & 149 & 94.3 & \\
\hline UNSM 48498 & 134 & 110 & 82.0 & & & & & \\
\hline \multicolumn{9}{|c|}{ Daphoenodon superbus } \\
\hline CM 1589 & 210 & 182 & 86.7 & & 230 & 205 & 89.1 & \\
\hline \multicolumn{9}{|l|}{ AMPHICYONINAE } \\
\hline \multicolumn{9}{|l|}{ Ysengrinia americana } \\
\hline CM 2400 & 300 & & & & & & & \\
\hline UNSM 44606 & 287 & & & & & & & \\
\hline F:AM 54147 & 270 & $\sim 241$ & 89.3 & & & & & \\
\hline USNM 186993 & & & & & 351 & $\sim 280$ & 79.8 & \\
\hline UNSM 44600 & & 260 & & & & & & \\
\hline UNSM 44601 & & 250 & & & & & & \\
\hline UNSM 44691 & & 252 & & & & & & \\
\hline UNSM 44624 & & & & & 364 & & & \\
\hline UNSM 44690 & & & & & 353 & & & \\
\hline UNSM 44620 & & & & & & 287 & & \\
\hline
\end{tabular}


TABLE 11

(Continued)

\begin{tabular}{|c|c|c|c|c|c|c|c|c|}
\hline Mus. No. & Humerus & Radius & $\mathrm{R} / \mathrm{H}$ & MC4 & Femur & Tibia & $\mathrm{T} / \mathrm{F}$ & MT4 \\
\hline UNSM 44621 & & & & & & 297 & & \\
\hline UNSM 44622 & & & & & & 287 & & \\
\hline UNSM 44623 & & & & & & 288 & & \\
\hline Cynelos lemanensis $^{\mathrm{d}}$ & 220 & 197 & 89.5 & & 282 & 240 & 85.1 & \\
\hline Amphicyon major ${ }^{\mathrm{e}}$ & 294 & 239 & 81.3 & & 330 & 258 & 78.2 & \\
\hline
\end{tabular}

$\mathrm{R} / \mathrm{H}=$ humeroradial ratio, $\mathrm{T} / \mathrm{F}=$ femorotibial ratio (Davis, 1964), MC, MT = metacarpal, metatarsal.

${ }^{\mathrm{a}}$ All limb bone lengths in $\mathrm{mm}$.

${ }^{\mathrm{b} C a l c u l a t e d ~ f r o m ~ u l n a ~ l e n g t h . ~}$

${ }^{\mathrm{c}}$ Metacarpal 3.

${ }^{\mathrm{d}}$ From Ginsburg (1977).

${ }^{\mathrm{e}}$ From Bergounioux and Crouzel (1973).

juv Juvenile individual (Schlain, 1980).

survive (table 11). A complete set of associated metacarpals is known only for $T$. ferox (table 8 ), preserved in a strongly silicacemented, recalcitrant matrix in which ana- tomical detail is obscured. The metatarsals fare better: a complete or nearly complete set is known for T. ferox, M. obtusidens, and $D$. oryktes. This is fortunate since the reduction

TABLE 12

Limb Proportions of Living Ursids, Felids, and Canids Relative to Oligocene-Miocene Amphicyonid Carnivorans, Hyaenodon and Dinictis

\begin{tabular}{|c|c|c|c|}
\hline Family & Species $^{\mathrm{a}}(\mathrm{N})$ & Humeroradial ratio & Femorotibial ratio \\
\hline \multirow[t]{3}{*}{ URSIDAE } & Ursus arctos (7) & $79.0-83.1$ & $67.9-73.9$ \\
\hline & Ursus americanus (3) & $78.3-84.4$ & $71.4-75.9$ \\
\hline & Thalarctos maritimus (2) & $84.4-86.3$ & $73.9-74.4$ \\
\hline \multirow[t]{2}{*}{ FELIDAE } & Panthera tigris (9) & $80.7-86.4$ & $83.4-87.6$ \\
\hline & Panthera leo (11) & $90.0-94.0$ & $83.7-89.3$ \\
\hline \multirow[t]{3}{*}{ CANIDAE } & Canis lupus (4) & $97.2-101.9$ & $96.5-100.9$ \\
\hline & Canis latrans (3) & $104.4^{\mathrm{b}}$ & $99.6^{\mathrm{b}}$ \\
\hline & Chrysocyon brachyurus (2) & $108.1^{\mathrm{b}}$ & $107.8^{\mathrm{b}}$ \\
\hline \multicolumn{4}{|l|}{ AMPHICYONIDAE } \\
\hline \multirow{4}{*}{ DAPHOENINAE } & Daphoenus vetus (8) & $73.0-83.8$ & $89.0-90.3^{\mathrm{c}}$ \\
\hline & Daphoenus hartshornianus $(1,2)$ & 83.0 & $93.4-94.4$ \\
\hline & Daphoenus (Chadronian) (3) & $80.1-82.0$ & $94.3-96.4^{\mathrm{c}}$ \\
\hline & Daphoenodon superbus (1) & 86.7 & 89.1 \\
\hline \multirow[t]{2}{*}{ AMPHICYONINAE } & Ysengrinia americana & $87.1-90.6^{\mathrm{d}}$ & $78.8-84.1^{\mathrm{e}}$ \\
\hline & Cynelos lemanensis (1) & 89.5 & 85.1 \\
\hline \multirow[t]{5}{*}{ TEMnOCyoninae } & Temnocyon altigenis (1) & 83.0 & \\
\hline & Temnocyon ferox (1) & 90.3 & 91.0 \\
\hline & Mammacyon obtusidens (1) & 94.5 & \\
\hline & Mammacyon ferocior (1) & 91.9 & 96.4 \\
\hline & Delotrochanter oryktes (1) & 95.4 & 92.7 \\
\hline HYAENODONTIDAE & Hyaenodon horridus (1) & 71.6 & 86.0 \\
\hline NIMRAVIDAE & Dinictis sp. (1) & 81.3 & 86.3 \\
\hline
\end{tabular}

${ }^{\mathrm{a}}$ Ratios for living species calculated from data in Hunt (2002a: table 2).

${ }^{\mathrm{b}}$ Mean, from Davis, 1964: 35.

${ }^{\mathrm{c}}$ Femorotibial ratio, D. vetus, $\mathrm{N}=4$; Chadronian Daphoenus, $\mathrm{N}=2$.

${ }^{\mathrm{d}}$ Range of values based on a humerus and three radii from the same quarry.

${ }^{\mathrm{e}} \mathrm{R}$ ange of values based on two femora and four tibiae from the same quarry - most probable ratio falls between 81.3 and 81.6. 
of the outermost metatarsals and digits can be identified in all of these species, supplying critical information on the evolution of the hind foot. Phalanges directly associated with the corresponding metapodials are only preserved in the fore- and hind foot of $T$. ferox; yet because its limbs are so like those of species in the other two genera, one can infer the presence of proportionately similar phalanges.

\section{Limb Proportions}

Limb proportions of temnocyonines are compared with those of living ursids, felids, and canids in table 12. Proportions of some daphoenine and amphicyonine beardogs are also included, with Daphoenus vetus representing the inferred plesiomorphic limb skeleton for North American daphoenine amphicyonids. (For further comparison, table 12 includes a contemporary White River creodont, Hyaenodon horridus, and White River nimravid cat, Dinictis sp., both with limb ratios indicating lack of limb elongation.)

The more complete data from the forelimb is supplemented by the sparser hind limb measurements. Together they demonstrate the lengthening of the lower limb segments in temnocyonines. The evident correspondence to the limb proportions of living canids is striking, and exceeds the degree of elongation in living ursids, felids, and in other amphicyonids. The forelimb of the lion Panthera leo is similar in length to those of several temnocyonines but the lion hind limb is not quite as elongate.

The Logan Butte temnocyonine skeleton (T. altigenis, UCMP 9999) is the most anatomically primitive. Most limb bones are present but few are complete. Although only the humerus is intact, an estimate of forelimb length can be based on a radius and ulna lacking only their distal ends. If this estimate is correct, the forelimb has not yet lengthened to the extent evident in younger, larger temnocyonine species. Temnocyon altigenis from Logan Butte retains a plesiomorphic cranium and dentition little different from the North American amphicyonid Daphoenus vetus, and forelimb measurements of these two species also show similar, less elongated limb proportions. However, UCMP 9999 displays less angulation of its elbow joint than seen in $D$. vetus, suggesting that a more parasagittal excursion of the forelimb had been achieved in $T$. altigenis relative to $D$. vetus. The inference that forelimb elongation in temnocyonines occurs in parallel as each lineage evolves over time is based on the absence of elongation in the forelimb of the Logan Butte Temnocyon (UCMP 9999), which retains the most plesiomorphic dentiton and skull of the subfamily.

The oldest species of Mammacyon and Delotrochanter associated with postcrania already possess elongated limbs. Whether the earlier representatives of these genera were similarly proportioned is unknown; there is no reason why they could not have evolved from an ancestral species such as the Logan Butte Temnocyon.

\section{Cursorial Adaptations in the Limb OSTEOLOGY OF TEMNOCYONINES}

Cursorial traits are particularly evident in the osteology of the forelimb and these approximate similar adaptations in the forelimb of the wolf (Canis lupus) and cheetah (Acinonyx jubatus). Plesiomorphic amphicyonid postcranial morphology is represented by the Oligocene Daphoenus vetus Leidy (Hatcher, 1902b; Scott and Jepsen, 1936). The following comparisons of the smaller temnocyonine species are with $D$. vetus, while the large temnocyonines are compared with Daphoenodon superbus (Peterson, 1910), whose skeleton can be considered an essentially unmodified, scaled-up version of that of $D$. vetus.

\section{FORELIMB}

SCAPULA: Delotrochanter oryktes (ACM 4804) preserves the only relatively complete scapula known for temnocyonines (fig. 57). The scapula of ACM 4804 is most similar in form to those of other contemporary amphicyonids (e.g., Daphoenodon superbus, Borocyon niobrarensis; Hunt, 2009: fig. 20A). Among the living Carnivora its shape approaches the scapular form of felids. Schlain (1980) established the presence of a postscapular fossa for the subscapularis muscle in this species, a feature typical of amphicyonids. The supraspinous fossa occupies pro- 
portionately more surface area than the infraspinous fossa, and acromnion and metacromnion processes are present. Schlain (1980) noted the narrow glenoid cavity implying restriction of the movement of humerus on scapula to a more fore-aft path. The spinodeltoid, which flexes the shoulder, runs from the scapular spine to the deltoid crest of the humerus; this crest in temnocyonines is a low arcuate ridge that traverses the upper two-thirds of the diaphysis.

In Temnocyon altigenis (UCMP 9999) only the glenoid of the scapula survives. Temnocyon ferox, the only other species of this genus that is represented by most of the postcranial skeleton, also retains a glenoid remnant as does Mammacyon ferocior (F:AM 27562). The holotype of Mammacyon (M. obtusidens, ACM 34-41) preserves the glenoid and adjoining portion of the scapular blade including the scapular spine. The spine terminates anteriorly in a very small, blunt acromnion process (there is no metacromnion process), much less developed than even that of the wolf. This suggests a reduced acromiodeltoid muscle, a forelimb abductor less necessary in a cursor. In this respect the scapula of $M$. obtusidens differs from the more plesiomorphic scapula of $D$. oryktes with its prominent acromnion and metacromnion processes.

Humerus: The humerus is complete in Temnocyon altigenis (UCMP 9999) and already displays a more specialized distal anatomy than seen in D. vetus (fig. 51). While these two species have humeri of equal length, the distal humerus of UCMP 9999 is transversely narrower, shows reduction of the medial epicondyle, and possesses a deeper olecranon fossa for reception of the ulna. These traits accompany a close congruent registration of the humeroulnar articulation, effective in restricting the ulna to flexionextension on the humerus when the lower $\operatorname{limb}$ is extended, and thus favoring a parasagittal trajectory for the lower forelimb. A rotational torque at the elbow is resisted by contact of a facet on the lateral face of the anconeal process of the ulna with the lateral margin of the olecranon fossa of the humerus, assisted by the tight contact of the ulna's coronoid process with the humeral trochlea. This type of humero-ulnar joint registration, which occurs in temnocyonines, was previously noted by Jenkins (1973) who observed that reduction of the medial epicondyle and its associated flexor musculature decreases torque at the elbow. These features are a prelude to a more erect forelimb stance, evident in both the Logan Butte $T$. altigenis and $T$. ferox.

Both Mammacyon obtusidens and $M$. ferocior preserve the humerus, damaged in the former species, nearly complete in the latter. In both species the form of the bone is identical except for greater size in $M$. ferocior. As in Temnocyon, the distal humerus is specialized for fore-aft excursion of ulna on humerus, as evidenced by a narrow transverse distal width, reduction of the medial epicondyle, and a deep symmetrical olecranon fossa (fig. 52). All temnocyonine humeri exhibit a more rounded capitulum and deeply grooved trochlea than seen in those of Daphoenus vetus and $D$. superbus, a condition seemingly related to the narrow distal articular width of this bone. This differs from the more cylinderlike, wider articular surface of Daphoenodon superbus and D. vetus, which lacks the rounded capitulum.

The humerus of Delotrochanter oryktes (ACM 4804), $\sim 22 \mathrm{~cm}$ in length, is much the same size as the humerus of $M$. obtusidens, and is nearly as large as the humerus of M. ferocior $(\sim 24.5 \mathrm{~cm})$. The humerus is straight-shafted, a trait common to all larger temnocyonines (figs. 53-55); the bone has a slimmer profile in lateral view due to the reduction of the plesiomorphic amphicyonid deltopectoral crest and its restriction to the proximal humerus. The proximal placement and reduction of this crest also occurs in Canis lupus. The distal anatomy of the humerus is identical to that seen in other temnocyonines (fig. 52), indicating a similar upright stance and fore-aft excursion of ulna on humerus.

RADIOULNA: The radius is known in species of Temnocyon, Mammacyon, and Delotrochanter. In the Logan Butte Temnocyon altigenis both radii are present but lack their distal ends. In Temnocyon ferox the forelimb preserves a fully articulated radius, ulna, and humerus (fig. 53) but these bones are so fragmented that details of the articular surfaces are obscure. The forelimb does not 

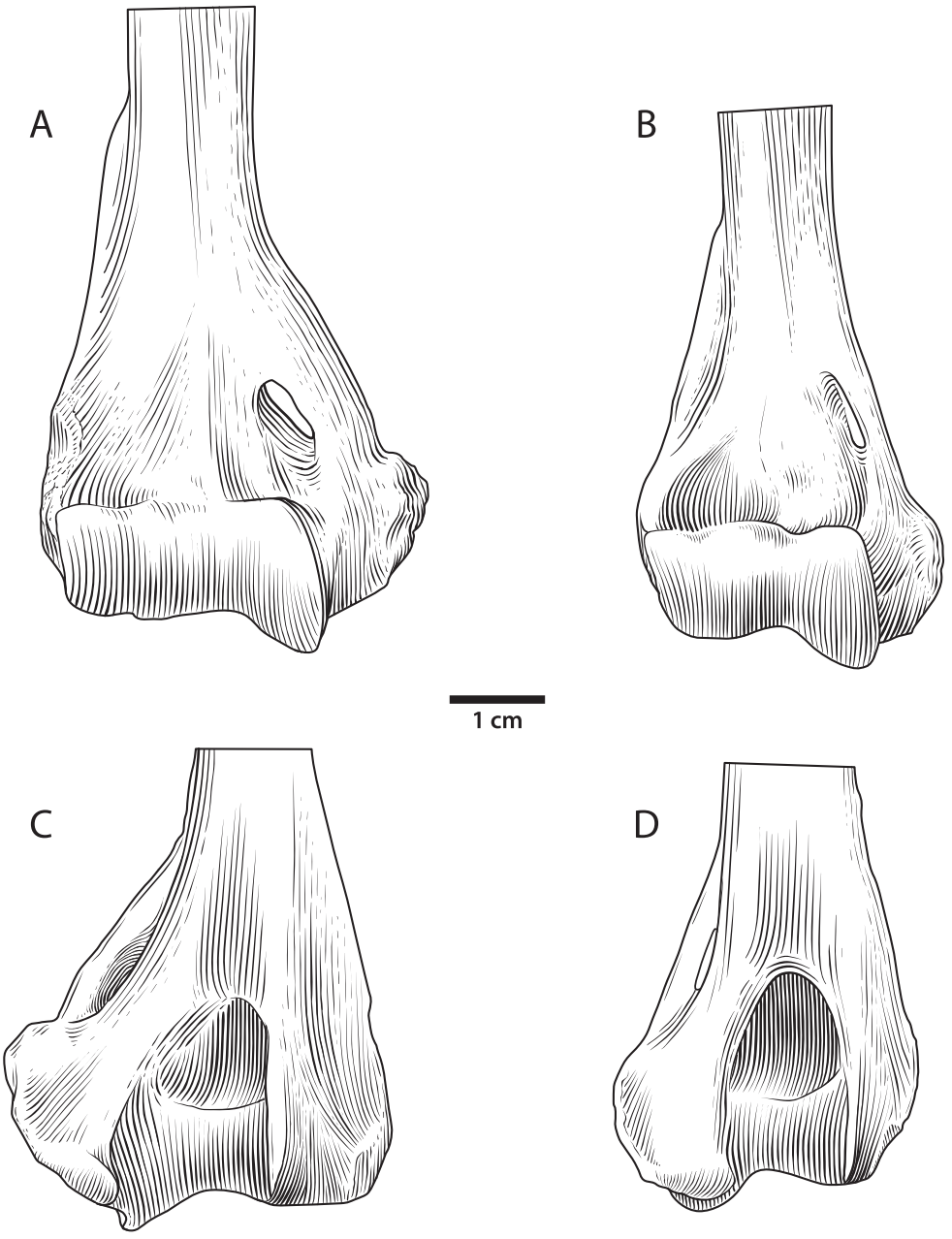

Daphoenus vetus FMNH P12138

Temnocyon altigenis UCMP 9999

Fig. 51. Comparison of the distal humerus of a stem daphoenine (A, C: Daphoenus vetus) and a plesiomorphic temnocyonine (B, D: Temnocyon altigenis). The daphoenine amphicyonid humerus is distally broad for developed flexors arising from the medial condyle and has an asymmetric olecranon fossa indicating an everted elbow. Temnocyonines have evolved the narrow distal humerus of cursorial carnivores with reduced medial condyle and symmetric olecranon fossa corresponding to an elbow with a more fore-aft alignment.

show significant elongation in $T$. altigenis, however with the younger $T$. ferox some elongation of the forelimb has taken place (table 11). The articulated forelimb of $T$. ferox makes possible a reliable estimate of limb proportions in this carnivore.

Forelimb proportions were also calculated from an associated humerus, radius, and ulna for T. altigenis, T. ferox, M. obtusidens, and $D$. oryktes and compared with other carnivorans (table 12). For M. ferocior where no radius was found, an associated humerus and ulna determine the length of the radius. The forelimb proportions for Mammacyon and Delotrochanter show that elongation of the radioulna contributes to lengthening of the limb. 

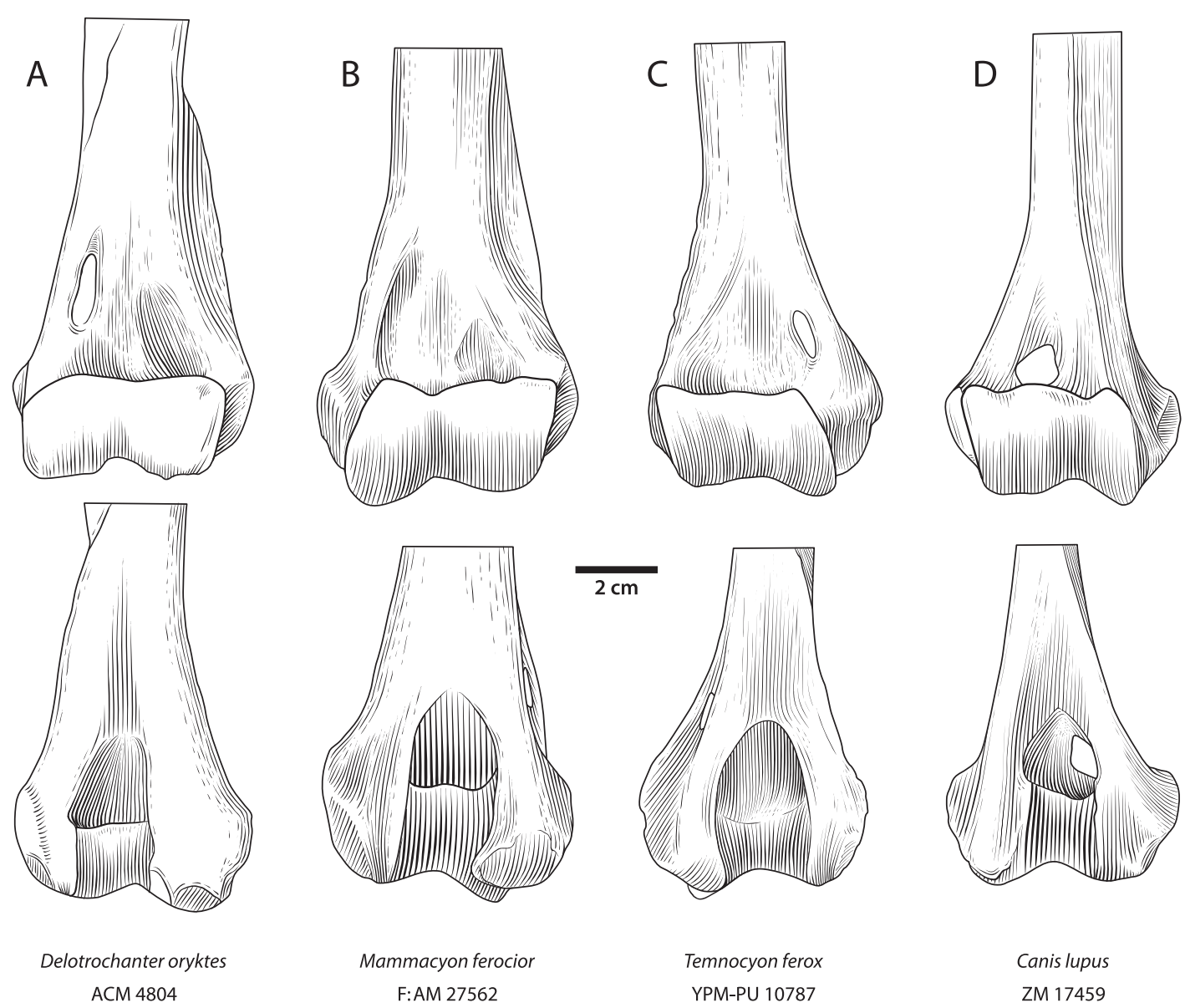

Fig. 52. All temnocyonines have developed a narrow distal humerus (with reduced medial condyle, symmetric olecranon fossa) in which the forelimb shows little or no eversion at the elbow as also seen in the wolf. These forelimbs adopt an erect digitigrade stance. Upper row, anterior view; lower row, posterior view. A, Delotrochanter oryktes; B, Mammacyon ferocior; C, Temnocyon ferox; D, Canis lupus. A, B: left humerus; C, D: right humerus.

Although no radius was collected with $M$. ferocior, its humerus and ulna (fig. 54) are identical to those of $M$. obtusidens and so a similar radius can be inferred; these two species differ only in the larger size of $M$. ferocior. Here the narrow distal humerus, best preserved in $M$. ferocior, confines the ulna to fore-aft flexion and extension. When the radioulna is extended on the humerus, the movement of the lower limb is plainly foreaft in direct parasagittal alignment with the humerus. The rounded capitulum and grooved trochlea of the distal humerus are congruent and register exactly with the circular, concave radial head and the semilu- nar notch and coronoid process of the ulnathese joint surfaces correspond closely in form to those of the wolf (fig. 54). However the radial head is not as limited in its rotation in the radial notch of the ulna as it is in the wolf, and the humeral trochlea not quite as narrow. Similarly, the bicipital tuberosity of the radius in Mammacyon remains better developed than in the wolf, suggesting that some ability to pronate/supinate the lower limb and forepaw was still retained.

Delotrochanter oryktes (ACM 4804) is represented by a humerus, radius, and ulna (fig. 55) that show anatomical modifications like those of Mammacyon. In particular, the 


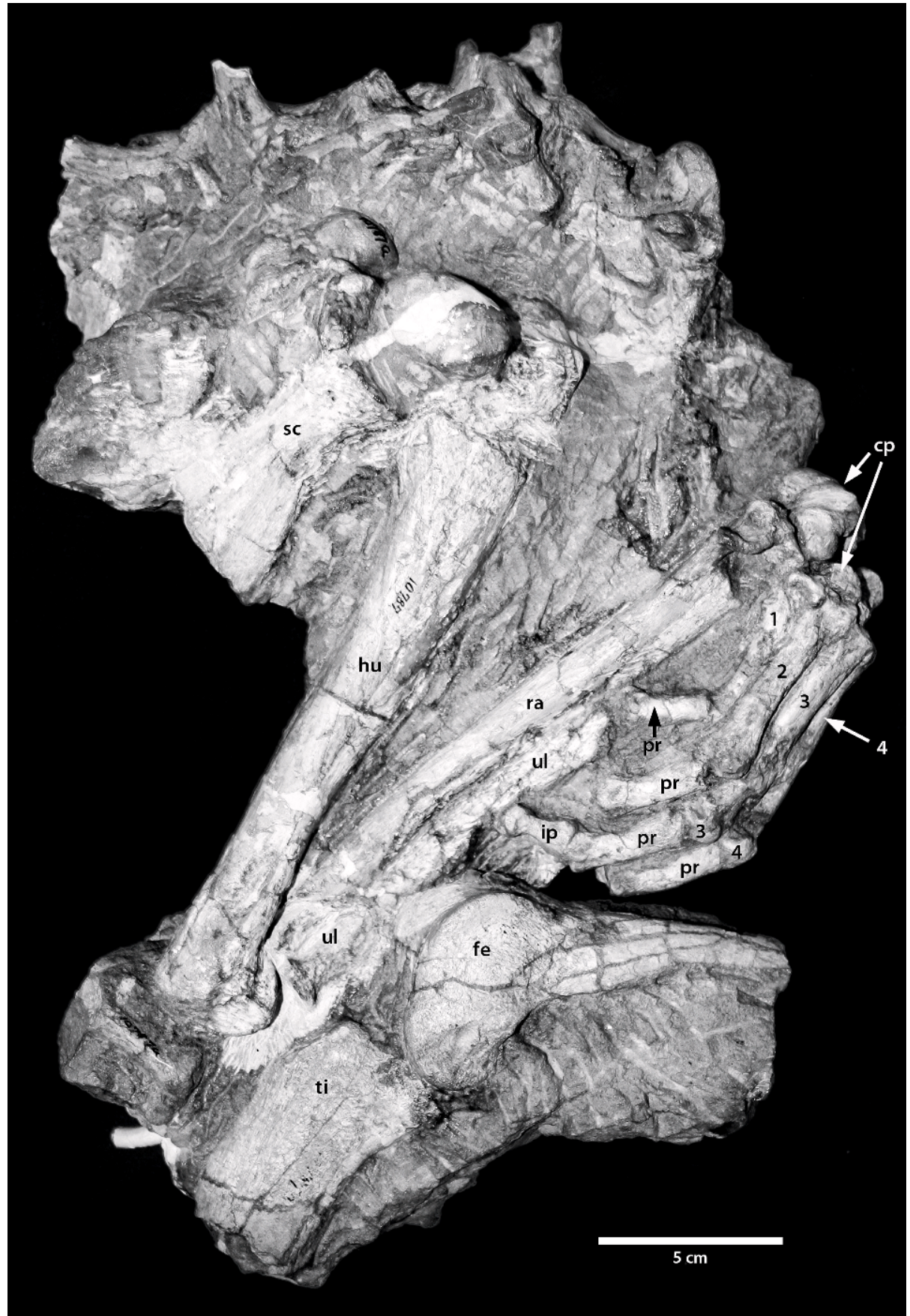

Fig. 53. Articulated right forelimb of the holotype of Temnocyon ferox (YPM-PU 10787), John Day Formation, Oregon. The forefoot shows elongation of the paraxonic metacarpals 3, 4, and their digits, with reduction of metacarpals 1, 2, and 5 (metacarpal 5 is hidden from view). A partial femur (fe) and tibia (ti) of an oreodont were entombed with the beardog. Abbreviations: sc, scapula; hu, humerus, ul, ulna; ra, radius; cp, carpus; nos. 1-4, metacarpals; pr, proximal phalanx; ip, intermediate phalanx. 
A

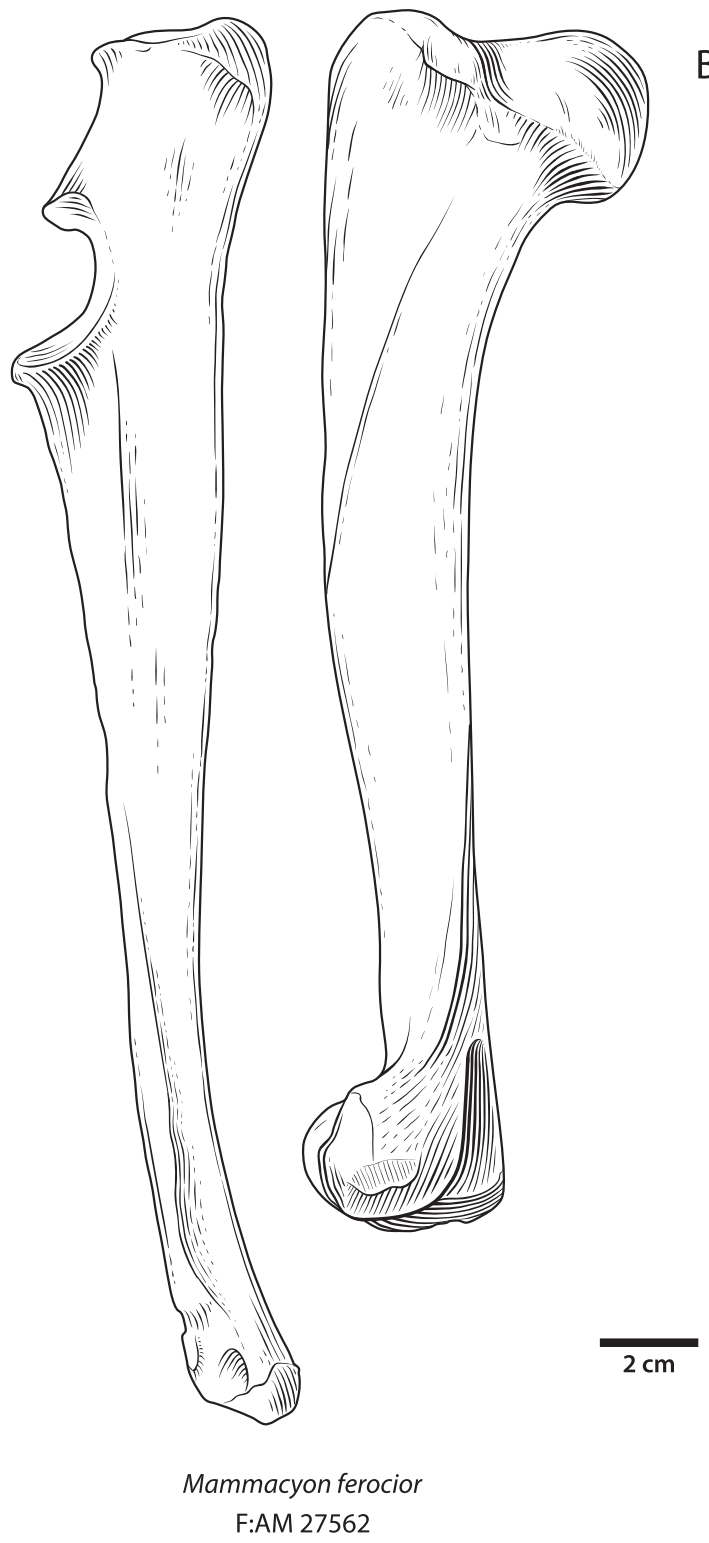

B

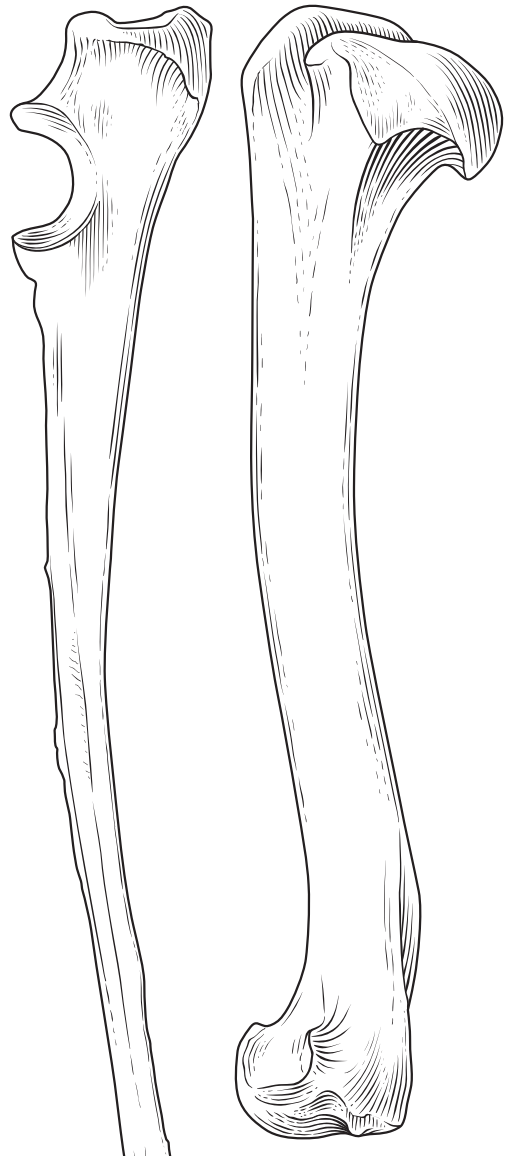

Canis lupus

ZM 17459

Fig. 54. Associated humerus and ulna of (A) Mammacyon ferocior and (B) Canis lupus showing elongation of the ulna (and radius) and pronounced reduction of the distal ulna in these cursors.

proximal ulna is a mediolaterally compressed, thin bone as in the wolf, and the semilunar notch is proximodistally divided by a low ridge, which fits into the groove of the trochlea of the humerus, aiding in humeroulnar registration in wolf and $D$. oryktes. These features are not found in the less cursorially patterned elbow joint of Daphoenodon superbus.
Moreover, the head of the radius has a precise articulation with the radial notch of the ulna in Delotrochanter and Mammacyon that differs from this articulation in the wolf: in the wolf when the radial head is placed in the radial notch, the radial head is positioned somewhat in front of the ulna. However in Mammacyon and Delotrochanter, when the radial head is placed in the laterally facing 
A

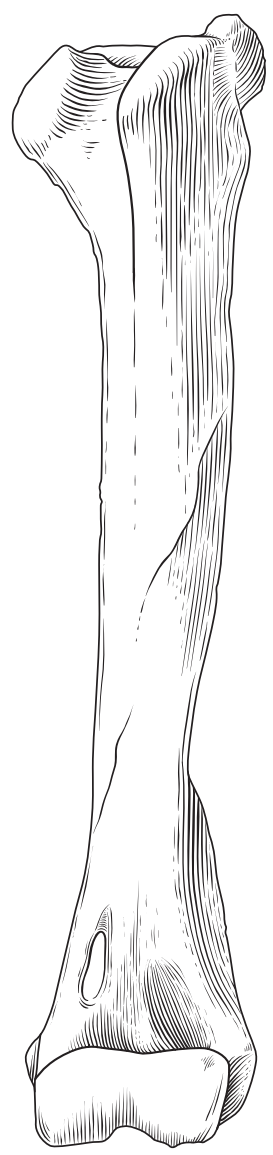

Delotrochanter oryktes ACM 4804

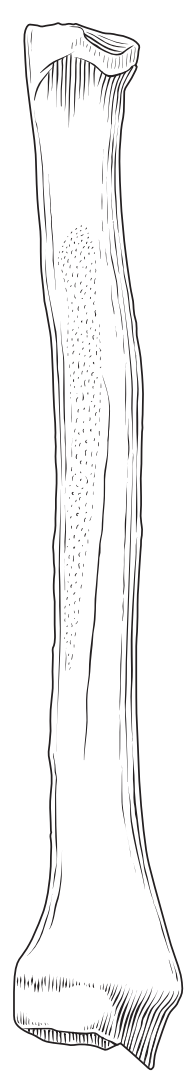

B
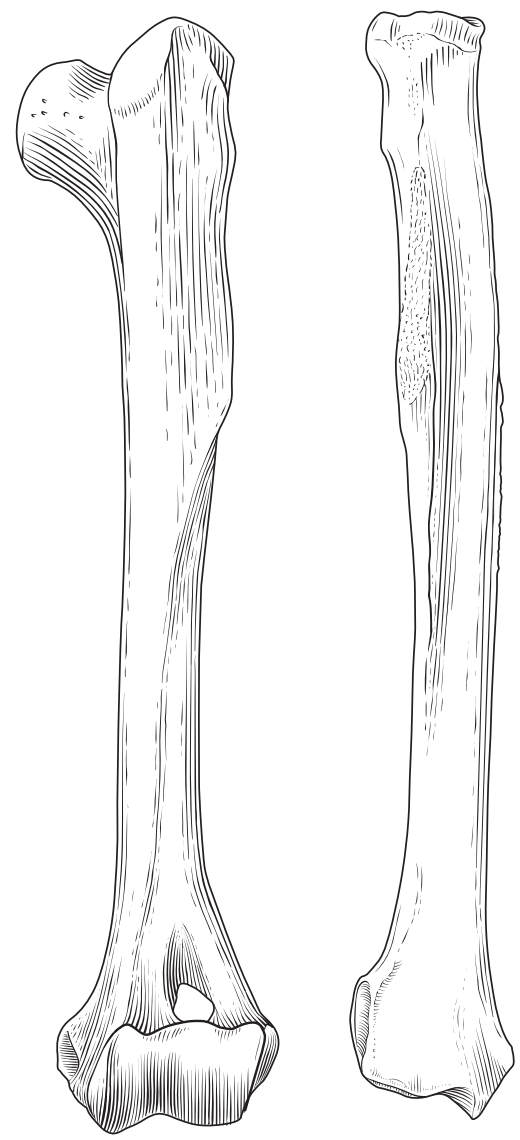

Canis lupus

ZM 17459

Fig. 55. Humerus and radius of (A) Delotrochanter oryktes and (B) Canis lupus. Anatomy of the D. oryktes forelimb and elongation of the radius and ulna are similar to these features in the wolf. Left humeri, anterior view; left radii, posterior view.

notch, the radial head is situated lateral to the ulna, which corresponds to the placement of the capitulum of the humerus directly lateral to the trochlea. This more side-by-side articular relationship of the proximal radius and ulna seems exclusive to temnocyonines. But most important for fore-aft excursion of the limb is that the shaft of the radius in these temnocyonines aligns more in parallel to the shaft of the ulna, as in the wolf. In D. oryktes and $M$. ferocior, the radius lies in close apposition to the ulna, much more so than in Daphoenodon superbus where the shaft of the radius is aligned at a greater angle to the shaft of the ulna.
Furthermore, in temnocyonines the extent of the articular facet on the radial head suggests that rotation of the radius on the ulna was limited. In the wolf a limit to the amount of rotation of the radius in the radial notch of the ulna is evident from the shape of a well-defined articular facet on the radial head that incorporates a bony stop on its lateral edge. The articular facet ends sharply where it articulates with the lateral extension of the coronoid process of the ulna, which has been reduced to a thin flange in both temnocyonines and the wolf. The even greater reduction of this flange in temnocyonines seems to be due to the more lateral 
placement of the radial head relative to the ulna in these beardogs.

In temnocyonines where the distal ulna is preserved, the distal articulation for the carpal cuneiform is present, but the articular process contacting the radius is much reduced. This parallels the condition in cursorial wolves and coyotes, in which rotation of radius on ulna is restricted.

FOREFOOT (CARPUS, METACARPUS, PHALANGES): Bones of the forefoot rarely survive among temnocyonines. In $T$. altigenis from Logan Butte no forefoot elements are known. The forelimb of Temnocyon ferox (YPM-PU 10787), however, includes a partially articulated paraxonic forefoot with carpals, metacarpals, and phalanges (fig. 53) that demonstrates the relative proportions of these elements. Metacarpals 1 to 5 of $T$. ferox are all slightly elongated relative to those of Daphoenodon superbus, and the paraxonic metacarpals 3-4 are more robust as well as longer. In $T$. ferox the trapezium, first metacarpal, and its phalanx indicate a much reduced, thin first digit in the forefoot. However, this degree of reduction of the first digit does not equal the more extreme state seen in the wolf. Although the metacarpals of T. ferox are not tightly appressed as in the wolf, they are in closer contact than in Daphoenodon.

In the forefoot of $T$. ferox the proximal phalanges of digits 3-4 are long (both $\sim 31 \mathrm{~mm}$ ), those of digits 2 and 5 shorter ( 27-29 $\mathrm{mm}$ ), and that of metacarpal 1 reduced (length, $21.8 \mathrm{~mm}$ ). Intermediate phalanges of digits 3-4 are short (length, $\sim 19 \mathrm{~mm}$ ). Only in digit 4 has the ungual been preserved; it is short (length, $\sim 13 \mathrm{~mm}$ ) and rather blunt. The phalanges of paraxonic digits 3-4 are more robust than those of $D$. superbus. If $T$. ferox is representative of the subfamily, temnocyonines lack the extreme elongation of the proximal and intermediate phalanges seen in the wolf.

The scapholunar, unciform and trapezium of Temnocyon ferox are proportionately smaller than those of $D$. superbus and are most like those of the wolf (a small carpal cuneiform is obscured by sediment). Thus the carpus is transversely narrow in order to accommodate a distally narrow radius and ulna, as in the wolf.
TABLE 13

Measurements (in mm) of the Unciform in Temnocyon, Delotrochanter, Daphoenodon, and the Live Oak Carnivore

\begin{tabular}{lcc}
\hline \hline \multicolumn{1}{c}{ Taxon } & $\begin{array}{c}\text { Greatest } \\
\text { height }\end{array}$ & $\begin{array}{c}\text { Greatest } \\
\text { width }^{\mathrm{a}}\end{array}$ \\
\hline $\begin{array}{c}\text { Temnocyon ferox } \\
\text { (YPM-PU 10787) }\end{array}$ & 14.0 & 14.6 \\
$\begin{array}{l}\text { Live Oak (TRO 661) } \\
\text { Delotrochanter oryktes } \\
\quad \text { (ACM 4804) }\end{array}$ & 18.0 & 18.5 \\
$\begin{array}{l}\text { Daphoenodon superbus } \\
\text { (CM 1589) }\end{array}$ & 19.2 & 20.0 \\
\hline
\end{tabular}

${ }^{\mathrm{a}}$ Width measured across the anterior face of the unciform.

However, the carpus lacks some anatomical features evident in wolves. The unciform serves as a case in point. The temnocyonine unciform from the Live Oak site in Florida (table 13) confirms that this bone was low and broad, much different in form from the tall, narrow unciforms seen in living ursids and felids. The Live Oak unciform shows a marked similarity to that of Canis lupus (the wolf is $23 \%$ smaller) except that a stop facet on the wolf unciform for the scapholunar is absent in the Live Oak beardog (Hunt, 2009: fig. 25, Canis lupus, \#3). In both temnocyonine and wolf the unciform articulates with metacarpals 4-5, but in the wolf the carpal cuneiform, in close contact with the unciform, bends down around the unciform and articulates by a defined concave facet with the head of metacarpal 5. There is no evidence of such a specialized carpal cuneiform in temnocyonines, and it is not present in the articulated carpus of Temnocyon ferox or in Delotrochanter oryktes (ACM 4804). The canine carpal cuneiform strengthens the carpalmetacarpal joint where it extends outward in the wrist between the fifth metacarpal and unciform. In the wolf, the fifth metacarpal is a large bone but it is much reduced in Temnocyon ferox and Delotrochanter oryktes.

The few metacarpals of Delotrochanter and Mammacyon that are known (table 8) conform anatomically to those of $T$. ferox and indicate elongation of the paraxonic forefoot (fig. 56). The considerable length of paraxonic metacarpals 3-4, and the shorter metacapal 5 evident in D. oryktes (UNSM 


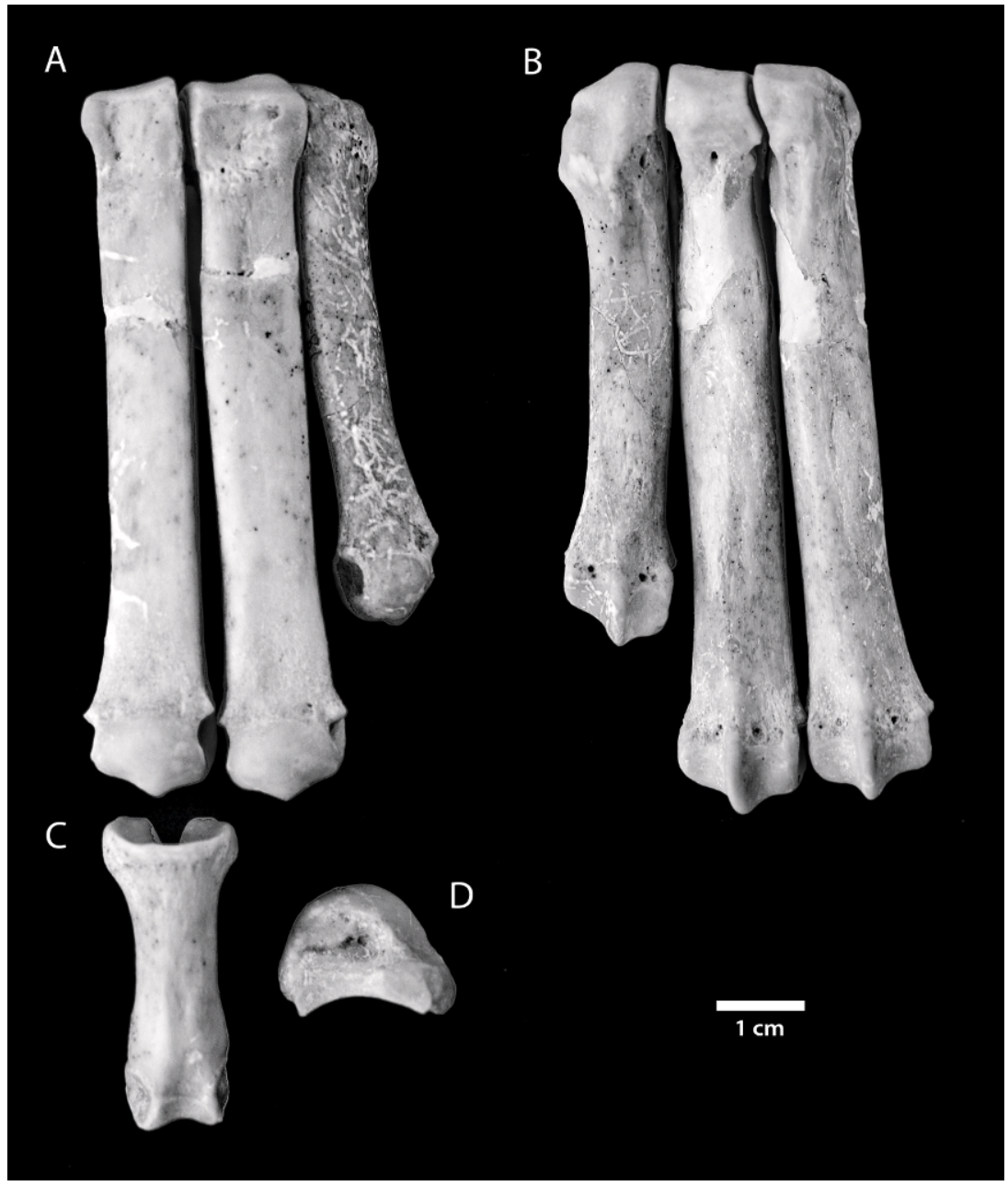

Fig. 56. Forefoot of Delotrochanter oryktes (UNSM 48700), from carnivore den, Beardog Hill, Agate Fossil Beds National Monument, Sioux Co., Nebraska. Metacarpals 3, 4, 5 (A, anterior view; B, posterior view); $\mathbf{C}$, proximal phalanx of paraxonic digit of forefoot; $\mathbf{D}$, magnum.

47800), together with metacarpals 2 and 5 in ACM 4804, show that the flanking metacarpals 2 and 5 were of similar length and were more reduced than those of the wolf, in which a robust metacarpal 5 plays a more prominent role. Only ACM 4804 preserves metacarpal 1, a small, thin, elongate bone (length, $37-38 \mathrm{~mm}$ ), not as reduced as in the wolf.

\section{Hind LimB}

INNOMINATE: The pelvis with sacrum in direct articulation survives in Temnocyon ferox and a damaged innominate is present in Delotrochanter oryktes, however a complete pelvis is not preserved in other temnocyonines. Only a partial innominate of the Logan Butte T. altigenis and fragments of the innominate of $M$. ferocior are known; these do not differ from the innominates of $T$. ferox and Daphoenodon superbus except in size. The innominate of Delotrochanter or$y$ ktes (ACM 4804) lacks only the terminus of the ischium and shares the same form and proportions as in T. ferox (fig. 57).

During excavation of the carnivore dens at Agate National Monument in 1985, we 

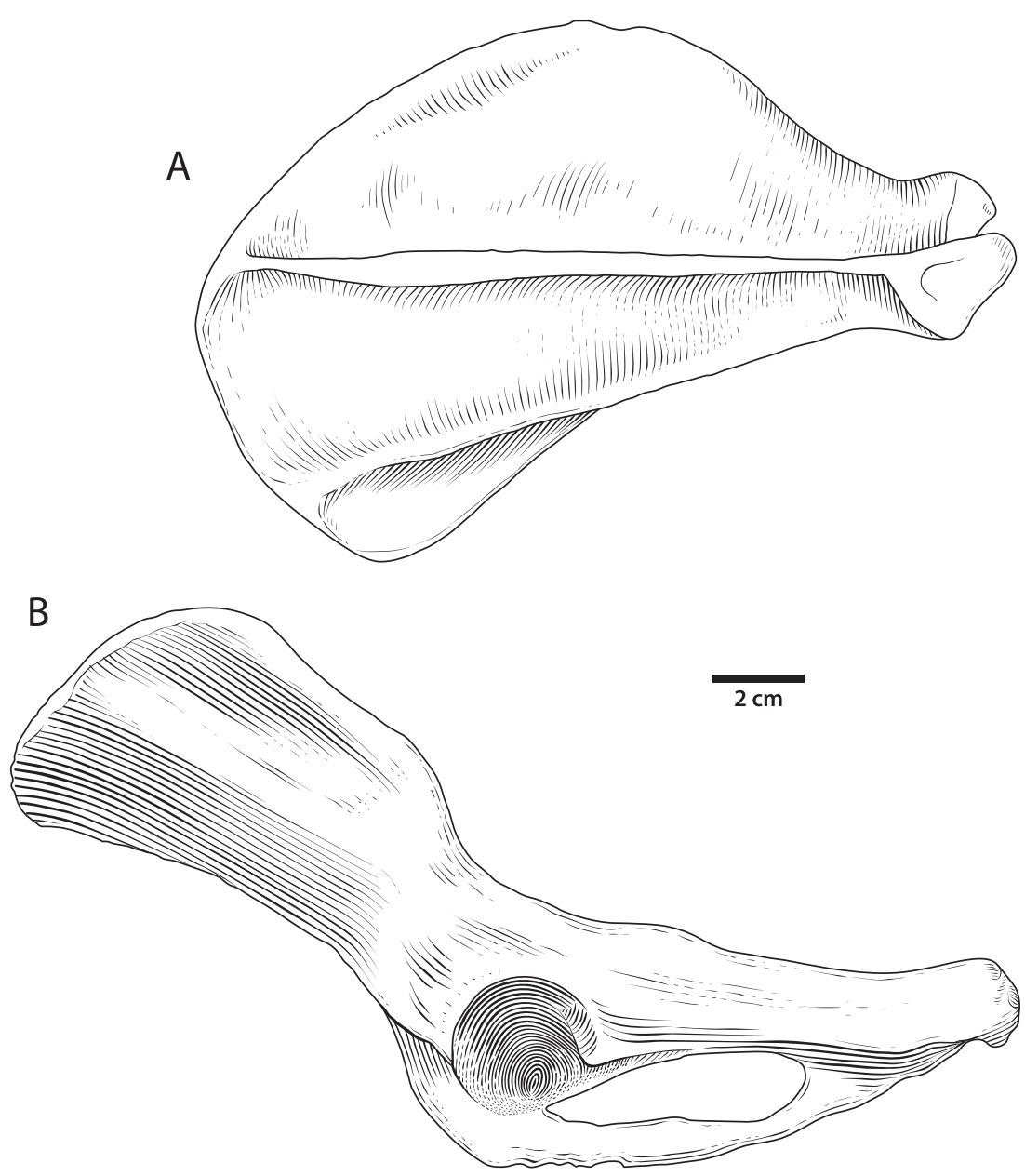

Fig. 57. Scapula (A) and innominate (B) of Delotrochanter oryktes (ACM 4804, ischium restored in part). The temnocyonine scapula did not often survive but in this species it is most similar to the plesiomorphic scapulae of Daphoenus and Daphoenodon superbus. The innominate, also known in Daphoenodon superbus and in Temnocyon ferox, has an extended ischium that presumably provided a mechanical advantage for the action of hamstring muscles.

recovered a nearly complete innominate of $D$. superbus with ischium and pubis intact. The most striking difference in the pelvis of Daphoenodon and the temnocyonines relative to that of a wolf is the much longer ischial region relative to the ilium - the postacetabular distance in the wolf is $\sim 68 \%$ of the preacetabular distance, whereas in $T$. ferox this is $84 \%$, in D. oryktes $83 \%-87 \%$, and in $D$. superbus $98 \%$. In the wolf the posterior ischium is rotated outward, presumably to increase the mechanical advantage of the hamstring muscles. This ischial eversion is absent in temnocyonines, but the simple lengthening of the ischium may have provided a similar mechanical advantage.

The temnocyonine sacrum also differs from that of the wolf in its narrow, elongate shape compared to the short, broad sacrum of Canis lupus. These sacra all include three fused vertebrae but the transverse processes are more elongated and developed in the wolf, giving the sacrum its broader appearance. In the Logan Butte Temnocyon altigenis, T. ferox, and Mammacyon ferocior, and in Daphoenodon superbus, the width of the sacrum (measured at the 2 nd sacral vertebra) is $44-46 \%$ of the length but 
A

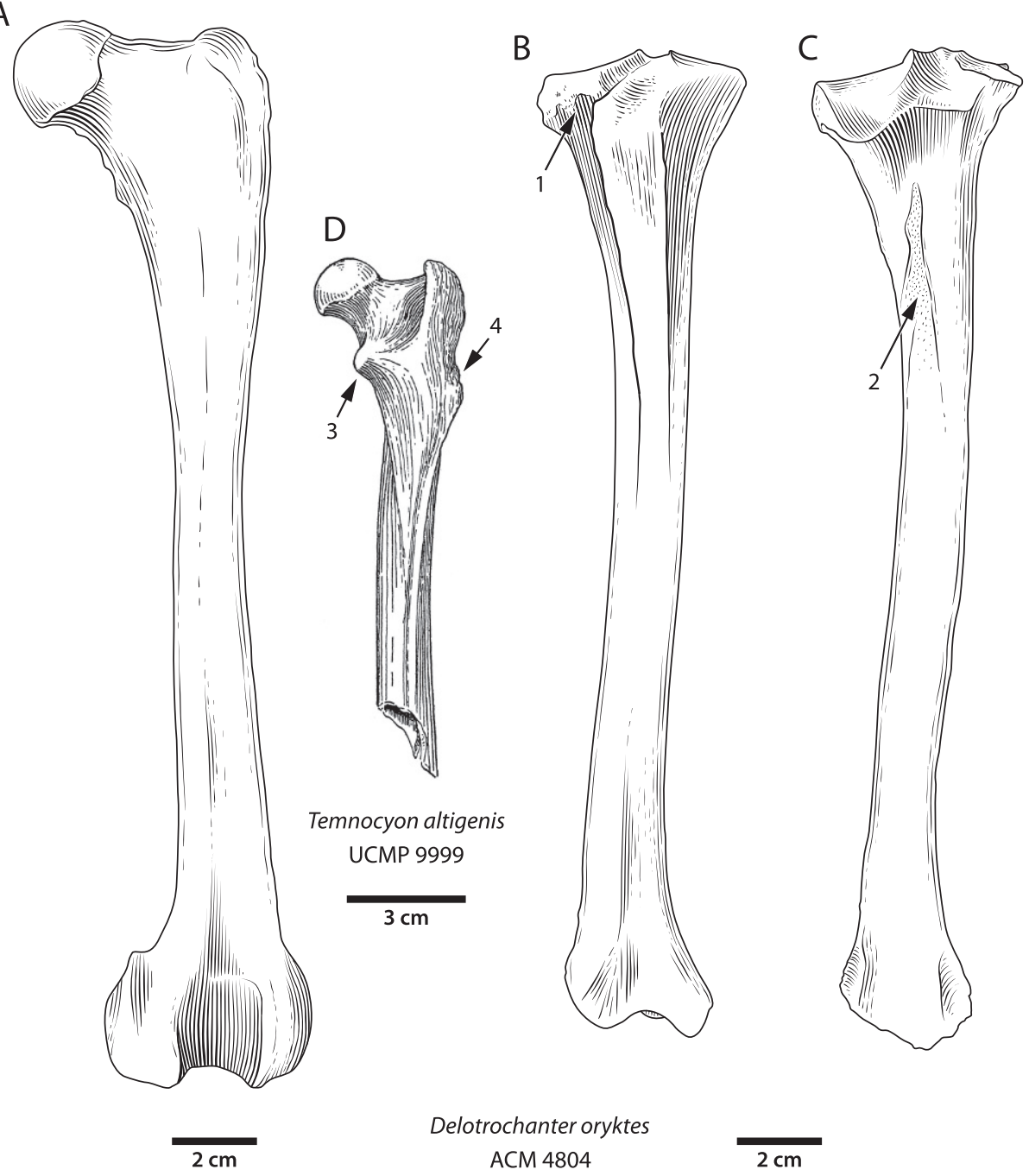

Fig. 58. Femur and tibiae of Delotrochanter oryktes, Stenomylus Quarry, Harrison Formation, Agate Fossil Beds National Monument, Nebraska. The long slender femur (A) and tibiae (B, right; C, left) are similar in proportion and form to those of the wolf whose tibia is $\sim 8 \%$ longer. An arrow (1) marks the sulcus muscularis in $\mathbf{B}$. Muscle scars (2, stippled) on the posterior tibia $(\mathbf{C})$ indicate proximally situated posterior tibial and long digital flexor muscles. The femur (D) of Temnocyon altigenis, the smallest and most primitive temnocyonine, retains a lesser trochanter (3), gluteal flange, and third trochanter (4). A, B in anterior view; $\mathrm{C}, \mathrm{D}$, posterior view.

in the wolf this value is $88 \%$. Nonetheless, the articular surface of the ilium with the sacrum is of similar proportions in all these carnivores.

Femur-Tibia: An associated femur and tibia occur in Temnocyon ferox, Mammacyon ferocior, and Delotrochanter oryktes (fig. 58). Thus, hind limb proportions can be estimated for representatives of the three principal temnocyonine genera (tables 11-12). In these three species the femorotibial proportion varies from $91 \%$ to $96 \%$, approaching the ratio found in wolves $(\sim 96 \%-101 \%)$. Lower indices of $67 \%-76 \%$ in ursids, and $83 \%-89 \%$ in felids, reflect the shorter tibiae in these living carnivores. The indices for the daphoenine amphicyonids (89\%-96\%), while similar to those of temnocyonines $(91 \%-96 \%)$, are 
lower for the large, terrestrial Daphoenus vetus $(\sim 89 \%-90 \%)$ and higher for the small scansorial D. hartshornianus and the Chadronian forms $(\sim 93 \%-96 \%)$. Despite the proportionately longer hind limbs in these latter two groups, their forelimbs remain quite short $(80 \%-83 \%$, ratio $\mathrm{R} / \mathrm{H}$, table 11$)$ and show that $D$. hartshornianus and the Chadronian daphoenines differ from the temnocyonines who evolved longer forelimbs $(\sim 90 \%-95 \%$, ratio $\mathrm{R} / \mathrm{H})$ relative to the hind limb. The earliest temnocyonines probably retained short, plesiomorphic forelimb proportions, since the forelimb of the Logan Butte Temnocyon altigenis lacks conspicuous elongation.

The temnocyonine femorotibial ratios suggest that other morphological correlates of an elongate cursorial hind limb might be present, and such is the case. For both Delotrochanter oryktes and Mammacon ferocior a prominent groove, the sulcus muscularis for the tendon of the long digital extensor, indents the lateral margin of the tibial platform immediately anterior to the lateral condyle (fig. 58B). From its origin on the femur, the tendon travels distad to extend the digits and participate in tarsal dorsiflexion. Although common in artiodactyls and perissodactyls, the sulcus is well developed among living Carnivora only in canine canids and the cheetah, and is not found in other arctoid carnivorans (ursids, procyonids, mustelids) or in Daphoenus and Daphoenodon. The sulcus is not quite as deep in Mammacyon ferocior and Delotrochanter oryktes as in the wolf. The tibia of T. ferox does not have a sulcus muscularis; thus it may have been acquired independently in Mammacyon and Delotrochanter (the proximal tibia was not recovered in $T$. altigenis). Except for size, the tibiae of Temnocyon ferox, Mammacyon ferocior, and Delotrochanter oryktes correspond closely in form and anatomy; the diaphyses are somewhat more robust when compared to the more slender tibia of the wolf.

Mammacyon ferocior and Delotrochanter orkytes also compare closely with the wolf in the pattern of muscle scars on the posterior surface of the tibia (fig 58C). The pattern indicates that the posterior tibial (PT) and long digital flexor (FDL) muscles have been reduced, and are proximally situated, a condition seen in the wolf (Evans, 1993) where the hind foot is specialized for fore-aft movement on level ground. The large temnocyonines, Canis lupus, and the cheetah Acinonyx exhibit this PT-FDL reduction more so than the large, living felids and ursids. For M. ferocior, tibial length $(265 \mathrm{~mm})$ relative to the width of the PT-FDL scar $(\sim 5 \mathrm{~mm})$ corresponds to the values found for the wolf and cheetah (Hunt, 2009: fig. 30). However, temnocyonines differ from the wolf in the shallower registration of the astragular trochlea in the distal tibia, which is like that of the cheetah; deeper penetration of the astragalus in the wolf creates a more tightly registered joint.

Delotrochanter oryktes (ACM 4804) preserves both femora, described by Schlain (1980), who noted their resemblance to those of Canis. The femur is long, slender, slightly curved in the sagittal plane as in the wolf, but with the femoral head and neck almost at a right angle to the diaphysis (fig. 58A). This orientation of femoral head, neck, and diaphysis is typical of most amphicyonids and contributes to the adduction of the limb. The distal femur is transversely narrow and the condyles extend posteriorly as in the large living canids. In all these features the femur of $D$. oryktes is nearly identical to the femur of the cursorial daphoenine amphicyonid Borocyon robustum (Hunt, 2009).

The width of the femur across the distal condyles is narrow relative to femoral length in cursorial carnivores, and is similar among temnocyonines and the wolf, between $16 \%$ and $18 \%$ (table 14). However, the width of the groove for the patella relative to condylar width differs, for in temnocyonines the groove is from $41 \%$ to $46.5 \%$ of condylar width and in the wolf only $28 \%$, indicating a narrower patellar groove in Canis lupus.

The femur of Temnocyon altigenis from Logan Butte (fig. 58D) can be articulated with the corresponding innominate to estimate the alignment of the hind limb in that species. Here the femur appears to be abducted $\sim 20^{\circ}-25^{\circ}$ from the vertical, whereas abduction of $10^{\circ}$ has been reported as the characteristic posture of living canids (Jenkins and Camzine, 1977). In T. altigenis the pit (fovea capitis) for the femoral ligament on the femoral head is situated as 
TABLE 14

Dimensions of Femoral Condyles and Patellar Groove Relative to Femoral Length in Temnocyonines and Canis lupus (in $\mathrm{mm}$ )

\begin{tabular}{lrrrrr}
\hline \hline \multicolumn{1}{c}{ Taxon } & $\mathrm{CW}^{\mathrm{a}}$ & $\mathrm{FL}^{\mathrm{b}}$ & $\mathrm{CW} / \mathrm{FL}$ & $\mathrm{WPG}^{\mathrm{c}}$ & $\mathrm{WPG} / \mathrm{CW}(\%)$ \\
\hline Temnocyon ferox & 40.0 & 244 & $16.4 \%$ & 16.4 & 41.0 \\
Mammacyon ferocior & 47.0 & $\sim 275$ & $17.1 \%$ & 19.7 & 41.9 \\
Delotrochanter oryktes & 40.8 & 246 & $16.6 \%$ & 19.0 & 46.5 \\
Canis lupus & 44.5 & 252 & $17.6 \%$ & 12.5 & 28.0 \\
\hline
\end{tabular}

${ }^{\mathrm{a}} \mathrm{CW}=$ transverse width across distal condyles.

${ }^{\mathrm{b}} \mathrm{FL}=$ greatest femoral length.

${ }^{\mathrm{c}} \mathrm{WPG}=$ width of patellar groove (or patellar width as proxy).

in the larger canids (Canis lupus, Lycaon pictus) measured by Jenkins and Camazine (1977: fig. 9) and does not adopt the more extreme position found in living ursids and procyonids. In Temnocyon ferox, Mammacyon ferocior, and Delotrochanter oryktes the fovea capitis is similar in its placement to the fovea of $T$. altigenis.

The extent and orientation of the articular surface of the femoral head as it registers in the acetabulum provides a measure of the range of motion of the femur. Jenkins and Camazine (1977) measured the angle formed by a line drawn along the margin of the anterior articular surface of the femoral head and the femoral diaphysis; this angle in $D$. oryktes and $M$. ferocior $\left(\sim 38^{\circ}-40^{\circ}\right)$ was similar to that of Canis lupus $\left(\sim 40^{\circ}\right)$, which suggests that the temnocyonines hold the femur in a more abducted position than in small cats and foxes, but with much less abduction than in procyonids and the large living ursids.

Jenkins and Camazine (1977) observed only modest extension of the articular surface of the femoral head in the proximal and posterior directions in canids. In $T$. altigenis and $T$. ferox the articular surface of the femoral head approximates that seen in the wolf, and does not extend downward on the posterior surface as in carnivores such as procyonids and ursids with greater femoral excursion employed in actions such as climbing, where a greater range of abduction-adduction occurs. In D. oryktes and apparently in $M$. ferocior the extent of the articular surface on the posterior femoral head does somewhat exceed that of the wolf so that the excursion of the femoral head in the acetabulum may have been more similar to the conformation in the large living cats (Schlain, 1980).

The femur of $T$. altigenis is unusual in having a gluteal ridge distal to the greater trochanter, forming a pronounced flange that continues along the outer diaphysis (Merriam, 1906: 27). The flange thickens to form a third trochanter $\sim 35 \mathrm{~mm}$ distal to the greater trochanter for insertion of the superficial gluteal (fig. 58D, \#4). This gluteal flange also occurs in Daphoenus and in archaic carnivores such as the mesonychid Pachyaena ossifraga (O'Leary and Rose, 1995) and the miacid Miacis petilus (Heinrich and Rose, 1995). The presence of the gluteal flange, large third trochanter, and prominent lesser trochanter suggests retention of some mediolateral mobility in the hip joint of $T$. altigenis indicative of more abduction-adduction than found in small living canids. This is also supported by the prominent knoblike lesser trochanter in $T$. altigenis (fig. 58D, \#3) that projects posteromedially as in terrestrial small carnivorans in which some abduction and lateral femoral rotation occur.

TARSUS: The astragalus and calcaneum in temnocyonines, together with rare distal tarsals in Temnocyon altigenis, T. ferox, Mammacyon ferocior, and Delotrochanter oryktes, demonstrate a modified daphoenine tarsal pattern evolving toward a hind foot similar to the canine type, adapted for foreaft flexion and extension and an erect digitigrade stance.

The form of astragalus and calcaneum approach that of living large canids, most closely in $T$. ferox, $M$. ferocior, and $D$. oryktes. The temnocyonine calcaneum is 
both proximally and distally narrow relative to Daphoenus, Daphoenodon superbus, and amphicyonines (fig. 59, table 15). Calcaneal width at the sustentaculum is $\sim 35 \%-42 \%$ of calcaneal length in temnocyonines, but in short-limbed daphoenines this measures from $46.6 \%$ to $52.1 \%$ (fig. 60). This reduction in width is already evident in Temnocyon altigenis. Also in temnocyonines, the sustentaculum appears proximally elevated because the distal calcaneum is lengthened below the sustentaculum, and its posterior surface becomes deeply grooved for the deep digital flexor (flexor digitorum profundus), active during the stance phase in dogs (Evans, 1993). A calcaneum of this type occurs in the wolf and is also common to living felids whose proximal tarsals are similarly lengthened distad contributing to hind foot elongation.

The temnocyonine astragalus (table 16) shows three derived features that correspond to the form of the calcaneum. The distal process for articulation with the navicular is no longer tranversely aligned as in Daphoenus vetus and Daphoenodon superbus but has shifted to a more angled alignment (a long axis directed anterolaterad to posteromesad) beneath the trochlea. This type of astragalus is known in Temnocyon altigenis, T. ferox, Mammacyon obtusidens, M. ferocior, and Delotrochanter oryktes. These temnocyonines also share a derived placement of the sustentacular facet situated proximally on the neck whereas in D. superbus and amphicyonines this facet extends far distad. Temnocyonines also possess a relatively narrow astragalar trochlea when compared to $D a$ phoenodon superbus (table 16). By articulating the calcaneum and astragalus with the tibia in T. ferox, M. ferocior, and D. oryktes, the alignment of joint surfaces suggests a more erect hind foot stance as in large living cats and Canis lupus.

The complete articulated tarsus of Temnocyon ferox was illustrated by Eyerman (1896). The plesiomorphic tarsal pattern of daphoenines such as Daphoenus vetus and Daphoenodon superbus differs from the derived pattern evident in Temnocyon ferox (fig. 61), in which a mediolaterally narrow tarsus had evolved, paralleling the cursorial wolf. This derived state was also present in Mammacyon and Delotrochanter.

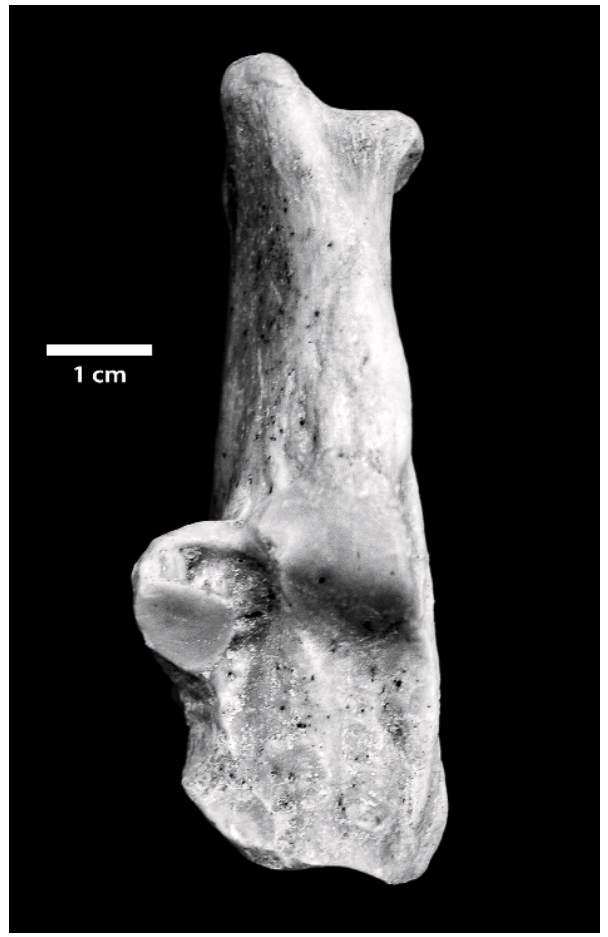

Fig. 59. Calcaneum of Delotrochanter oryktes (UNSM 47800), from temnocyonine carnivore den, Beardog Hill, Agate Fossil Beds National Monument, Sioux Co., Nebraska.

Distal tarsals of temnocyonines have survived in $M$. ferocior (F:AM 27562: associated navicular, cuboid, and ectocuneiform) and in D. oryktes (ACM 4804: navicular and ectocuneiform). In primitive daphoenines the cuboid shows the expected facets for the ectocuneiform and navicular but also retains a plesiomorphic contact with the astragalus, whereas in the wolf and temnocyonines this astragalar contact is lost (fig. 62). Furthermore, in temnocyonines where the articulations among calcaneum, astragalus, navicular, and cuboid can be determined from facets, the distal calcaneum contacts the navicular, but in Daphoenus and Daphoenodon superbus the astragalus excludes the navicular from contact with the calcaneum. The calcaneal facet on the navicular is well developed in $M$. ferocior and D. oryktes and appears to be present in Temnocyon altigenis and $T$. ferox.

In wolf, Mammacyon, and Delotrochanter, the cuboid and navicular are in close contact, 
TABLE 15

Calcaneal Dimensions of Temnocyonine and Daphoenine Amphicyonids (in mm)

\begin{tabular}{llccc}
\hline \hline \multicolumn{1}{c}{ Mus. No. } & \multicolumn{1}{c}{ Taxon } & Calcaneal height $(\mathrm{H})$ & Sustentacular width $(\mathrm{SW})^{\mathrm{a}}$ & $\mathrm{SW} / \mathrm{H}(\%)$ \\
\hline TEMNOCYONINAE & & & & \\
UCMP 9999 & Temnocyon altigenis & 48.6 & 20.6 & 42.4 \\
YPM-PU 10787 & Temnocyon ferox & 60.9 & 23.8 & 39.0 \\
F:AM 27562 & Mammacyon ferocior & 78.0 & 28.0 & 35.9 \\
UNSM 47800 & Delotrochanter oryktes & 71.1 & 26.0 & 36.6 \\
YPM-PU 24872 & Delotrochanter oryktes & 66.0 & 26.6 & 40.3 \\
UF 16908 & temnocyonine indet. & 63.1 & 22.4 & 35.5 \\
DAPHOENINAE & & & & \\
FMNH P12138 & Daphoenus vetus & 43.6 & 22.7 & 52.1 \\
CM 1589 Left & Daphoenodon superbus & 58.7 & 28.9 & 49.2 \\
CM 1589 Right & Daphoenodon superbus & 59.2 & 32.3 & 48.0 \\
CM 1589b & Daphoenodon superbus & 67.4 & 31.3 & 47.9 \\
CM 1589b & Daphoenodon superbus & 64.6 & 29.7 & 48.5 \\
CM 1589c & Daphoenodon superbus & 63.7 & 29.0 & 46.6 \\
CM 2199 & Daphoenodon superbus & 60.1 & 30.7 & 48.3 \\
UNSM 72-90 & Daphoenodon superbus & $\sim 64$ & 28.1 & 48.0 \\
UNSM 423-78 & Daphoenodon superbus & $\sim 60$ & 34.0 & 46.8 \\
UNSM 99420 & Daphoenodon falkenbachi & 72.4 & & 47.0 \\
\hline
\end{tabular}

${ }^{a}$ Transverse width of the calcaneum measured at the level of the sustentaculum.

${ }^{\mathrm{b}}$ Calcanea numbered CM1589b represent two different individuals.

and their articular surfaces for the proximal tarsals lie in an essentially horizontal plane; the cuboid surface is only slightly convex and the navicular modestly concave. As a result of this nearly coplanar articulation of the proximal tarsals (calcaneum-astragalus) with the cuboid and navicular, the motion possible at the intratarsal joint limits rotation around

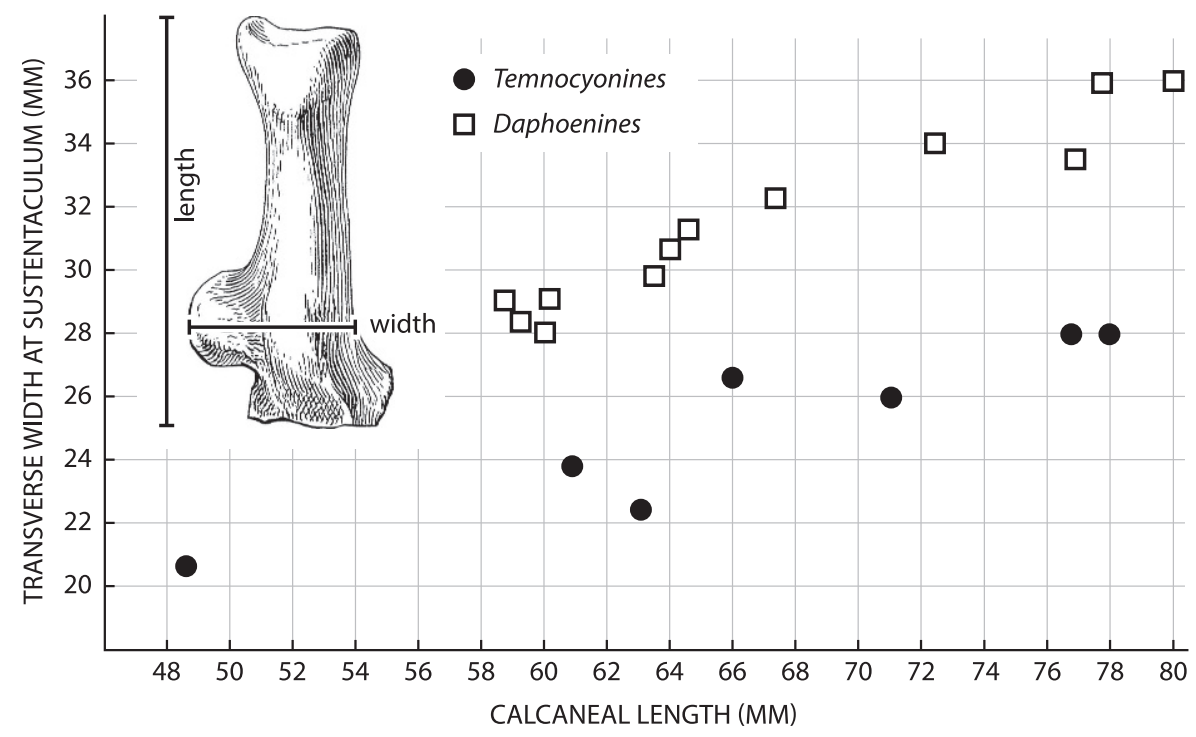

Fig. 60. Bivariate graph of calcaneal dimensions of temnocyonines relative to calcanea of daphoenine amphicyonids. A narrow, distally extended calcaneum similar to that of living digitigrade felids is characteristic of temnocyonines. 
TABLE 16

Dimensions of the Astragalus in Temnocyonine and Daphoenine Amphicyonids (in mm)

\begin{tabular}{clccc}
\hline \hline \multicolumn{1}{c}{ Mus. No. } & \multicolumn{1}{c}{ Taxon } & Height $(\mathrm{H})$ & Trochlear width (TW) & TW/H (\%) \\
\hline TEMNOCYONINAE & & & & -15 \\
UCMP 9999 & Temnocyon altigenis & - & 14.0 & 54.0 \\
UCMP 1986 & Temnocyon altigenis & 25.9 & $\sim 17$ & 50.3 \\
YPM-PU 10787 & Temnocyon ferox & 33.8 & 19.2 & 53.9 \\
ACM 34-41 & Mammacyon obtusidens & 35.6 & 23.5 & 55.8 \\
F:AM 27562 & Mammacyon ferocior & 42.1 & 21 & 55.3 \\
ACM 4804 & Delotrochanter oryktes & 38.0 & & 57.2 \\
DAPHOENINAE & & & 20.2 & 57.5 \\
CM 1589 left & Daphoenodon superbus & 35.3 & 20.2 & 57.6 \\
CM 1589 right & Daphoenodon superbus & 35.1 & 21.9 & 57.6 \\
CM 1589c & Daphoenodon superbus & 38.0 & 22.7 & \\
CM 2199 & Daphoenodon superbus & 39.4 & & \\
\hline
\end{tabular}

the long axis of the hind foot, yet still allows some limited inversion/eversion as the foot accommodates to uneven ground. Other than this adjustment to the substrate, the hind foot of wolf and temnocyonines is committed to fore-aft flexion/extension at the ankle joint $\left(1^{\circ}\right.$ of rotational freedom at the tibioastragalar articulation).

Metatarsals and Phalanges: A remarkable modification of the metatarsals of the hind foot can be documented for Temnocyon and Delotrochanter and is likely in Mammacyon. This involves the near loss of the first metatarsal and marked reduction of metatarsals 2 and 5, resulting in a strongly paraxonic hind foot in which metatarsals 3-4 bear the weight in the erect digitigrade stance (fig. 61A). In Temnocyon ferox, Mammacyon obtusidens, and Delotrochanter oryktes, the metatarsals are proximally appressed as is evident in large living canines (fig. 63).

Representation of temnocyonine metatarsals is shown in table 8: In Temnocyon altigenis (UCMP 9999) only metatarsal 2 is complete, with proximal parts of metatarsals 3-4 and distal metatarsal 1; in $T$. ferox (YPM-PU 10787) metatarsals 1-5 survived; in Mammacyon obtusidens (ACM 34-41) metatarsals 3-5; and in M. ferocior (F:AM 27562) only a complete metatarsal 2, a proximal metatarsal 5, and metatarsal 3 lacking the proximal end were recovered. For D. oryktes (UNSM 47800, CM 1589b) there are metatarsals $2-5$. Feet of the large species of Temnocyon are unknown but similar cursorial adaptations are likely, given the derived hind foot anatomy of $T$. ferox.

All of these temnocyonine metatarsals indicate a paraxonic hind foot with elongate metatarsals 3-4 and shorter, more slender metatarsals 2 and 5. The most complete hind foot (fig. 61), that of T. ferox, shows metatarsals 2 and 5 to be $\sim 1 \mathrm{~cm}$ shorter than metatarsals 3-4, with metatarsal 5 even more reduced than metatarsal 2. Metatarsal 1 also shows marked reduction (length, $45 \mathrm{~mm}$; midshaft width, $4.8 \mathrm{~mm}$ ). Delotrochanter oryktes exhibits even greater reduction of metatarsals 2 and 5, more so than in the wolf (fig. 63). Although the first metatarsal was not recovered, the scar for it on metatarsal 2 shows it was quite reduced, nonfunctional, yet not as small as the minute bone known in the canid. Metatarsal 2 of $M$. ferocior lacks an obvious scar for metatarsal 1 and so reduction of the latter bone in that species likely exceeded the state in D. oryktes and possibly equalled that found in the wolf. Reduction of the metatarsals flanking the paraxonic metatarsals 3-4 in $D$. oryktes is the most pronounced in the subfamily; consequently this reduction also probably occurred in $D$. major.

The lengths of paraxonic metatarsals relative to metacarpals are similar to those proportions in the wolf. In T. ferox where this can be measured, metatarsals $3-4$ are $16 \%-17 \%$ longer than metacarpals $3-4$, and in D. oryktes (UNSM 47800) this is $9 \%-10 \%$, 

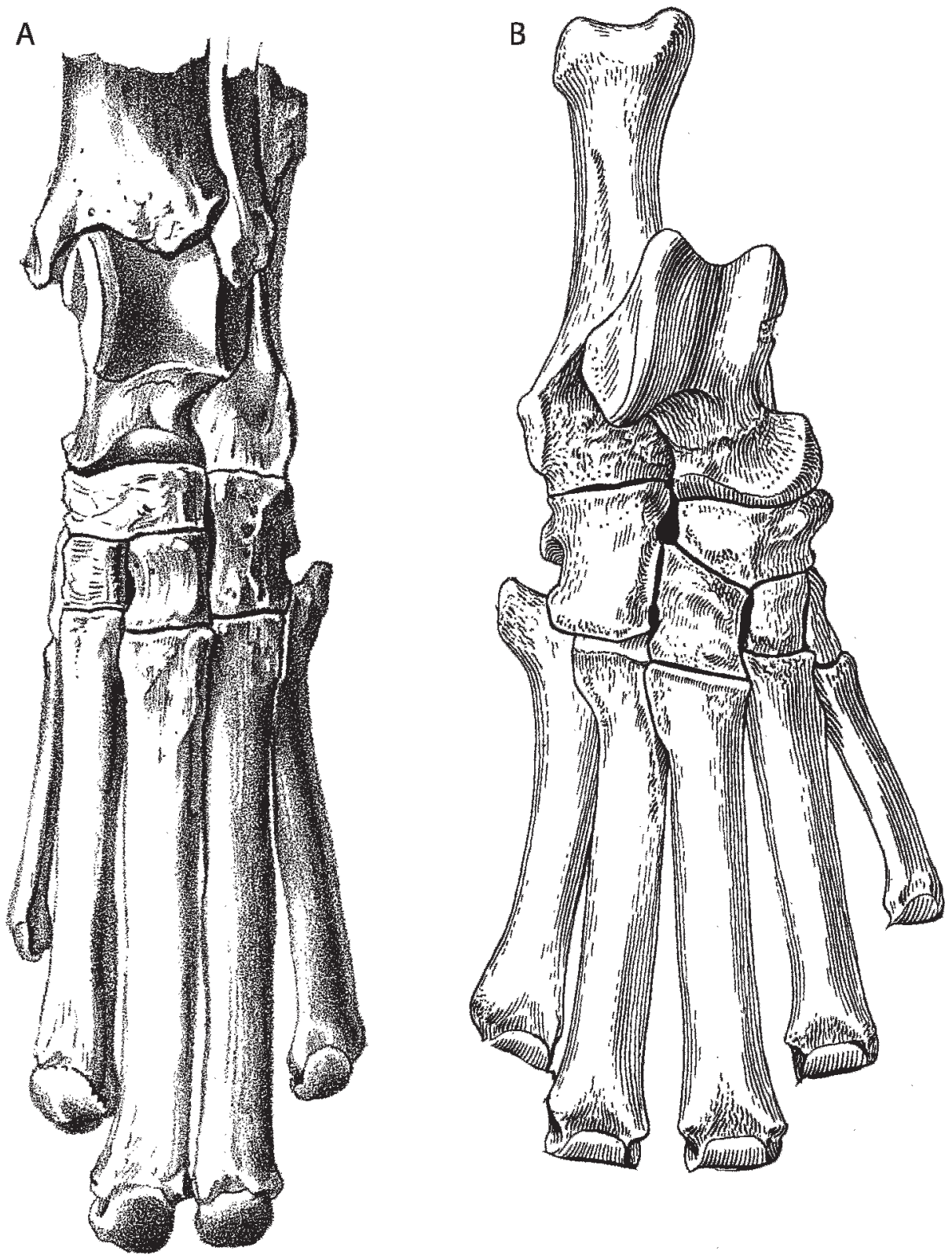

Fig. 61. Hind foot of (A) Temnocyon ferox (YPM-PU 10787) and (B) Daphoenodon superbus (CM 1589). The narrow columnar tarsus and appressed metatarsals in the cursorial temnocyonine differ from the more splayed and mobile foot of the daphoenine. T. ferox after Eyerman (1896); D. superbus after Peterson (1910).

whereas in the wolf the difference is $10 \%$ $13 \%$, a clear indication of the elongation of the forefoot in Delotrochanter.

Metapodials of these temnocyonines have prominent, sharp distal keels that fit into a groove at the base of each proximal phalanx (fig. 56). A pair of sesamoid bones within the tendons of each interosseous muscle would have bordered each keel in the articulated hind foot of Temnocyon ferox and together 
A

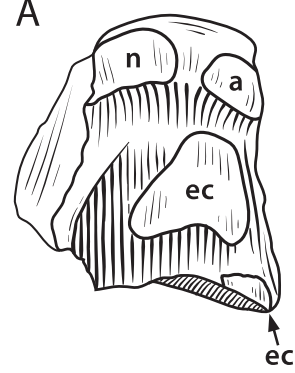

Daphoenodon superbus CM 1589
B

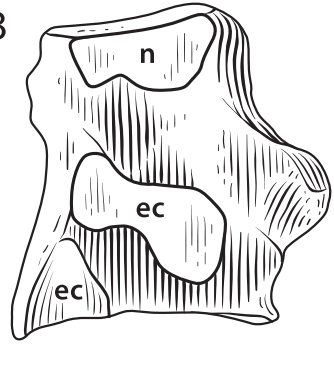

Mammacyon ferocior

F:AM 27562
C

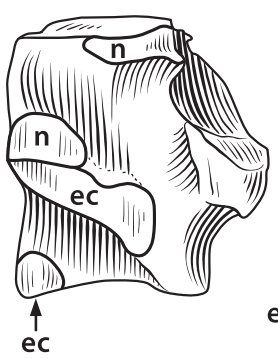

Canis lupus

ZM 17459

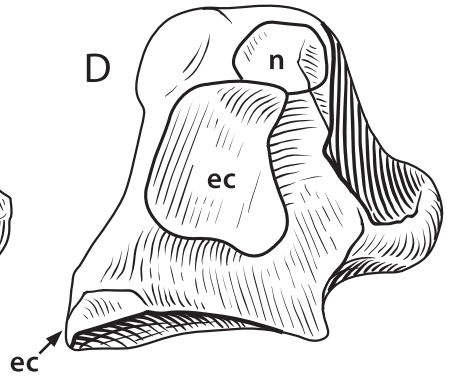

Amphicyon galushai UNSM 26394

\section{$1 \mathrm{~cm}$}

Fig. 62. Comparison of the cuboids of (A) Daphoenodon superbus, (B) Mammacyon ferocior, (C) Canis lupus, and (D) Amphicyon galushai. In temnocyonines and daphoenines, the proximal (upper) ectocuneiform facet (ec) is well separated from the navicular facet (n) but in Amphicyon they are confluent. The wolf cuboid has two navicular facets, one in direct contact with the ectocuneiform facet. In D. superbus the cuboid also contacts the astragalus (a), likely the plesiomorphic state in both daphoenines and temnocyonines. A, left cuboid; B, C, D, right.

with the grooved phalanx would help to align and stabilize the digits. The position of the keel permits extension but little flexion at the metapodial-phalangeal joint. The metapodial-phalangeal joint is prevented from hyperextension in the erect digitigrade stance by contraction of the interosseous and digital flexor muscles.

Reduction of the side-toes in these temnocyonines (Temnocyon ferox, Delotrochanter oryktes, and less complete remains of Mammacyon) parallels reduction in the wolf and other large cursorial canines and is the first example of this type of paraxonic hind foot to evolve in the Carnivora.

No phalanges certainly attributable to the hind foot of temnocyonines were recovered with the exception of much reduced, intermediate (length, $15 \mathrm{~mm}$ ) and ungual (length, $\sim 13 \mathrm{~mm}$ ) phalanges of digit 5 in $T$. ferox. This suggests, however, that the intermediate phalanges in the hind foot were quite short, as in the forefoot. Eleven proximal and six intermediate phalanges and one ungual were recovered with the skeleton of $D$. oryktes (ACM 4804), but attribution to fore- or hind feet was not recorded (Schlain, 1980). These proximal phalanges are shorter, not as slender, and more robust than those of the wolf. Intermediate phalanges are uniformly short and somewhat asymmetrical; the distal trochlea extends proximad on the dorsal surface, indicating a moderate ungual retractility similar to that of the wolf.

The claws of $T$. ferox do not appear to have been very long. In the wolf, the keratin sheath covering the ungual phalanx adds $\sim 50 \%$ to its length so that in $T$. ferox, if similar, the functional claw on digit 5 of the hindfoot would measure $\sim 21 \mathrm{~mm}$ in length. This does not give us the length of the claw on a paraxonic digit of the hind foot; however, digit 4 of the forefoot also retains an ungual of similar size, suggesting that the claw length might have been about the same on the paraxonic digits of both fore- and hind feet. This situation is in conformity with the wolf where claws on fore- and hind feet are of similar lengths.

\section{BASICRANIAL ANATOMY}

Basicrania of temnocyonines are rarely preserved. Those that are known demonstrate that a plesiomorphic amphicyonid auditory region survived in those species (table 17). However, basicranial detail is often lacking and in most temnocyonines the auditory bulla has been lost prior to burial because it was not ankylosed to the 


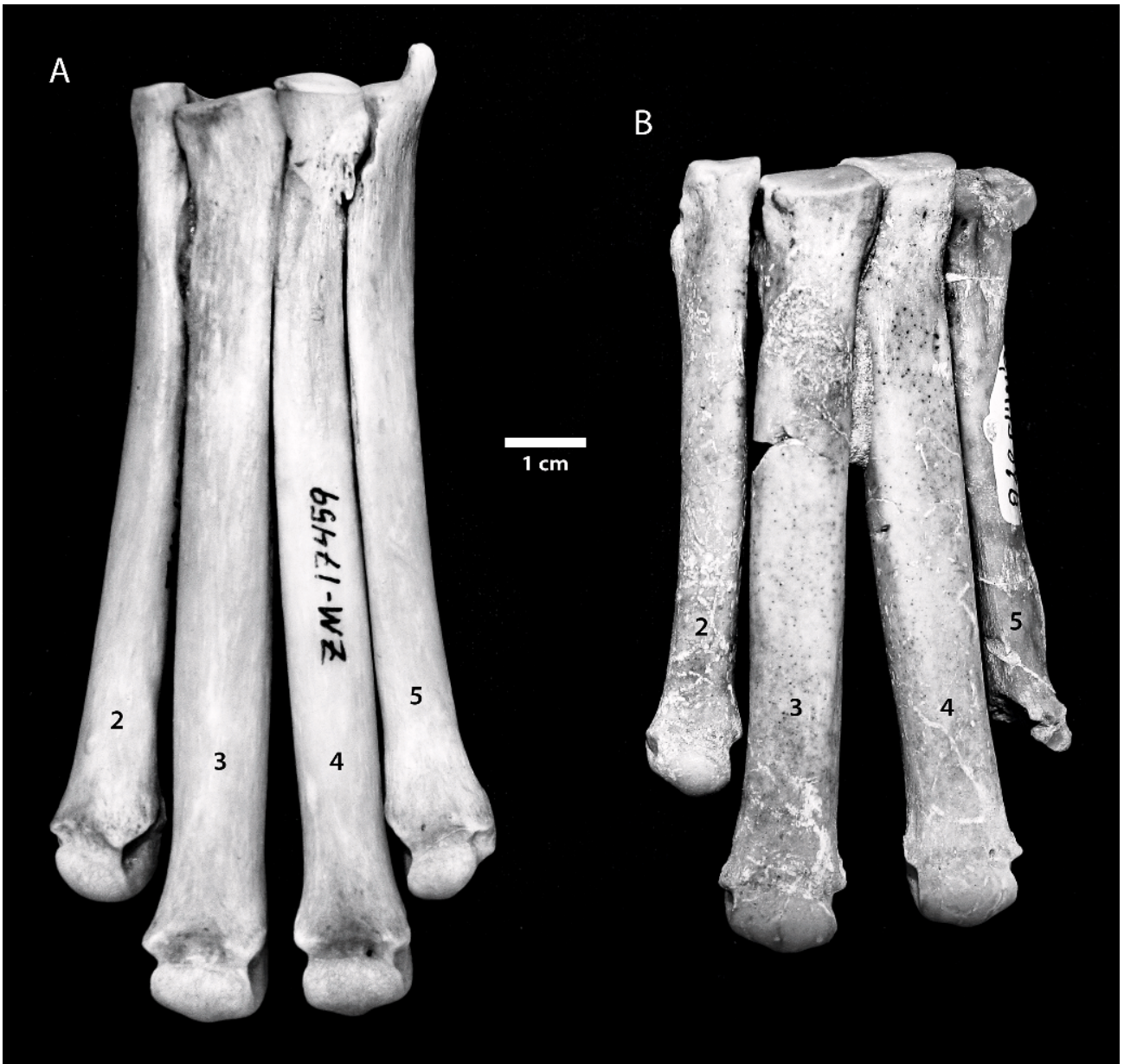

Fig. 63. Metatarsals 2-5 of Canis lupus (A) and Delotrochanter oryktes (B). Paraxonic metatarsals 3-4 are flanked by markedly reduced metatarsals 2 and 5 in D. oryktes (UNSM 47800), indicating a narrow hind foot.

skull. In a few individuals the fragile bulla remained attached to the skull: its form and composition in Temnocyon subferox and Mammacyon obtusidens are comparable to the rudimentary plesiomorphic bullae of the stem amphicyonids, Daphoenus and Cynodictis (fig. 64).

Intact temnocyonine basicrania show the embayed basioccipital typical of amphicyonid carnivores. Medial to the petrosal, the margin

TABLE 17

Temnocyonine Species with Preservation of Basicranial Morphology

\begin{tabular}{llccc}
\hline \hline \multicolumn{1}{c}{ Taxon } & Mus. No. & Basioccipital embayment & Auditory bulla & Petrosal \\
\hline Temnocyon altigenis & UCMP 9999 & Yes & No & Yes \\
Temnocyon subferox & YPM 10065 & Yes & Yes & Yes \\
Temnocyon fingeruti & NM 280/61 & Yes & Yes & Yes \\
Mammacyon obtusidens & ACM 34-41 & Yes & Yes & Yes \\
Mammacyon ferocior & F:AM 54134 & Yes & No & No \\
Delotrochanter oryktes & ACM 4084 & Yes & No & Yes \\
\hline
\end{tabular}




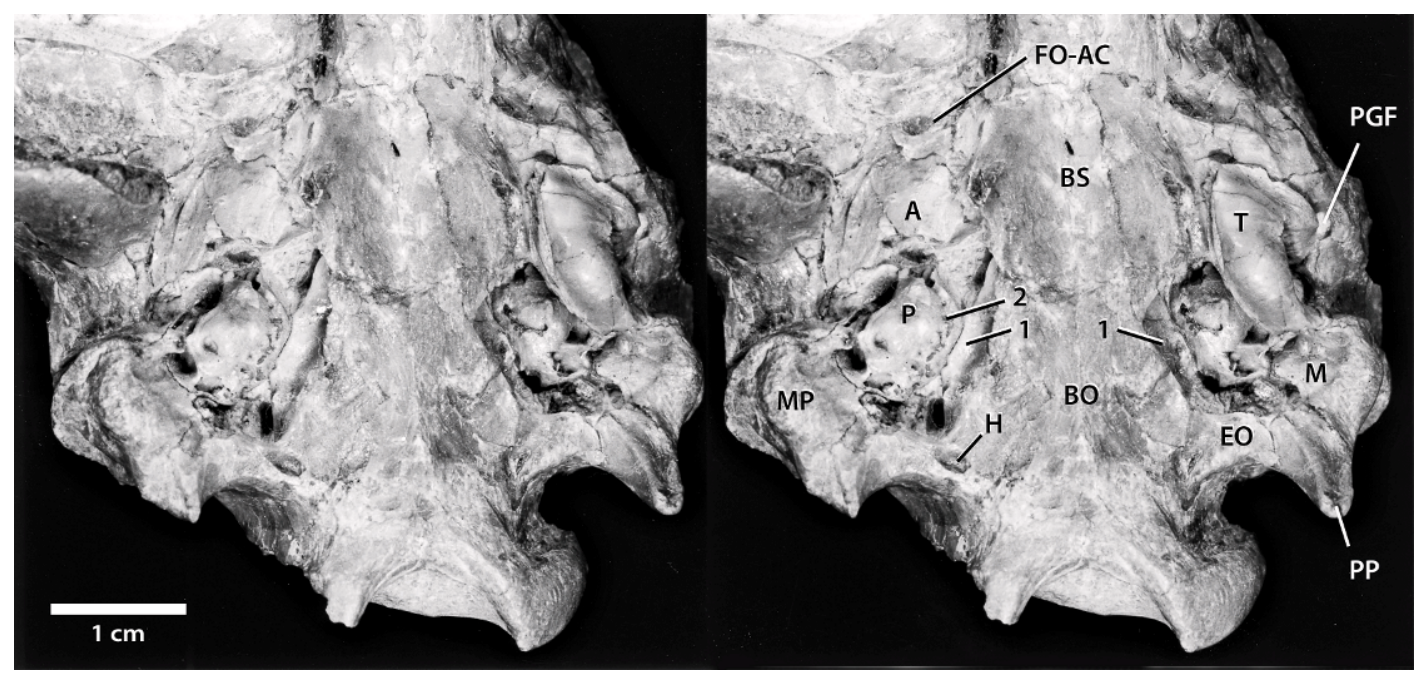

Fig. 64. Basicranium of the holotype of Daphoenus vetus Leidy (USNM 658, stereopair), White River Group, South Dakota, with auditory bulla formed by ectotympanic crescent (T). The margins of the basioccipital bone reveal the embayment for the inferior petrosal venous sinus (1). A cancellous medial wall of the promontorium (2) is broken open forming a ledge contacting the basioccipital. For abbreviations, see page 5 .

of the amphicyonid basioccipital bone is pocketed by a deep recess (fig. 64, \#1), presumably for the inferior petrosal venous sinus containing a loop of the internal carotid artery, functioning as a counter-current heat exchange mechanism (Hunt, 1977; Hunt and Barnes, 1994). In temnocyonines this embayment for the sinus presents as a deep semicircular pocket penetrating far into the basioccipital. The embayment is found in the most plesiomorphic temnocyonine, Temnocyon altigenis (UCMP 9999), in which the floor of the sinus is open to view, revealing its shape and dimensions (fig. 65, C/IPS). It is also developed in T. subferox and T. fingeruti and occurs in the holotype of Mammacyon obtusidens (ACM 34-41); in the skull of the large Mammacyon ferocior (F:AM 54134); and in Delotrochanter oryktes (ACM 4804). Thus, a deeply embayed basioccipital is characteristic of the subfamily and was present in the earliest temnocyonines.

The petrosals of temnocyonines and Daphoenus are defined by a low, rounded, pear-shaped promontorium (fig. 65, UCMP 9999), and are similar in form in the five temnocyonine species where they are preserved (table 17). As in Daphoenus, the temnocyonine petrosal in mature adults can appear slightly rugose where the bulla contacts the promontorium along its medial margin, but it lacks the prominent ventral process found in aeluroid carnivorans (Hunt, 1989). Previously described North American amphicyonids belonging to daphoenine and amphicyonine subfamilies have petrosals with promontoria of this type. The promontorium in ventral view is posteriorly broad, tapering as it slopes anteriorly to a blunt terminus in the anteromedial corner of the auditory region. Dimensions of the promontoria (length, width) reflect the increase in size of these species: ( $T$. altigenis, 10.6, $7.8 \mathrm{~mm} ; T$. subferox, $\sim 12,9.5 \mathrm{~mm}$; $M$. obtusidens, 12.3, $9.9 \mathrm{~mm}$; D. oryktes, 12.4, $11.4 \mathrm{~mm})$. The tegmen tympani, although damaged to some degree in all these skulls, is anatomically similar to the tegmen of Daphoenus in that the the fossa muscularis major, epitympanic recess, path for the facial nerve, and stapedius fossa are of the same plesiomorphic configuration and proportions, and the middle ear space does not invade surrounding basicranial bones.

The most remarkable anatomical trait of the temnocyonine basicranium is the rudimentary condition of the auditory bulla in these carnivores. The temnocyonine bulla 

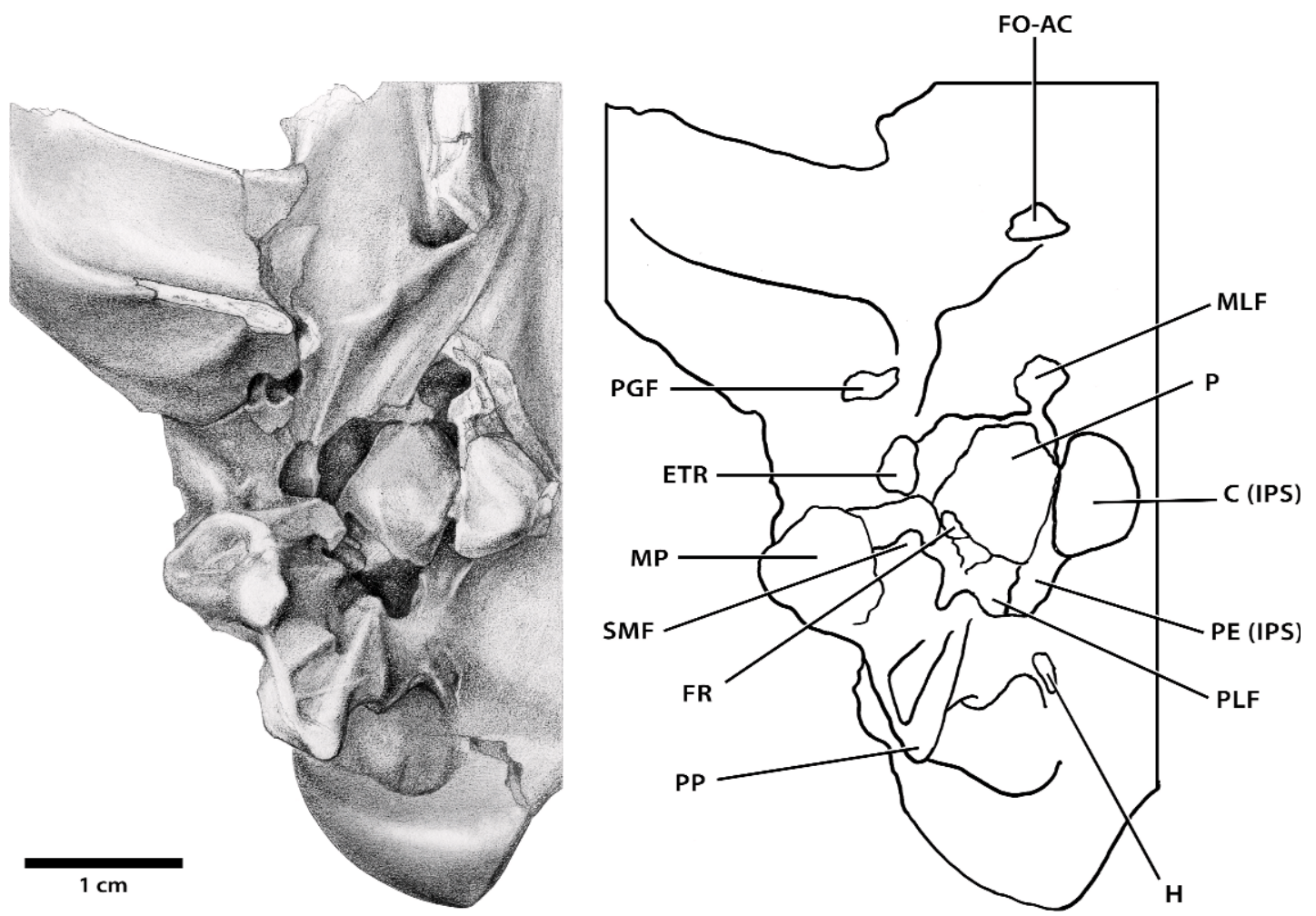

Fig. 65. Basicranium of the Logan Butte Temnocyon altigenis (UCMP 9999): the basioccipital has been opened to show sediment [C(IPS)] filling the deep embayment in the bone for the inferior petrosal venous sinus characteristic of temnocyonines. For abbreviations, see page 5.

was previously unknown and survives in only three species: Temnocyon subferox (YPM 10065); Mammacyon obtusidens (ACM 3441); and $T$. fingeruti (NM 280/61). These bullae are little derived beyond the plesiomorphic state seen in the earliest daphoenines and are among the most plesiomorphic auditory bullae of North American amphicyonids, their small size and lack of development atypical for such large carnivorans.

Species of Daphoenus and Cynodictis demonstrate the most primitive state of the amphicyonid auditory bulla, a simple osseous ectotympanic crescent loosely attached to the skull (fig. 64, T). If rostral or caudal entotympanics were present, they were hyaline or fibrocartilaginous elements that formed a medial wall of the bulla. A cartilaginous caudal entotympanic would have been restricted to a narrow space between the inner edge of the ectotympanic and the petrosal, a space defined in life by the orientation of the bony ectotympanic crescent. In Daphoenus vetus a cartilaginous caudal entotympanic was almost certainly joined to the medial border of the osseous ectotympanic. It attached to a thin rim along the inner inflected edge of the ectotympanic and also to the surface of the petrosal promontorium and did not ossify during the life of the carnivore (fig. 64). These primitive amphicyonid bullae show no expansion of the ectotympanic in order to more completely enclose the middle ear space. They must have functioned much like the similarly constructed bullae of the living African palm civet (Nandinia binotata) in which a bony ectotympanic crescent, joined to a hyaline cartilage caudal entotympanic, together enclose a middle ear of small volume.

Figures 66 and 67 illustrate the auditory bullae of Temnocyon subferox and Mammacyon obtusidens. In both, the bulla is attached to the skull in the same manner as in 


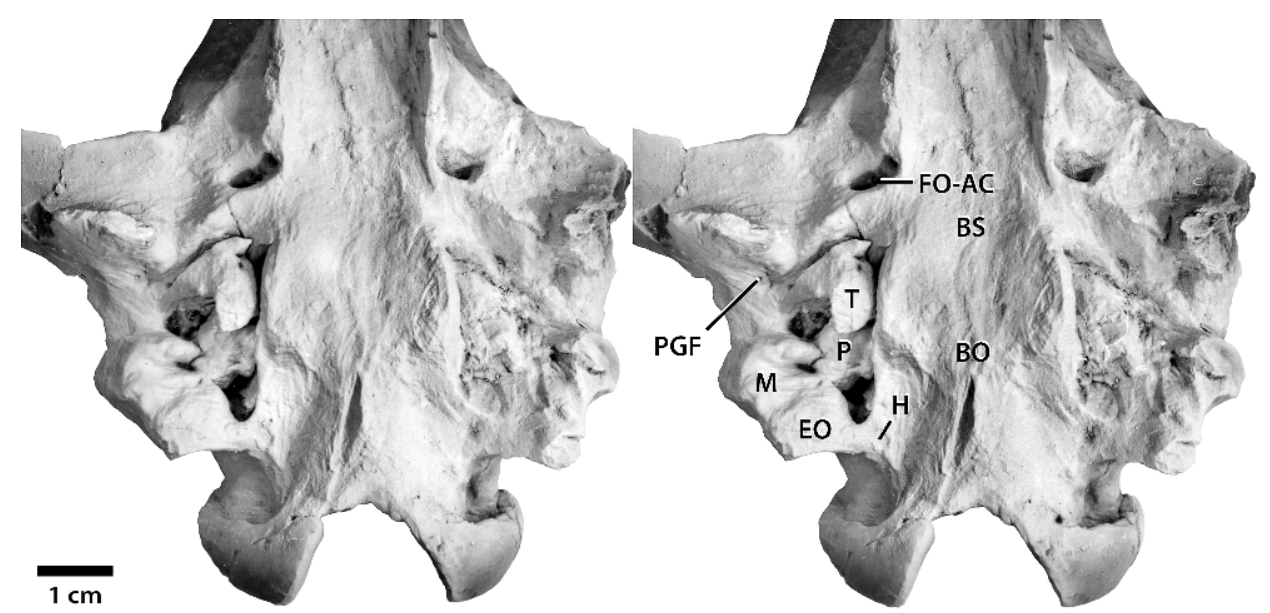

Fig. 66. Holotype basicranium of Temnocyon subferox (YPM 10065), John Day Formation, Oregon (stereopair). The bulla fragment in the auditory region is a remnant of an ectotympanic crescent (T) similar to that seen in Daphoenus. YPM 10065 represents the plesiomorphic state of the temnocyonine auditory bulla. For abbreviations, see page 5 .

Daphoenus and Cynodictis. In Daphoenus vetus (fig. 64) the anterior crus of the ectotympanic fits in a small circular depression medial to the postglenoid foramen of the squamosal. The posterior crus attaches to the posttympanic process of the squamosal that forms the anterior margin of the mastoid process. These squamosal attachments for the anterior and posterior crura are the plesiomorphic contacts of the ectotympanic with the skull for species of the Order Carnivora.

In more evolved daphoenines and amphicyonines, the ectotympanic crescent eventually expands to a more capsular bulla form. Whether the capsule incorporates entotympanic elements or is formed entirely by the expanded ectotympanic is uncertain in many adult amphicyonids since the bulla does not show convincing evidence of discrete entotympanics that form the medial and posterior walls of the capsule. Amphicyonid bullae commonly lack significant medial and/or posterior bulla inflation that might suggest the presence of an expanding entotympanic.

In Temnocyon subferox (YPM 10065) the ectotympanic represents the most plesiomorphic state recognized in the subfamily (fig. 66). Here a small ectotympanic fragment, nearly situated as in life, with a width of only a few $\mathrm{mm}$ (14 $\mathrm{mm}$ from tip of anterior crus to inner margin of the crescent; $6 \mathrm{~mm}$ width at center of crescent), shows that the crescent and attached tympanic membrane would have been positioned directly below (ventral to) the petrosal delimiting a relatively small middle ear space. Although the posterior half of the crescent is missing, the remaining anterior half shows that there could have been no expansion of the middle ear posterior to the petrosal. There is also no extension of the ectotympanic to form an osseous external auditory meatus. This is essentially the same ectotympanic configuration as in Daphoenus and Cynodictis. In YPM 10065 the crescent has been slightly displaced postmortem so that its medial margin approaches the promontorium. If restored to its correct placement, a small space for an elliptical caudal entotympanic element configured as in $D a$ phoenus is available; this entotympanic would contact a low, narrow ridge on the medial border of the promontorium.

In Mammacyon obtusidens (ACM 34-41), as in T. subferox, only the anterior half of the ectotympanic has survived, yet in ACM 3441 this remnant is in its life position (fig. 67). In both species the alignment of the tympanic membrane was similar, oriented at $\sim 45^{\circ}$ from the horizontal. The width of the bulla of $M$. obtusidens measured from the external meatal aperture to the bulla's medial wall is only $5 \mathrm{~mm}$; the tympanic crista occupies $2.2 \mathrm{~mm}$ of this distance, its thin margin positioned only $2.8 \mathrm{~mm}$ from the medial wall, 


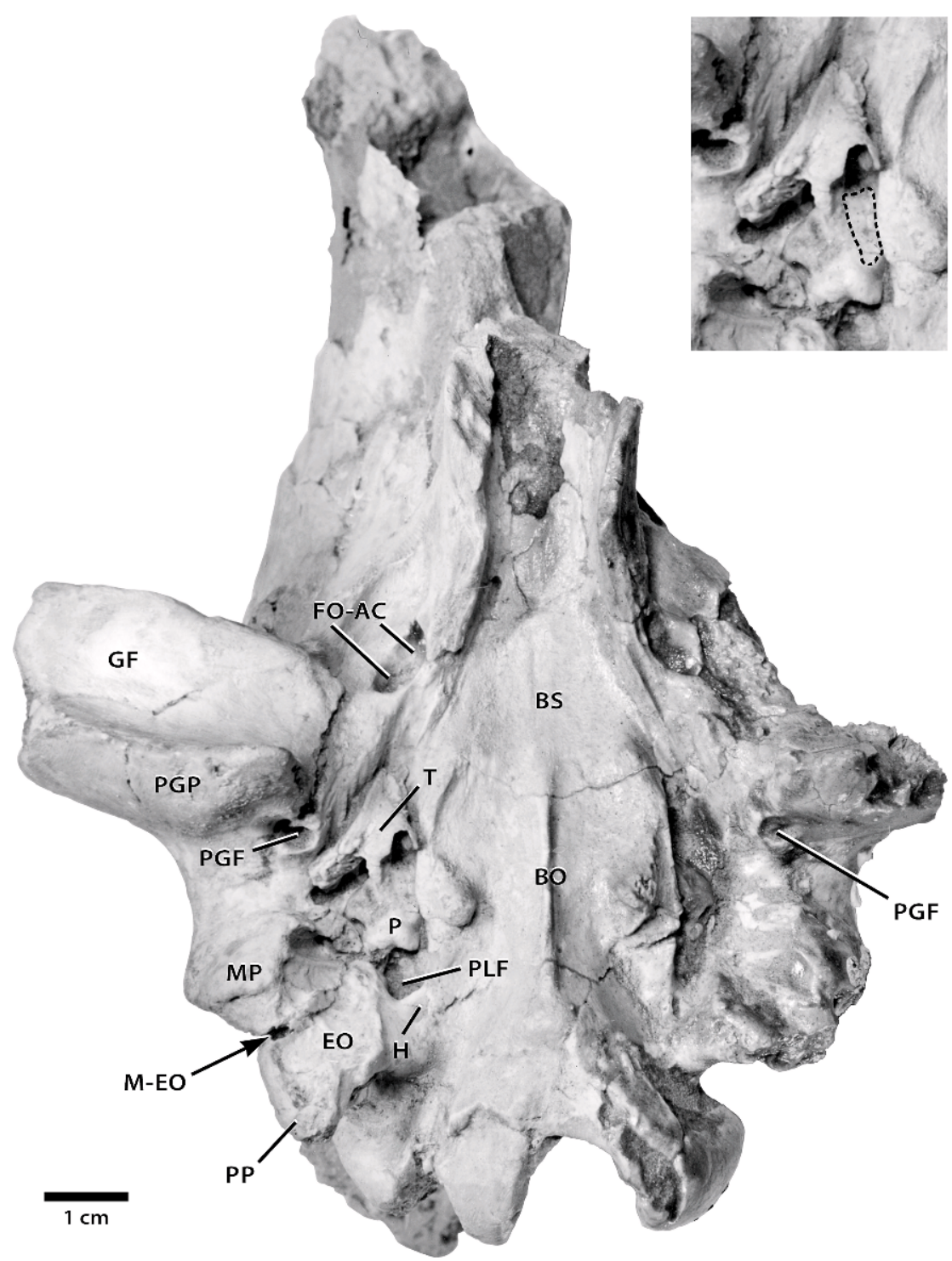

Fig. 67. Holotype basicranium of Mammacyon obtusidens (ACM 34-41) with the remnant of the ectotympanic auditory bulla $(\mathrm{T})$ in life position. The posterior portion of the bulla was lost but contacted the medial margin of the promontorium $(\mathrm{P})$, evidenced at that location by a shallow depression (indicated by dashed line on inset). For abbreviations, see page 5 .

indicating the extremely small volume of the auditory bulla and middle ear. There was no bony external auditory meatus; here, as in $T$. subferox and Daphoenus, the meatal tube must have been cartilaginous. Remarkably, ACM 34-41 preserves a vestige of the inner (medial) wall of the bulla: an extremely thin osseous lamina resting on the medial edge of the petrosal promontorium. The surface of the promontorium displays a shallow linear depression that receives this bony lamina, once part of a continuous partition forming the medial wall. The identity of the ontogenetic element (ecto- or entotympanic) making up the medial bulla wall is uncertain.

The basicranium of Temnocyon fingeruti (NM 280/61) includes both auditory bullae (fig. 68), the left one intact, the best preserved 




Fig. 68. Holotype basicranium of Temnocyon fingeruti (NM 280/61), Balm Creek, Haystack Valley Member (revised), John Day Formation, Wheeler Co., Oregon. A, epoxy cast of basicranium showing left and right auditory bullae each composed of an ectotympanic, an $\mathrm{E}_{1}$ caudal entotympanic forming the medial wall, and an $\mathrm{E}_{2}$ caudal entotympanic completing the posterior wall of the bulla. $\mathbf{B}$, basicranium of NM 280/61 in ventral view (stereopair). C, detail of the auditory region and the principal bulla elements (stereopair). For abbreviations, see page 5. 

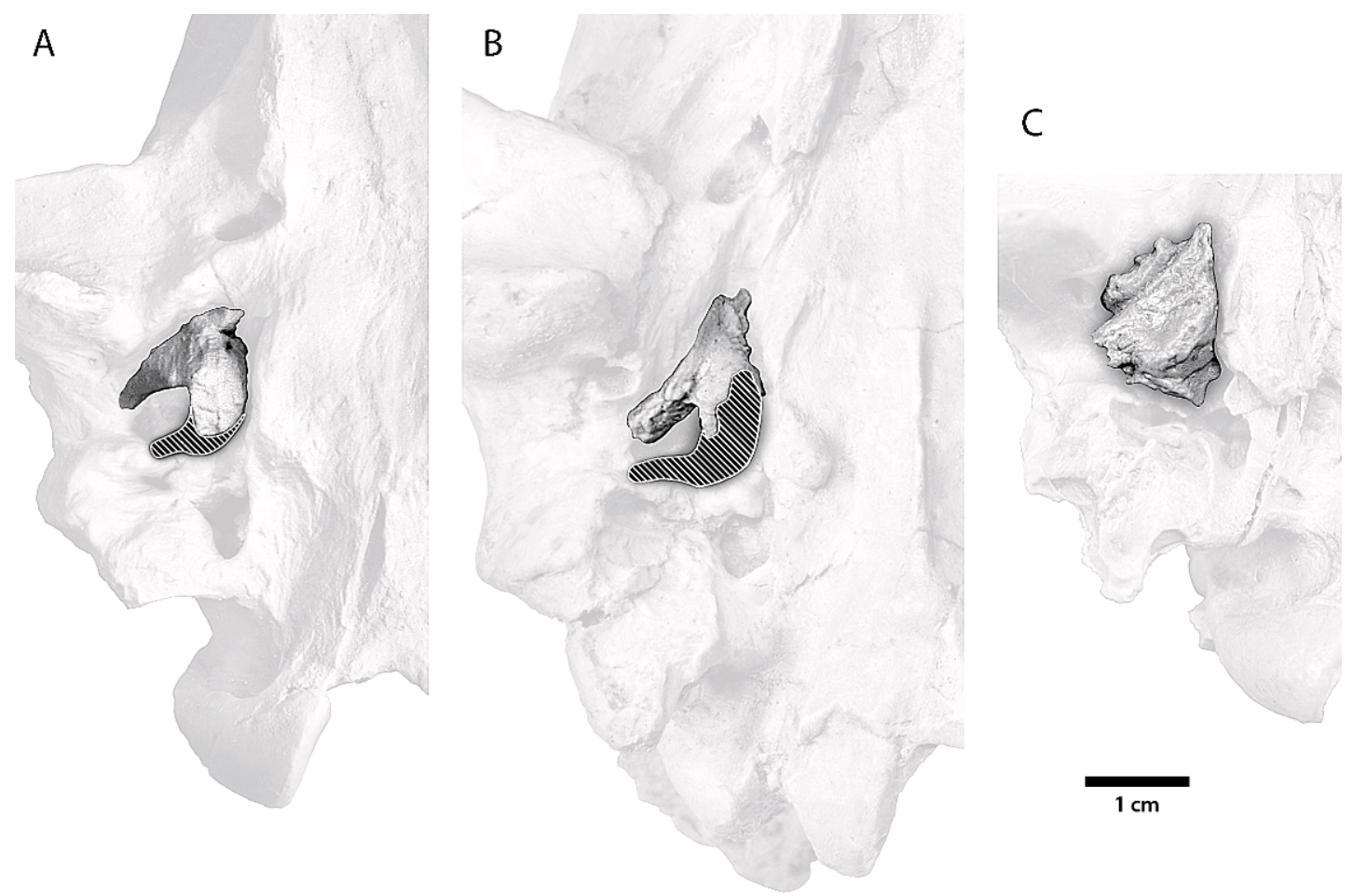

Fig. 69. Evolution of the auditory bulla in temnocyonines: A, plesiomorphic ectotympanic crescent in Temnocyon subferox; $\mathbf{B}$, a larger ectotympanic with styloid process in Mammacyon obtusidens; $\mathbf{C}$, a small capsular rudimentary bulla in Temnocyon fingeruti enclosing the middle ear and formed by an ectotympanic $(\mathrm{T})$ and two caudal entotympanic $\left(\mathrm{E}_{1}, \mathrm{E}_{2}\right)$ elements. These bullae are only loosely attached to the skull. Posterior part of $\mathbf{A}$ and $\mathbf{B}$ restored as in life (cross-hatched).

of any temnocyonine, and more derived than the bullae of $T$. ferox and $M$. obtusidens. The bullae of YPM 10065, ACM 34-41, and NM 280/61 comprise an anatomical progression demonstrating the progressive enclosure of the temnocyonine middle ear (fig. 69). Although achieving complete enclosure in $T$. fingeruti, the middle ear volume is quite small, and the species fails to evolve the large, inflated, well-ossified and often firmly ankylosed bullae of many living carnivorans that enclose a much larger middle ear space.

The auditory bulla of Temnocyon fingeruti is critical to interpretation of the temnocyonine middle ear. In NM 280/61 the bullae are situated as in life. Their relationship to the remainder of the basicranium shows that they are unusually small relative to the size of the skull. Although the middle ear is fully enclosed by the bulla, the bony capsule is rudimentary, only slightly evolved beyond that inferred for $M$. obtusidens. Bulla inflation or other enlargement of the capsule to enclose an expanded middle ear cavity does not occur, middle ear volume is minimal, and the bony bulla does not extend behind (posterior to) the mastoid process. Here the contribution to the osseous bulla by the ectotympanic and two caudal entotympanics is evident from the surface configuration of the bulla. The anterior part of the bulla is formed entirely by the ectotympanic (fig. 68, T), including a short osseous external auditory meatus. Fused to the medial edge of the ectotympanic is an ossified caudal entotympanic, forming the medial wall of the bulla (fig. 68, $\mathrm{E}_{1}$ ), which in its anterior part is nearly vertical but posteriorly becomes broader and outwardly convex at the posteromedial corner of the bulla, partly enclosing the posterior carotid foramen for the internal carotid artery. 
The suture between ecto- and caudal entotympanic $\left(E_{1}\right)$ traverses the bulla surface from its anteromedial to posterolateral corner, marking the line of fusion between the two elements (fig. 68A, 68C, dashed line). As in several living arctoid carnivorans (Hunt, 1974), a small elliptical ossification is applied to the posterior margin of the $E_{1}$ caudal entotympanic to complete the bulla's posterior wall. This small element, evident in both bullae, appears to be a posterior caudal entotympanic or $E_{2}$ element (fig. 68) like that known in Ursus americanus (Hunt, 1974: pl. 4). It fuses to the $E_{1}$ caudal entotympanic that forms the medial wall. As such, the $T$. fingeruti bulla shows a similar disposition of ontogenetic elements as in living ursids. This pattern is also seen in some pinnipeds, procyonids, and mustelids and in the ailurid lesser panda Ailurus fulgens (Hunt, 1974: pls. 6, 8, 9; Hunt and Barnes, 1994). Rather than evidence of close relationship with ursids, these auditory bullae reflect retention of an early plesiomorphic stage in the development of the arctoid bulla.

The relevant anatomical characteristics of the temnocyonine auditory region are: (a) an extremely rudimentary bulla capsule, at first (Temnocyon subferox) formed by an ectotympanic crescent, probably with an initial cartilaginous entotympanic contribution; then (M. obtusidens) incorporating weak ossification of the medial bulla wall; and later ( $T$. fingeruti) by ossification of caudal entotympanic $\left(\mathrm{E}_{1}\right.$ and $\left.\mathrm{E}_{2}\right)$ elements fusing with the ectotympanic to form a fully ossified auditory bulla; (b) absence of inflation of the bulla capsule despite increasing body size, resulting in a middle ear space of very small volume; (c) absence of a prominent bony external auditory meatus in $T$. ferox and $M$. obtusidens, incipient in T. fingeruti; (d) failure of the bulla to extend backward in the auditory region behind the mastoid process (the posterior carotid foramen marks the posterior extent of the bulla in $T$. fingeruti, as in many living ursids); (e) no bulla contact with the exoccipital bone and its paroccipital process; (f) presence of the deep embayment in the margin of the basioccipital bone for the inferior petrosal venous sinus.

These temnocyonine bullae can be distinguished from the auditory bullae of large daphoenine and amphicyonine beardogs, yet these amphicyonid subfamilies apparently all evolved from stem arctoid carnivores with a plesiomorphic auditory region, perhaps much like those of Daphoenus and Cynodictis. The rudimentary auditory bullae of YPM 10065, ACM 34-41, and NM 280/61 (fig. 69) suggest that development of a well-ossified capsular enclosure for the middle ear was retarded in the phylogeny of the Temnocyoninae relative to many small contemporary arctoid and cynoid carnivorans. Many canids by the late Oligocene had fully enclosed their auditory regions in an osseous bulla capsule firmly attached (even ankylosed) to the basicranium and made up of moderately to well-inflated ecto- and entotympanic elements. These temnocyonine skulls show that even by $\sim 23.8 \mathrm{Ma}$ in the latest Oligocene, the Temnocyon lineage had not yet evolved a middle ear volume even approaching the greater volumes found in large living carnivores of similar body mass; such expanded bullae presumably enclose a middle ear capable of more sensitive frequency-enhanced audition (Hunt and Korth, 1980; Stebbins, 1983; Rosowski, 1994). It is possible that temnocyonines may not have acquired a capability for perception of low-frequency sound, if a small middle ear volume damped mobility of the auditory ossicles. We do not know if the plesiomorphic bullae of the Oligocene temnocyonines were retained or possibly "improved" in the early Miocene species: auditory bullae and intact basicrania have not been found for Temnocyon macrogenys and $T$. percussor, or for Delotrochanter major and $D$. oryktes, or even for the latest Oligocene Mammacyon ferocior.

\section{AGE AND CORRELATION}

\section{RADIOISOTOPIC AND BIOCHRONOLOGIC Calibration of Temnocyonine Sites}

Although the provenance of some temnocyonines was never recorded or has been lost, a significant number were found in proximity to volcanic tuffs or ignimbrites that have been radioisotopically dated by the ${ }^{40} \mathrm{Ar} /{ }^{39}$ $\mathrm{Ar}$ or K/Ar methods. These occurrences, in company with faunal associations and known stratigraphic placements, are the basis 
for the temporal range diagram presented here (fig. 70). In the John Day region Temnocyon altigenis (UCMP 1549, 9999), $T$. fingeruti (NM 280/61), Mammacyon obtusidens (LACM 5386), and Rudiocyon amplidens (LACM 480) were found in proximity to dated stratigraphic horizons. Similarly, in the Great Plains, the temnocyonines from sites along the Niobrara River in the vicinity of Agate Fossil Beds National Monument occur in an established stratigraphic relationship to the Agate Ash, a consolidated tuff dated repeatedly since 1964 . References for dated tuffs and ignimbrites are listed in Tedford et al. (2004: 219-221) or are mentioned here.

\section{JOHN DAY BASIN}

The geologically oldest records of John Day temnocyonines are the reports of Temnocyon altigenis (Merriam, 1906) at Logan Butte (UCMP 9999, locality 898), and near the village of Monument (UCMP 1549, locality 874) along the north fork of the John Day River (see Fisher and Wilcox, 1960; Wilcox and Fisher, 1966). Locality 874 is a low bluff where gray to olive-buff volcaniclastic sediments are exposed below the capping Picture Gorge ignimbrite (28.7 Ma); the gray fine-grained tuffaceous sandstone adhering to the skull suggests that UCMP 1549 was collected from gray beds directly below the ignimbrite. At Logan Butte, $75 \mathrm{mi}$ southwest of Monument, a number of superposed, dated tuffs are interbedded with John Day rocks that form the butte and adjacent badlands (T. Fremd, personal commun., 1994); here the youngest tuff, near the top of the stratigraphic section at the butte, dates at 28.87 Ma. Temnocyon altigenis (UCMP 9999) comes from badlands below this stratigraphic level that include tuffs dated at 29.11 and $29.25 \mathrm{Ma}$. These two T. altigenis skulls, both from the lower John Day Formation, are the only individuals of this species found in proximity to radioisotopically dated beds. The Logan Butte occurrence (UCMP 9999) establishes the approximate time of origin of the subfamily. The holotype of $T$. altigenis (AMNH 6855) and other mandibles of the species found in the 19th century cannot be placed in a stratigraphic context except to state that the patina and mineralization of these jaws suggests they also came from lower John Day sediments.

The skull of Temnocyon subferox (YPM 10065) was collected from the "Middle John Day" Formation, possibly late in the 19th century by a collector in the employ of O.C. Marsh, and is without precise stratigraphic or geographic information. A pale gray, very fine tuffaceous sandstone is present within the braincase. Although its age is uncertain, it was probably collected from John Day rocks above the Picture Gorge ignimbrite $(28.7 \mathrm{Ma})$. The larger size of the skull and more derived dentition support an age somewhat younger than the $T$. altigenis hypodigm.

An exact stratigraphic level is known for the skull of Temnocyon fingeruti (NM 280/61) collected in the Haystack Valley Member (as revised, Hunt and Stepleton, 2004) of the John Day Formation along Balm Creek. An ${ }^{40} \mathrm{Ar} /{ }^{39} \mathrm{Ar}$ date of $\sim 23.8 \mathrm{Ma}$ was obtained on sanidine from a tuffaceous siltstone $62 \mathrm{ft}$ (19 $\mathrm{m}$ ) beneath the beardog site (Hunt and Stepleton, 2004: 81). Sediments between the dated level and the beardog include fluvial channel conglomerate fining upward to tuffaceous sandstones and siltstones with immature paleosols that together represent a single, possibly brief depositional interval; thus the skull may be not much younger than the $\sim 23.8$ date. It is of latest Oligocene age.

Locality records at Princeton University state that the holotype skull and skeleton of Temnocyon ferox (YPM-PU 10787) was found "near Maginnis' ranch, Turtle Cove, John Day river, Oregon," collected in the “Upper John Day" by L.S. Davis in 1889. The skeleton is embedded in a gray fine tuffaceous sandstone, the bone a pale tan to light brown color. The skull's large size and derived dentition indicate a stratigraphic level above the Picture Gorge ignimbrite, most likely from gray sandstones of the Kimberly Member. However, our examination of Kimberly Member outcrops along Maginnis Creek, west of the John Day River (secs. 25, 26, 35, 36, T10S, R25E, Mt. Misery 7.5minute quadrangle), led us to doubt that this area was the source of the holotype, as its rocks were unfossiliferous and somewhat inaccessible. Further research brought us to the Son Hill ranch, $2 \mathrm{mi}$ northwest of 
Kimberly on Oregon Highway 19. Here, Son Hill, related to the Hamilton Maginnis family by marriage, informed us that his ranch was the actual location of the 19th century Maginnis homestead. Fossiliferous gray tuffaceous sandstones assigned to the Kimberly Member occur in the vicinity of the Maginnis ranch and trend northwest from Kimberly for $3.6 \mathrm{mi}(5.8 \mathrm{~km})$ along Oregon Highway 19; this is a more probable, general locale for YPM-PU 10787. Gray tuffaceous sandstones attributed to the Kimberly Member range widely in age, from slightly younger than 25.9 Ma (Tin Roof tuff) to possibly as young as $\sim 23 \mathrm{Ma}$ along the John Day river south of Kimberly, and to 27.9 Ma (Deep Creek tuff) at Rudio Creek. Temnocyon ferox is clearly a more advanced species in skeletal and dental anatomy than $T$. altigenis and $T$. subferox. Because T. ferox is dentally similar yet less evolved than $T$. percussor, a species dated by the Agate Ash (22.9 Ma), an age older than $\sim 23 \mathrm{Ma}$ is likely for the Maginnis ranch beardog. Here the age of $T$. ferox is thought to fall somewhere between the Tin Roof tuff $(25.9 \mathrm{Ma})$ and the occurrence at $\sim 23.8 \mathrm{Ma}$ of the more dentally advanced $T$. fingeruti at Balm Creek.

The mandible of Rudiocyon amplidens (LACM 480), the largest of the John Day temnocyonines, comes from California Institute of Technology (CIT) locality 31, "from gray beds east of the road, 1.5 to 2 miles south of the Johnson ranch at the mouth of Rudio Creek." Gray tuffaceous sandstones and siltstones of the Kimberly Member are the principal lithologies east of the road along the creek over this distance. The most probable source outcrop is a fluvial channel complex prominently exposed in a northfacing bluff situated $1.5 \mathrm{mi}(2.4 \mathrm{~km})$ south of the ranch in the NW4, NE4, NE4, sec. 27, T9S, R26E. Here an oreodont maxilla and other bone fragments having the same pale brown-buff color and mineralization as LACM 480 were found in these channel beds, which include fluvial conglomerate, friable gray tuffaceous sandstones and siltstones, clayey siltstone, clay lenses, and diatomite. At the base of the bluff only a few meters to the northeast is a consolidated ash thought to be equivalent to the Deep Creek tuff by R.V. Fisher during his mapping of the John Day Formation along Rudio Creek (Fisher and Rensberger, 1972: 14). The ash occurs $80-90 \mathrm{ft}(\sim 24-27 \mathrm{~m})$ below the channel sediments that likely yielded LACM 480. If the ash is correctly attributed, the mandible and associated braincase of Rudiocyon are then younger than the Deep Creek tuff $(\sim 27.9 \mathrm{Ma})$ and occur at the approximate level of the stratigraphically higher Biotite tuff (27.18 Ma), which provides a plausible age estimate for $R$. amplidens.

Green tuffaceous sediment adhering to the maxilla of Mammacyon obtusidens (LACM 5386) from Haystack Valley indicates that it came from dark green claystones attributed to the Turtle Cove Member making up the floor of the valley (Hunt and Stepleton, 2004: 74, map E, Tjt). The maxilla was found at CIT locality 29, " a large exposure of green beds on the north side of Haystack Valley," which occurs in proximity to an outcrop of the Picture Gorge ignimbrite. Whether the maxilla came from above or below the ignimbrite is uncertain but the size and evolved state of the teeth support an age somewhat younger than $28.7 \mathrm{Ma}$, the age of the ash-flow.

\section{Arikaree Group, Great Plains}

The Great Plains temnocyonines are more difficult to place in a temporal context relative to most John Day species due to the scarcity of isotopically dated volcanic ash beds in the Arikaree rocks of northwest Nebraska and southeast Wyoming. Far removed from their source volcanoes, Arikaree tuffs are primarily vitric and extremely fine-grained, and often lack crystals amenable to radioisotopic analysis. The tuff known as the Agate Ash occurring within the Harrison Formation at Agate Fossil Beds National Monument in northwest Nebraska has been a frequently sampled principal calibration point (Evernden et al., 1964; Tedford et al., 1987: 198). Recently ${ }^{40} \mathrm{Ar} /{ }^{39} \mathrm{Ar}$ analysis on sanidine gave an age of $22.9 \pm$ $0.08 \mathrm{Ma}$ (Izett and Obradovich, 2001), placing the tuff immediately above the Oligocene-Miocene boundary (23.03 Ma, Lourens et al., 2004).

The Agate Ash establishes a reliable age estimate for the occurrence of Temnocyon percussor at nearby Syndyoceras Quarry, and 


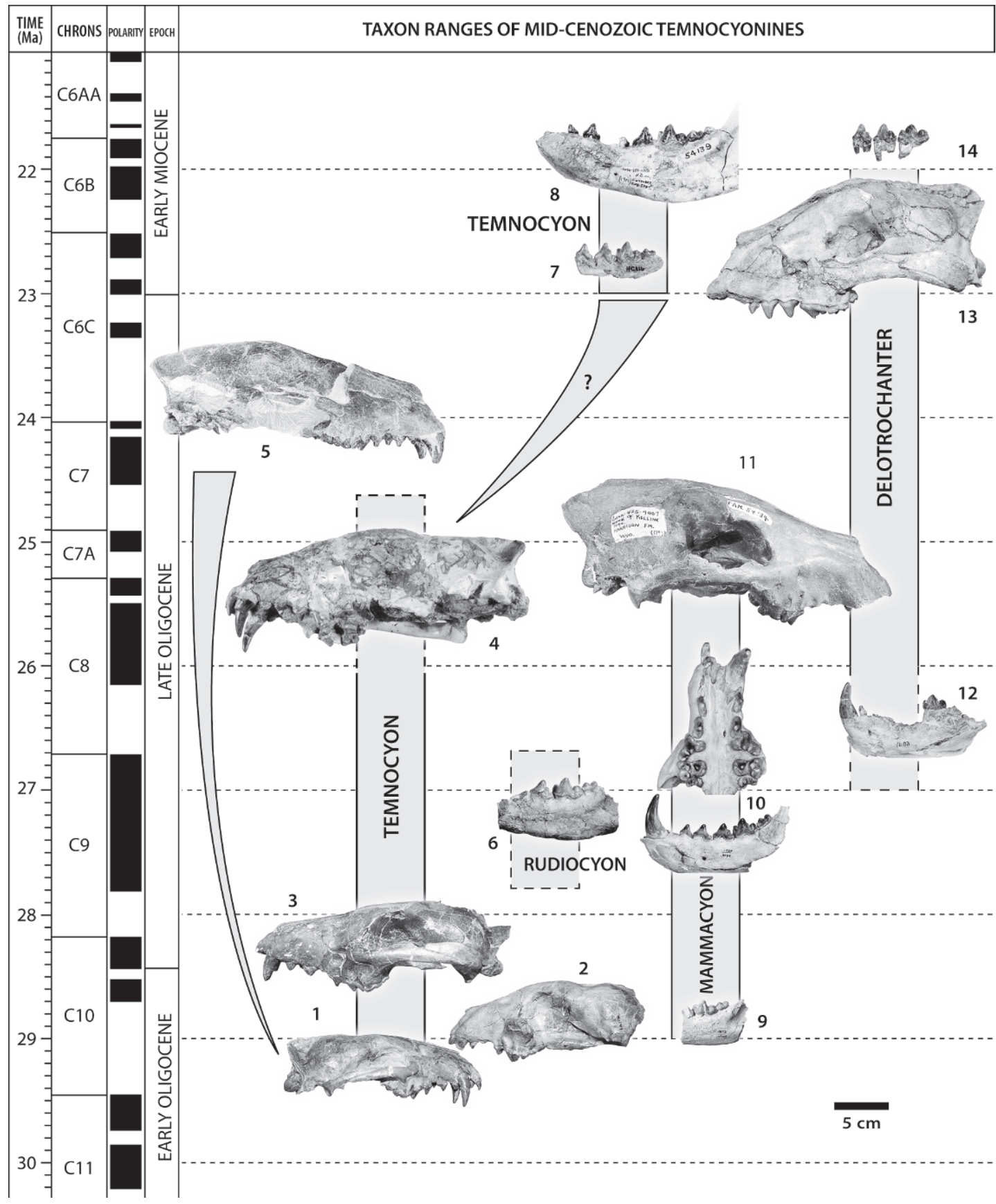

Fig. 70. Taxon ranges of North American temnocyonines in the Pacific Northwest and Great Plains. 1, Temnocyon altigenis (Logan Butte); 2, T. altigenis; 3, T. subferox; 4, T. ferox; 5, T. fingeruti; 6, Rudiocyon amplidens; 7, T. percussor; 8, T. macrogenys; 9, cf. Mammacyon (Sharps Fm.); 10, M. obtusidens; 11, M. ferocior; 12, Delotrochanter petersoni; 13, D. oryktes; 14, D. major. Placement for 3, 4, 6, and 12 are best estimates indicated by dashed lines. Numbers 1-6, John Day Formation; numbers 7-14, Great Plains. Temnocyon occurs chiefly in the John Day Formation of the Pacific Northwest; terminal species of the genus are from the Great Plains. Mammacyon and Delotrochanter are common in Arikaree Group 
also for Delotrochanter oryktes at Stenomylus Quarry. Both quarries occur within the Harrison Formation in proximity to this tuff. The isolated teeth assigned to $T$. percussor from the AMNH-Cook Quarry, and the skull of $D$. oryktes from the carnivore den excavated into the Agate waterhole bonebed, come from the basal Anderson Ranch Formation, which is directly superposed on the Harrison Formation throughout the national monument. So these fossils are somewhat younger. The temporal separation appears to be geologically brief, given the similarity of the Harrison Formation fauna to the fauna from the waterhole bonebed on Carnegie and University Hills.

The geologically youngest species of Temnocyon and Delotrochanter (T. macrogenys, $D$. major) come from higher stratigraphic levels of the early Miocene Anderson Ranch Formation (Hunt, 1990, 2002b) in southeast Wyoming and northwest Nebraska. These are the last surviving temnocyonines in North America. There is little doubt that T. macrogenys and $D$. major are descended from the Harrison $T$. percussor and $D$. oryktes. Since they have evolved to a marked degree in size and dentition, it appears that substantial time has elapsed-previously a crystal-vitric tuff (Eagle Crag Ash, Hunt et al., 1983) has provided the only radiometric age (19.2 \pm 0.5 Ma, fission track-zircon) for the Anderson Ranch Formation. Attempts to obtain an ${ }^{40} \mathrm{Ar} /{ }^{39} \mathrm{Ar}$ analysis on sanidine from this tuff have not been successful. However, zircons extracted from the tuff have undergone SHRIMP U-Pb analysis yielding a preliminary age estimate $(22.4 \pm 0.3 \mathrm{Ma})$ much older than the Eagle Crag fission track date. An effort is now underway to date tuffs in the Anderson Ranch Formation by ID-TIMS zircon $\mathrm{U}-\mathrm{Pb}$ geochronology to resolve this question.

Temnocyonine fossils referred to Mammacyon in the North American midcontinent lack proximity to tuffs but are associated with mammals that provide a biochronologic age. South Dakota Mammacyon obtusidens from the Porcupine Creek area occurs with early Arikareean mammals (Miohippus, Desmatochoerus, Enhydrocyon, Nimravus) that became extinct before the late Arikareean and do not occur in Harrison Formation faunas in western Nebraska. Faunas from southwestern South Dakota that include Mammacyon obtusidens are considered older than 25 Ma (Tedford et al., 2004).

Mammacyon ferocior from the Frick Laboratory's "north of Keeline" collecting area in southeast Wyoming is doubtless younger than M. obtusidens from South Dakota and is said to come from "Harrison" Formation rocks. However, the mammal fauna from north of Keeline does not include several of the most common Harrison Formation species (Menoceras arikarense, Moropus elatus, Stenomylus hitchcocki) from northwest Nebraska that occur in the stratotype of the formation at the head of Monroe Creek and also at Agate Fossil Beds National Monument. The small rhinoceros Menoceras and chalicothere Moropus are first occurrences in the Harrison Formation and are considered to be Asian immigrants. The absence of Moropus and Menoceras holds true for all Arikaree rocks termed "Harrison" by the Frick Laboratory collectors along the Wyoming Pine Ridge escarpment: these exposures extend from north of Keeline east nearly to the town of Van Tassell, a distance of $\sim 38 \mathrm{mi}$ $(61 \mathrm{~km})$. Additionally, the fauna from north of Keeline differs from the fauna of the Harrison Formation in northwest Nebraska in the presence of not only Mammacyon ferocior, a species unknown in Nebraska Harrison faunas, but also by the inclusion of a more primitive stenomyline camel (Stenomylus keelinensis), two rhinoceroses (Diceratherium armatum and D. annectens), the oreodont Desmatochoerus, and a small species of the equid Kalobatippus that precedes $K$. agatensis from the Harrison Formation at Agate. These mammals indicate an age for the Keeline "Harrison" fauna somewhat older than the mammal fauna from the stratotype Harrison Formation and the correlative Harrison sediments at Agate National Monument in Nebraska, dated by

$\leftarrow$

sediments of the North American midcontinent indicative of semiarid to arid grassland and savanna. All fossils to common scale. 
the 22.9 Ma Agate Ash. Thus, Mammacyon ferocior, the terminal species of its lineage, is considered here to be of latest Oligocene age, older than 23 Ma.

The age of Mammacyon ferocior and the "Harrison" beds north of Keeline (and their continuation eastward along the Wyoming Pine Ridge escarpment) can also be estimated from paleomagnetic sampling of the stratotype Monroe Creek-Harrison section in northwest Nebraska along Monroe Creek, north of the village of Harrison, and from a correlative section $5 \mathrm{mi}(8 \mathrm{~km})$ east at Pants Butte (MacFadden and Hunt, 1998; Hayes, 2004). The Keeline fauna seems to correspond stratigraphically to paleomagnetically calibrated sandstones termed the "upper Monroe Creek" beds (Peterson, 1907) that lie below the stratotype Harrison Formation of Hatcher (1902a) at the head of Monroe Creek. There the "upper Monroe Creek" beds comprise $240 \mathrm{ft}$ of mostly unfossiliferous gray tuffaceous eolian sandstones (from 4640 to $4880 \mathrm{ft}$ in elevation) that span approximately 3 million years from $\sim 24.8$ to $27.8 \mathrm{Ma}$. These beds appear to fall primarily within polarity chrons $\mathrm{C} 9 \mathrm{n}, \mathrm{C} 8 \mathrm{r}, \mathrm{C} 8 \mathrm{n}$, and C7Ar of the Global Polarity Time Scale (Hayes, 2004). Mammacyon ferocior and the "north of Keeline" fauna suggest a placement in the younger part of this interval due to affinity with the later-occurring Harrison fauna and the common occurrence of the oreodont Promerycochoerus.

The earliest evidence of Delotrochanter (CM 1603, D. petersoni) was collected in 1904 by O.A. Peterson from the Pine Ridge escarpment at the head of Warbonnet Creek in northwest Nebraska (Peterson, 1907). An identifiable gray tuffaceous sandstone adhering to these jaws allows them to be placed within an estimated stratigraphic interval of 200-300 ft in the upper part of the Pine Ridge Arikaree sequence. However, Peterson's (1907) attribution to the "upper Monroe Creek" horizon, and the field label indicating "middle Monroe Creek beds," does not permit assignment to a more limited stratigraphic level within these gray eolian sandstones. Nonetheless, D. petersoni is a much less advanced form in size and dentition than D. oryktes from the Harrison Formation, indicating a probable derivation from low in the "upper Monroe Creek" beds in Sioux County, possibly within or near polarity chron C8r. If correct, the first appearance of Delotrochanter conceivably could occur from $\sim 26$ to $27 \mathrm{Ma}$.

Sediments in the lower part of the Monroe Creek Canyon section along Monroe Creek, attributable to what Peterson (1907) would have termed "lower Monroe Creek" and "Gering" beds, show clear polarities correlating to chrons C9r and C10n (Hayes, 2004), establishing that this stratigraphic interval extends from 27.8 Ma to no older than 28.7 Ma (Gradstein et al., 2004). Rocks placed in chron $\mathrm{C} 10 \mathrm{n}$ are anchored by an unpublished dated ash. The "lower Monroe Creek" beds at Wildcat Ridge in the southern Nebraska panhandle yielded an ash dated at $\sim 27.8 \mathrm{Ma}$ (Olson's Third Ash, Tedford et al., 1996: 316, 321), a date in agreement with polarity chrons inferred for the "lower Monroe Creek" beds at Pine Ridge.

\section{Kew Quarry, California}

The temnocyonine from Kew Quarry in the Sespe Formation of California is of particular interest since the fractured mandible (Temnocyon cf. T. subferox, LACM 470) is the only record of the subfamily in western North America outside the John Day region. LACM 470 and the rare remains from Florida show that temnocyonines likely occupied the southern United States from California to the Gulf and Atlantic coasts during the later Oligocene.

The age of the Kew Quarry fauna for some time has been considered problematic. Certain mammals are suggestive of a late Whitneyan, others of an early Arikareean age (Stock, 1932, 1933a, b, 1948; Wilson, 1949; Lander, 1983; Whistler and Lander, 2003; Tedford et al., 2004). Preference for the younger age of the Kew Quarry fauna is influenced largely by carnivores (Temnocyon cf. T. subferox, Mesocyon brachyops, Eusmilus cerebralis), the equid Miohippus, camel Miotylopus gibbi, and a cricetid rodent (?Paciculus), whereas a late Whitneyan age has been inferred from taxa occurring in the early Arikareean whose ranges extend into the Whitneyan: the rhinoceros Subhyracodon, nimravid Nimravus brachyops, canid $\mathrm{Ar}$ - 
chaeocyon pavidus, anthracothere Elomeryx armatus, and hypertragulid Hypertragulus calcaratus.

Although a radioisotopic date for the quarry is not available, several carnivores from Kew Quarry were also found in the John Day Formation at Logan Butte, Oregon, where the beds are bracketed by the previously mentioned tuffs dating from 28.87 to $29.25 \mathrm{Ma}$. Thus, the Logan Butte fauna is apparently equivalent to the more northern John Day fauna occurring immediately below the Picture Gorge ignimbrite (28.7 Ma). Bryant (1996) thought fossils of Eusmilus cerebralis from Logan Butte and Kew Quarry were of early Arikareean age. Wang (1994: 57; Wang and Tedford, 2008) also regarded the holotype of Mesocyon brachyops from the butte and the sample of $M$. brachyops from Kew Quarry as early Arikareean. The M. brachyops holotype and the skull and partial skeleton of the plesiomorphic Temnocyon altigenis (UCMP 9999) were both found at UCMP locality 898 at Logan Butte. Thus, these carnivores date with some certainty between $\sim 28.8$ and 29.3 Ma, and collectively support an early Arikareean age. Of interest here is that Temnocyon cf. T. subferox (LACM 470) from Kew Quarry is not only a larger, more derived species than $T$. altigenis (UCMP 9999) from Logan Butte, but also relative to the entire $T$. altigenis sample from the John Day Formation. The presence of LACM 470 in the Kew Quarry fauna seems a particularly strong indicator of an early Arikareean age.

Some mammals from the quarry are mentioned as most compatible with a Whitneyan age. The nimravid mandible from Kew Quarry, assigned to Nimravus brachyops by Toohey (1959), was reported to be smaller than all John Day specimens of this species and closest in size to a $N$. brachyops mandible (UNSM 25491) from $2 \mathrm{ft}$ above the upper Whitney ash (30.6 Ma, Prothero and Swisher, 1992) in western Nebraska. One of the largest John Day skulls of $N$. brachyops comes from UCMP locality 898 at Logan Butte: the Kew Quarry jaw and this skull are at the extremes of size for this species (possibly a small female and large male); both were regarded as conspecific and of early Arikareean age by Bryant (1996). The small rhinoceros, Subhyracodon occidentalis, considered a pre-Arikareean indicator based on its premolar dentition (Stock, 1933a; Lander, 1983), has been an influential taxon for those favoring a Whitneyan age (Lander, personal commun., 2002). Finally, the Kew Quarry equid Miohippus, also identified as a Whitneyan form, was considered by M.F. Skinner (personal commun., 1970) to be postWhitneyan in age based on the crown height of $\mathrm{m} 1$ and twinned metastylid-metaconids of dp3-4 and $\mathrm{m} 1$.

Kew Quarry occurs in the upper member of the Sespe Formation in the Ventura Basin of southern California. Here a $\sim 500 \mathrm{~m}$ composite section measured in the Las Posas Hills was mostly paleomagnetically reversed and initially correlated to either polarity chron C10r or C11r (Prothero et al., 1996) in the late early Oligocene. The upper member in the Santa Anna Mountains ( $\sim 100 \mathrm{~km}$ southeast of the Las Posas Hills) was later correlated to chrons $\mathrm{C} 10 \mathrm{n}-\mathrm{C} 10 \mathrm{r}$ (Calvano et al., 2003). More recent paleomagnetic and radioisotopic dating of the Sespe Formation in Los Angeles and Orange counties concluded that the regional episode of Oligocene Sespe deposition occurred from 28 to $30 \mathrm{Ma}$ (Calvano et al., 2008: 58), with no Oligocene sediments older than $30 \mathrm{Ma}$, the lower boundary of the Arikareean NALMA. A Whitneyan age for Kew Quarry then seems unlikely. The current consensus accords the early Arikareean indicators priority and favors correlation to within chron C10r (Tedford et al., 2004), which extends from 28.7 to $29.4 \mathrm{Ma}$ (Gradstein et al., 2004). The Whitneyan determinations apparently rest on preservation of relict taxa in the Kew Quarry fauna, a possibility initially noted by Stock (1932).

\section{DISCUSSION AND CONCLUSIONS}

\section{Origin AND GeOgRaphic Distribution of an Archaic Predator Guild}

The continent-wide geographic distribution of temnocyonines from the Pacific Northwest to the central Great Plains and Florida suggests that the subfamily occupied a significant ecologic niche in North America for at least 7 million years from the late early 
Oligocene to the early Miocene. Our knowledge of the group is primarily based upon the fossil record of two regions, the John Day basin of Oregon, where they were first discovered, and the central Great Plains of western Nebraska and eastern Wyoming. The John Day temnocyonines are radioisotopically documented from $\sim 29$ to $23.8 \mathrm{Ma}$; in the Great Plains, two lineages (Temnocyon, Delotrochanter) survive into the early Miocene.

Temnocyonine evolution is characterized by a progression from small $(5-10 \mathrm{~kg})$ to quite large $(\sim 65-80 \mathrm{~kg})$ species and, simultaneously, involves a branching into both hypercarnivorous and durophagous lineages, defined by a singular dentition that allows the subfamily to be tracked over time. John Day temnocyonines differ sufficiently from Great Plains species to indicate a regional distinction, in accord with a long-recognized disparity between John Day and Great Plains faunas of Oligocene age (Tedford et al., 2004). The smaller carnivorous species, best represented in the John Day basin, were likely generalists with a rather catholic diet, whereas the large durophagous forms found in the Great Plains seem to be specialists responding to specific regional selection pressures.

Beginning with small fox-sized forms at the end of the early Oligocene, the subfamily evolved three principal lines, recognized in this study as genera (Temnocyon, Mammacyon, Delotrochanter). Temnocyonine diversity was established by the late Oligocene with the appearance of large hypercarnivorous (Temnocyon ferox, T. fingeruti) and durophagous (Mammacyon obtusidens, $M$. ferocior; Delotrochanter petersoni) species (fig. 70). Possibly extinct in the John Day basin by the end of the Oligocene, temnocyonines continued into the early Miocene in the Great Plains as four surviving species (T. percussor, T. macrogenys, D. oryktes, D. major).

Overall, the history of the Temnocyoninae appears to have been influenced by changes in the faunal dynamic of the time: (a) the absence of catlike predators (nimravids) after $25 \mathrm{Ma}$; (b) the absence of large boneprocessing canids throughout the late Oligocene-early Miocene; (c) the development of semiarid to arid grassland ecosystems in the late Oligocene-Early Miocene; (d) the immigration of large Eurasian amphicyonine amphicyonids and hemicyonine ursids into North America accompanying a new climatic/tectonic regime unfolding during the early Miocene.

The dominant role of indigenous temnocyonines as predators during the late Oligocene-early Miocene interval in North America appears closely tied to the increase in body size in the various lineages. This increase is apparently linked to the opening of previously occupied niches as less-adapted species declined to extinction. Prior to the appearance of large temnocyonines, the hypercarnivorous niche in the Oligocene belonged to nimravid cats (Bryant, 1991, 1996; Martin, 1998), and the niche for processing hard food materials to durophagous hesperocyonine canids (Enhydrocyon, Philotrox; Wang, 1994), essentially small "hyaenoid" dogs. When most species in these groups become extinct in the late Oligocene, temnocyonines begin to diversify. By the early Miocene, nimravids and bone-crushing hesperocyonines are gone, replaced by large species of Temnocyon and Delotrochanter. True cats and hyaenids were late arrivals in North America, the first felids migrating into North America from Eurasia at $\sim 16.5-17 \mathrm{Ma}$ at the end of the early Miocene, and a hyaenid not appearing until the Pliocene.

Temnocyonines have not been identified outside of North America. However, European paleontologists (Viret, 1929; Bonis, 1973) have noted a pronounced dental similarity between temnocyonines and late Oligocene-early Miocene European haplocyonine amphicyonids. The two groups apparently evolved in parallel from a common Eocene or early Oligocene amphicyonid ancestry, each becoming geographically isolated, the haplocyonines in Europe and temnocyonines in North America. Neither group is certainly identified in Asia. The tall premolars (p2-4, P2-3) and specialized crushing cheek teeth (p4-m2, P4-M1) shared by the two subfamilies comprise the principal evidence for relationship. Late Oligocene and early Miocene temnocyonines evolved the most highly developed crushing dentitions, which are not found among haplocyonines: Haplocyonopsis crassidens (Bonis, 1973) and 


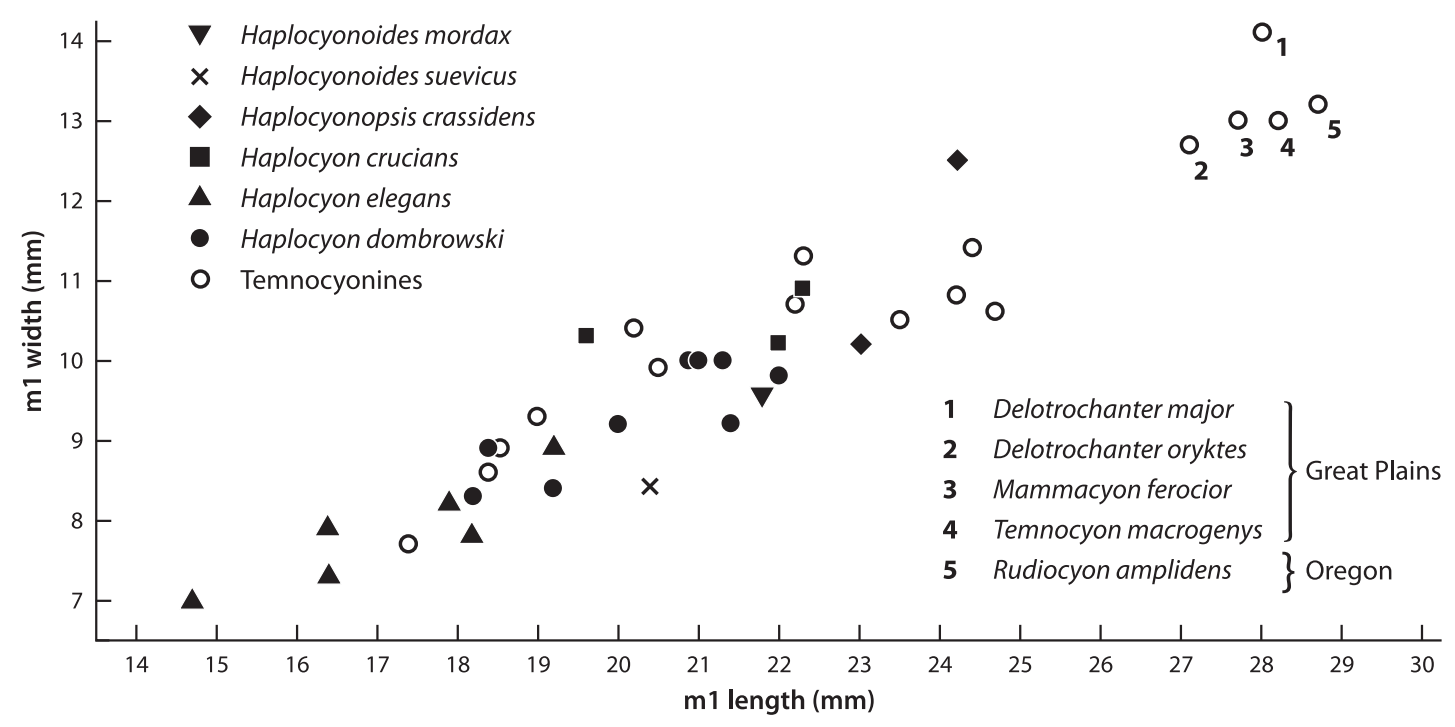

Fig. 71. Dimensions of $\mathrm{m} 1$ for species of North American temnocyonine and European haplocyonine amphicyonids as an indication of body size. The largest of these carnivores are durophagous temnocyonines (\#1-5) occupying grassland-savannas of the Great Plains and Oregon.

Haplocyonoides mordax and Hcyd. suevicus (Hürzeler, 1940; Peigné and Heizmann, 2003) make the closest approach.

The proportions of M1 and P4 (A/B, C/D ratios, table 6) best illustrate the more pronounced crushing adaptations of these teeth in Mammacyon and Delotrochanter relative to haplocyonines. Haplocyonines show a progressive development of a modest crushing P4 (C/D ratios: Haplocyon elegans, 1.54-1.59; H. dombrowski, 1.45-1.46; $H$. crucians, 1.32; Haplocyonoides suevicus, $\sim 1.35$; Haplocyonoides mordax, 1.23-1.26, Haplocyonopsis crassidens, 1.27), yet they fail to develop the particularly robust $\mathrm{P} 4$ proportions and large crushing protocones of Mammacyon and Delotrochanter species (C/ $\mathrm{D}$ ratios, 1.13-1.27). Similarly, the lingual expansion of M1 to form a crushing platform in haplocyonines (A/B ratios: 1.42-1.63) approximates the grade of M1 development found in species of Temnocyon (1.44-1.66) but does not result in the massive M1 crushing platforms of Mammacyon and Delotrochanter reflected in their A/B ratios (1.12-1.36). Dimensions of the lower carnassial, plotted as a proxy for body size for all species of the two subfamilies (fig. 71), show that the largest of these carnivorans were North American: the terminal durophagous species of Mammacyon and Delotrochanter, the huge Temnocyon macrogenys, and the John Day Rudiocyon amplidens.

\section{Global Climate and the TEMNOCYONINE RADIATION}

The temnocyonine radiation in North America immediately followed a marked climatic transition from the warmer, more equable world of the Eocene to the cooler, more seasonal climates of the Oligocene. Once the subfamily is established, species were subjected to an interval of much warmer climate during the late Oligocene. Global deep-sea oxygen isotope records orbitally tuned to the Global Polarity Time Scale (GPTS, Zachos et al., 2001, 2008; Billups et al., 2004; Francis et al., 2009) provide a temporal context for evaluation of the climate during temnocyonine diversification (fig. 72).

The cooler climate of the Oligocene, prefaced by the Oi-1 glaciation of Antarctica at $\sim 34 \mathrm{Ma}$, preceded the first appearance of temnocyonines between 29 and $30 \mathrm{Ma}$. The principal temnocyonine lineages must have been established during the relatively stable climate of the earlier Oligocene from $\sim 33 \mathrm{Ma}$ to $26.8 \mathrm{Ma}$. Species of Temnocyon and 


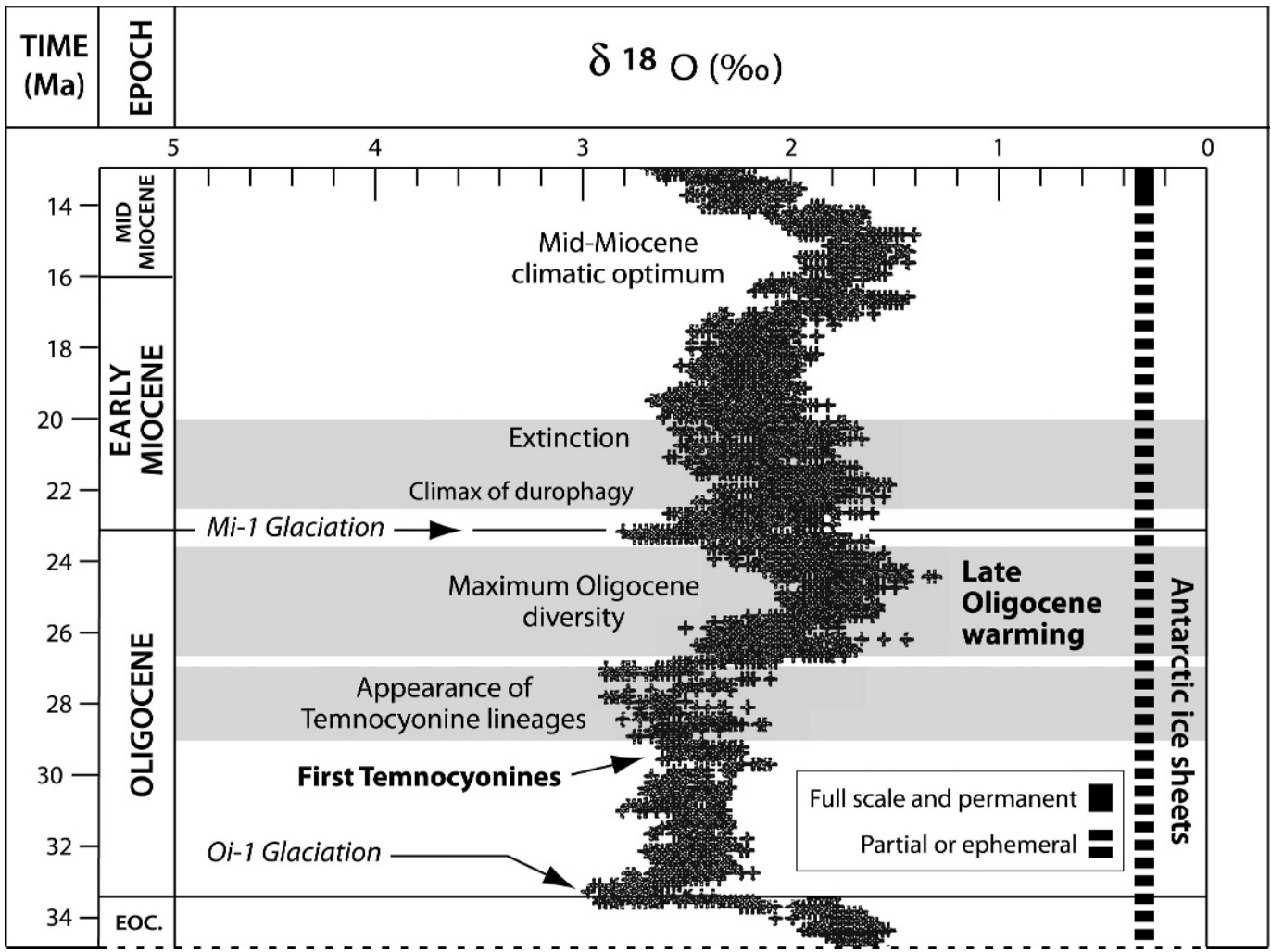

Fig. 72. Orbitally tuned Oligocene-Miocene global oxygen isotope record (after Zachos et al., 2008; Francis et al., 2009) relative to the appearance and radiation of North American temnocyonine amphicyonids.

Mammacyon first appear in this interval, as does Rudiocyon amplidens and the earliest species of Delotrochanter. From $\sim 26.8 \mathrm{Ma}$ to immediately prior to the end of the Oligocene at $23 \mathrm{Ma}$, temnocyonines achieved their maximum diversity. A size increase in Temnocyon and Mammacyon occurred at this time, and likely included Delotrochanter. Of interest is that temnocyonine diversification coincides with the Late Oligocene Warming (LOW) event, an accelerated warming trend beginning at $\sim 26.8 \mathrm{Ma}$ that reached a maximum at $\sim 25-24 \mathrm{Ma}$, and then declined until the global cooling that accompanied the Mi-1 glaciation at $23 \mathrm{Ma}$, the OligoceneMiocene $(\mathrm{O} / \mathrm{M})$ boundary (Francis et al., 2009; Zachos et al., 2008).

The climax of the LOW, occurring between $\sim 25$ and $24 \mathrm{Ma}$, may have attained a regional warmth equivalent to that achieved in the late Eocene (fig. 72). This interval is difficult to discern with precision in terrestrial sediments, both in Oregon and the Great Plains, due to the scarcity of reliably dated tuffs or ash-flows of that age. However, in the midcontinent, the overall sedimentary record indicates that this was a stable, warm period characterized by an arid to semiarid seasonal climate. Species of Temnocyon and Delotrochanter apparently were increasing in size at this time since large species of both of these genera appear at $\sim 23 \mathrm{Ma}$ in the early Miocene.

The warmth of the late Oligocene yielded abruptly to an acute cold interval at the O/M boundary at $23 \mathrm{Ma}$ (Billups et al., 2004; Zachos et al., 2008; Francis et al., 2009). In the midcontinent, emerging grasslands may have been favored by this cooler episode. By the late Oligocene there is evidence of the spread of expansive grasslands and open woodlands, later transitioning to savanna with riparian elements in the early Miocene (Stromberg, 2004). 
Temnocyonines (Temnocyon percussor, T. macrogenys; Delotrochanter oryktes, $D$. major) at the dawn of the Neogene are large durophagous carnivores. They were joined by immigrant carnivores and ungulates that appear in North America at the time of the Mi-1 glacial event at $\sim 23 \mathrm{Ma}$ (Webb and Updyke, 1995; Tedford et al., 2004). These temnocyonines from the Harrison and Anderson Ranch formations represent the climax of the radiation, and persist into the latest Arikareean (Ar4), where the formidable Temnocyon macrogenys and Delotrochanter major are the last of the subfamily.

Following the Mi-1 glacial episode, a warmer climate returned in the early Miocene and continued to the mid-Miocene climatic optimum, an 8 million-year interval characterized by abundant and diversified ungulate and carnivorous mammals adapted to open terrain and the spread of regional grasslands and savanna. Global ice volume remained, but was much reduced (Zachos et al., 2001). However, by the beginning of the Hemingfordian NALMA $(\sim 18.5-18.8 \mathrm{Ma})$, temnocyonines are no longer evident as members of the predator guild.

\section{Regional Climate and TEMnOCYONINE Diversity}

Recent investigations in biochronology, stratigraphy, sedimentology, and taphonomy of the John Day region and the central Great Plains (western Nebraska-southeast Wyoming) contribute to a more nuanced picture of the temnocyonine radiation relative to the climate and faunal dynamic in these areas.

In the Pacific Northwest, a warm climate in the late Eocene supported humid, forested habitats in the John Day basin. Based on paleosol analysis (Retallack, 1997, 2007), the early Oligocene to the early late Oligocene (30-27 Ma) saw a continuation of generally warm and wet conditions in the region. Significant woodlands occur as late as $30 \mathrm{Ma}$, then decline to $27 \mathrm{Ma}$, as grassland expanded. Predominantly bunch grassland and sagebrush steppe is reported in central Oregon, appearing at $27 \mathrm{Ma}$ (Retallack, 2007). A second expansion of grassland in the late Oligocene $(25-24 \mathrm{Ma})$ is thought to have accompanied a decline in sagebrush. The terminal Oligocene is seen as unusually cool and dry, possibly influenced by the rain shadow created by the ancestral Cascades. However, wooded stream courses must have been present in the terminal Oligocene and early Miocene, as evidenced by fossil wood common in stream channel sediments after $\sim 24 \mathrm{Ma}$ (Hunt and Stepleton, 2004). The drying trend of the Oligocene culminated in cooler, semiarid, open grasslands with riparian woodland and possible savanna in the early Miocene. Paleosol sequences interpreted as evidence of Milankovitch cyclicity are said to indicate periodic climatic oscillation (Retallack et al., 2004).

In the central Great Plains east of the Rocky Mountains, there is substantial evidence that a continental climate prevailed during the late Oligocene and early Miocene at the time of temnocyonine diversification (Stanley, 1976; Stanley and Benson, 1979; Vicars and Breyer, 1981; Swinehart et al., 1985; Hunt, 1978, 1985, 1990). The Arikaree Group is represented by a vast expanse of eolian sediment, distributed over a terrain of extremely low relief, incised by shallow, broad paleovalleys of the braided-channel, distributary type. Arikaree lithofacies are the residuum of dryland environments transected by ephemeral drainages bordered by dunes, dikaka, grassland, and savanna. Fluvial bedforms indicate stream energies consonant with rare, episodic floods, interrupting prolonged intervals of nondeposition or brief eolian influx. Interchannel reaches made up of loessic, wind-blown fine sand and silt, are devoid of evidence of vegetation other than grasses and other low-growing plants. Fossil wood is rare and only occasionally found in fluvial deposits; paleosols are immature, and dune bedforms are common. Shallow ephemeral lakes and waterholes are the only standing bodies of water and share a depauperate biota of pulmonate gastropods, ostracods, charophyte algae, and diatoms. Evidence of aquatic vertebrates is infrequent. In the early Miocene, fossils of waterdependent mammals (notably chalicotheres and rhinoceros) are concentrated in waterholes and in stream channels, whereas the common species of the interfluves are camels and oreodonts, which appear to tolerate dry 
conditions. Enduring catastrophic droughts are evidenced by several mass death events.

This setting would impose a daunting series of demands upon medium- to largesized carnivores. Perhaps most relevant is the lack of vegetative cover, requiring the search and pursuit of prey in the open, and over long distances. The necessity of concealing, protecting, and feeding pups in an open, arid landscape, while hunting at a great distance from them, no doubt led to denning behaviors and perhaps (but not necessarily) to pack formation. Cooperative hunting is reported as essential for lions in the plains of Namibia during the dry season, a time of environmental stress (Stander, 1992a, b). More assuredly, durophagy would improve reproductive success by enabling adults to rapidly process meat and bone, thereby adding an important nutrient source (bone and bone marrow) to the diet, and also perhaps (but again, not certainly) adding regurgitative food transfer to the repertoire of pup rearing strategies. Van Valkenburgh (1989) noted that carnivores utilizing bone are likely to prosper in settings such as the plains of the Serengeti where carcasses become seasonally available, an environment comparable to the central Great Plains in the early Miocene.

The only competitors for a durophagous role during the Oligocene and early Miocene are large entelodont artiodactyls (Joeckel, 1990; Hunt and Tedford, 1993; Hunt, 2004). Entelodonts are much larger than temnocyonines, suggesting a partitioning of the food resource since the largest herbivores (chalicotheres and several large rhinoceroses) would supply carcasses that entelodonts could utilize more easily than even the largest temnocyonines. The temnocyonine-entelodont association (Hunt and Tedford, 1993) is thought to be important for durophagous processing of carcasses in open dryland environments of the Great Plains during the late Oligocene-earliest Miocene in North America.

The large, cursorial, crushing-toothed species of Mammacyon and Delotrochanter seem a direct response to the development of open, semiarid to arid grassland environments found in the North American midcontinent at the end of the Oligocene and continuing into the early Miocene. In these grasslands east of the Rocky Mountain uplifts, ungulate biomass would be expected to contribute both active prey and a steady supply of carcasses over time, as it does in the present East African savannas. The crushing dentitions and cursorial limbs of the large temnocyonines appear to be adaptations to these environments. A cursorial striding gait allows travel over a large territory, and robust skulls and teeth were well suited for both active carnivory and grinding of hard material such as bone.

\section{Epilogue: Cursorial Predators AND DUROPHAGY}

Durophagous cursorial temnocyonines existed in the Great Plains for about 5 million years from $\sim 27 \mathrm{Ma}$ to at least $22 \mathrm{Ma}$. An explanation for the scarcity of these large durophagous temnocyonines in the John Day Formation is not readily apparent: perhaps it is simply the random, haphazard nature of fossil preservation or even the result of numerically small and declining populations. However, based on the present fossil record, the youngest John Day species are not as specialized for durophagy as those in the Great Plains, and no John Day skeletons attain the advanced cursorial limbs seen in the temnocyonines from the Great Plains. Temnocyon fingeruti, dated at $\sim 23.8 \mathrm{Ma}$, is a large hypercarnivore, with a wolflike dentition, and is of latest Oligocene age. Cursorial limbs seem likely but remain undocumented.

No early Miocene temnocyonines have been found in the John Day basin. A few rare John Day fossils, such as the Haystack Valley Mammacyon maxilla (LACM 5386) and the jaw fragment of Rudiocyon (LACM 480), indicate the existence of durophagous species, but these are probably early late Oligocene $(>27 \mathrm{Ma})$ in age; hence they precede the large durophagous Great Plains species of the late Oligocene and early Miocene. The small postcarnassial molars of Rudiocyon are less developed than the equivalent crushing teeth in the Great Plains species, and suggest a more diverse diet.

Active hunting of large prey seems within the capability of the large cursorial temnocyonines. That large durophagous temnocyonines were exclusively scavengers seems 
unlikely. Spotted hyenas (Crocuta crocuta), while scavengers, are also capable hunters. Similarly, most large carnivores scavenge when carrion is available. Living carnivores that hunt large prey have broad muzzles, large, strong incisor and canine teeth, and deep jaws that come into play when encountering the stresses of grasping and holding a large animal (Van Valkenburgh and Ruff, 1987; Van Valkenburgh and Koepfli, 1993). Dependance on skull and jaws during a kill derives from an inability to use a cursorially adapted forelimb for prey capture and retention. Mammacyon and Delotrochanter have forelimbs similar to those of the wolf, ill-adapted for grasping; however, they do have robust skulls, broad snouts with large canines and incisors, strong mandibular symphyses, and deep mandibles that far exceed jaw depth in the living pack-hunting canids. The prominent premolar battery of temnocyonines is doubtless an added advantage in grasping and holding prey, and the carnassials and crushing molars contribute a complementary ability to utilize both meat and bone in the diet. These beardogs likely combined active hunting with scavenging. Some temnocyonines (Delotrochanter oryktes, D. major) could be termed hyaenid ecomorphs based on skull form and crushing cheek teeth, whereas others (Temnocyon fingeruti, $T$. ferox) parallel the large living canids in their skull and dentition, with several of the larger species (Mammacyon ferocior, M. obtusidens, Delotrochanter or$y k t e s)$ tending toward a cursorial capability reminiscent of living wolves.

Temnocyonines are extinct by the end of the Arikareean NALMA. They share the late/latest Arikareean interval (Ar3, Ar4) with daphoenine beardogs (Hunt, 2002b) and the amphicyonine Ysengrinia (Hunt, 2002a). In the early Hemingfordian, temnocyonines are replaced by amphicyonines (Amphicyon, Cynelos), a large cursorial daphoenine (Borocyon), and hemicyonine ursids. Amphicyonines and hemicyonines first appear in North America in the late Arikareean as Eurasian immigrants and become the dominant predators of the later Hemingfordian, living together at that time with midsized felids and canids. The ArikareeanHemingfordian faunal turnover, both in the
Great Plains and Pacific Northwest, involves a dramatic change in the large carnivore guild in North America.

As temnocyonine lineages increased in body size in parallel during the late Oligocene and early Miocene, becoming dentally specialized for divergent ecologic roles, their decline to extinction conforms to an iterative pattern common to large Cenozoic hypercarnivores (Van Valkenburgh, 2007): the vulnerability of small populations isolated at high trophic levels to extreme environmental stress, here likely the result of the documented climatic instability occurring during the Paleogene-Neogene transition in North America and to competition from immigrant Eurasian carnivores.

\section{ACKNOWLEDGMENTS}

This research would not have been possible without the generous loan of material by curators of North American collections: R.H. Tedford and M.C. McKenna, American Museum of Natural History; Wm. Clemens and A. Barnosky, University of CaliforniaBerkeley; M.C. Coombs, Amherst College Museum; M. Dawson, Carnegie Museum of Natural History; J.A. Gauthier and C. Norris, Yale-Peabody Museum; L. Barnes and X. Wang, Natural History Museum of Los Angeles County; D. Taylor, Northwest Museum of Natural History; B.J. MacFadden, Florida Museum of Natural History. Preparation of specimens commenced at the American Museum skillfully undertaken by O. Simonis and R. Brown, and later concluded in the Vertebrate Paleontology Division (UNSM) by E. Stepleton and R.I. Skolnick, the former working out the extremely difficult skull and mandibles of Temnocyon fingeruti from the John Day beds and the latter preparing the fragile skull of Delotrochanter oryktes from the carnivore dens at Agate Fossil Beds National Monument. Wm. McIntosh and L. Peters, New Mexico Bureau of Geology and Mineral Resources, generously provided the radioisotopic analysis that made possible an age estimate for the skull of $T$. fingeruti (Hunt and Stepleton, 2004: 29).

The skull of $T$. fingeruti was found and collected by M. Fingerut and G. Pierson 
along Balm Creek, east of Haystack Valley, in the John Day Formation. The discovery of the skull initiated our lithostratigraphic/biochronologic research on the upper John Day beds in the Kimberly-Haystack Valley region (Hunt and Stepleton, 2004, 2006). It was loaned for preparation and description to UNSM by $M$. Fingerut and D. Taylor at Portland State University, Portland, Oregon. T. Fremd, John Day Fossil Beds National Monument, Oregon, provided an introduction to temnocyonine localities in the John Day Formation and helpful collaboration over many years. The National Park Service (NPS) at Agate National Monument permitted excavation of the carnivore dens at Beardog Hill where UNSM discovered the skull and foot elements of Delotrochanter oryktes. Research at the national monument received the constant support and cooperation of rangers and staff: D. Buckley, M. Hertig, B. and D. Mack, L. Mansfield, W. Matthews, R. Miller, W. Taylor, R. Todd, A. Wilson, and superintendents A.J. Banta, J. Hill, R. Knudson, J. Kyral, J. Rapier, L. Reed, B. Stransky, and R. Weaver. Midwest Regional Chief of Interpretation (NPS) T. Richter has been an enthusiastic advocate and participant in all Agate research.

M. Schlain, Amherst College, supplied a copy of her capable master's thesis on Delotrochanter oryktes from Stenomylus Quarry, one of the most complete temnocyonine skeletons and the only postcranial skeleton of Delotrochanter. J.S. Waldrop of Timberlane Research in Lake Wales, Florida, permitted casting of temnocyonine material from the Live Oak locality (SB-1A fauna) in his personal collection, previously described by Frailey (1978: 6-8).

Illustrations were prepared or adapted by Angie Fox, UNSM Scientific Illustrator. Her skill and insight were essential to completion of the figures in this research effort. I am indebted to Jennifer Emry for figure 65, and to the late Ray Gooris for figures 43-45.

B. MacFadden, B. Van Valkenburgh, and E. Stepleton provided useful reviews of the manuscript. Comments by Van Valkenburgh considerably aided the analysis of dental and mandibular mechanics.

The initial stimulus for a study of temnocyonines came from Dick Tedford during my doctoral research at the American Museum from 1965-1970. This bulletin is dedicated to Dick in appreciation for his sustained collegial interest, insight, and guidance.

\section{REFERENCES}

Alexander, R.M. 2003. Principles of animal locomotion. Princeton, NJ: Princeton University Press, $370 \mathrm{pp}$.

Barbour, E.H. 1892. Notes on a new order of gigantic fossils. University Studies 4: 301-335.

Barbour, E.H. 1905. Notice of a new fossil mammal from Sioux County, Nebraska. Publication of the Nebraska Geological Survey 2 (3): 303-310.

Bergounioux, F.M., and F.C. Crouzel. 1973. Amphicyon major Blainville du Miocène moyen de Sansan (Gers). Annales de Paléontologie 59 (1): 27-76.

Biewener, A.A. 1989a. Mammalian terrestrial locomotion and size: mechanical design principles define limits. Bioscience 39: 776-783.

Biewener, A.A. 1989b. Scaling body support in mammals: limb posture and muscle mechanics. Science 245: 45-48.

Biknevicius, A.R., and C.B. Ruff. 1992a. The structure of the mandibular corpus and its relationship to feeding behaviors in extant carnivorans. Journal of the Zoological Society of London 228: 479-507.

Biknevicius, A.R., and C.B. Ruff. 1992b. Use of biplanar radiographs for estimating crosssectional geometric properties of mandibles. Anatomical Record 232: 157-163.

Biknevicius, A.R., and B. Van Valkenburgh. 1996. Design for killing: craniodental adaptations of predators. In J.L. Gittleman (editor), Carnivore behavior, ecology, and evolution, Vol. 2: 393-428. Ithaca, NY: Cornell University Press.

Billups, K., H. Pälike, J.E. Channell, J.C. Zachos, and N.J. Shackleton. 2004. Astronomic calibration of the late Oligocene through early Miocene geomagnetic polarity time scale. Earth and Planetary Science Letters 224: 33-44.

Bonis, L. de. 1966. Sur l'évolution du genre Haplocyon Schlosser (Carnivora). Bulletin de la Société Géologique de France 8: 114-117.

Bonis, L. de. 1973. Contribution a l'étude des mammifères de l'Aquitanien de l' Agenais. Mémoires de Muséum National d'Histoire Naturelle (sér. C) 28: 1-192.

Bowdich, T.E. 1821. An analysis of the natural classifications of Mammalia for the use of students and travellers. Paris: J. Smith, 115 pp.

Bryant, H.N. 1991. Phylogenetic relationships and systematics of the Nimravidae (Carnivora). Journal of Mammalogy 72: 56-78. 
Bryant, H.N. 1996. Nimravidae. In D.R. Prothero and R.J. Emry (editors), The terrestrial EoceneOligocene transition in North America: 453-475. Cambridge and New York: Cambridge University Press.

Calvano, G., et al. 2003. Lithostratigraphic, biostratigraphic, and magnetostratigraphic documentation of a major unconformity in the middle Eocene to early Miocene continental Sespe Formation, northern Santa Ana Mountains, Orange County, southern California. American Association of Petroleum Geologists, Pacific Section Convention: LA Basin 2003, Conference Program and Abstracts: 56-57.

Calvano, G., et al. 2008. Magnetic stratigraphy of the Eocene to Miocene Sespe and Vaqueros formations, Los Angeles and Orange counties, California. Natural History Museum of Los Angeles County, Science Series 41: 43-61.

Cook, H. 1909. Some new Carnivora from the lower Miocene beds of western Nebraska. Bulletin of the Nebraska Geological Survey 3 (9): 261-272.

Cope, E.D. 1878. On some of the characters of the Miocene fauna of Oregon. Paleontological Bulletin 30: 1-16.

Cope, E.D. 1879a. Observations on the faunae of the Miocene Tertiaries of Oregon. Bulletin of the U.S. Geological Survey 5 (1): 55-69.

Cope, E.D. 1879b. On the genera of Felidae and Canidae. Proceedings of the Academy of Natural Sciences of Philadelphia 1879: 1-27.

Cope, E.D. 1881. On the Nimravidae and Canidae of the Miocene period. Bulletin of the U.S. Geological Survey of the Territories 6 (1): 165-181.

Cope, E.D. 1883. On the extinct dogs of North America. American Naturalist 17 (3): 235-249.

Cope, E.D. 1884. The Vertebrata of the Tertiary Formations of the West. Book 1. Department of the Interior: Report of the U.S. Geological Survey of the Territories (F.V. Hayden) 3: 1-1009.

Davis, D.D. 1964. The giant panda: a morphological study of evolutionary mechanisms. Fieldiana Zoology, Memoirs 3: 1-339.

Evans, H.E. 1993. Miller's anatomy of the dog. 3rd ed. Philadelphia: W.B. Saunders, 1113 pp.

Evernden, J., D. Savage, G. Curtis, and G. James. 1964. Potassium-argon dates and the Cenozoic mammalian chronology of North America. American Journal of Science 262: 145-198.

Eyerman, J. 1896. The genus Temnocyon and a new species thereof and the new genus Нypotemnodon from the John Day Miocene of Oregon. American Geologist 17 (5): 267-287.

Fisher, R.V. 1967. Early Tertiary deformation in north-central Oregon. Bulletin of the American Association of Petroleum Geologists 51 (1): 111-123.
Fisher, R.V., and J.M. Rensberger. 1972. Physical stratigraphy of the John Day Formation, central Oregon. University of California Publications in Geological Sciences 101: 1-33.

Fisher, R.V., and R.E. Wilcox. 1960. The John Day Formation in the Monument Quadrangle, Oregon. U.S. Geological Survey Professional Paper 400-B: B302-B304.

Flower, W.H. 1869. On the value of the characters of the base of the cranium in the classification of the Order Carnivora, and on the systematic position of Bassaris and other disputed forms. Proceedings of the Zoological Society of London 1869: 4-37.

Frailey, D. 1978. An early Miocene (Arikareean) fauna from north-central Florida (the SB-1A local fauna). Occasional Papers of the Museum of Natural History, University of Kansas 75: $1-20$.

Frailey, D. 1979. The large mammals of the Buda local fauna (Arikareean: Alachua County, Florida). Bulletin of the Florida State Museum 24 (2): 123-173.

Francis, J.E., et al. (2009). From greenhouse to icehouse - the Eocene-Oligocene in Antarctica. In F. Florindo and M. Siegert (editors), Developments in earth and environmental sciences 8: 309-368.

Gill, T. 1872. Arrangement of the families of mammals with analytical tables. Smithsonian Miscellaneous Collections 11: 1-98.

Ginsburg, L. 1977. Cynelos lemanensis (Pomel), carnivore ursidé de l'Aquitanien d'Europe. Annales de Paléontologie 63 (1): 57-104.

Gittleman, J.L., and B. Van Valkenburgh. 1997. Sexual dimorphism in the canines and skulls of carnivores: effects of size, phylogeny, and behavioural ecology. Journal of Zoology (London) 242: 97-117.

Gradstein, F.M., J.G. Ogg, and A.G. Smith (editors), A geologic time scale 2004. Cambridge and New York: Cambridge University Press, $589 \mathrm{pp}$.

Gunnell, G.F. 1998. Creodonta. In C. Janis, K. Scott, and L. Jacobs (editors), Tertiary mammals of North America: 91-109. Cambridge and New York: Cambridge University Press.

Haeckel, E. 1866. Generelle Morphologie der Organismen. Volume 2. Berlin: Georg Reimer, 62 pp.

Hatcher, J.B. 1902a. Origin of the Oligocene and Miocene deposits of the Great Plains. Proceedings of the American Philosophical Society 41: 113-131.

Hatcher, J.B. 1902b. Oligocene Canidae. Memoir of the Carnegie Museum 1 (2): 65-108. 
Hay, R.L. 1963. Stratigraphy and zeolitic diagenesis of the John Day Formation of Oregon. University of California Publications in Geological Sciences 42 (5): 199-262.

Hayes, F.G. 2004. Paleomagnetics and biostratigraphy of the Pine Ridge Arikaree Group. Unpublished doctoral thesis, University of Nebraska, Lincoln.

Haynes, G. 1982. Utilization and skeletal disturbances of North American prey carcasses. Arctic 35 (2): 266-281.

Heglund, N.C., and C.R. Taylor. 1988. Speed, stride frequency and energy cost per stride: how do they change with body size and gait? Journal of Experimental Biology 138: 301-318.

Heinrich, R.E., and K.D. Rose. 1995. Partial skeleton of the primitive carnivoran Miacis petilus from the early Eocene of Wyoming. Journal of Mammalogy 76 (1): 148-162.

Helbing, H. 1928. Carnivoren des oberen Stampien. Schweizerische Palaeontologische Abhandlungen 47: 1-83.

Hildebrand, M. 1962. Walking, running, and jumping. American Zoologist 2: 151-155.

Hough, J.R. 1948. The auditory region in some members of the Procyonidae, Canidae, and Ursidae. Bulletin of the American Museum of Natural History 92 (2): 67-118.

Hunt, R.M., Jr. 1972. Miocene amphicyonids (Mammalia, Carnivora) from the Agate Spring Quarries, Sioux County, Nebraska. American Museum Novitates 2506: 1-39.

Hunt, R.M., Jr. 1974. The auditory bulla in Carnivora: an anatomical basis for reappraisal of carnivore evolution. Journal of Morphology 143: 21-76.

Hunt, R.M., Jr. 1977. Basicranial anatomy of Cynelos Jourdan (Mammalia, Carnivora), an Aquitanian amphicyonid from the Allier Basin, France. Journal of Paleontology 51 (4): 826-843.

Hunt, R.M., Jr. 1978. Depositional setting of a Miocene mammal assemblage, Sioux County, Nebraska (U.S.A.). Palaeogeography, Palaeclimatology, Palaeoecology 24: 1-52.

Hunt, R.M., Jr. 1984. Extinct carnivores entombed in 20 million year old dens. The George Wright Forum 4 (1): 29-39.

Hunt, R.M., Jr. 1985. Faunal succession, lithofacies, and depositional environments in Arikaree rocks (lower Miocene) of the Hartville Table, Nebraska and Wyoming. In J.E. Martin (editor), Fossiliferous Cenozoic deposits of western South Dakota and northwestern Nebraska. Dakoterra 2 (2): 155-204.

Hunt, R.M., Jr. 1989. Evolution of the aeluroid Carnivora: significance of the ventral promontorial process of the petrosal, and the origin of basicranial patterns in the living families. American Museum Novitates 2930: 1-32.
Hunt, R.M., Jr. 1990. Taphonomy and sedimentology of Arikaree (lower Miocene) fluvial, eolian, and lacustrine paleoenvironments, $\mathrm{Ne}$ braska and Wyoming: a paleobiota entombed in fine-grained volcaniclastic rocks. Geological Society of America Special Paper 244: 69-111.

Hunt, R.M., Jr. 1998. Amphicyonidae. In C. Janis, K. Scott, and L. Jacobs (editors), Tertiary Mammals of North America:196-227. Cambridge and New York: Cambridge University Press.

Hunt, R.M., Jr. 2002a. Intercontinental migration of Neogene amphicyonids (Mammalia, Carnivora): appearance of the Eurasian beardog Ysengrinia in North America. American Museum Novitates 3384: 1-53.

Hunt, R.M., Jr. 2002b. New amphicyonid carnivorans (Mammalia, Daphoeninae) from the early Miocene of southeastern Wyoming. American Museum Novitates 3385: 1-41.

Hunt, R.M., Jr. 2004. Global climate and the evolution of large mammalian carnivores during the later Cenozoic in North America. Bulletin of the American Museum of Natural History 285: 139-156.

Hunt, R.M., Jr. 2009. Long-legged pursuit carnivorans (Amphicyonidae, Daphoeninae) from the early Miocene of North America. Bulletin of the American Museum of Natural History 318: 1-95.

Hunt, R.M., Jr., and L.G. Barnes. 1994. Basicranial evidence for ursid affinity of the oldest pinnipeds. Proceedings of the San Diego Society of Natural History: Symposium on Marine Mammal Evolution 29: 57-67.

Hunt, R.M., Jr., and W.W. Korth. 1980. The auditory region of Dermoptera: morphology and function relative to other living mammals. Journal of Morphology 164: 167-211.

Hunt, R.M., Jr., and E. Stepleton. 2004. Geology and paleontology of the Upper John Day beds, John Day River Valley, Oregon: lithostratigraphic and biochronologic revision in the Haystack Valley and Kimberly areas (Kimberly and Mt. Misery Quadrangles). Bulletin of the American Museum of Natural History 282: 1-90.

Hunt, R.M., Jr., and E. Stepleton. 2006. Biochronologic and lithostratigraphic reappraisal of the upper John Day Formation, north-central Oregon. Paleobios 26 (2): 21-25.

Hunt, R.M., Jr., and R.H. Tedford. 1993. Phylogenetic relationships within the aeluroid Carnivora and implications of their temporal and geographic distribution. In F. Szalay, $\mathrm{M}$. Novacek, and M.C. McKenna (editors), Mammal phylogeny (placentals): 53-73. New York: Springer Verlag.

Hunt, R.M., Jr., X.X. Xue, and J. Kaufman. 1983. Miocene burrows of extinct beardogs: indica- 
tion of early denning behavior of large mammalian carnivores. Science 221: 364-366.

Hürzeler, J. 1940. Haplocyonoides nov. gen., ein aberranter Canide aus dem Aquitanien des Hesslers (Mainzer Becken). Eclogae Geologicae Helvetiae 33 (2): 224-229.

Izett, G.A., and J.D. Obradovich. 2001. ${ }^{40} \mathrm{Ar} /{ }^{39} \mathrm{Ar}$ ages of Miocene tuffs in basin-fill deposits (Santa Fe Group, New Mexico, and Troublesome Formation, Colorado) of the Rio Grande system. The Mountain Geologist 38 (2): 77-86.

Jenkins, F.A., Jr. 1973. The functional anatomy and evolution of the mammalian humero-ulnar articulation. American Journal of Anatomy 137: 281-298.

Jenkins, F.A., Jr., and S.M. Camazine. 1977. Hip structure and locomotion in ambulatory and cursorial carnivores. Journal of the Zoological Society of London 181: 351-370.

Joeckel, R.M. 1990. A functional interpretation of the masticatory system and paleoecology of entelodonts. Paleobiology 16 (4): 459-482.

Lander, E.B. 1983. Continental vertebrate faunas from the upper member of the Sespe Formation, Simi Valley, California, and the terminal Eocene event. In R.R. Squires and M.V. Filewicz (editors), Cenozoic geology of the Simi Valley area, southern California. SEPM (Society of Economic Paleontologists and Mineralogists), Pacific Section, Field Trip and Guidebook: 142-153.

Linnaeus, C. 1758. Systema naturae per regna tria naturae, secundum classes, ordines, genera, species, cum characteribus, differentiis, synonymis, locis. Vol. 1. Regnum animale. Editio decima, reformata. Stockholm: Laurentii Salvii, 824 pp.

Loomis, F.B. 1910. Osteology and affinities of the genus Stenomylus. American Journal of Science 29: 297-323.

Loomis, F.B. 1936. Three new Miocene dogs and their phylogeny. Journal of Paleontology 10 (1): 44-52.

Lourens, L., F. Hilgen, N.J. Shackleton, J. Laskar, and D. Wilson. 2004. The Neogene Period. In F.M. Gradstein, J.G. Ogg, and A.G. Smith (editors), A geologic time scale 2004: 409-440. Cambridge and New York: Cambridge University Press.

Macdonald, J.R. 1963. The Miocene faunas from the Wounded Knee area of western South Dakota. Bulletin of the American Museum of Natural History 125 (3): 139-238.

Macdonald, J.R. 1970. Review of the Miocene Wounded Knee faunas of southwestern South Dakota. Bulletin of the Los Angeles County Museum of Natural History 8: 1-82.

MacFadden, B.J. 1980. An early Miocene land mammal (Oreodonta) from a marine limestone in northern Florida. Journal of Paleontology 54 (1): 93-101.

MacFadden, B.J., and R.M. Hunt, Jr. 1998. Magnetic polarity stratigraphy and correlation of the Arikaree Group, Arikareean (late Oligocene-early Miocene) of northwestern Nebraska. Geological Society of America Special Paper 325: 143-165.

Martin, L.D. 1998. Nimravidae. In C. Janis, K. Scott, and L. Jacobs (editors), Tertiary mammals of North America: 228-235. Cambridge and New York: Cambridge University Press.

Matthew, W.D. 1923. Fossil bones in the rock. Natural History 23: 358-369.

Mech, L.D. 1970. The wolf: ecology and behavior of an endangered species. New York: Natural History Press, 384 pp.

Mellett, J.S. 1977. Paleobiology of North American Hyaenodon (Mammalia, Creodonta). Contributions to Vertebrate Evolution 1: 1-134.

Merriam, J.C. 1901. A contribution to the geology of the John Day basin. Bulletin of the Department of Geology, University of California 2 (9): 269-314.

Merriam, J.C. 1906. Carnivora from the Tertiary Formations of the John Day Region. Bulletin of the Department of Geology, University of California 5 (1): 1-64.

Myers, M.J., and K. Steudel. 1985. Effect of limb mass and its distribution on the energetic cost of running. Journal of Experimental Biology 116: 363-373.

O’Leary, M.A., and K.D. Rose. 1995. Postcranial skeleton of the early Eocene mesonychid $\mathrm{Pa}$ chyaena (Mammalia: Mesonychia). Journal of Vertebrate Paleontology 15 (2): 401-430.

Olsen, S. 1958. Some problematical carnivores from the Florida Miocene. Journal of Paleontology 32 (3): 595-602.

Parker, T.J., and W.A. Haswell. 1897. A text-book of zoology. London: Macmillan, Vol. 2, 683 pp.

Peigné, S., and E.P.J. Heizmann. 2003. The Amphicyonidae (Mammalia: Carnivora) from Ulm-Westtangente (MN2, Early Miocene), Baden-Württemberg, Germany-Systematics and ecomorphology. Stuttgarter Beiträge zur Naturkunde (ser. B) 343: 1-133.

Peterson, O.A. 1907. The Miocene beds of western Nebraska and eastern Wyoming and their vertebrate faunae. Annals of the Carnegie Museum 4 (1): 21-72.

Peterson, O.A. 1909. A revision of the Entelodontidae. Memoir of the Carnegie Museum 4: 41-158.

Peterson, O.A. 1910. Description of new carnivores from the Miocene of western Nebraska. Memoir of the Carnegie Museum 4 (5): 205-278.

Peterson, O.A. 1923. A fossil-bearing slab of sandstone from the Agate Spring Quarries of western 
Nebraska, exhibited in the Carnegie Museum. Annals of the Carnegie Museum 15: 91-93.

Prothero, D.R., and C.C. Swisher, III. 1992. Magnetostratigraphy and geochronology of the terrestrial Eocene-Oligocene transition in North America. In D.R. Prothero and W.A. Berggren (editors), Eocene-Oligocene climatic and biotic evolution: 46-73. Princeton, NJ: Princeton University Press.

Prothero, D.R., J.L. Howard, and T.H.H. Dozier. 1996. Stratigraphy and paleomagnetism of the Upper Middle Eocene to Lower Miocene (Uintan to Arikareean) Sespe Formation, Ventura County, California. In D.R. Prothero and R.J. Emry (editors), The terrestrial Eocene-Oligocene transition in North America: 171-188. Cambridge and New York: Cambridge University Press.

Retallack, G.J. 1997. Neogene expansion of the North American prairie. Palaios 12: 380-390.

Retallack, G.J. 2007. Cenozoic paleoclimate on land in North America. Journal of Geology 115: 271-294.

Retallack, G.J., J.G. Wynn, and T.J. Fremd. 2004. Glacial-interglacial-scale paleoclimatic change without large ice sheets in the Oligocene of central Oregon. Geology 32 (4): 297-300.

Robinson, P.T., G.F. Brem, and E.H. McKee. 1984. John Day Formation of Oregon: a distal record of early Cascade volcanism. Geology 12 (4): 229-232.

Rosowski, J.J. 1994. Outer and midde ears. In R.R. Fay and A.N. Popper (editors), Comparative hearing: mammals: 172-247. New York: Springer-Verlag.

Scapino, R. 1981. Morphological investigation into functions of the jaw symphysis in carnivorans. Journal of Morphology 167: 339-375.

Schlain, M.R. 1980. A description of the postcranial anatomy of a Miocene amphicyonid (Mammalia, Carnivora). Unpublished master's thesis, University of Massachusetts-Amherst.

Scott, T.M. 1988. The lithostratigraphy of the Hawthorn Group (Miocene) of Florida. Florida Geological Survey Bulletin 59: 1-148.

Scott, W.B., and G.L. Jepsen. 1936. The mammalian fauna of the White River Oligocene: Part I. Insectivora and Carnivora. Transactions of the American Philosophical Society 25: 55-78.

Stander, P.E. 1992a. Foraging dynamics of lions in a semi-arid environment. Canadian Journal of Zoology 70: 8-21.

Stander, P.E. 1992b. Cooperative hunting in lions: the role of the individual. Behavioral Ecology and Sociobiology 29: 445-454.

Stanley, K.O. 1976. Sandstone petrofacies in the Cenozoic High Plains sequence, eastern Wyoming and Nebraska. Geological Society of America Bulletin 87: 297-309.
Stanley, K.O., and L.V. Benson. 1979. Early diagenesis of High Plains Tertiary vitric and arkosic sandstone, Wyoming and Nebraska. Society of Economic Paleontologists and Mineralogists Special Publication 26: 401-423.

Stebbins, W.C. 1983. The acoustic sense in animals. Cambridge, MA: Harvard University Press, 168 pp.

Stock, C. 1932. An upper Oligocene mammalian fauna from southern California. Proceedings of the National Academy of Sciences 18 (8): 550-554.

Stock, C. 1933a. Perissodactyla from the Sespe of the Las Posas Hills, California. Carnegie Institution of Washington Publications: Contributions to Paleontology 440 (3): 15-28.

Stock, C. 1933b. Carnivora from the Sespe of the Las Posas Hills, California. Carnegie Institution of Washington Publications: Contributions to Paleontology 440 (4): 29-41.

Stock, C. 1948. Pushing back the history of land mammals in western North America. Bulletin of the Geological Society of America 59: 327-332.

Stromberg, C.A.E. 2004. Using phytolith assemblages to reconstruct the origin and spread of grass-dominated habitats in the Great Plains of North America during the late Eocene to early Miocene. Palaeogeography, Palaeoclimatology, Palaeoecology 207: 239-275.

Swinehart, J., V. Souders, H. Degraw, and R. Diffendal. 1985. Cenozoic paleogeography of western Nebraska. In R. Flores and S. Kaplan (editors), Paleogeography of the west-central United States: 209-229, Rocky Mountain Section, Society of Economic Paleontologists and Mineralogists, Denver, Colorado.

Tedford, R.H., et al. (1987). Faunal succession and biochronology of the Arikareean through Hemphillian interval (late Oligocene through earliest Pliocene epochs) in North America. In M.O. Woodburne (editor), Cenozoic mammals of North America: 153-210. Berkeley: University of California Press.

Tedford, R.H., et al. (1996). The WhitneyanArikareen transition in the High Plains. In D.O. Prothero and R.J. Emry (editors), The terrestrial Eocene-Oligocene transition in North America, 312-334. Cambridge and New York: Cambridge University Press.

Tedford, R.H., et al. (2004). Mammalian biochronology of the Arikareean through Hemphillian interval (late Oligocene through early Pliocene epochs). In M.O. Woodburne (editor), Late Cretaceous and Cenozoic mammals of North America: 169-231. New York: Columbia University Press.

Therrien, F. 2005. Mandibular force profiles of extant carnivorans and implications for the feeding behavior of extinct predators. Journal 
of the Zoological Society of London 267: 249-270.

Thorpe, M.R. 1922. Oregon Tertiary Canidae, with descriptions of new forms. American Journal of Science 3 (12): 162-176.

Toohey, L. 1959. The species of Nimravus (Carnivora, Felidae). Bulletin of the American Museum of Natural History 118 (2): 71-112.

Van Valkenburgh, B. 1989. Carnivore dental adaptations and diet: a study of trophic diversity within guilds. In J.L. Gittleman (editor), Carnivore behavior, ecology, and evolution: 410-436. Ithaca, NY: Cornell University Press.

Van Valkenburgh, B. 1996. Feeding behavior in free-ranging large African carnivores. Journal of Mammalogy 77 (1): 240-254.

Van Valkenburgh, B. 2007. Déjà vu: the evolution of feeding morphologies in the Carnivora. Integrative and Comparative Biology 47 (1): 147-163.

Van Valkenburgh, B., and C.B. Ruff. 1987. Canine tooth strength and killing behaviour in large carnivores. Journal of the Zoological Society of London 212: 379-397.

Van Valkenburgh, B., and K.-P. Koepfli. 1993. Cranial and dental adaptations to predation in canids. Symposium of the Zoological Society of London 65: 15-37.

Van Valkenburgh, B., T. Sacco, and X. Wang. 2003. Pack hunting in Miocene borophagine dogs: evidence from craniodentral morphology and body size. Bulletin of the American Museum of Natural History 279: 147-162.

Vicars, R.G., and J.A. Breyer. 1981. Sedimentary facies in air-fall pyroclastic debris, Arikaree Group (Miocene), northwest Nebraska, U.S.A. Journal of Sedimentary Petrology 51 (3): 900-921.

Viret, J. 1929. Les faunes des mammifères de l'Oligocène supérieur de la Limagne Bourbonnaise. Annales de l'Université de Lyon (n. ser.) 47: $1-328$.

Wang, X. 1994. Phylogenetic systematics of the Hesperocyoninae (Carnivora: Canidae). Bulletin of the American Museum of Natural History 221: 1-207.
Wang, X., and R.H. Tedford. 2008. Fossil dogs (Carnivora, Canidae) from the Sespe and Vaqueros formations in southern California, with comments on relationships of Phlaocyon taylori. Natural History Museum of Los Angeles County, Science Series 41: 255-272.

Webb, S.D., and N.D. Opdyke. 1995. Global climatic influence on Cenozoic land mammal faunas. In S.D. Webb and N.D. Opdyke (editors), Effects of past global change on life: 184-208. Washington, DC: National Academy Press.

Whistler, D.P., and E.B. Lander. 2003. New late Uintan to early Hemingfordian land mammal assemblages from the undifferentiated Sespe and Vaqueros formations, Orange County, and from the Sespe and equivalent marine formations in Los Angeles, Santa Barbara, and Ventura counties, southern California. Bulletin of the American Museum of Natural History 279: 231-268.

Wilcox, R.E., and R.V. Fisher. 1966. Geologic Map of the Monument Quadrangle, Grant County, Oregon. U.S. Geological Survey Map GQ-541.

Wilson, R.W. 1949. Rodents and lagomorphs of the Upper Sespe, Carnegie Institution of Washington Publications: Contributions to Paleontology 584 (3): 53-65.

Woodburne, M.O., and P.T. Robinson. 1977. A new Late Hemingfordian mammal fauna from the John Day Formation, Oregon, and its stratigraphic implications. Journal of Paleontology 51 (4): 750-757.

Wortman, J.L., and W.D. Matthew. 1899. The ancestry of certain members of the Canidae, the Viverridae, and Procyonidae. Bulletin of the American Museum of Natural History 12 (6): 109-139.

Zachos, J., M. Pagani, L. Sloan, E. Thomas, and K. Billups. 2001. Trends, rhythms, and aberrations in global climate, $65 \mathrm{Ma}$ to present. Science 292: 686-693.

Zachos, J., G.R. Dickens, and R.E. Zeebe. 2008. An early Cenozoic perspective on greenhouse warming and carbon-cycle dynamics. Nature 451: 279-283. 
APPENDIX 1

Minimum Number of Individuals (MNI) of Temnocyoninae in North American Collections

\begin{tabular}{|c|c|c|}
\hline Taxon & $\mathrm{N}$ & Museum No. \\
\hline Temnocyon altigenis & 6 & (AMNH 6855-6857, USNM 7940, UCMP 1549, 9999) \\
\hline Temnocyon subferox & 1 & (YPM 10065) \\
\hline Temnocyon cf. T. subferox & 1 & (LACM 470) \\
\hline Temnocyon fingeruti & 1 & $(\mathrm{NM} 280 / 61)$ \\
\hline Temnocyon ferox & 1 & (YPM-PU 10787) \\
\hline Temnocyon percussor & 3 & (AMNH 81005, 81054, 81047) \\
\hline Temnocyon macrogenys & 1 & $(\mathrm{~F}: \mathrm{AM} 54139)$ \\
\hline Rudiocyon amplidens & 1 & (LACM 480) \\
\hline Mammacyon obtusidens & 3 & (ACM 34-41, LACM 9194, 5386) \\
\hline Mammacyon ferocior & 2 & (F:AM 27562, 54134) \\
\hline cf. Mammacyon & 1 & (LACM 15908) \\
\hline Delotrochanter petersoni & 1 & $(\mathrm{CM} 1603)$ \\
\hline Delotrochanter oryktes & 4 & (ACM 4804, 4804A, UNSM 47800, YPM 24872) \\
\hline Delotrochanter major & 1 & $(\mathrm{~F}: \mathrm{AM} 27561)$ \\
\hline \multirow[t]{2}{*}{ Temnocyoninae indet. } & 2 & (UF 16908, 24203) \\
\hline & 1 & (TRO 386-388, 390, 661) \\
\hline Total MNI & 30 & \\
\hline
\end{tabular}

APPENDIX 2

Measurement of Temnocyonine Mandibles (in mm) and Derived $\log _{10}$ Values

\begin{tabular}{|c|c|c|c|c|c|c|c|c|}
\hline Taxon & Mus. no. & $\mathrm{DL}^{\mathrm{a}}$ & LAP $^{\mathrm{a}}$ & LAM $^{\mathrm{a}}$ & $\mathrm{D}_{\mathrm{y}} \mathrm{P}$ & $\mathrm{D}_{\mathrm{x}} \mathrm{P}$ & $\mathrm{D}_{\mathrm{y}} \mathrm{M}$ & $\mathrm{D}_{\mathrm{x}} \mathrm{M}$ \\
\hline T. altigenis & UCMP 9999 & 136 & 79 & 62 & 21.5 & 10.0 & 23.3 & 9.2 \\
\hline T. ferox & YPM-PU 10787 & 195 & 110 & 88 & 37.3 & 15.7 & 39.6 & 14.5 \\
\hline T. fingeruti & NM 280/61 & 200 & 112 & 89 & 32.8 & 12 & 34.5 & $12-13$ \\
\hline T. macrogenys & F:AM 54139 & 254 & 143 & 115 & 53.5 & 15.2 & 53.0 & 14.2 \\
\hline M. obtusidens & LACM 9194 & 188 & 107 & 84 & 32.9 & 15.1 & 38 & 14.5 \\
\hline D. oryktes & ACM 4804 & 202 & 119 & 90 & 39.1 & 14.6 & 45.6 & 14.0 \\
\hline T. altigenis & UCMP 9999 & 2.13 & 1.90 & 1.79 & 1.33 & 1.00 & 1.37 & 0.96 \\
\hline T. ferox & YPM-PU 10787 & 2.29 & 2.04 & 1.94 & 1.57 & 1.20 & 1.60 & 1.16 \\
\hline T. fingeruti & NM 280/61 & 2.30 & 2.05 & 1.95 & 1.52 & 1.08 & 1.54 & 1.08 \\
\hline T. macrogenys & F:AM 54139 & 2.40 & 2.15 & 2.06 & 1.73 & 1.20 & 1.72 & 1.15 \\
\hline M. obtusidens & LACM 9194 & 2.27 & 2.03 & 1.92 & 1.52 & 1.18 & 1.58 & 1.16 \\
\hline D. oryktes & ACM 4804 & 2.31 & 2.08 & 1.95 & 1.59 & 1.16 & 1.66 & 1.15 \\
\hline
\end{tabular}

${ }^{a} \mathrm{DL}, \mathrm{LAP}$, and LAM measurements are estimated because the ascending ramus and articular condyle are missing in all mandibles except for those of T. macrogenys and D. oryktes, which are intact.

Abbreviations: DL, dentary length; LA, working side lever arm length; $\mathrm{D}_{\mathrm{y}}$, mandibular depth; $\mathrm{D}_{\mathrm{x}}$, mandibular width; $\mathrm{P}$, measured at interdental gap between $\mathrm{p} 4$ and $\mathrm{m} 1 ; \mathrm{M}$, measured at interdental gap between $\mathrm{m} 1$ and $\mathrm{m} 2$. 
APPENDIX 3

Calculations from Mandibular Measurements (in cm): Section Moduli (Zx, Zy), Working Side Lever Arm (L), Parasagittal and Transverse Bending Strength $(\mathrm{Zx} / \mathrm{L}, \mathrm{Zy} / \mathrm{L})$, and Relative Magnitude of Bending Resistance (Zx/ Zy) at Various Loci along the Mandibular Corpus ${ }^{\text {a }}$

\begin{tabular}{|c|c|c|c|c|c|c|c|}
\hline & canine & p3p4 & $\mathrm{p} 4 \mathrm{~m} 1$ & $\mathrm{~m} 1 \mathrm{~m} 2$ & $\mathrm{~m} 2 \mathrm{~m} 3$ & post $\mathrm{m} 3$ & dentary length $(\mathrm{cm})$ \\
\hline \multicolumn{8}{|c|}{ Temnocyon macrogenys } \\
\hline $\mathrm{Zx}$ & 5.97 & 2.65 & 3.20 & 3.92 & 5.03 & 5.70 & 25.4 \\
\hline $\mathrm{Zy}$ & 4.57 & 0.82 & 1.20 & 1.05 & 1.24 & 1.31 & \\
\hline $\mathrm{L}$ & 22.60 & 16.69 & 14.30 & 11.50 & 9.72 & 8.77 & \\
\hline $\log \mathrm{Zx} / \mathrm{L}$ & -0.58 & -0.80 & -0.65 & -0.46 & -0.28 & -0.19 & \\
\hline $\log \mathrm{Zy} / \mathrm{L}$ & -0.69 & -1.30 & -1.07 & -1.05 & -0.89 & -0.83 & \\
\hline $\mathrm{Zx} / \mathrm{Zy}$ & 1.30 & 3.23 & 2.66 & 3.73 & 4.05 & 4.35 & \\
\hline \multicolumn{8}{|c|}{ Canis lupus } \\
\hline $\mathrm{Zx}$ & 2.00 & 1.32 & 1.82 & 1.79 & 1.83 & 2.00 & 19.13 \\
\hline $\mathrm{Zy}$ & 2.22 & 0.68 & 0.86 & 0.67 & 0.59 & 0.62 & \\
\hline $\mathrm{L}$ & 16.73 & 12.28 & 10.62 & 7.90 & 6.56 & 5.95 & \\
\hline $\log \mathrm{Zx} / \mathrm{L}$ & -0.92 & -0.97 & -0.77 & -0.64 & -0.55 & -0.47 & \\
\hline $\log \mathrm{Zy} / \mathrm{L}$ & -0.87 & -1.25 & -1.09 & -1.07 & -1.05 & -0.98 & \\
\hline $\mathrm{Zx} / \mathrm{Zy}$ & 0.90 & 1.94 & 2.12 & 2.67 & 3.10 & 3.23 & \\
\hline \multicolumn{8}{|c|}{ Borocyon robustum } \\
\hline$Z x$ & 6.07 & 3.61 & 4.23 & 5.71 & 5.87 & 7.22 & 24.0 \\
\hline $\mathrm{Zy}$ & 5.06 & 1.62 & 1.75 & 2.22 & 2.04 & 2.17 & \\
\hline $\mathrm{L}$ & 21.80 & 16.90 & 14.80 & 11.54 & 9.57 & 8.50 & \\
\hline $\log \mathrm{Zx} / \mathrm{L}$ & -0.55 & -0.67 & -0.54 & -0.31 & -0.21 & -0.07 & \\
\hline $\log \mathrm{Zy} / \mathrm{L}$ & -0.63 & -1.02 & -0.93 & -0.71 & -0.67 & -0.59 & \\
\hline $\mathrm{Zx} / \mathrm{Zy}$ & 1.20 & 2.23 & 2.41 & 2.56 & 2.88 & 3.33 & \\
\hline \multicolumn{8}{|c|}{ Delotrochanter oryktes } \\
\hline $\mathrm{Zx}$ & 5.12 & 1.97 & 2.19 & 2.88 & 3.57 & 3.61 & 20.2 \\
\hline $\mathrm{Zy}$ & 3.50 & 0.63 & 0.82 & 0.89 & 0.89 & 0.80 & \\
\hline $\mathrm{L}$ & 18.10 & 13.80 & 11.81 & 9.00 & 7.73 & 6.90 & \\
\hline $\log \mathrm{Zx} / \mathrm{L}$ & -0.55 & -0.85 & -0.73 & -0.49 & -0.34 & -0.28 & \\
\hline $\log \mathrm{Zy} / \mathrm{L}$ & -0.71 & -1.34 & -1.16 & -1.00 & -0.94 & -0.94 & \\
\hline \multirow[t]{2}{*}{$\mathrm{Zx} / \mathrm{Zy}$} & 1.46 & 3.13 & 2.67 & 3.24 & 4.01 & 4.51 & \\
\hline & canine & \multicolumn{2}{|c|}{ p3p4 } & $\mathrm{p} 4 \mathrm{~m} 1$ & \multicolumn{2}{|r|}{ post $\mathrm{m} 1$} & \\
\hline \multicolumn{8}{|c|}{ Crocuta crocuta } \\
\hline $\mathrm{Zx}$ & 3.79 & \multicolumn{2}{|c|}{2.31} & 3.06 & \multicolumn{2}{|r|}{3.40} & 17.50 \\
\hline $\mathrm{Zy}$ & 3.16 & \multicolumn{2}{|c|}{1.20} & 1.29 & \multicolumn{2}{|r|}{0.99} & \\
\hline $\mathrm{L}$ & 15.47 & \multicolumn{2}{|c|}{10.85} & 8.67 & \multicolumn{2}{|r|}{5.76} & \\
\hline $\log \mathrm{Zx} / \mathrm{L}$ & -0.61 & \multicolumn{2}{|c|}{-0.67} & -0.45 & \multicolumn{2}{|r|}{-0.23} & \\
\hline $\log \mathrm{Zy} / \mathrm{L}$ & -0.69 & \multicolumn{2}{|c|}{-0.95} & -0.83 & \multicolumn{2}{|r|}{-0.76} & \\
\hline $\mathrm{Zx} / \mathrm{Zy}$ & 1.20 & \multicolumn{2}{|c|}{1.92} & 2.37 & \multicolumn{2}{|r|}{3.43} & \\
\hline \multicolumn{8}{|c|}{ Panthera leo } \\
\hline $\mathrm{Zx}$ & 8.21 & \multicolumn{2}{|c|}{3.58} & 4.35 & \multicolumn{2}{|r|}{5.17} & 22.95 \\
\hline $\mathrm{Zy}$ & 6.58 & & 85 & 2.06 & & 2.27 & \\
\hline $\mathrm{L}$ & 19.79 & & & 12.98 & & 9.97 & \\
\hline $\log \mathrm{Zx} / \mathrm{L}$ & -0.38 & & & -0.47 & & -0.28 & \\
\hline $\log \mathrm{Zy} / \mathrm{L}$ & -0.48 & & & -0.80 & & -0.64 & \\
\hline $\mathrm{Zx} / \mathrm{Zy}$ & 1.25 & & 94 & 2.11 & & 2.28 & \\
\hline
\end{tabular}

${ }^{a}$ Data for Canis lupus, Crocuta crocuta, and Panthera leo are from Therrien (2005) and represent sample means for these species. Data for the amphicyonids (Temnocyon macrogenys, Delotrochanter oryktes, Borocyon robustum) were calculated from single mandibles. 